\title{
LAJES NERVURADAS DE CONCRETO ARMADO: PROJETO E EXECUÇÃO
}

\section{CARLOS FERNANDO BOCCHI JÚNIOR}

Dissertação apresentada à Escola de Engenharia de São Carlos, da Universidade de São Paulo, como parte dos requisitos para obtenção do Título de Mestre em Engenharia de Estruturas.

ORIENTADOR: Prof. Dr. José Samuel Giongo.

São Carlos

1995 


\section{Bocchi Jr, Carlos Fernando \\ Lajes nervuradas de concreto armado: \\ projeto e execução - São Carlos, 1995.}

Dissertação (mestrado) - Escola de Engenharia

de São Carlos - Universidade de São Paulo, 1995

Orientador: Prof. Dr. José Samuel Giongo

1.Concreto-lajes nervuradas. I. Titulo 
Aos meus pais,

à minha esposa Denise

e minha filha Heloísa,

pelo incentivo e compreensão 


\section{AGRADECIMENTOS}

Ao Professor José Samuel Giongo pela dedicação, compreensão e excelente orientação prestada durante a elaboração deste trabalho.

Aos colegas, professores e funcionários do Departamento de Estruturas, em especial aos Professores Márcio R. S. Corrêa, João Batista de Paiva, pelo apoio.

A Coordenadoria de Aperfeiçoamento de Pessoal de Nível Superior - CAPES, pela bolsa de estudo concedida, a qual permitiu a realização deste trabalho.

Ao Sr. Vladimir Maestrello da Silva pelo auxílio na digitação do texto e ao Sr. Aguinaldo Alves de Lima pela execução dos desenhos.

A todos que de alguma maneira contribuiram para a realização deste trabalho. 


\section{SUMÁRIO}

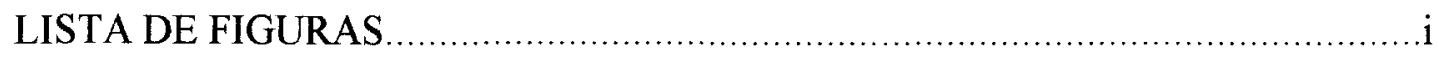

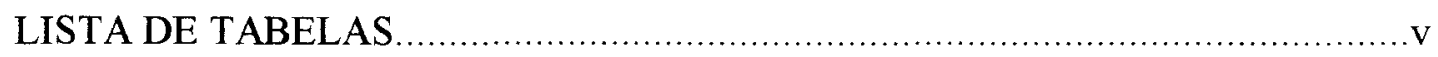

LISTA DE ABREVIATURAS, SIGLAS E SÍMBOLOS ......................................vi

RESUMO

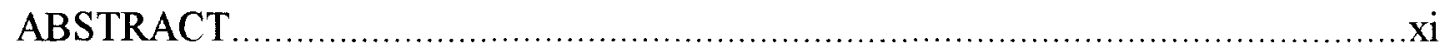

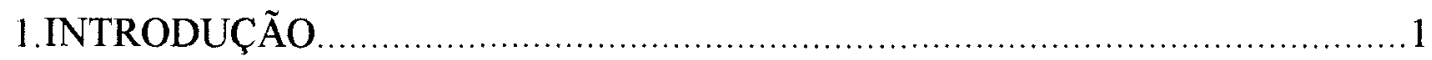

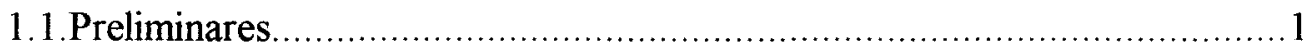

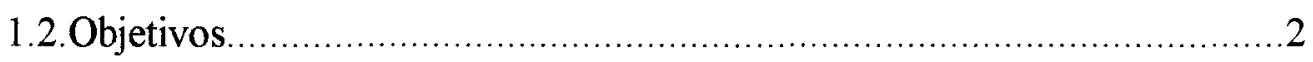

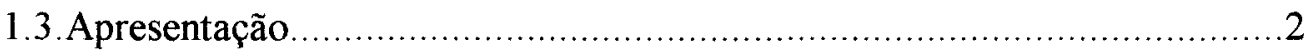

1.4. Tipologia das lajes nervuradas de concreto armado................................3

2.CONSIDERAÇÕES GERAIS SOBRE AS LAJES NERVURADAS ...................9

2.1. Vinculação das Lajes nervuradas.................................................... 9

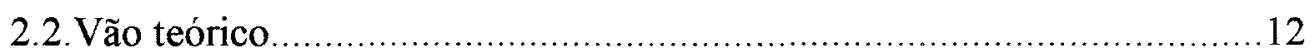

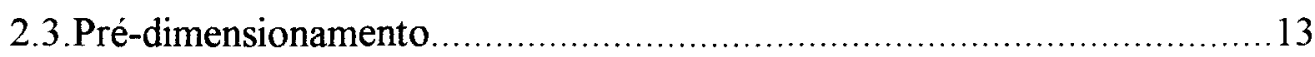

2.3.1. Recomendações da norma brasileira NB-1/78 .................... 14

2.3.2. Comité Euro-Internacional du Béton CEB-124/125F .............16

2.3.3.American Concrete Institute ACI-318M/89 .........................17

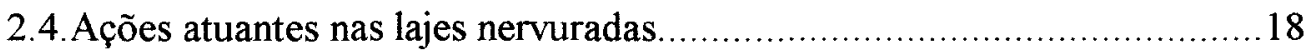

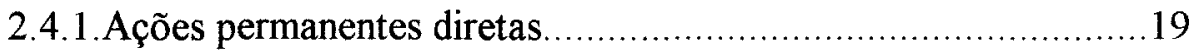

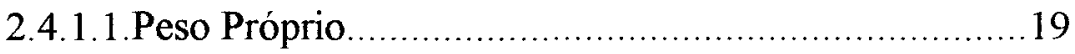


2.4.1.2.Revestimento.

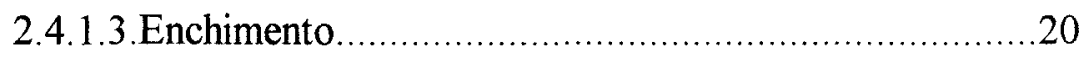

2.4.1.4.Ações provenientes às alvenarias............................21

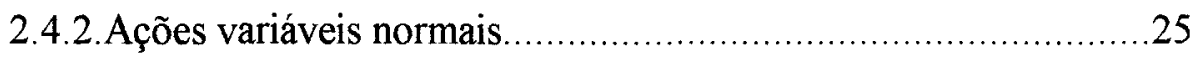

2.5.Comportamento estático das lajes nervuradas.................................26

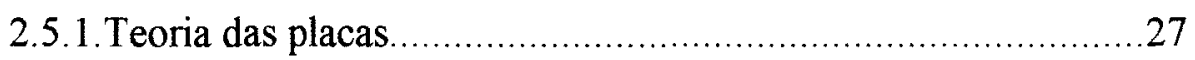

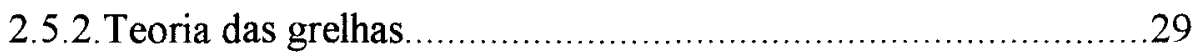

2.5.3.Estudo comparativo dos resultados obtidos na determinação dos esforços solicitantes...

3.VERIFICAÇÃO DA SEGURANÇA COM RELAÇÃO AOS ESTADOS LIMITES

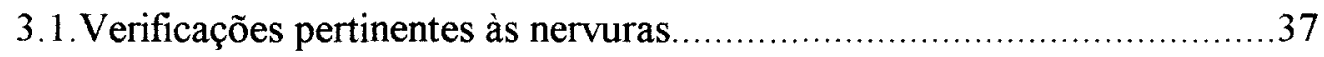

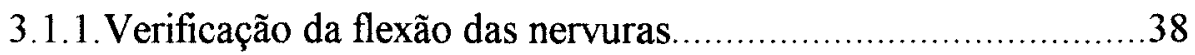

3.1.2. Verificação do cisalhamento nas nervuras..............................45

3.2. Verificação da resistência da mesa ..................................................50

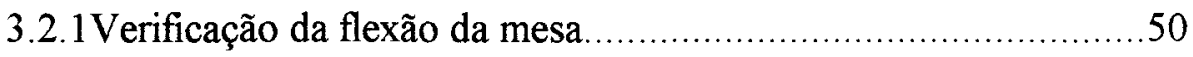

3.2.2. Verificação do cisalhamento na mesa................................51

3.3. Verificação das tensões de cisalhamento nas ligações mesa-nervura.......52

3.3.1. Verificação das tensões de cisalhamento nas ligações mesanervura com a mesa comprimida. .53

3.3.2. Verificação das tensões de cisalhamento nas ligações mesanervura com a mesa tracionada...... .57

3.4. Verificação do estado limite de deformação excessiva. 59

3.4.1.Definições e recomendações da Norma Brasileira de Projeto e Execução de Obras de Concreto Armado (NB-1/78). 60

3.4.2. Recomendações da Norma Brasileira de Projeto de Estruturas de Concreto Protendido (NB-116/89). 61

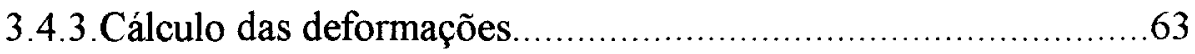

4.LAJES NERVURADAS MOLDADAS “IN LOCO” ...................................70

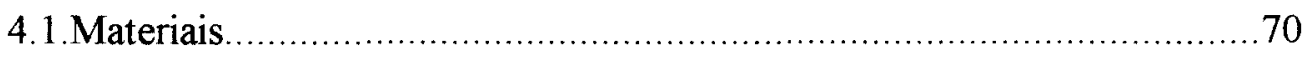

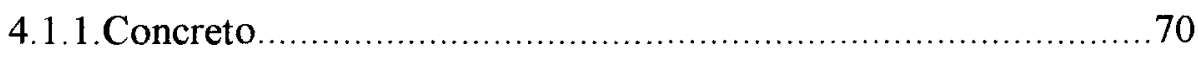




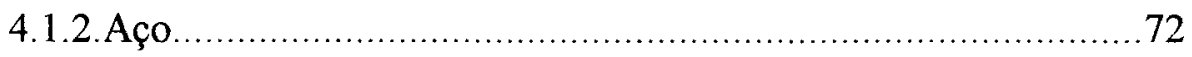

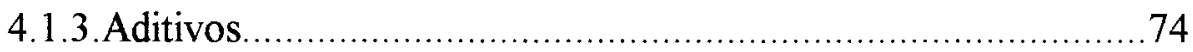

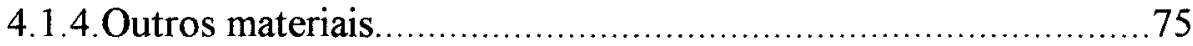

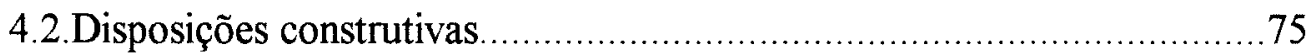

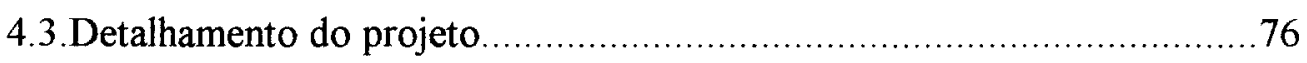

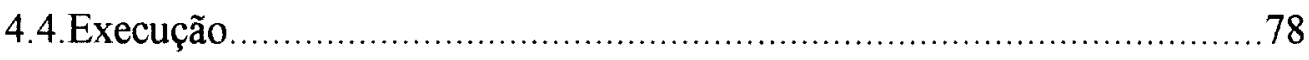

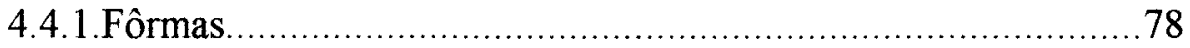

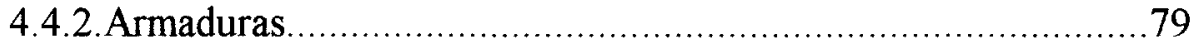

4.4.3.Preparação e lançamento do concreto .................................. 80

4.4.4.Adensamento do concreto................................................ 81

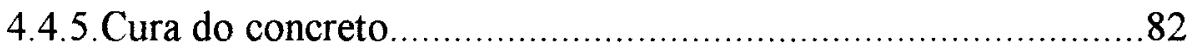

4.4.6.Retirada das fôrmas e dos escoramentos............................82

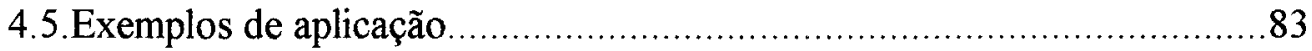

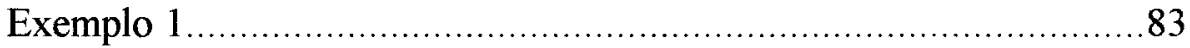

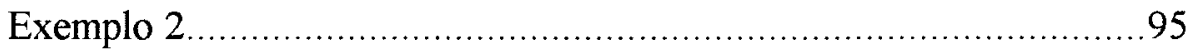

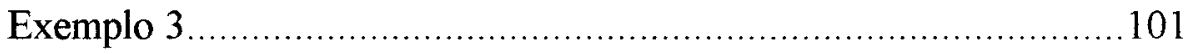

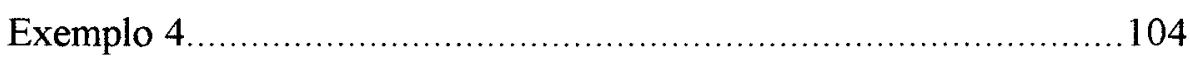

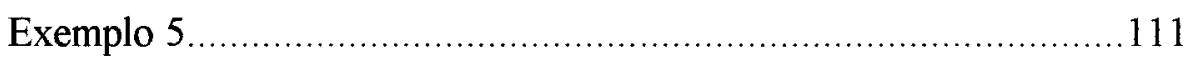

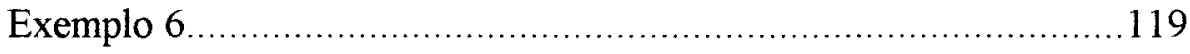

5.LAJES NERVURADAS PRÉ-MOLDADAS ........................................ 125

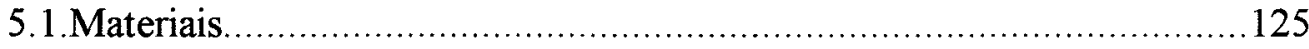

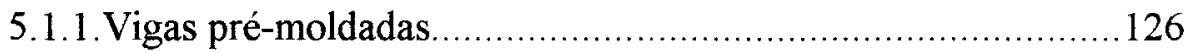

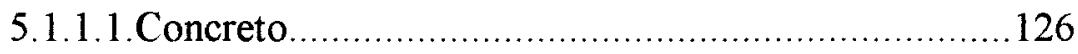

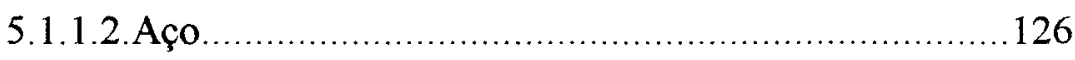

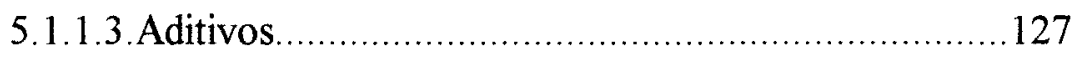

5.1.2. Capa ou mesa da laje nervurada pré-moldada.................... 127

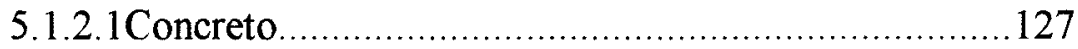

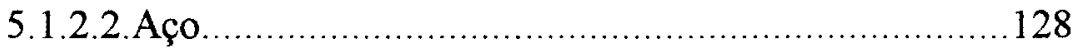

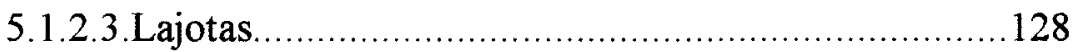

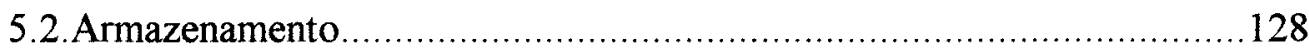

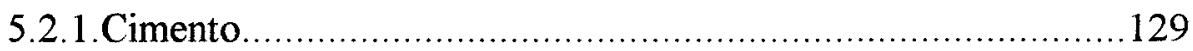


5.2.2. Agregados 129

5.2.3. Aço. 129

5.2.4.Aditivos. 130

5.3.Fabricação do elemento pré-moldado. 130

5.3.1.Fôrmas. 130

5.3.2.Limpeza e preparação das fồrmas. 131

5.3.3.Preparação do concreto. 132

5.3.4. Lançamento do concreto. 132

5.3.5. Armaduras 133

5.3.6. Vibração 134

5.3.7. Cura do concreto. 134

5.3.7.1. Cura normal do concreto 134

5.3.7.2. Cura acelerada do concreto 135

5.3.8. Codificação. 135

5.3.9.Desfồrma e estocagem das vigas. 136

5.3.10. Transporte das vigas 136

5.4. Técnicas de execução. 137

5.4.1.Planta de execução 137

5.4.2. Escoramento da laje. 138

5.4.3. Colocação das vigas 139

5.4.4. Colocação das lajotas. 140

5.4.5. Distribuição da armadura posicionada junto à face superior..... 141

5.4.6. Concretagem da capa ou mesa................................... 142

5.5.Presença de fissuras nas lajes nervuradas pré-moldadas...................... 144

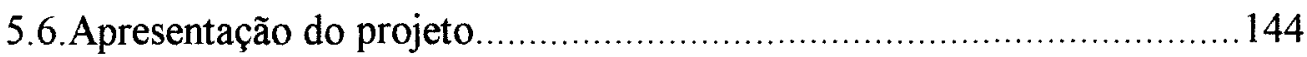

5.7. Observações gerais quanto às lajes nervuradas pré-moldadas...............145

5.7.1. Sobrecarga de utilização .................................................145

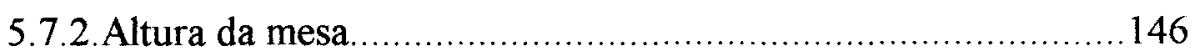

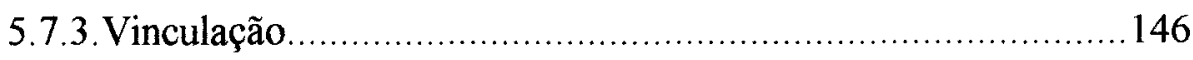

5.7.4. Verificação da mesa de concreto...................................... 147 
5.7.5. Verificação do cisalhamento na ligação concreto pré-moldado e concreto moldado "in loco" 154

5.8.Exemplo de aplicação. 155

6.CONCLUSÕES FINAIS. 175

7.REFERÊNCIAS BIBLIOGRÁFICAS 180

8.BIBLIOGRAFIA CONSULTADA. 182 


\section{LISTA DE FIGURAS}

Figura 1.1 - Laje nervurada normal (direta) ................................................. 4

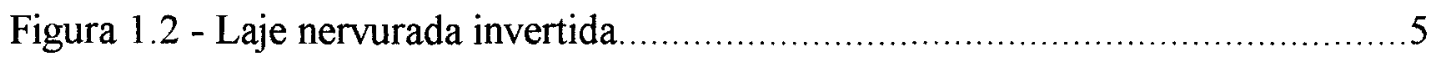

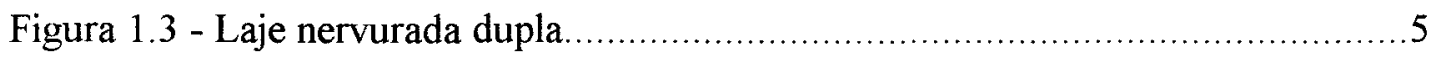

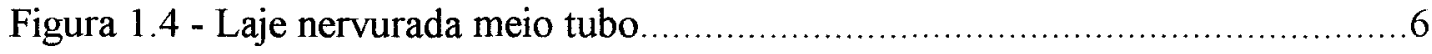

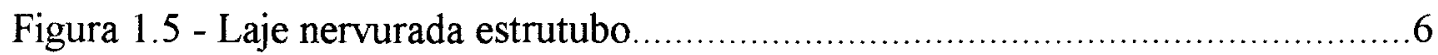

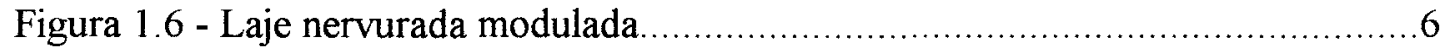

Figura 1.7 - Laje nervurada pré-moldada volterrana ....................................

Figura 1.8 - Laje nervurada pré-moldada treliça........................................... 7

Figura 2.1 - Laje nervurada em balanço ....................................................... 10

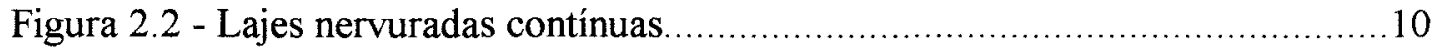

Figura 2.3 - Laje nervurada com as bordas apoiadas ......................................11

Figura 2.4 - Diagrama de momentos fletores para as lajes nervuradas contínuas

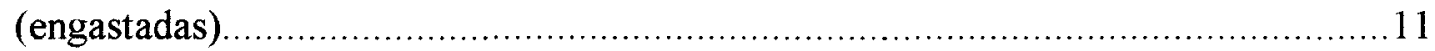

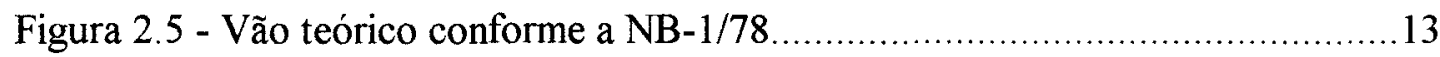

Figura 2.6 - Bloco utilizado na execução das lajes nervuradas............................21

Figura 2.7 - Distribuição de ações de alvenaria ................................................22

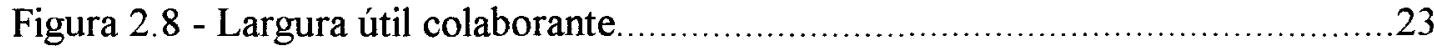

Figura 2.9 - Largura útil colaborante(simplificação) ….......................................23

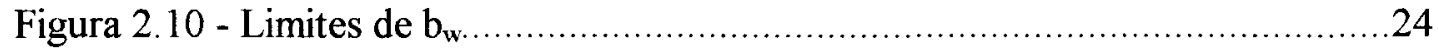

Figura 2.11 - Ilustração do sistema de coordenadas.............................................28

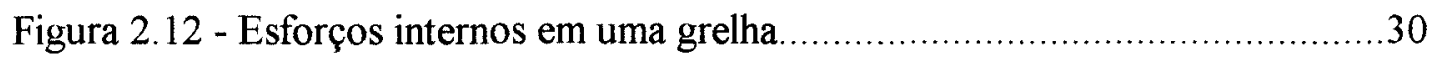

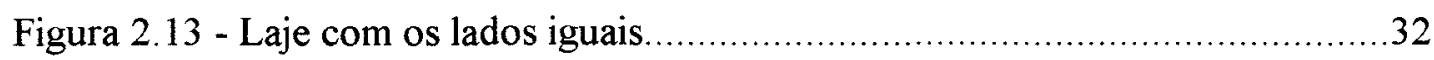

Figura 2.14 - Largura colaborante de viga de seção T, segundo a NB-1/78 ............36 
Figura 3.1 - Mesa da laje nervurada na face tracionada ..................................... 38

Figura 3.2 - Linha neutra na mesa da laje nervurada ............................................39

Figura 3.3 - Linha neutra na alma da laje nervurada (processo simplificado).............39

Figura 3.4 - Laje nervurada com mesa invertida................................................40

Figura 3.5 - Verificação das nervuras à flexão (diagrama retangular de tensões no

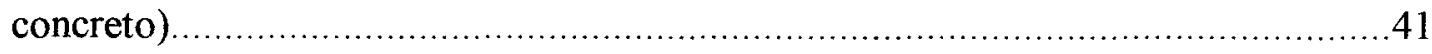

Figura 3.6 - Cisalhamento nas nervuras das lajes nervuradas ..............................45

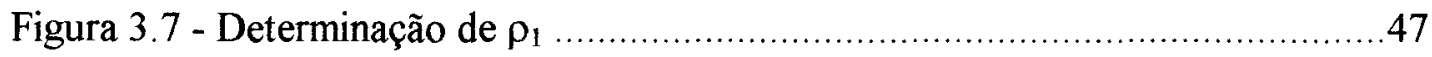

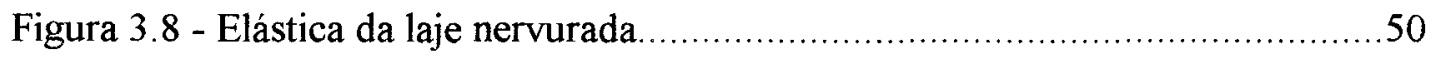

Figura 3.9 - Elástica da mesa........................................................... 51

Figura 3.10 - Elemento de argura $\mathrm{dx}$ de uma viga de seção $\mathrm{T}$ solicitada à flexão $\mathrm{e}$

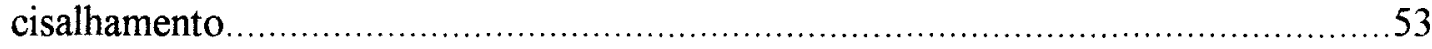

Figura 3.11 - Representação das forças de compressão atuantes no concreto...........54

Figura 3.12 - Armadura para absorver os esforços de tração provocados por $\tau_{\text {md }} \ldots .55$

Figura 3.13 - Elemento de largura dx de uma viga de seção $\mathrm{T}$ solicitada à flexão e

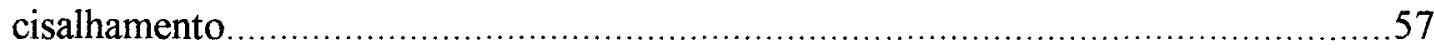

Figura 3.14 - Armadura para absorver aos esforços de tração provocados por $\tau_{\mathrm{md}} \ldots 58$

Figura 3.15 - Deslocamento para laje armada em uma direção, com carregamento

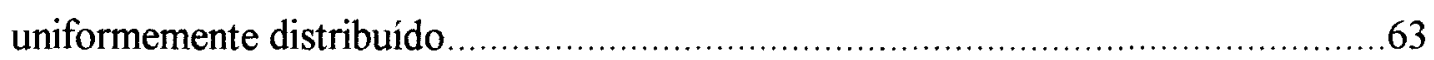

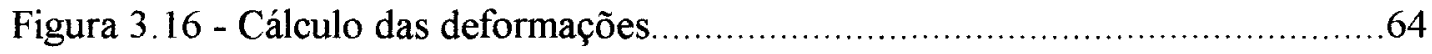

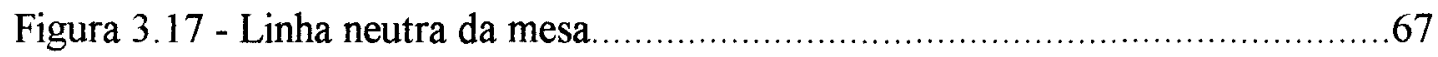

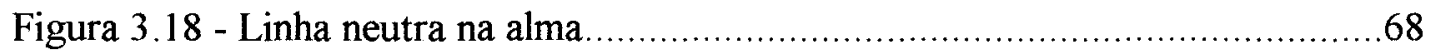

Figura 4.1 - Diagrama tensão-deformação do concreto.........................................71

Figura 4.2 - Aços empregados na execução das estruturas de concreto armado........73

Figura 4.3 - Diagrama tensão-deformação simplificado para os aços classe A, segundo

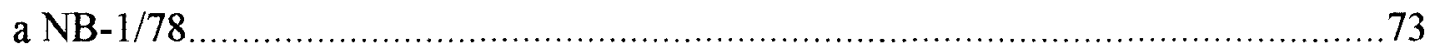

Figura 4.4 - Diagrama tensão-deformação simplificado para os aços classe B, segundo

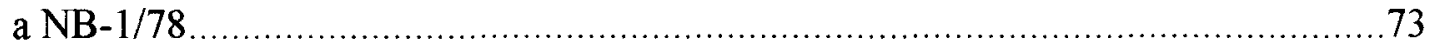

Figura 4.5 - Detalhamento de uma laje nervurada de concreto armado .................77

Figura 4.6 - Montagem dos blocos para as lajes nervuradas moldadas "in loco"......79

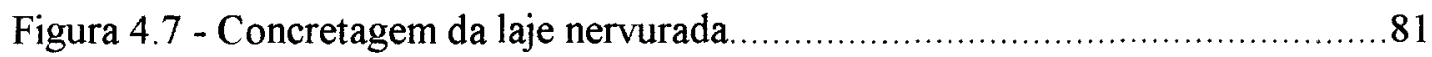


Figura 4.8 - Laje com nervuras nas duas direções $(a>50 \mathrm{~cm}) \ldots \ldots \ldots \ldots \ldots \ldots \ldots \ldots . \ldots \ldots$

Figura 4.9 - Seção à ser considerada para as direções x e y .................................8. 84

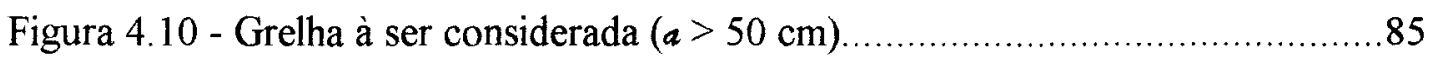

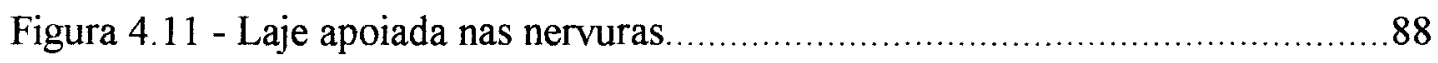

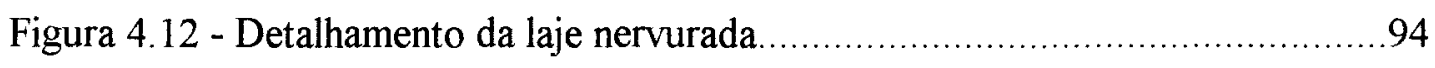

Figura 4.13 - Laje com nervuras nas duas direções $(a \leq 50 \mathrm{~cm}) \ldots \ldots \ldots \ldots \ldots \ldots \ldots \ldots . . . \ldots 5$

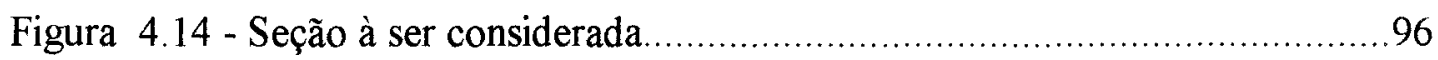

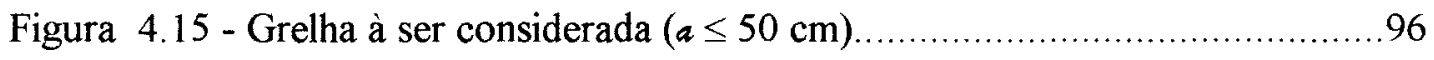

Figura 4.16 - Detalhamento da laje nervurada............................................ 100

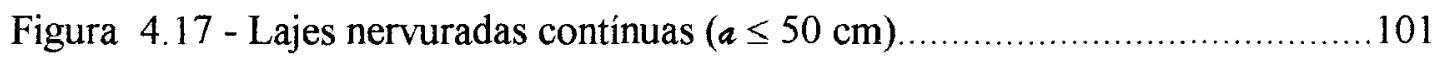

Figura 4.18 - Esquema estático das lajes contínuas.......................................... 101

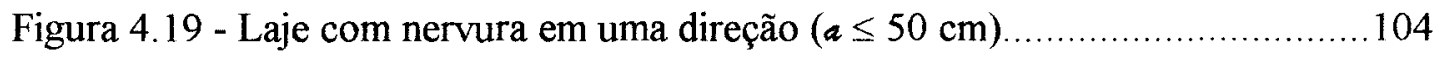

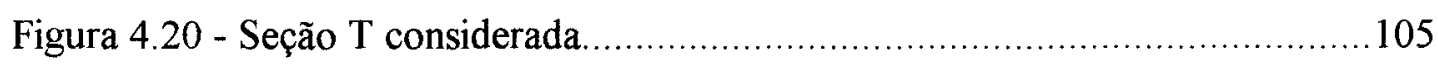

Figura 4.21 - Esquema estático da laje nervurada com nervura em uma direção.....105

Figura 4.22 - Detalhamento da laje nervurada.......................................... 110

Figura 4.23 - Laje com nervuras em uma direção $(a<50 \mathrm{~cm})$, com paredes apoiadas

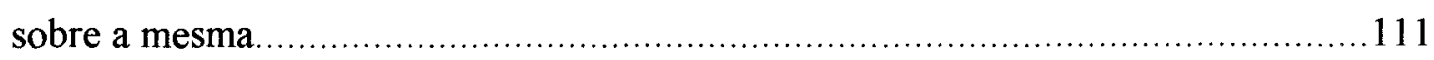

Figura 4.24 - Detalhamento da laje nervurada ........................................... 118

Figura 4.25 - Laje com nervuras em uma direção, sendo parte em balanço............119

Figura 4.26 - Esquema estático da laje com nervuras em uma direção, sendo parte em

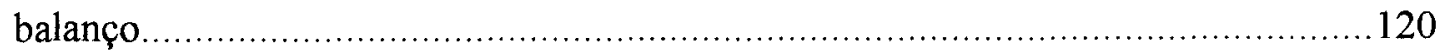

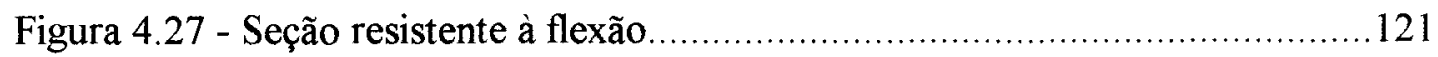

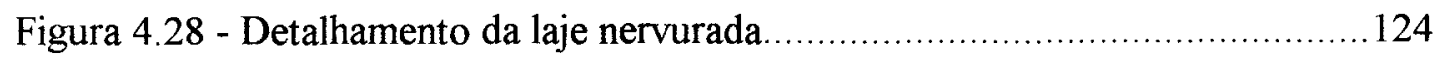

Figura 5.1 - Fôrmas para vigas das lajes tipo volterrana................................131

Figura 5.2 - Fôrmas para vigas com treliças................................................. 131

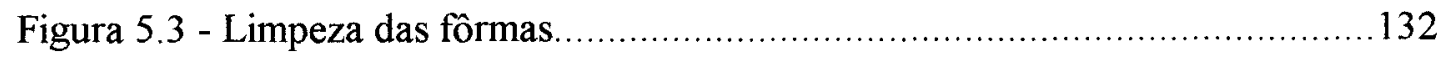

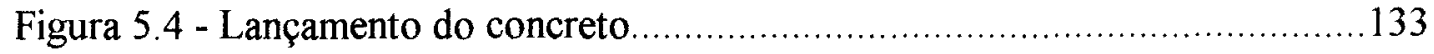

Figura 5.5 - Colocação das armaduras ................................................. 133

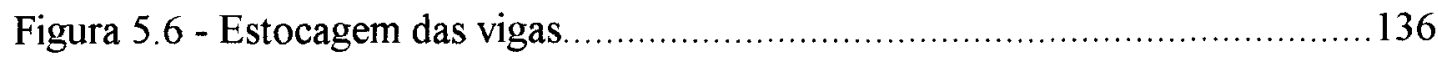

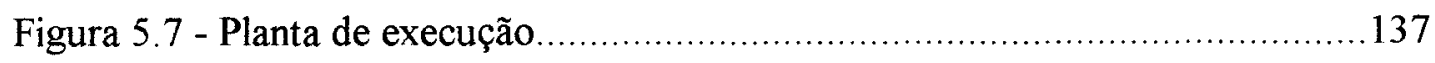




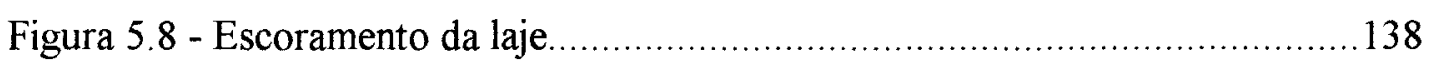

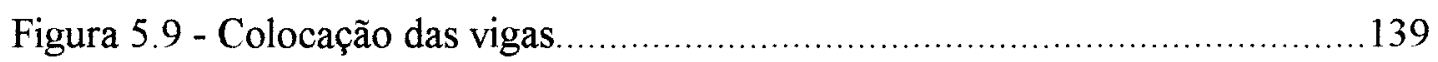

Figura 5.10 - Laje com nervuras nas duas direções............................................... 140

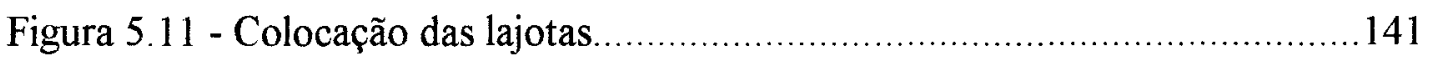

Figura 5.12 - Distribuição da armadura posicionada junto à face superior da mesa. 142

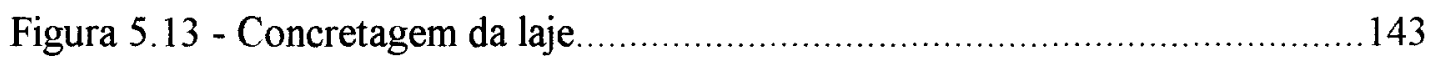

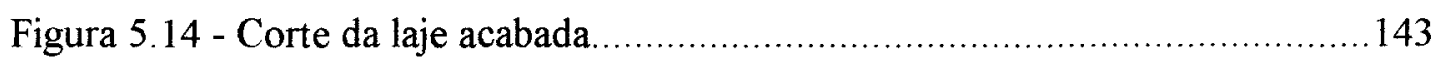

Figura 5.15 - Simbologia empregada na planta de execução das lajes nervuradas pré-

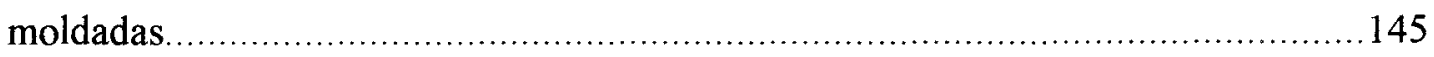

Figura 5.16 - Alguns detalhes das lajes nervuradas pré-moldadas..........................147

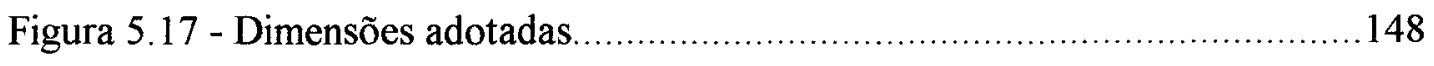

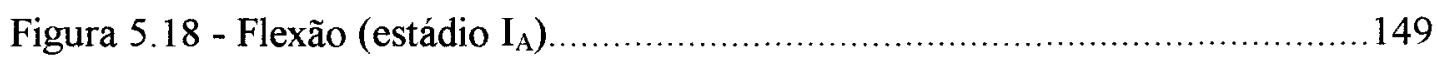

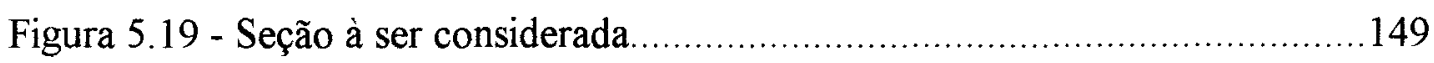

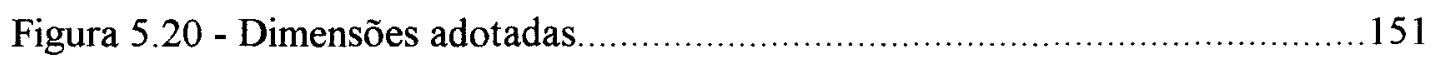

Figura 5.21 - Planta baixa do projeto exemplo................................................... 156

Figura 5.22 - Planta de fồrma fornecida pelo engenheiro de estruturas....................159

Figura 5.23 - Seção transversal da laje nervurada pré-moldada ............................... 162

Figura 5.24 - Planta de execução fornecida pelo fabricante...................................171 


\section{LISTA DE TABELAS}

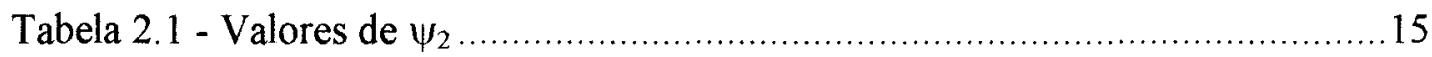

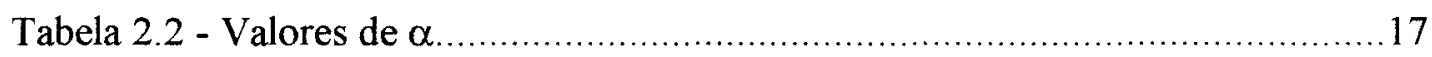

Tabela 2.3 - Valores dos momentos fletores obtidos pelos processos estudados.......32

Tabela 3.1 - Flexão simples em seção retangular...............................................4

Tabela 5.1 - Verificação das tensões oriundas da flexão e do cisalhamento na mesa das lajes nervuradas, altura da mesa $\left(\mathrm{h}_{\mathrm{f}}\right)$ de $3 \mathrm{~cm}$. 152

Tabela 5.2 - Verificação das tesnões oriundas da flexão e do cisalhamento na esa das

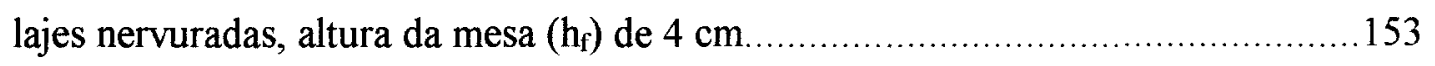

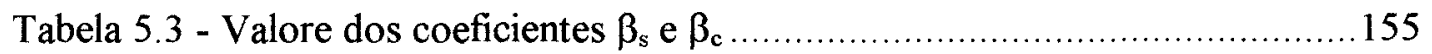

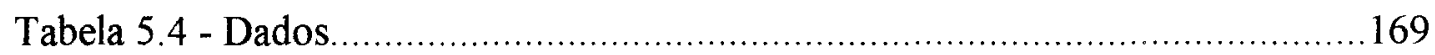

Tabela 5.5 - Verificação quanto ao estado limite último.................................. 169

Tabela 5.6 - Verificação quanto ao estado limite de deformação..........................169

Tabela 5.7 - Verificação quanto ao estado limite de deformação..........................170 


\section{LISTA DE SÍMBOLOS}

a - distância livre entre nervuras, $\mathrm{cm}$

a - deslocamento inicial, $\mathrm{cm}$

A - área da seção transversal, $\mathrm{cm}^{2}$

$A_{c} \quad$ - área da seção de concreto, $\mathrm{cm}^{2}$

$A_{c} \quad$ - área limitada pela linha média da parede, incluindo a parte vazada, $\mathrm{cm}^{2}$

a. - deslocamento final, $\mathrm{cm}$

$\mathrm{A}_{90}$ - área da seção transversal de um estribo, $\mathrm{cm}^{2}$

$A_{s} \quad$ - área da seção de armadura, $\mathrm{cm}^{2}$

$\mathrm{A}_{\mathrm{sl}}$ - soma das áreas das seções das barras longitudinais, $\mathrm{cm}^{2}$

$\mathrm{A}_{\mathrm{st}}$ - área da seção de armadura na ligação mesa-nervura, $\mathrm{cm}^{2}$

$A_{\mathrm{sw}}$ - área da seção de armadura tranversal, $\mathrm{cm}^{2}$

$\alpha$ - coeficiente para determinação de $\psi_{4}$

$\alpha$ - coeficiente para estimativa da altura das lajes, segundo o CEB

$\alpha_{e}$ - relação entre os módulos de deformação do aço e do concreto

$b_{f}$ - largura da mesa, $\mathrm{cm}$

$b_{w}$ - largura da nervura, $\mathrm{cm}$

$\beta_{c} \quad$ - coeficiente para a determinação de $\tau_{\mathrm{sd}}$

$\beta_{\mathrm{s}} \quad$ - coeficiente para a determinação de $\tau_{\mathrm{sd}}$

d - altura útil da laje, $\mathrm{cm}$

D - rigidez da placa, $\mathrm{cm}^{4}$

$\mathrm{E}^{*}$ - módulo de deformação longitudinal do concreto fissurado, $\mathrm{MPa}$

$E_{c}$ - módulo de deformação longitudinal do concreto, MPa

$\mathrm{E}_{\mathrm{s}}$ - módulo de deformaçãolongitudinal do aço, MPa 
$\varepsilon_{\mathrm{c}} \quad$ - deformação específica no concreto

$\varepsilon_{\mathrm{s}}$ - deformação específica no aço

$\mathrm{f}_{\mathrm{cd}}$ - resistência de cálculo do concreto à compressão, MPa

$\mathrm{f}_{\mathrm{ck}}$ - resistência característica do concreto à compressão, aos 28 dias, $\mathrm{Mpa}$

$F_{m d}$ - força atuante na ligação concreto pré-moldado - concreto moldado in loco, $\mathrm{kN}$

$f_{\text {td }}$ - resistência de cálculo do concreto à tração, $\mathrm{MPa}$

$\mathrm{f}_{\mathrm{tk}}$ - resistência característica do concreto à tração, $\mathrm{MPa}$

$f_{y d}$ - resistência de cálculo do aço, $\mathrm{MPa}$

$\mathrm{f}_{\mathrm{yk}}$ - resistência característica do aço, Mpa

$\phi \quad$ - coeficiente de majoração da carga em garagens e estacionamentos

$\mathrm{g}$ - ações permanentes, $\mathrm{kN} / \mathrm{m}^{2}$

$\mathrm{G}_{\mathrm{c}}$ - módulo de deformação transversal do concreto, Mpa

$\gamma_{c}$ - coeficiente de minoração do concreto

$\gamma_{\mathbf{f}}$ - coeficiente de majoração das ações

$\gamma_{\mathrm{s}}$ - coeficiente de minoração do aço

h - altura da laje nervurada, $\mathrm{cm}$

$h_{\mathrm{eq}}$ - altura equivalente, $\mathrm{cm}$

$\mathrm{h}_{\mathrm{f}}$ - altura da mesa, $\mathrm{cm}$

I - momento de inércia à flexão da seção transversal, $\mathrm{cm}^{4}$

$I_{e}$ - momento de inércia equivalente dado pela Fórmula de Bränson, $\mathrm{cm}^{4}$

$\mathrm{I}_{\mathrm{t}}$ - momento de inércia à torção da seção transversal $\mathrm{cm}^{4}$

k - coeficiente para determinação de $\psi_{4}$

$k_{c} \quad$ - coeficiente para o cálculo da armadura de peças, com seções retangulares, de concreto armado sujeitas à flexão simples, $\mathrm{cm}^{2} / \mathrm{kN}$

$\mathrm{k}_{\mathrm{s}} \quad$ - coeficiente para o cálculo da armadura de peças, com seções retangulares, de concreto armado sujeitas à flexão simples, $\mathrm{cm}^{2} / \mathrm{kN}$

$\ell$ - vão da laje, cm

$\mathrm{M}_{\mathrm{d}}$ - momento fletor de cálculo, $\mathrm{kN} . \mathrm{cm}$

$\mathrm{M}_{\mathrm{k}}$ - momento fletor característico, $\mathrm{kN} . \mathrm{cm}$ 
$\mathrm{M}_{\mathrm{r}}$ - momento de fissuração do concreto, $\mathrm{kN} . \mathrm{cm}$

$\mathrm{M}_{\mathrm{tot}}$ - momento fletor de todas as ações atuantes, $\mathrm{kN} . \mathrm{cm}$

$\mu$ - coeficiente para a determinação dos momentos fletores em placas

n - número de ramos dos estribos

$v$ - coeficiente de Poisson do concreto

$\mathrm{p}$ - carregamento uniformemente distribuído, $\mathrm{kN} / \mathrm{m}$

$\psi_{1}$ - coeficiente para determinação de $\tau_{\mathfrak{c}}$

$\psi_{2}$ - coeficiente da NB-1/78 para estimativa da altura das lajes

$\psi_{3}$ - coeficiente da NB-1/78 para estimativa da altura das lajes

$\psi_{4}$ - coeficiente para a determinação de $\tau_{\mathrm{wu} 1}$

q - ações variáveis, $\mathrm{kN} / \mathrm{m}^{2}$

$\mathrm{R}_{\mathrm{cc}}$ - força resultante de compressão no concreto, $\mathrm{kN}$

$\mathrm{R}_{\mathrm{ct}}$ - força resultante de tração no concreto, $\mathrm{kN}$

$\mathrm{R}_{\mathrm{st}}$ - força resultante de tração na armadura, $\mathrm{kN}$

$\rho_{1}$ - taxa de armadura

S - espaçamento dos estribos

$\sigma_{\mathrm{cc}}-$ tensão de compressão no concreto, MPa

$\sigma_{\mathrm{s}}$ - tensão na armadura, $\mathrm{MPa}$

$\sigma_{\text {sd }}$ - tensão de cálculo na armadura, MPa

$\tau_{\mathrm{c}} \quad$ - tensão de cisalhamento a ser decrescida da tensão de cálculo, para determinação da armadura transversal, MPa

$\tau_{\mathrm{d}} \quad$ - tensão de cisalhamento de cálculo para determinação da armadura transversal, MPa

$\tau_{\mathrm{md}}$ - tensão de cisalhamento na ligação mesa-nervura, MPa

$\tau_{\text {sd }}$ - tensão de cisalhamento na ligação concreto pré-moldado - concreto moldado in loco, MPa

$\tau_{\text {wd }}$ - tensão de cisalhamento de cálculo, MPa

$\tau_{\mathrm{wu}}$ - valor último de $\tau_{\mathrm{wd}}, \mathrm{MPa}$

$\tau_{\text {wul }}$ - valor de referência para a verificação do cisalhamento em lajes, Mpa

u - perímetro de $A_{e}, \mathrm{~cm}$

$\mathrm{V}_{\mathrm{d}}$ - valor de cálculo da força cortante, $\mathrm{kN}$ 
$\mathrm{V}_{\mathrm{k}}$ - valor característico da força cortante, $\mathrm{kN}$

$\mathrm{x}$ - posição da linha neutra, $\mathrm{cm}$ 


\section{RESUMO}

As lajes nervuradas de concreto armado são constituídas por vigas solidarizadas por uma mesa de concreto, estas lajes podem ser totalmente moldadas "in loco", ou possuirem parte das vigas (nervuras) pré-moldadas.

Existem algumas particularidades tanto no dimensionamento, desde a obtenção dos esforços solicitantes, quanto na execução das lajes nervuradas. O conhecimento dessas particularidades, bem como o caminhamento correto, desde o projeto até a execução das lajes é fundamental para o bom desempenho das mesmas, de maneira segura e econômica. Estas particularidades são analisadas, incluindo-se algumas recomendações das normas, sendo apresentados resultados e comentários embasados na bibliografia pesquisada e algumas considerações do autor deste trabalho.

Analisam-se, também, através de exemplos de aplicação os casos mais comuns de lajes nervuradas, inclusive com o detalhamento das armaduras. 


\section{ABSTRACT}

The rib reinforced concrete slabs are made solid beams on a concrete table; these slabs can be completely shaped in loco or they have a part of the beams pre-shaped.

There are some particularities even in the dimensions (since the acquisition of the solicitant efforts) as in the execution of the rib reinforced concrete slabs. The knowledge of these particularities, as well as the correct procedures, since the project till the execution of the slabs is fundamental for the good perfomance of them, in a safe and economic mood. These particularities are analysed including some recommendations of the norms; the results and the commentaries are based and presented in the researched bibliography and some considerations of the author of this work.

The most common cases of the rib reinforced concrete slabs are analysed through application examples, including the armature details. 


\section{INTRODUÇÃO}

\subsection{PRELIMINARES}

A crescente necessidade de racionalização na construção civil com a minimização dos custos e prazos vem fazendo das lajes nervuradas uma opção cada vez mais difundida. Entende-se por lajes nervuradas aquelas que a mesa de concreto resiste aos esforços de compressão e as armaduras aos esforços de tração, sendo que uma nervura de concreto faz a ligação mesa-armadura.

O presente trabalho tem por objetivo servir como roteiro de projeto, desde os processos empregados na obtenção dos esforços solicitantes, verificação quanto à segurança (estado limite de utilização e último), diferenciação entre os diversos tipos de lajes nervuradas, detalhamento de projeto até as recomendações pertinentes à execução. Para tanto, este trabalho divide-se em sete capítulos conforme descreve-se abaixo:

1 - Introdução

2 - Considerações Gerais Quanto às Lajes Nervuradas

3 - Verificação da Segurança Quanto aos Estados Limites

4 - Lajes Nervuradas Moldadas no Local

5 - Lajes Nervuradas Pré-Moldadas

6 - Conclusões Finais

7 - Referências Bibliográficas 


\subsection{OBJETIVOS}

Destacam-se entre os principais objetivos deste trabalho:

- reunir em um único trabalho recomendações pertinentes às lajes nervuradas, encontradas em publicações da bibliografia técnica;

- apresentar os diferentes tipos de lajes nervuradas de concreto armado, hoje empregadas;

- fazer o estudo comparativo dos processos empregados na obtenção dos esforços solicitantes e considerações a serem feitas;

- verificações quanto à segurança das lajes nervuradas para os estados últimos e de utilização;

- estudos sobre as lajes nervuradas pré-moldadas, incluindo-se a fabricação do elemento pré-moldado e o projeto de execução;

- servir como roteiro de projeto para as lajes nervuradas, inclusive com exemplos de aplicação;

\subsection{APRESENTAÇÃO}

No capítulo 1 deste trabalho apresenta-se os objetivos da pesquisa, além de ilustrar os tipos mais comuns de lajes nervuradas desenvolvidas atualmente.

O capitulo 2 aborda todas as considerações preliminares que permitem a determinação dos esforços solicitantes nas lajes nervuradas. Entende-se por considerações preliminares todas aquelas referentes ao pré-dimenssionamento e a determinação das ações atuantes. Na obtenção dos esforços solicitantes analisam-se os resultados advindos da teoria das placas, através de emprego de tabelas (cálculo simplificado) e da teoria das grelhas com o emprego do programa GPLAN3. 
A verificação da segurança das lajes nervuradas quanto aos estados limite último e dos estados limite de utilização é analisada no capítulo 3. Aborda-se todas as verificações exigidas pela norma brasileira NB-1/78 (1978), o cálculo da armaduras correspondentes em cada caso, a necessidade ou não de contraflecha, as considerações e simplificações possíveis.

$\mathrm{O}$ capitulo 4 refere-se exclusivamente às lajes nervuradas moldadas no local, destacam-se a forma de apresentação do projeto estrutural das lajes nervuradas. Apresenta-se também a verificação de lajes, como exemplos ilustrativos, além de algumas recomendações pertinentes à execução.

No capítulo 5, aborda-se as lajes nervuradas pré-moldadas. Apresenta-se as técnicas empregadas pelos fabricantes da porção pré-moldada (vigas) incluindo-se as verificações pertinentes. Destaca-se o detalhamento do projeto, principalmente como deve-se apresentar um projeto de estrutura com laje nervurada pré-moldada e como o fabricante deve fornecer o projeto de execução das lajes nervuradas pré-moldadas. Neste capítulo também apresenta-se um exemplo ilustrativo, e as recomendações relativas à execução.

O capítulo 6 apresenta as conclusões obtidas na elaboração deste trabalho, bem como as indicações para o prosseguimento da pesquisa.

No capítulo 7 apresenta-se toda referência bibliográfica devidamente normalizada, citada neste trabalho.

\subsection{TIPOLOGIA DAS LAJES NERVURADAS DE CONCRETO ARMADO}

Entende-se por tipologia das lajes nervuradas as várias modalidades de lajes com comportamento estático de uma laje nervurada. Neste trabalho dividiu-se em dois grandes grupos as lajes nervuradas:

- lajes nervuradas moldadas "in loco"

- lajes nervuradas pré-moldadas. 
Embora o funcionamento estático dos dois grupos seja bastante semelhante, existem algumas diferenças principalmente quanto à execução.

- Lajes Nervuradas moldadas "in loco"

As lajes nervuradas moldadas "in loco" são aquela executadas em toda sua totalidade na obra, na posição definitiva. Existem várias classificações para este tipo de lajes, tanto quanto à forma como quanto aos materiais empregados.
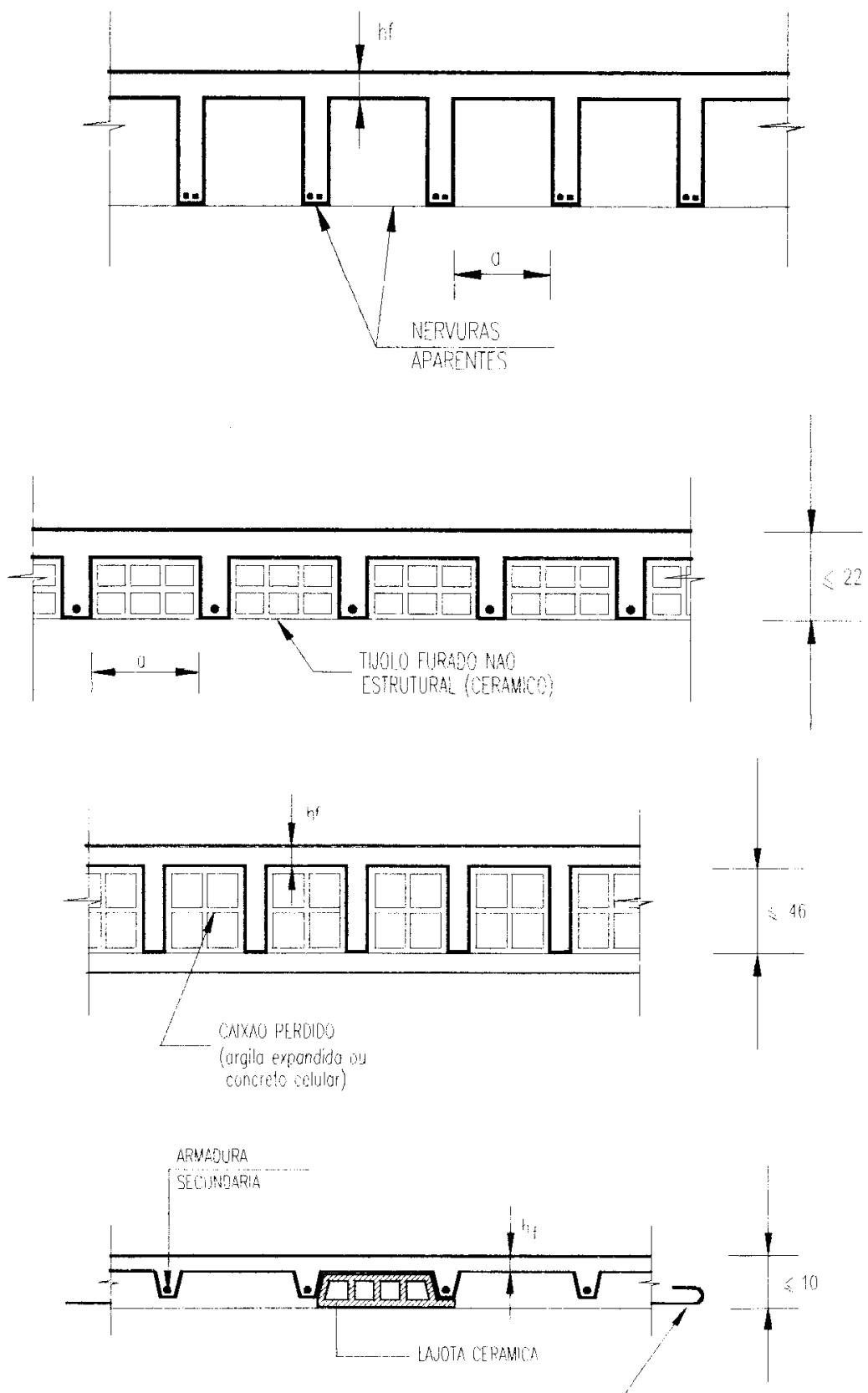

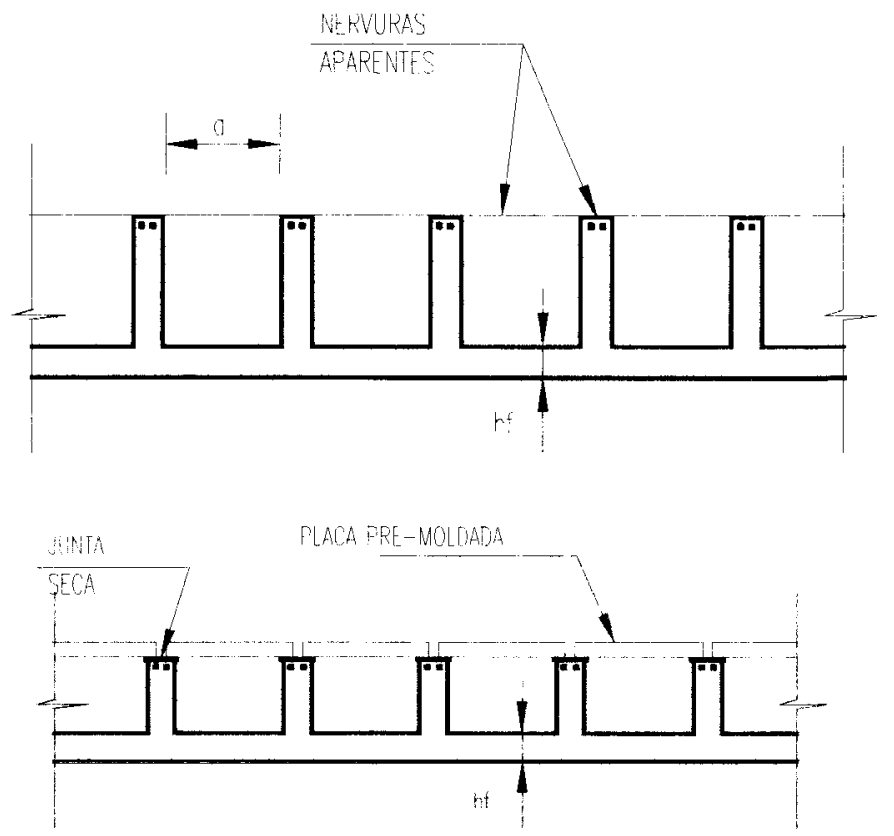

FIGURA 1.2 - LAJE NERVURADA INVERTIDA
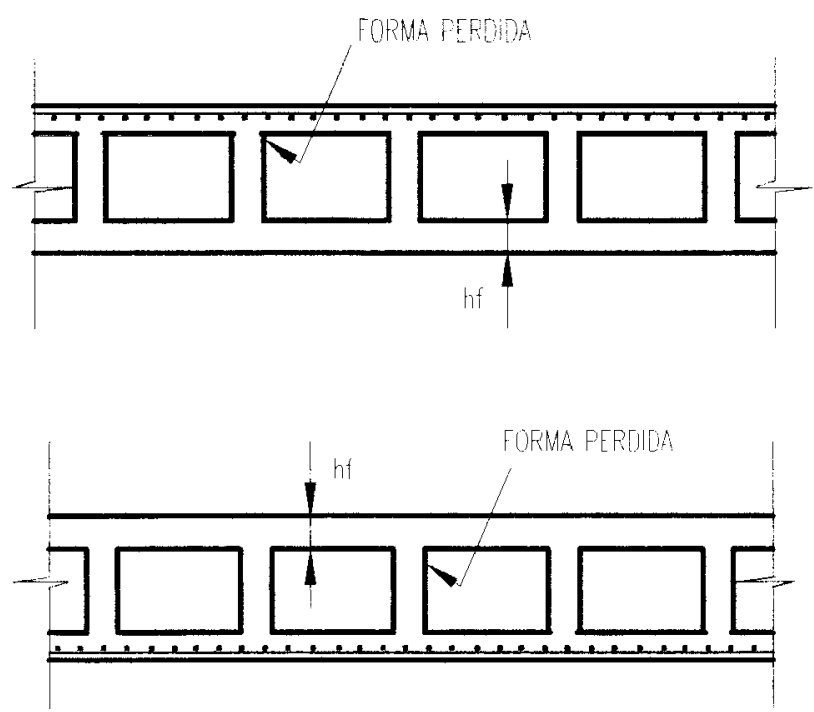

FIGURA 1.3 - LAJE NERVURADA DUPLA 


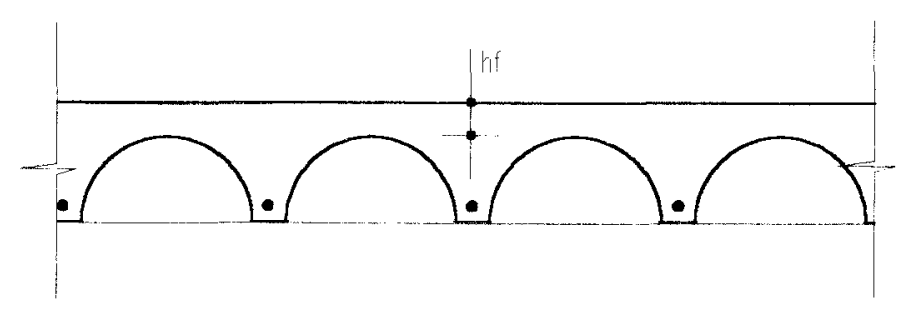

FIGURA 1.4 - LAJE NERVURADA MEIO TUBO

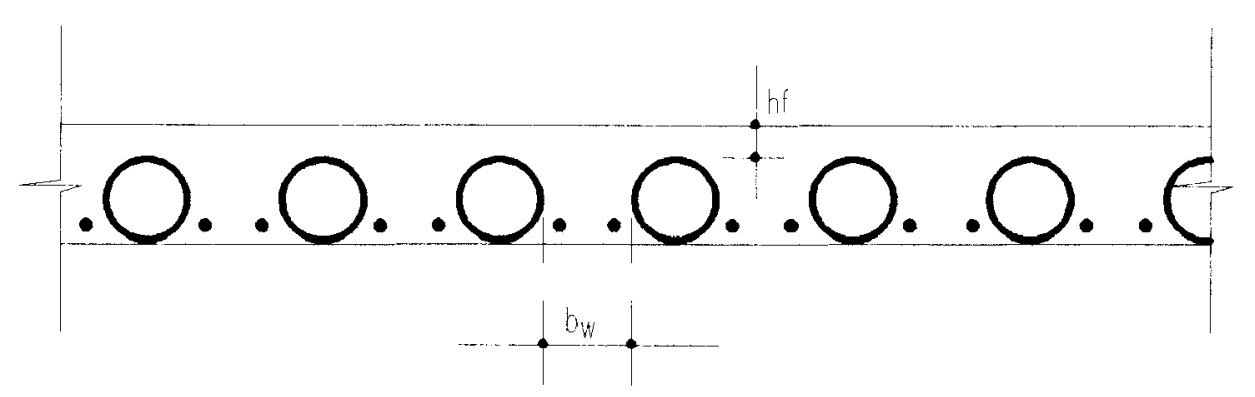

FIGURA 1.5 - LAJE NERVURADA ESTRUTUBO

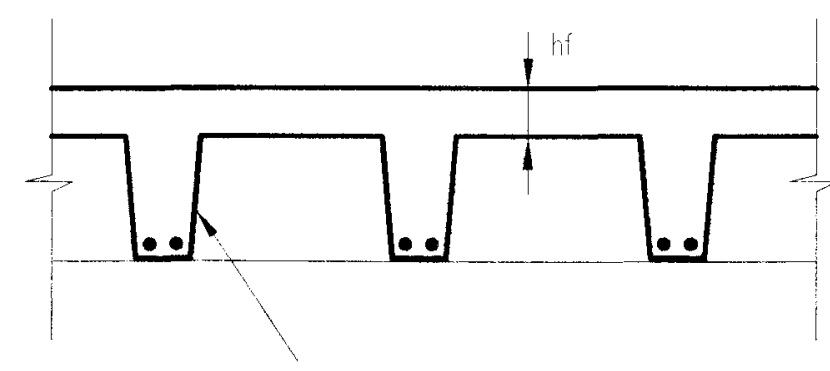

INCLINACAD P/ FACULIAR A

RETIRADA DA FOFMA

(FORMA METALLA)

FIGURA 1.6 - LAJE NERVURADA MODULADA

Fôrma metálica ou de fibra para atender exigências arquitetônicas.

A tendência atual é para o emprego de lajes nervuradas conforme a figura 1.1, com blocos, principalmente de blocos de baixa densidade como fồma perdida, tendo como vantagens redução do peso próprio da laje, redução da quantidade de fồrmas, agilização da obra com redução da mão-de-obra. Para estas lajes nervuradas pode-se ter também fôrmas metálicas de fibra a fim de atender-se as exigências arquitetônicas. 
- Lajes Nervuradas Pré-Moldadas:

Entende-se por lajes nervuradas pré-moldadas aquelas em que parte da laje é executada fora do local definitivo.
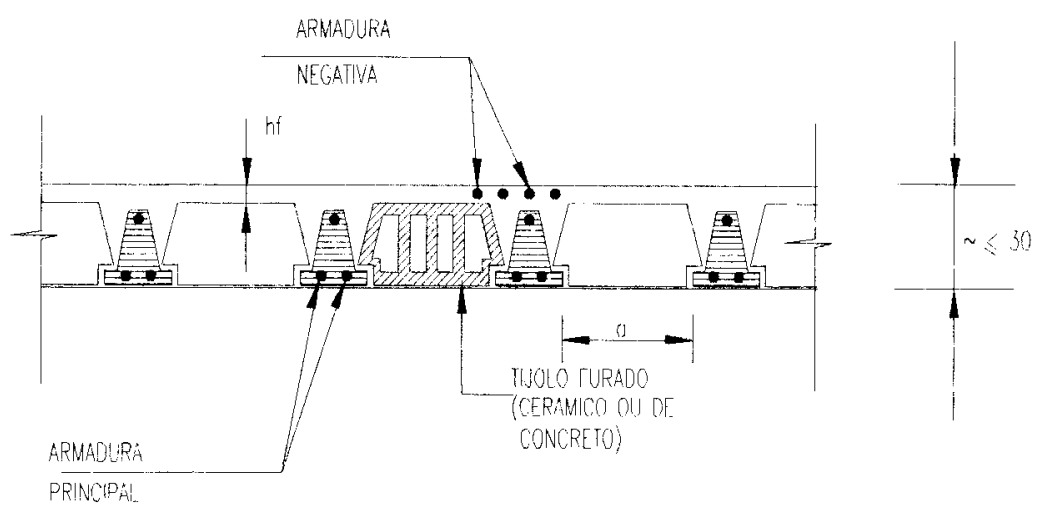

FIGURA 1.7 - LAJE NERVURADA PRÉ-MOLDADA VOLTERRANA

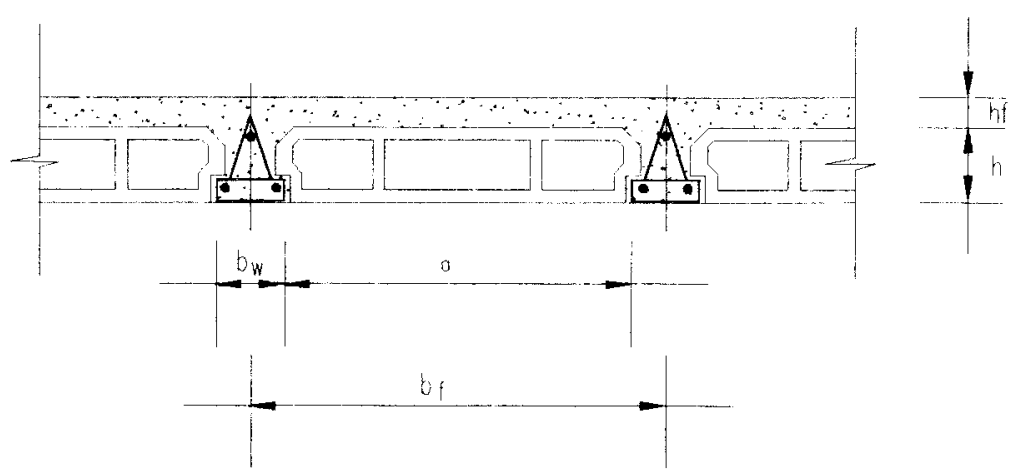

FIGURA 1.8 - LAJE NERVURADA PRÉ-MOLDADA TRELIÇA

Nestes dois tipos de lajes parte da nervura é executada fora do local onde a laje deverá permanecer. Na obra montam-se a laje e concreta-se a parte restante da nervura e a mesa de concreto.

Em muitas publicações, e em catálogos de fabricantes de lajes muitas vezes este tipo de laje também é chamado de laje mista. Segundo a NB-4/78 (1978) entende-se por laje mista como sendo aquela em que o material de enchimento, no caso blocos cerâmicos ou de concreto, colaboram na resistência da laje. Sabe-se que a resistência dos blocos é muito pequena se comparada com o concreto, sendo assim, desprezível. Logo não temos lajes mistas e sim lajes nervuradas em que os blocos servem apenas como fôrma para as lajes. 
Outras modalidades de lajes nervuradas moldadas "in loco" ou lajes nervuradas pré-moldadas também podem ser encontradas mas com menor freqüência. 


\section{CONSIDERAÇÕES GERAIS SOBRE AS LAJES NERVURADAS}

\subsection{VINCULAÇÃO DAS LAJES NERVURADAS}

As lajes nervuradas, bem como as lajes maciças, podem ter suas bordas apoiadas, engastadas ou em balanço (figuras $2.1,2.2$ e 2.3). Entretanto, recomenda-se, para as lajes nervuradas de concreto armado evitar engastes e balanços, visto que, nestes casos têm-se esforços de tração na face superior, onde encontra-se a mesa de concreto, e esforços de compressão na parte inferior, região em que a área de concreto é reduzida. Sabe-se que o concreto é um material que apresenta elevada resistência à compressão e baixa resistência à tração, sendo assim, necessário aumentar-se as seções, ou utilizar-se de uma mesa na parte inferior, implicando em aumento do peso próprio da estrutura e elevação dos custos da obra (figura 2.4).

A prática usual consiste em fazer painéis com vãos maiores que os das lajes maciças, apoiados em vigas mais rígidas que as nervuras. 

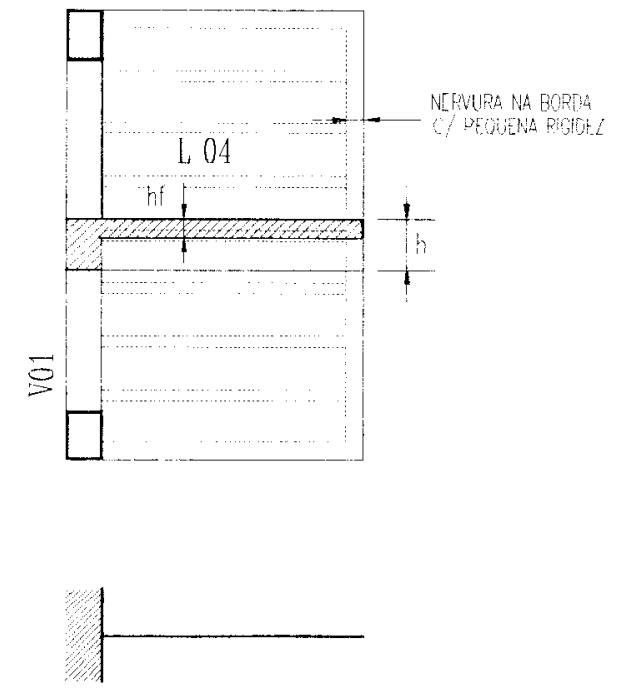

ESQLIFMA FSTATICO

FIGURA 2.1 - LAJE NERVURADA EM BALANÇO
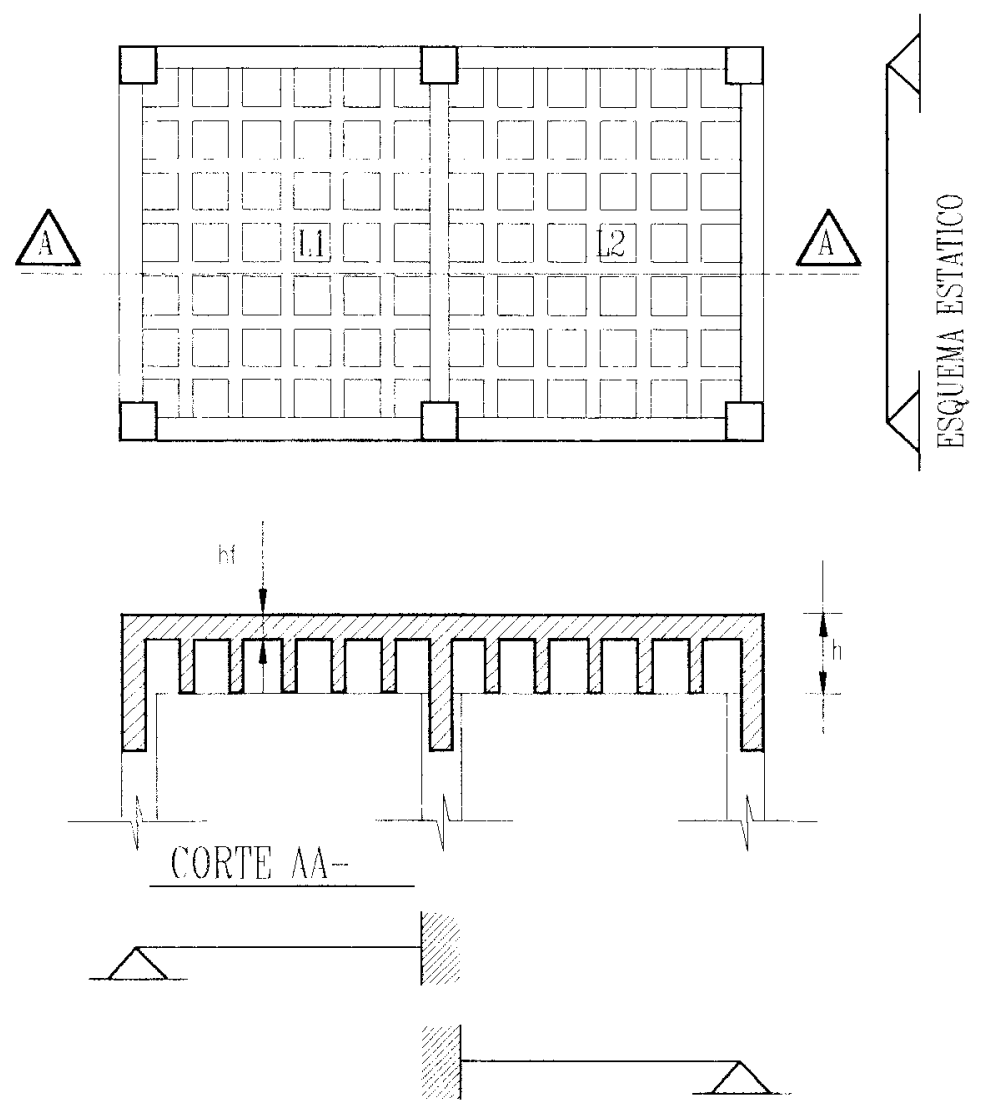

FEQUTFMA FSTATICO

FIGURA 2.2 - LAJES NERVURADAS CONTÍNUAS 


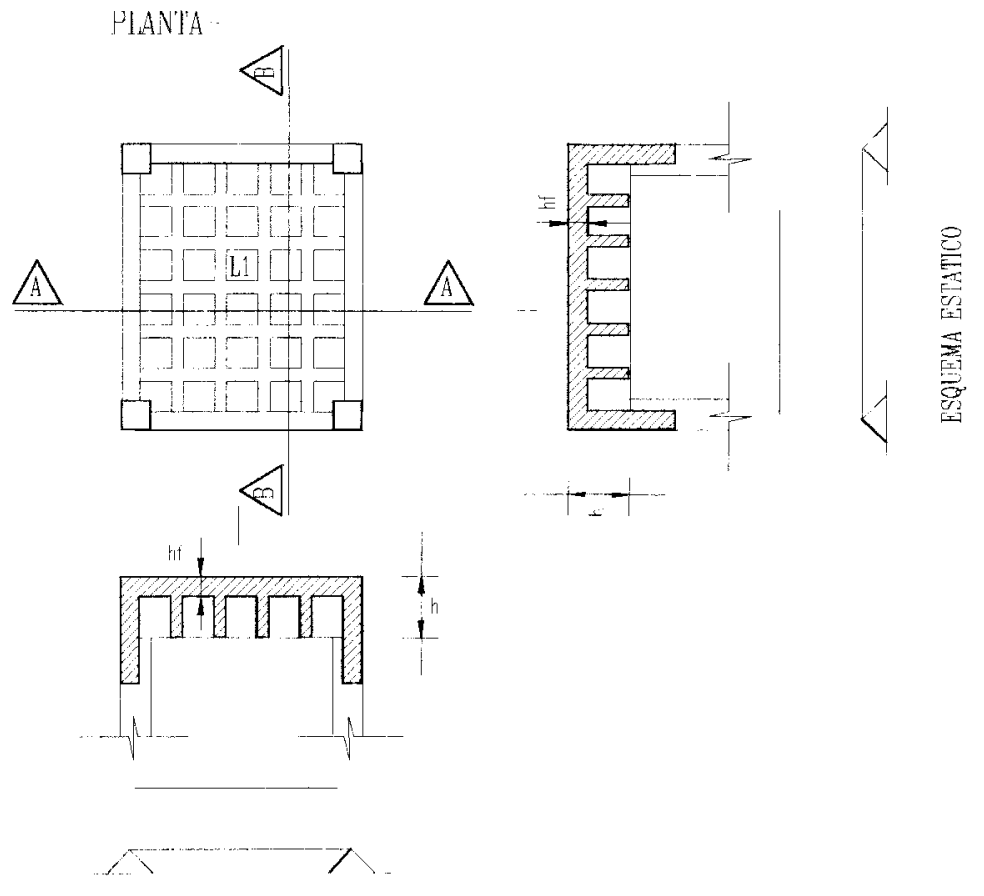

ENOUEMA FSTATICO

FIGURA 2.3 - LAJE NERVURADA COM AS BORDAS APOIADAS

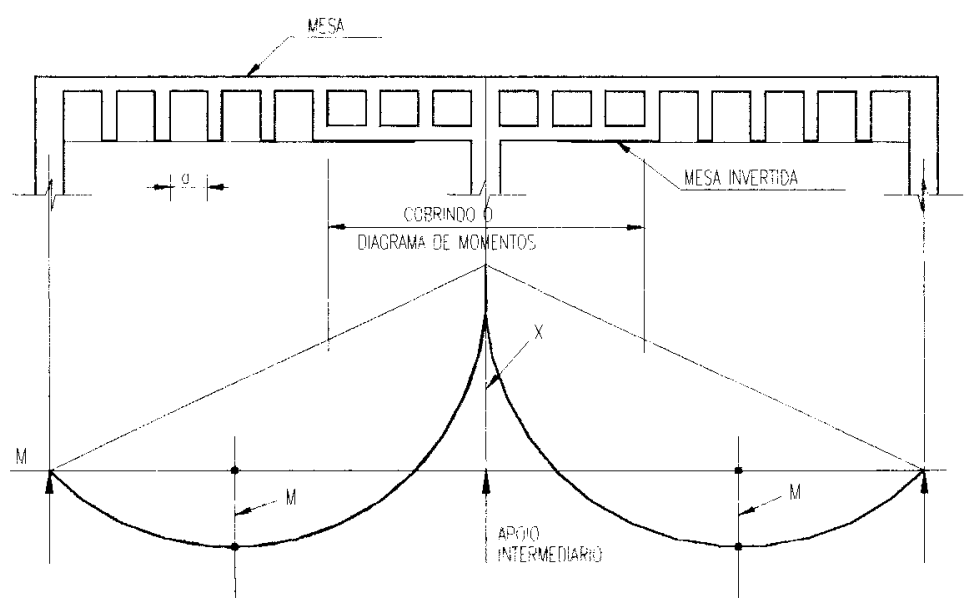

FIGURA 2.4 - DIAGRAMA DE MOMENTOS FLETORES PARA AS LAJES NERVURADAS CONTÍNUAS (ENGASTADAS) 


\subsection{VÃO TEÓRICO}

A Norma Brasileira NB-1/78, apresenta as seguintes considerações quanto ao vão teórico.

O vão teórico é a distância entre os centros dos apoios, não sendo necessário adotar valores maiores que:

a) em laje isolada: o vão acrescido da espessura da laje no meio do vão;

b) em laje contínua, vão extremo: o vão acrescido da semilargura do apoio interno e da semi-espessura da laje no meio do vão.

Nas lajes em balanço, o comprimento da extremidade até o centro do apoio, não sendo necessário considerar valores superiores ao comprimento livre acrescido da metade da espessura da laje junto ao apoio.

Usualmente a diferença entre a altura da laje e a largura dos apoios é pequena em relação à distância entre os centros dos mesmos, adotando-se como vão teórico, a distância entre eixos de apoios. A figura 2.5 ilustra as situações previstas na NB-1/78. 

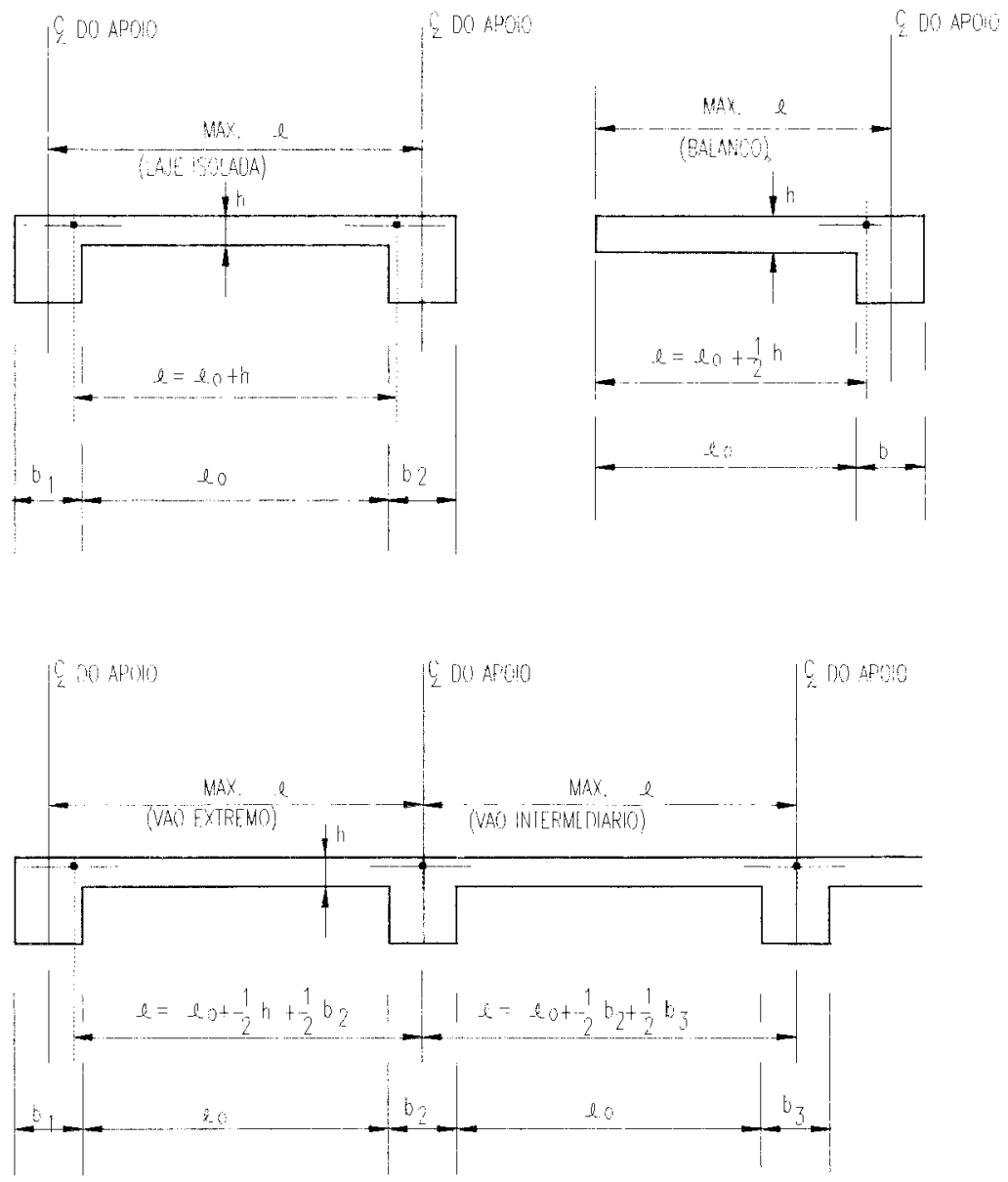

FIGURA 2.5 - VÃO TEÓRICO CONFORME A NB-1/78

\subsection{PRÉ-DIMENSIONAMENTO}

A determinação das dimensões das lajes nervuradas pode ser feita através dos conhecimentos adquiridos pelo engenheiro de estruturas, com base na experiência profissional ou seguindo recomendações das normas, devendo-se sempre respeitar as dimensões mínimas exigidas. 


\subsubsection{RECOMENDAÇÕES DA NORMA BRASILEIRA NB-1/78}

A Norma Brasileira NB-1/78, com relação às lajes nervuradas, estabelece:

"Nas lajes nervuradas, além das demais prescrições desta Norma, deve ser observado o seguinte:

a) a distância entre as nervuras não deve ultrapassar $100 \mathrm{~cm}$;

b) a espessura das nervuras não deve ser inferior a $4 \mathrm{~cm}$ e da mesa não deve ser menor que $4 \mathrm{~cm}$ nem que $1 / 15$ da distância livre entre nervuras;

c) o apoio das lajes deve ser feito ao longo de uma nervura;

d) nas lajes armadas numa só direção, são necessárias nervuras transversais sempre que haja ações concentradas a distribuir ou quando o vão teórico for superior a $4 \mathrm{~m}$, exigindo-se duas nervuras no mínimo se esse vão ultrapassar $6 \mathrm{~m}$;

e) nas nervuras com espessura inferior a $8 \mathrm{~cm}$ não é permitido colocar armadura de compressão no lado oposto à mesa."

Para se estimar a altura da laje nervurada a Norma Brasileira NB-1/78 faz com que sejam atendidas as condições de esbeltez máxima, sem que haja necessidade de verificar as flechas.

A altura útil da laje não deve ser inferior a $\ell / \psi_{2} \psi_{3}$, sendo $\ell$ o menor vão e os valores $\psi_{2}$ e $\psi_{3}$ apresentados a seguir.

Para lajes armadas em uma direção:

Valores de $\psi_{2}$

simplesmente apoiadas. 1,0

contínuas..

duplamente engastadas. . 1,7

em balanço. 0,5

Lajes armadas em duas direções: 
Os valores de $\psi_{2}$ são apresentados na tabela 2.1 onde:

$\ell_{y}$ - vão menor;

$\ell_{x}=$ vão maior;

número superior: $\psi_{2}$ para $\ell_{x} / \ell_{1}=1$

número inferior: $\psi_{2}$ para $\ell_{x} \quad b_{y}=2$, podendo usar-se para razão entre os lados maior que 2, exceto nos casos assinalados com asterisco.

Para $1<\ell_{x} / \ell_{y}<2$ interpolar linearmente.

TABELA 2.1 - VALORES DE $\psi_{2}$
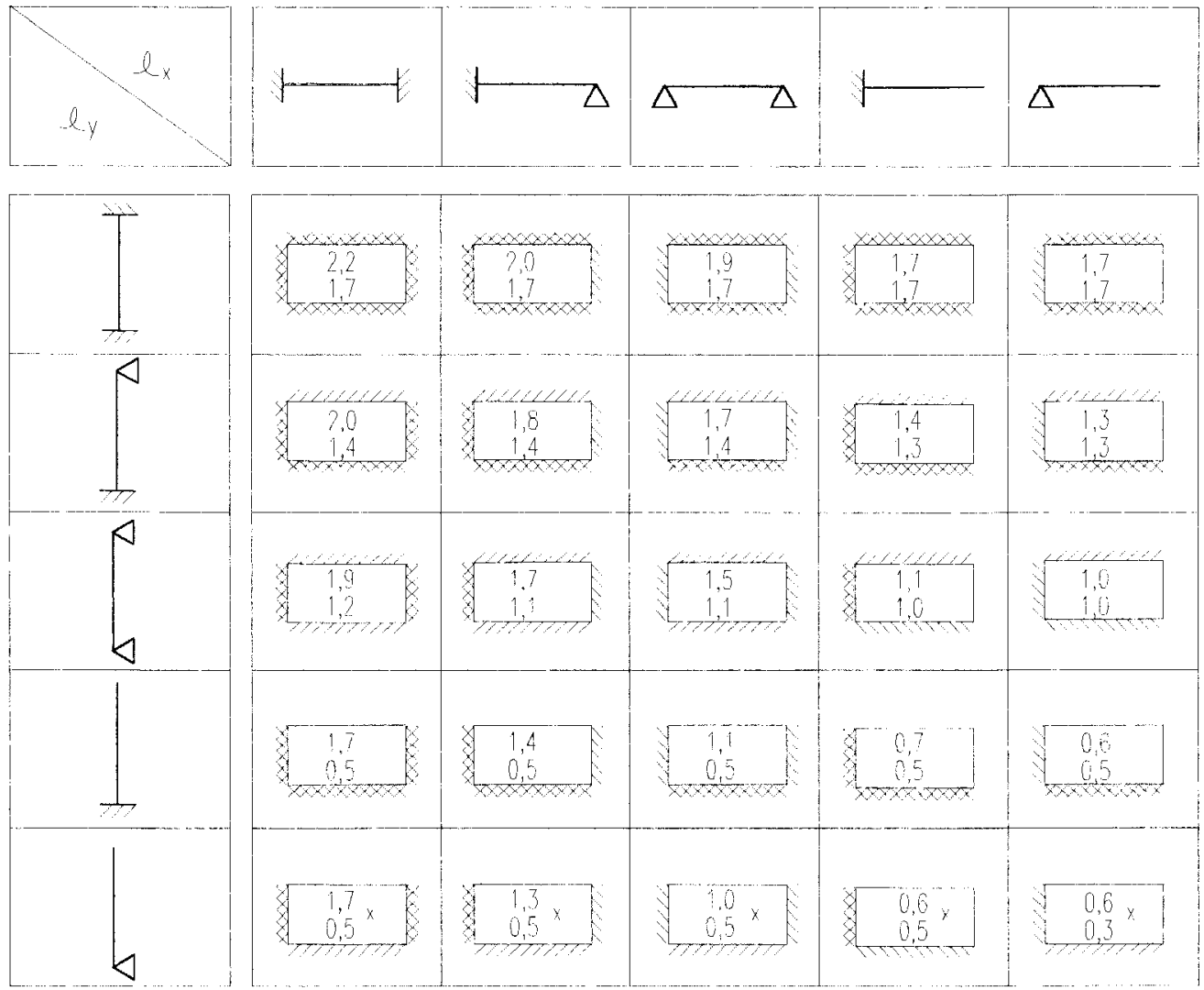

Para $\psi_{3}$ tem-se os seguintes valores:

Tensão na armadura para a solicitação

de cálculo $\left(\sigma_{\mathrm{sd}}\right)$

$215 \mathrm{MPa}$

$435 \mathrm{MPa}$

$520 \mathrm{MPa}$
Valores de $\psi_{3}$

(lajes nervuradas) 
Os valores de $\sigma_{\text {sd }}$ correspondem aos valores aproximados de $f_{y d}$ dos aços CA-25, CA-50, CA-60, respectivamente, $\operatorname{com} \gamma_{\mathrm{s}}=1,15$.

Para as lajes, com mais de $4 \mathrm{~m}$ de vão teórico, que suportarem paredes na direção do vão suscetiveis de fissuração, as alturas úteis mínimas calculadas por este item deverão ser multiplicadas por $\ell / 4$ ( $\ell$ em metros).

\subsubsection{COMITÉ EURO-INTERNACIONAL DU BÉTON CEB-124/125F}

Para o CEB a verificação das flechas é dispensada, quando as deformações não excedam determinados valores $\mathrm{e}$ não ofereçam danos aos revestimentos. A verificação das deformações pode ser dispensada quando:

a) lajes com vãos que não excedam $5 \mathrm{~m}$;

b) lajes com $\frac{\alpha \ell}{h} \leq 30$

onde,

$\mathrm{h}=$ espessura da laje

$\ell=$ vão da laje

$\alpha=$ valor tabelado, que depende do tipo de vinculação da laje.

Para lajes que suportam paredes ou divisórias, que podem

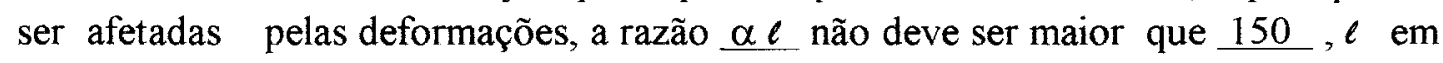
$\mathrm{h}$

$\alpha \ell$ em metro. 
TABELA 2.2 - VALORES DE $\alpha$

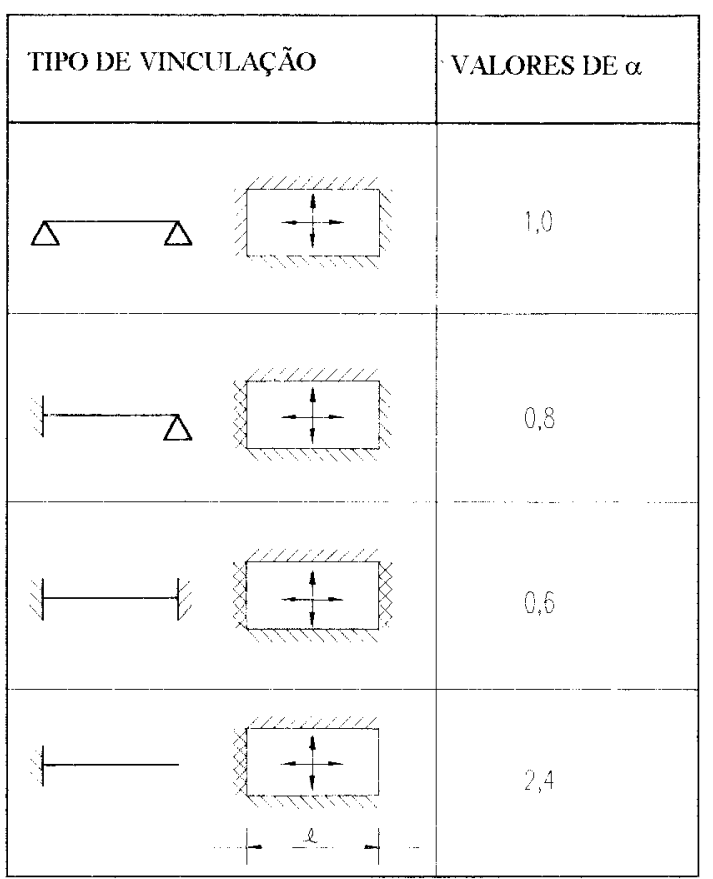

\subsubsection{AMERICAN CONCRETE INSTITUTE ACI-318M/89}

O ACI (1989) estabelece alturas mínimas para as lajes. As lajes armadas em uma direção, que não estejam ligadas ou suportando elementos que possam ser danificados pelas deformações, as alturas mínimas são:

Valores de $\mathrm{h}$

simplesmente apoiada.. $\ell / 20$

um lado contínuo $e / 24$

dois lados contínuos. e/28

em balanço. e/10 
Para as lajes armadas em cruz, o ACI propõe um método complexo e trabalhoso, não sendo indicado seu emprego para o prédimensionamento.

As recomendações apresentadas pelas normas conduzem a valores exagerados para as alturas mínimas das lajes nervuradas, como estas normas permitem adotar-se valores menores, desde que se verifiquem as deformações e estas não ultrapassem os valores limites (ver capítulo 3 deste trabalho), torna-se esta prática a mais recomendada.

Alguns autores propõe métodos alternativos de prédimensionamento, como o apresentado por MACHADO (1983), indicando um valor para a altura útil dado por:

$$
\mathrm{d}=1,5(2,5-0,1 \mathrm{n}) \ell^{*}
$$

onde,

$\mathrm{n}$ = número de bordas engastadas da laje;

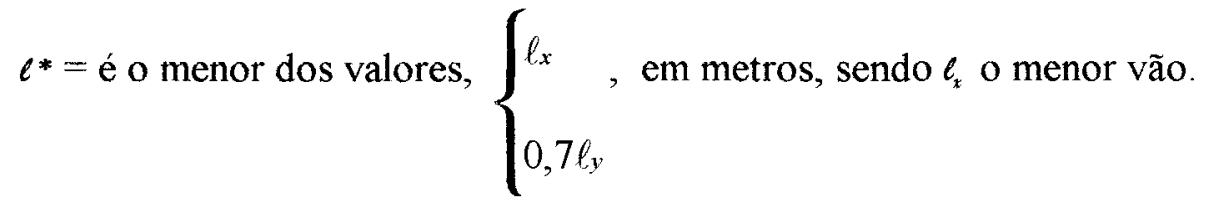

\subsection{AÇÕES ATUANTES NAS LAJES NERVURADAS}

As ações que atuam nas lajes nervuradas podem ser divididas em ações permanentes diretas e ações variáveis normais (sobrecargas de utilização). Estas ações devem obedecer as prescrições das Normas Brasileiras NB-1/78 e NB$5 / 80$. 


\subsection{1 - AÇÕES PERMANENTES DIRETAS}

As ações permanentes diretas são aquelas que ocorrem com valores constantes ou de pequena variação em torno de sua média, durante praticamente toda vida útil da estrutura. Encontram-se incluídos nestas ações: peso próprio, revestimentos, enchimentos, e alvenarias.

\subsubsection{PESO PRÓPRIO}

O peso próprio da laje nervurada é obtido considerando-se as dimensões determinadas na fase de pré-dimensionamento, com o peso específico do concreto armado igual a $25 \mathrm{kN} / \mathrm{m}^{3}$, segundo especificação da Norma Brasileira NB$5 / 80$, salvo situação em que se tenham concretos especiais, leves ou pesados, entre outros.

O peso próprio deve ser considerado uniformemente distribuído em toda área da laje, embora sendo uma simplificação os resultados obtidos são satisfatórios, além de facilitarem os cálculos pertinentes ao dimensionamento das lajes nervuradas.

\subsubsection{REVESTIMENTO}

As ações provenientes dos revestimentos devem ser avaliadas com base no peso especifico dos materiais que os constituem. Usualmente os revestimentos de pisos variam de $0,5 \mathrm{kN} / \mathrm{m}^{2}$ a $1,0 \mathrm{kN} / \mathrm{m}^{2}$, entretanto em alguns casos 
como por exemplo o granito, pode-se ter valores mais elevados, além disso o contrapiso deverá ter pequena espessura, caso contrário acarretará ações adicionais na laje, ações estas não previstas no projeto. Os revestimentos de forros variam de $0,1 \mathrm{kN} / \mathrm{m}^{2}$ a $0,5 \mathrm{kN} / \mathrm{m}^{2}$.

\subsubsection{ENCHIMENTO}

A determinação das ações devidas aos enchimentos é feita considerando-se o peso específico do material que os constitui. Nas lajes nervuradas é muito comum a utilização de blocos de enchimento, a fim de se reduzir o emprêgo das fồrmas, facilitando-se e barateando-se a execução. Hoje encontram-se no mercado nacional uma gama muito grande de blocos, de vários tamanhos e de diversos materiais, tornando-se essencial que o fabricante forneça ao engenheiro de estruturas o peso próprio dos mesmos.

Alguns materiais destinados ao enchimento das lajes nervuradas e seu peso específico, segundo a NB-5/80:

Blocos de concreto celular. $4,00 \mathrm{kN} / \mathrm{m}^{3}$

Blocos de argamassa. $22,00 \mathrm{kN} / \mathrm{m}^{3}$

Cimento amianto $20,00 \mathrm{kN} / \mathrm{m}^{3}$

Lajotas cerâmicas. $18,00 \mathrm{kN} / \mathrm{m}^{3}$

Tijolos furados. $13,00 \mathrm{kN} / \mathrm{m}^{3}$

Tijolos maciços. $18,00 \mathrm{kN} / \mathrm{m}^{3}$

Tijolos sílico-calcáreos. $20,00 \mathrm{kN} / \mathrm{m}^{3}$ 


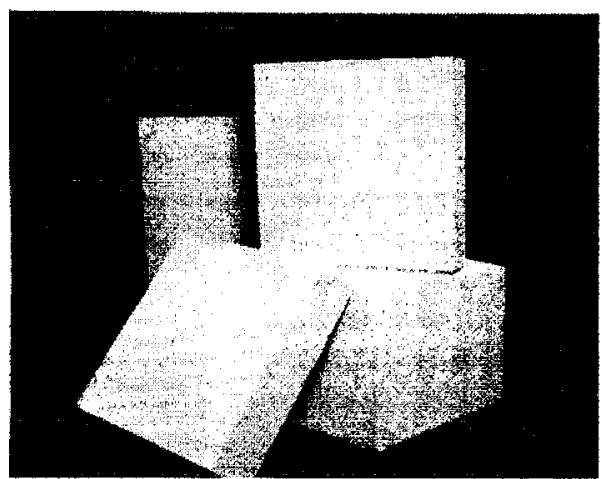

FIGURA 2.6 - BLOCO UTILIZADO NA EXECUÇÃO DAS LAJES NERVURADAS

Os blocos facilitam a execução das lajes nervuradas já que permitem a redução do emprêgo de fôrmas e permitem a execução do teto plano

Recentemente os blocos de concreto celular tem apresentado algumas vantagens, haja visto, a redução do peso próprio da estrutura e a facilidade de montagem.

\subsubsection{AÇÕES PROVENIENTES DAS ALVENARIAS}

Todas as ações permanentes apresentadas anteriormente são uniformemente distribuídas na área da laje nervurada, sendo que isto não ocorre quando há paredes apoiadas diretamente na laje, neste caso existem soluções simplificadas, que apresentam bons resultados e que se aplicam diferentemente para cada tipo de ação ou laje. A Norma Brasileira NB-1/78 admite que cargas concentradas ou parcialmente distribuídas, se distribuam a $45^{\circ}$, até o plano médio da laje conforme mostrado na figura 2.7 . 


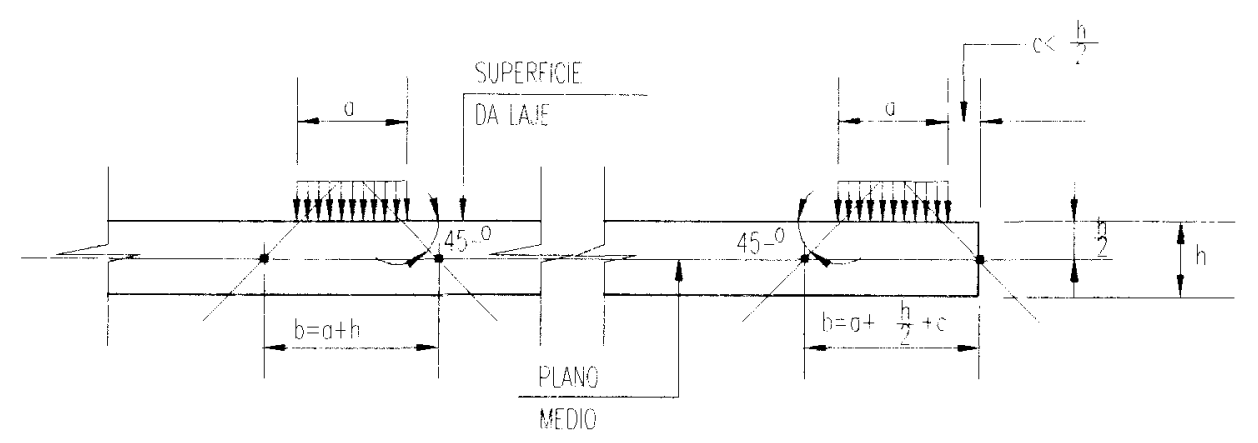

FIGURA 2.7 - DISTRIBUIÇÃO DE AÇÕES DE ALVENARIA

Nas lajes armadas em uma direção a NB-1/78 permite o cálculo simplificado como viga de largura $b_{w}$ igual a largura $b$ da ação, se b não for menor que o vão teórico $\ell$ ou que o comprimento teórico (balanço) e, em caso contrário, igual a:

a) para momentos fletores positivos

$\mathrm{b}_{\mathrm{w}}^{*}=\mathrm{b}+\frac{2 \mathrm{a}_{1}}{\ell} \frac{\left(\ell-\mathrm{a}_{1}\right)}{\ell}\left(1-\frac{\mathrm{b}}{\ell}\right)$

b) para momentos fletores negativos

$\mathrm{b}^{*}{ }_{\mathrm{w}}=\mathrm{b}+\frac{\mathrm{a}_{1}\left(2 \ell-\mathrm{a}_{1}\right)}{\ell}(1-\underline{\mathrm{b}})$

c) para forças cortantes

$b^{*}{ }_{w}=b+a_{1}\left(1-\frac{b}{\ell}\right)$

d) para momentos fletores em lajes em balanço

$\mathrm{b}_{\mathrm{w}}{ }_{\mathrm{w}}=\mathrm{b}+1,5 \mathrm{a}_{1}\left(1-\frac{\mathrm{b}}{\ell}\right)$

e) para forças cortantes em lajes em balanço

$\mathrm{b}^{*}{ }_{\mathrm{w}}=\mathrm{b}+0,5 \mathrm{a}_{1}(1-\underline{\mathrm{b}})$ 
onde $\mathrm{a}_{1}$ é a distância do centro da carga ao apoio para cujo lado está a seção que se estuda (fig. 2.8).

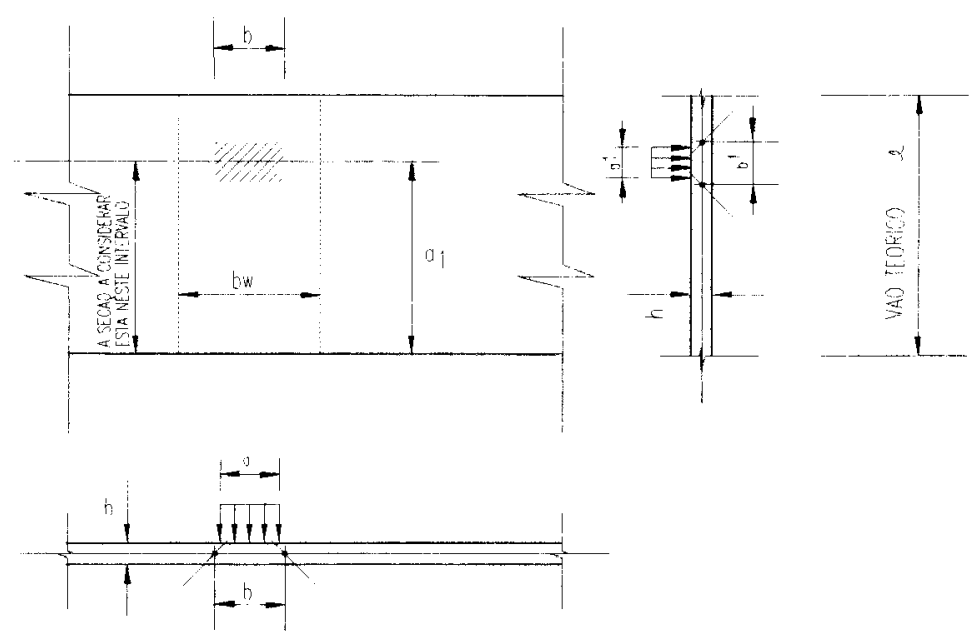

FIGURA 2.8 - LARGURA ÚTIL COLABORANTE

No caso específico de paredes de alvenaria nos edificios, onde os carregamentos são parciais distribuídos ao longo de todo o vão e em faixas de pequena largura $(\mathrm{b}<\ell)$ o formulário anterior pode ser simplificado segundo ANDRADE (1977), conforme a figura 2.9 para:
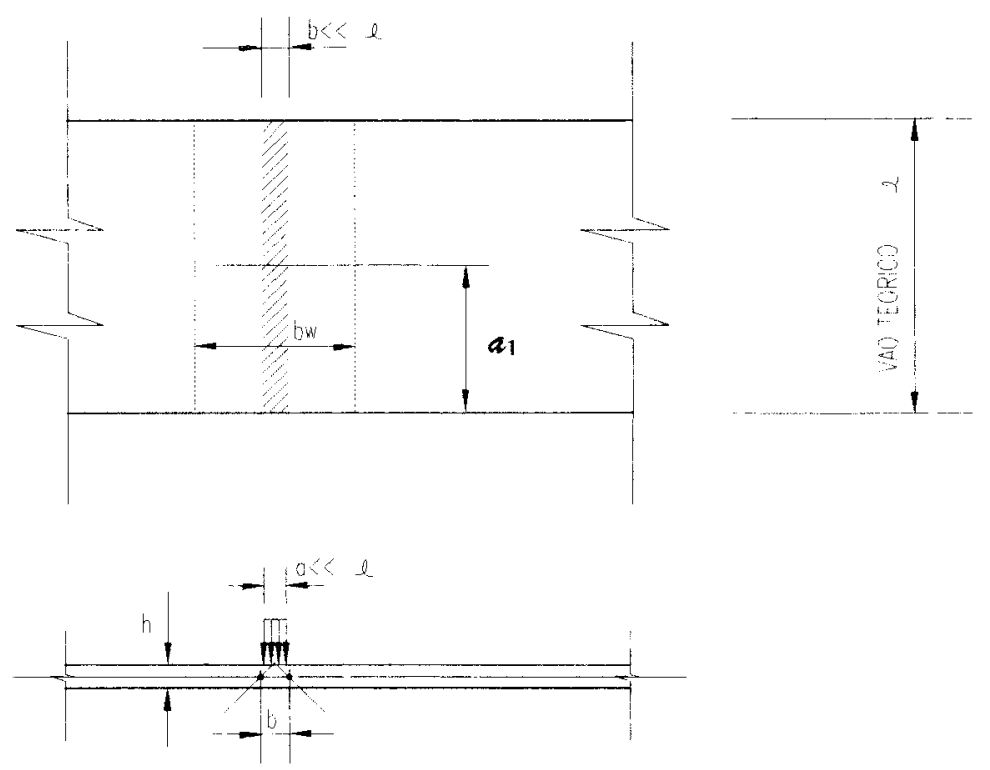

FIGURA 2.9 - LARGURA ÚTIL COLABORANTE (SIMPLIFICAÇÃO) 
a) momentos fletores positivos e forças cortantes:

$b_{w}=0,5 \ell$

b) para momentos fletores negativos e balanços

$\mathrm{b}_{\mathrm{w}}=0,75 \ell$

c) para forças cortantes, em balanços

$b_{w}=0,25 \ell$

Os valores indicados de $b_{w}$ estão limitados pelas seguintes condições:

1) que $b_{w}$ não seja maior que a largura da laje (fig. 2.10), nem maior que a distância do centro da carga à borda mais próxima da laje acrescida de $0,5 b_{w}$.

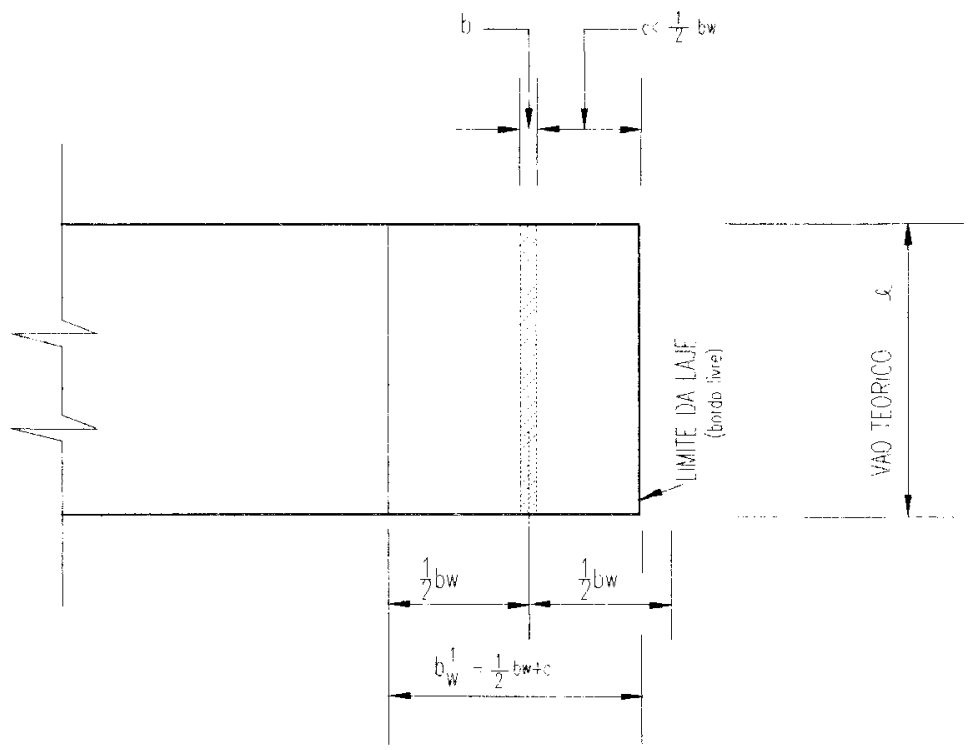

FIGURA 2.10 - LIMITES DE $b_{\mathrm{W}}$

2) que a armadura de distribuição por metro não seja menor que a fração da principal por metro dada por $1-0,80 / b_{w}$ e que se estenda sobre a largura $b_{w}$ acrescida dos comprimentos de ancoragem.

Para as lajes armadas em duas direções com ações parcialmente distribuídas, no caso de paredes de alvenaria de edificio podem simplesmente ser consideradas como uniformemente distribuídas pela área total da laje. 


\subsubsection{AÇÕES VARIÁVEIS NORMAIS}

As ações variáveis normais ou sobrecargas de utilização são constituídas pelos móveis, pessoas, e objetos destinados ao pleno funcionamento do ambiente previsto no projeto arquitetônico. As sobrecargas foram estabelecidas pela Norma Brasileira NB-5/80, com base em critérios estatísticos e de acordo com a finalidade a que se destinam as lajes.

Deve-se, portanto, durante a vida útil da construção, fazer com que as condições de ocupação dos ambientes previstas no projeto arquitetônico sejam respeitadas, caso contrário, pode-se submeter as lajes e conseqüentemente toda estrutura, a carregamentos maiores aos que foram projetadas, colocando em risco a segurança das mesmas.

No caso de sobrecargas especiais, ou seja, fábricas, depósitos, entre outros, em que seus valores não são estabelecidos pôr normas, cabe ao engenheiro de estruturas em conjunto com o arquiteto determiná-las, através de um levantamento das ações que estarão presentes na utilização do ambiente.

Apresenta-se a seguir, alguns valores para as sobrecargas, recomendadas pela Norma NB-5/80.

a) em forros não destinados a depósitos e sem acesso público $0,5 \mathrm{kN} / \mathrm{m}^{2}$

b) em dormitórios, salas, copas, cozinhas e banheiros de edificios residenciais $1,5 \mathrm{kN} / \mathrm{m}^{2}$

c) em áreas de serviço, lavanderia e despensa de edificios residenciais ........2,0 kN/m ${ }^{2}$

d) em áreas de uso geral e banheiros de edificios destinados a escritórios, bancos, escolas e hospitais $2,0 \mathrm{kN} / \mathrm{m}^{2}$

e) em áreas de circulação, corredores, escadas, hall de entrada e terraços com acesso público. $3,0 \mathrm{kN} / \mathrm{m}^{2}$

f) idem, sem acesso ao público $2,0 \mathrm{kN} / \mathrm{m}^{2}$

g) em garagens e estacionamentos, para veículos de passageiros com carga máxima de $25 \mathrm{kN}$ $3,0 \mathrm{kN} / \mathrm{m}^{2}$

h) em arquibancadas.

$4,0 \mathrm{kN} / \mathrm{m}^{2}$ 
i) em locais destinados a ginástica, esportes e dança em clubes e ginásios de esporte. $5,0 \mathrm{kN} / \mathrm{m}^{2}$

j) em lavanderias, cozinhas e refeitórios não residenciais. $3,0 \mathrm{kN} / \mathrm{m}^{2}$

1) em laboratórios. $3,0 \mathrm{kN} / \mathrm{m}^{2}$

m) em lojas. $4,0 \mathrm{kN} / \mathrm{m}^{2}$

n) em salas de leitura de biblioteca. $.2,5 \mathrm{kN} / \mathrm{m}^{2}$

o) em depósito e estantes de livros de bibliotecas. $>6,0 \mathrm{kN} / \mathrm{m}^{2}$

Obs.: deve-se verificar em cada caso, podendo chegar a $15 \mathrm{kN} / \mathrm{m}^{2}$

p) em platéias de cinemas, clubes, teatros e anfiteatros de escolas, com assentos fixos. $3,0 \mathrm{kN} / \mathrm{m}^{2}$

q) idem, sem assentos fixos. $4,0 \mathrm{kN} / \mathrm{m}^{2}$

r) em salas de aula. $3,0 \mathrm{kN} / \mathrm{m}^{2}$

s) em casa de máquinas (para elevadores) de edificios em geral. $>7,5 \mathrm{kN} / \mathrm{m}^{2}$ Obs.: deve-se verificar em cada caso, podendo chegar a $25 \mathrm{kN} / \mathrm{m}^{2}$.

$O$ coeficiente $\phi$ de majoração da carga em garagens e estacionamentos deve ser:

$$
\begin{aligned}
& \phi=1,00, \text { quando } \ell>\ell \\
& \phi=\ell / \ell_{0}, \text { quando } \ell<\ell_{0} \\
& \text { onde: } \\
& \ell=\text { menor vão da laje; } \\
& \ell=3,00 \mathrm{~m}
\end{aligned}
$$

\subsection{COMPORTAMENTO ESTÁTICO DAS LAJES NERVURADAS}

As lajes nervuradas são constituídas por um conjunto de vigas (nervuras), solidarizadas entre si pela mesa, apresentando um comportamento estático 
intermediário entre placa e grelha. Os esforços de compressão nas lajes nervuradas devem ser resistidos pela mesa de concreto e parte pela nervura, dependendo da posição da linha neutra, enquanto que os esforçoes de tração são resistidos pela nervura com a armadura.

A Norma NB-1/78 denomina de lajes nervuradas aquelas cuja zona de tração é constituída por nervuras entre as quais podem ser colocados materiais inertes, de modo a tornar plana a superficie externa. A NB-1/78 permite o cálculo da laje nervurada como uma placa no regime elástico, desde que sejam observadas as recomendações expostas no pré-dimensionamento. Além do cálculo dos esforços solicitantes e deslocamentos segundo a teoria das placas pode-se fazê-lo seguindo a teoria das grelhas.

\subsubsection{TEORIA DAS PLACAS}

O cálculo dos esforços solicitantes e dos deslocamentos utilizando-se a teoria das placas de espessura constante é feito através da integração da equação de Lagrange:

$$
\begin{aligned}
& \frac{\partial^{4} w}{\partial x^{4}}+2 \frac{\partial^{4} w}{\partial x^{2} \partial y^{2}}+\frac{\partial^{4} w}{\partial y^{4}}=\frac{(g+q)(x, y)}{D} \\
& \text { onde: } \\
& \mathrm{D}=\frac{\mathrm{E}_{\mathrm{c}} \mathrm{h}^{3}}{12\left(1-\mathrm{v}^{2}\right)}{ }^{2} \\
& \mathrm{E}_{\mathrm{c}}=\text { módulo de deformação do concreto; } \\
& \mathrm{h}=\text { altura da laje; } \\
& \mathrm{v}=\text { coeficiente de Poison do concreto; } \\
& (\mathrm{g}+\mathrm{q})=\text { ação aplicada perpendicularmente ao plano da laje; }
\end{aligned}
$$


$\mathrm{x}, \mathrm{y}=$ coordenadas cartesianas que indicam a posição de um ponto genérico do plano da laje;

$\mathrm{w}=$ deslocamento medido perpendicularmente ao plano;

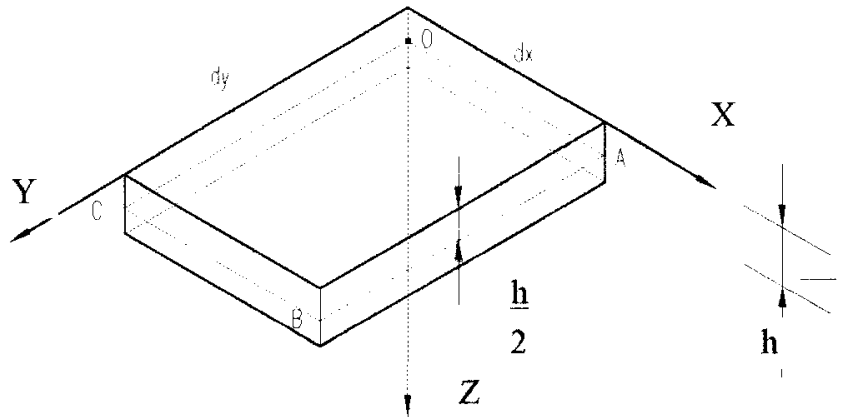

FIGURA 2.11 - ILUSTRAÇÃO DO SISTEMA DE COORDENADAS

A equação de Lagrange é válida para todos os pontos no interior da laje e deve ser resolvida com as condições de contorno seguintes:

a) para as bordas livres perpendiculares ao eixo $\mathrm{Ox}$, as reações $r_{x}$, e os momentos fletores $m_{x}$ ao longo desse apoio deverão ser nulos:

$$
\begin{aligned}
& \frac{\partial^{3} w}{\partial x^{3}}+(2-v) \frac{\partial^{3} w}{\partial x \partial y^{2}}=0 \\
& \frac{\partial^{2} w}{\partial x^{3}}+v \frac{\partial^{2} w}{\partial y^{2}}=0
\end{aligned}
$$

A equação referente às bordas livres perpendiculares a Oy escreve-se trocando as variáveis x e y. Isto também é válido para as demais condições de contôrno.

b) para os lados perpendiculares a Ox que estejam na condição de apoio simples, os deslocamentos e momentos fletores $m_{x}$ deverão ser nulos ao longo dessa borda:

$$
\mathrm{w}=0 \quad \mathrm{e} \quad \frac{\partial^{2} w}{\partial x^{2}}+v \frac{\partial^{2} w}{\partial y^{2}}=0
$$


c) para os lados perpendiculares a Ox que estejam na condição de engastamento perfeito, os deslocamentos e o giro $\phi_{\mathrm{x}}$ ao longo dessa borda deverão ser nulos:

$$
\mathrm{w}=0 \quad \mathrm{e} \quad \frac{\partial w}{\partial x}=0
$$

A integração da equação de Lagrange, para as lajes retangulares pode ser feita através de vários processos, existem várias tabelas na bibliografia nacional e internacional, como Bares, Czerny entre outros, encontradas em PINHEIRO (1993), SANTOS (1983), etc, as quais facilitam a obtenção de esforços solicitantes e deslocamentos. Existem, ainda, muitos programas para computadores com esta finalidade, estes utilizam-se de vários métodos como o das diferenças fínitas, método dos elementos finitos, e método dos elementos de contorno. Os programas estão cada vez mais sendo utilizados, principalmente em lajes não retangulares ou com condições de contorno não encontradas nas tabelas, ou quando desejam-se considerar o deslocamento vertical dos apoios, tendo em vista a deslocabilidade das vigas de borda, já que as tabelas consideram estas vigas indeslocáveis. Entre estes programas pode-se citar, por exemplo, os programas NEXP (NOVAES, 1990) e o SAP90, dentre outros.

\subsubsection{TEORIA DAS GRELHAS}

A determinação dos esforços solicitantes e deslocamentos de uma laje nervurada segundo a teoria das grelhas obteve grande impulso recentemente, com o advento da informática no cálculo estrutural. $\mathrm{O}$ alto grau de hiperasticidade $\mathrm{e}$ deslocabilidade das grelhas tornavam-se um obstáculo ao cálculo das mesmas; o microcomputador, aliado a programas específicos, rápidos e de fácil manejo, fez com que as dificuldades desaparecessem. Atualmente tornou-se comum a utilização de 
programas para o cálculo de grelhas na determinação dos esforços solicitantes e deslocamentos das lajes, maciças e nervuradas, pelos engenheiros de estrutura.

A grelha pode ser definida como uma estrutura plana, a qual recebe ação normal ao seu plano. Em sua análise estarão envolvidos apenas três esforços internos e consequentemente três deformações provocadas pelas ações previstas. Os esforços internos presentes são: um esforço cortante normal ao plano da grelha, e um momento fletor nesse plano, esse momento fletor pode ser considerado como composto de duas componentes, uma de flexão, normal ao eixo da barra, e uma de torção, axial à barra. Os esforços internos numa certa seção de uma grelha são esquematizados na fig. 2.12 .
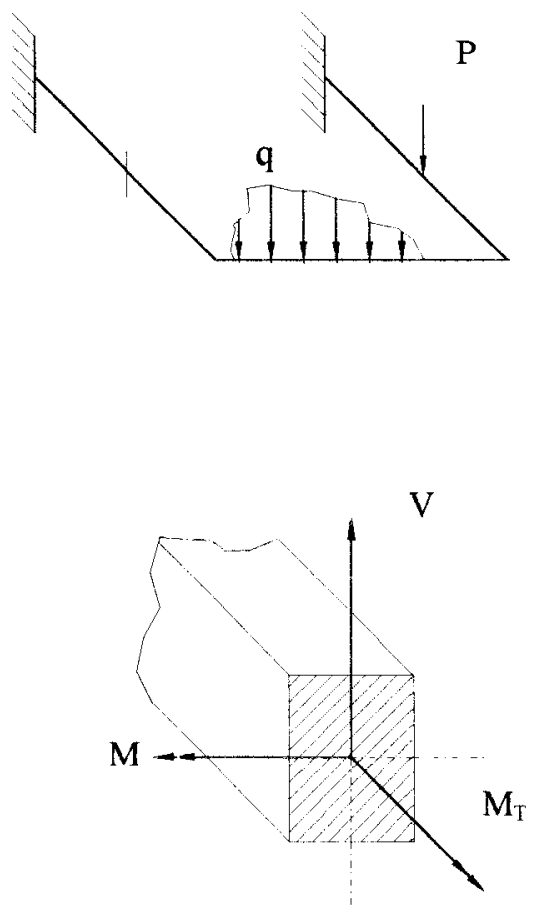

FIGURA 2.12 - ESFORÇOS INTERNOS EM UMA GRELHA

Quando determinam-se os esforços solicitantes e deslocamentos de uma laje nervurada segundo a teoria das grelhas, toda a estrutura resiste às ações, enquanto que no cálculo de vigas isoladas apenas uma direção é tida como resistente. Isto faz com que as vigas tenham maiores esforços solicitantes, consequentemente estas possuem maiores dimensões e a estrutura maior peso 
próprio. Para que o cálculo seja realmente econômico deve-se considerar que a transferência de ações ocorra no plano da estrutura e só é eficiente se as nervuras tiverem rigidezes semelhantes. Caso as nervuras em uma das direções sejam muito mais rígidas que as outras, elas absorverão maiores parcelas dos esforços solicitantes, e a transmissão dos mesmos ocorrerá em uma única direção.

Os esforços solicitantes nas grelhas são calculados por processos estáticos, entre eles podem ser citados:

a) processo dos esforços;

b) processo dos deslocamentos;

Este trabalho não tem como objetivo o detalhamento destes processos, sendo que existe na bibliografia técnica muitos trabalhos que tratam do tema, entre eles SUSSEKIND (1979) e ANTUNES (1992).

A determinação dos esforços solicitantes e deslocamentos das lajes nervuradas conforme a teoria das grelhas, cujos resultados e conclusões são apresentados neste trabalho, foram realizados com o emprego do Sistema ANSER Análise de Sistemas Estruturais Reticulados, programa GPLAN3, versão educativa, desenvolvida por Correa et alli (1985).

\subsubsection{ESTUDO COMPARATIVO DOS RESULTADOS OBTIDOS NA DETERMINAÇÃO DOS ESFORÇOS SOLICITANTES}

Para o estudo do comportamento das lajes nervuradas tomouse inúmeros exemplos, sendo que apresenta-se neste ítem o caso particular de uma laje com os lados iguais, conforme a figura 2.13. Este exemplo será retomado no capítulo 4 deste trabalho, onde serão estudados detalhadamente, desde o prédimensionamento da seção transversal, as verificações quanto aos estados limites até o detalhamento da armadura. 


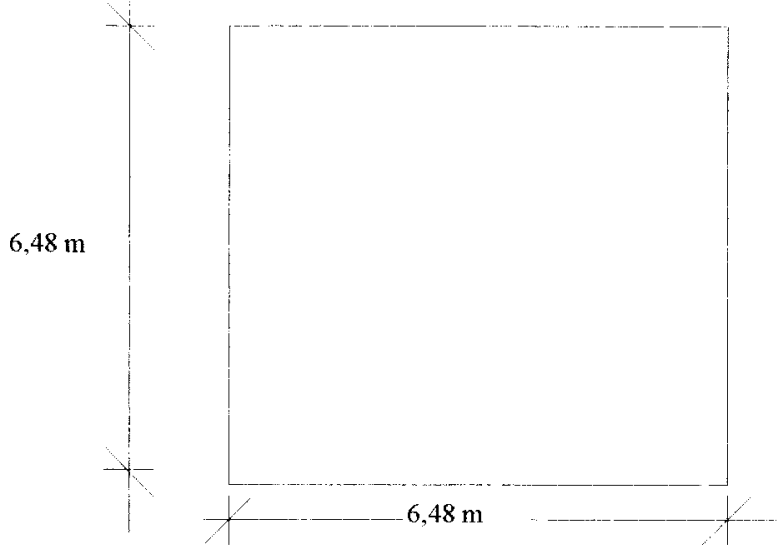

FIGURA 2.13 - 1.AJE COM OS LADOS IGUAIS

A laje da figura 2.13 foi considerada de duas maneiras distintas:

a) distância livre entre nervuras a $>50 \mathrm{~cm}$ (ver exemplo 1, capitulo 4)

b) distância livre entre nervuras $a<50 \mathrm{~cm}$ (ver exemplo 2 , capítulo 4 )

A determinação dos esforços solicitantes foi realizada com a utilização das tabelas para o cálculo de placas (PINHEIRO, 1993), e com os programas NEXP (NOVAES, 1990) e GPLAN3 (CORREA et alli, 1985).

$O$ estudo comparativo entre os resultados obtidos na determinação dos esforços solicitantes e deslocamentos empregando-se a teoria das placas e das grelhas para as lajes nervuradas, mostrou que os valores obtidos nem sempre são compatíveis, conforme observa-se no quadro (tabela 2.3), em todos os casos as vigas de borda foram admitidas indeslocáveis, para efeito de prédimensionamento das seções empregou-se as recomendações da NB-1/78 (ver exemplos 1 e 2 do capítulo 4).

TABELA 2.3 - VALORES DOS MOMENTOS FLETORES OBTIDOS PELOS

PROCESSOS ESTUDADOS

\begin{tabular}{|c|c|c|c|c|c|}
\hline \multirow{3}{*}{\multicolumn{2}{|c|}{ PROCESSO }} & \multicolumn{4}{|c|}{ MOMENTOS FLETORES } \\
\hline & & \multicolumn{2}{|c|}{$a>50 \mathrm{~cm}$} & \multicolumn{2}{|c|}{$a<50 \mathrm{~cm}$} \\
\hline & & $\begin{array}{c}\text { MESA } \\
(\mathrm{kNm} / \mathrm{m})\end{array}$ & $\begin{array}{l}\text { NERVURA } \\
\text { (kNm/nerv.) }\end{array}$ & $\begin{array}{c}\text { MESA } \\
(\mathrm{kNm} / \mathrm{m})\end{array}$ & $\begin{array}{l}\text { NERVURA } \\
\text { (kNm/nerv.) }\end{array}$ \\
\hline \multicolumn{2}{|c|}{ PINHEIRO } & & 10,01 & & 4,38 \\
\hline \multirow[t]{2}{*}{ NEXP } & ST & 4,44 & 10,08 & 0,57 & 7,45 \\
\hline & CT & 2,52 & 5,72 & 0,32 & 4,28 \\
\hline \multicolumn{2}{|c|}{ GPLAN3 } & & 11,76 & & 5,32 \\
\hline
\end{tabular}


(*) ST: Não considerando-se os efeitos da torção

CT: Considerando-se os efeitos da torção

Em face aos resultados obtidos pode-se verificar que o método dos elementos finitos (programa NEXP) apresentou momentos fletores elevados na mesa, principalmente para a distância livre entre nervuras $a>50 \mathrm{~cm}$, o que, no dimensionamento da mesa torna-se impraticável, além disso o fato de admitir-se a fissuração do concreto nos pequenos painéis da laje, junto às nervuras, ou seja, a idéia de ter-se pequenas lajes apoadas nas nervuras, faz com que este modelo não seja adotado. Partiu-se, então, para a concepção de um modelo para a grelha que expresse não só o comportamento da estrutura (laje nervurada) mas também do material (concreto armado). Assim algumas considerações devem ser observadas na elaboração da grelha, conforme apresenta-se à seguir:

a) Inércia à flexão das barras da grelha.

As nervuras da laje e as vigas devem ser representadas por barras com inércia à flexão tomada como uma seção $\mathrm{T}$, considerando-se a largura colaborante obtendo-se, então:

$$
I=\sum_{i=1}^{n}\left(\frac{b_{i} h_{i}{ }^{3}}{12}+A_{i} d_{i}{ }^{2}\right)
$$

onde:

$b_{i}=$ largura da porção i da seção transversal;

$h_{i}=$ altura da porção i da seção transversal;

$\mathrm{A}_{\mathbf{i}}=$ área da porção i da seção transversal;

$\mathrm{d}_{\mathrm{i}}=$ distância do centro de gravidade da porção $\mathrm{i}$ ao centro de gravidade da seção.

b) Inércia à torção das barras da grelha.

Mediante a análise de grelhas, os diagramas de momentos fletores e torçores, mostram que caso as barras possuam rigidez à torção, não existe liberdade absoluta de rotação, a deformação impedida faz com que apareçam momentos, que se constituirão em momentos de torção. À medida em que se reduz a rigidez à torção, os momentos de torção também reduzem, até que para uma situação 
teoricamente limite de rigidez nula à torção, tem-se os momentos de torção nulos Isto mostra que as torções neste caso são esforços meramente oriundos da compatibilidade de deformações, por isto chamadas de torção de compatibilidade, verificou-se ser possivel a ocorrência de uma situação em que há equilíbrio com torção nula, no caso de baixa rigidez à torção das barras.

A norma brasileira NB-1/78, item 4.3 .1 , tolera que se desprezem os momentos de torção de compatibilidade no dimensionamento feito no estado limite último, haja visto que, a intensa fissuração do concreto surge, na vizinhança dos estados limites últimos, em peças submetidas à torção, faz reduzir, enormemente, sua rigidez à torção, de forma que admitir-se esforços referentes a valor muito baixo da mesma, equivale a aproximar-se do modelo real de funcionamento.

SUSSEKIND (1985) recomenda considerar como inércia à torção, em peças de concreto armado (com fissuração), um número em torno de $20 \%$ da inércia $\mathrm{I}_{\mathrm{T}}$ da seção homogênea (estádio $\mathrm{I}$ ), tem-se:

$$
\begin{aligned}
& \left(\mathrm{I}_{\mathrm{T}}\right)_{\text {est. II }} \cong 0,20\left(\mathrm{I}_{\mathrm{T}}\right)_{\text {est. I }} \text {, sendo: } \\
& I_{T}=\frac{1}{3} \sum_{i=1}^{n} b_{i}^{3} h_{i}, \text { onde: }
\end{aligned}
$$

$b_{i}=$ largura da porçào i da seção transversal;

$\mathrm{h}_{\mathrm{i}}=$ altura da porção $\mathrm{i}$ da seção transversal.

Esta recomendação conduz em geral, a valores reduzidos para as torções

c) Módulo de deformação longitudinal do concreto ( $\left.E^{*}\right)$.

Tomou-se o módulo de deformação longitudinal do concreto igual à $0,7 \times 0,9 \mathrm{E}_{\mathrm{c}}$, o fato de considerar-se apenas $70 \%$ decorre da fissuração presente nas seções de concreto armado submetidas aos esforços de flexão.

$$
\begin{aligned}
& \mathrm{E}^{*}=0,7 \times 0,9 \mathrm{E}_{\mathrm{c}} \\
& \text { onde: } \\
& \mathrm{E}_{\mathrm{c}}=6600 \sqrt{\mathrm{f}_{\mathrm{ck}}+3,5}(\mathrm{em} \mathrm{MPa})
\end{aligned}
$$


d) Módulo de deformação transversal do concreto $\left(G_{c}\right)$

Embora alguns autores como por exemplo LEONHARDT (1978), recomenda dividir o módulo de deformação transversal do concreto por 100 , a fim de desprezar os efeitos provenientes da torção, ou ainda, TAKEYA (1985) que sugere adotar-se $\mathrm{G}_{\mathrm{c}}=0,15 \mathrm{E}_{\mathrm{c}}$, levando-se em conta os efeitos da fissuração do concreto, adotou-se, neste trabalho $\mathrm{G}_{\mathrm{c}}=0,40 \mathrm{E}_{\mathrm{c}}$, conforme recomenda a NB-1/78, admitindo-se o coeficiente de Poisson $v=0,2$. A fissuração do concreto, bem como a limitação dos esforços oriundos da torção já foram levados em conta, na determinação da inércia à torção, conforme descrito no ítem b).

e) Ações nas barras da grelha.

Todas as ações atuantes na laje nervurada devem ser distribuídas ao longo das barras da grelha. Pode-se imaginar a laje nervurada constituída por várias lajes menores apoiadas nas nervuras, onde as ações atuantes são distribuídas como reações de apoio às nervuras.

f) Consideração de parte da laje na rigidez das vigas.

Sabe-se que parte da laje na junção com as vigas de borda colabora para o aumento da rigidez das vigas, a NB-1/78 permite que a região de momento fletor positivo, como normalmente ocorre nas lajes nervuradas de concreto armado, seja considerada uma parte da laje contribuindo na rigidez da viga, para o cálculo de esforços e deformações. Neste caso, a viga passa a ser calculada como uma seção $\mathrm{T}$, com largura colaborante da laje dada por:

$$
\begin{gathered}
b_{1}\left\{\begin{array}{l}
0,10 a \\
8 h_{f} \\
0,5 b_{2}
\end{array}\right. \\
b_{3}\left\{\begin{array}{l}
0,10 a \\
6 h_{f}
\end{array}\right.
\end{gathered}
$$


Nas expressões anteriores as grandezas geométricas têm os seguintes significados, dependendo do tipo de vinculação:

Viga simplesmente apoiada $a=\ell$

Tramo com momento fletor em uma só extremidade:

$a=3 / 4 \ell$

Tramo com momento fletor nas duas extremidades:

$a=3 / 5 \ell$

Viga em balanço: $a=2 \ell$, sendo $\ell$ o comprimento do vão ou

tramo.
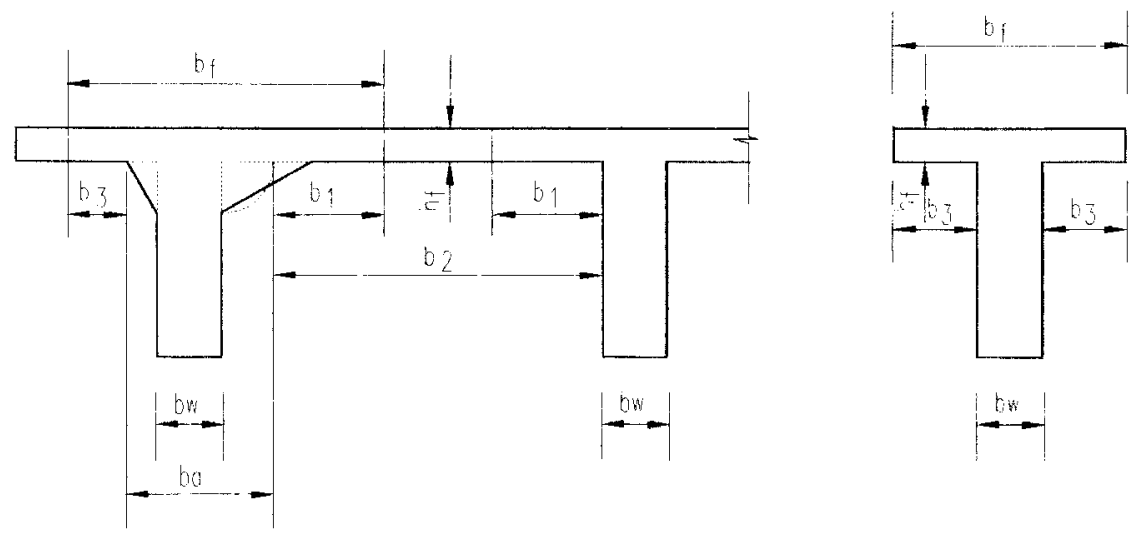

FIGURA 2.14 - LARGURA COLABORANTE DE VIGA DE SEÇÃO T, SEGUNDO A NB-1/78 


\section{VERIFICAÇÃO dA SEGURANÇA COM RELAÇÃO AOS ESTADOS LIMITES}

Determinados os esforços solicitantes, conforme exposto no capítulo 2, faz-se necessário verificar a segurança da laje nervurada com relação aos estados limites, a fim de que esta tenha condições de absorver os esforços solicitantes. Entende-se por estados limites como sendo estados a partir dos quais a estrutura apresenta desempenhos inadequados às finalidades da construção. Nas lajes nervuradas deve-se verificar separadamente a resistência da mesa e das nervuras, para os estados limites últimos, estados que pela sua ocorrência determinam a paralisação total ou parcial da construção. Estes estados podem levar a ruína convencional da laje. Os estados limites de utilização, também devem ser verificados, mesmo não levando a ruína imediata da laje, prejudicam o uso normal da construção, podendo comprometer a durabilidade da mesma.

\subsection{VERIFICAÇÕES PERTINENTES ÀS NERVURAS}

As nervuras das lajes nervuradas devem ser verificadas à flexão (tensões normais) e ao cisalhamento (tensões tangenciais), independentemente. 


\subsubsection{VERIFICAÇÃO DA FLEXÃO DAS NERVURAS}

A verificação da flexão das nervuras das lajes nervuradas devem obedecer as recomendações da NB-1/78, considerando-se como seção resistente, a seção $T$, submetida flexão simples, ou seja, só momento fletor atuando $(\mathrm{N}=0)$.

Caso a mesa da laje nervurada situe-se na face tracionada, a seção resistente é constituída apenas pela nervura, com altura h e largura $b_{w}$ (figura 3.1). Caso contrário, com a mesa na face comprimida, mas cortada pela linha neutra, a seção resistente passa a ser um falso $T$, sendo composto de uma seção retangular de altura h e largura $b_{f}$ (figura 3.2).

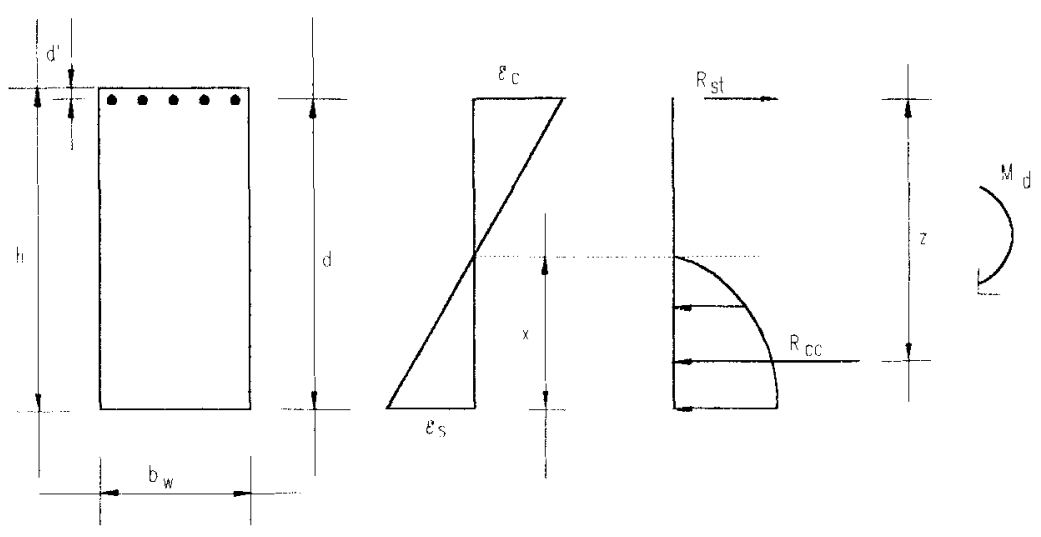

FIGURA 3.1 - MESA DA LAJE NERVURADA NA FACE TRACIONADA 


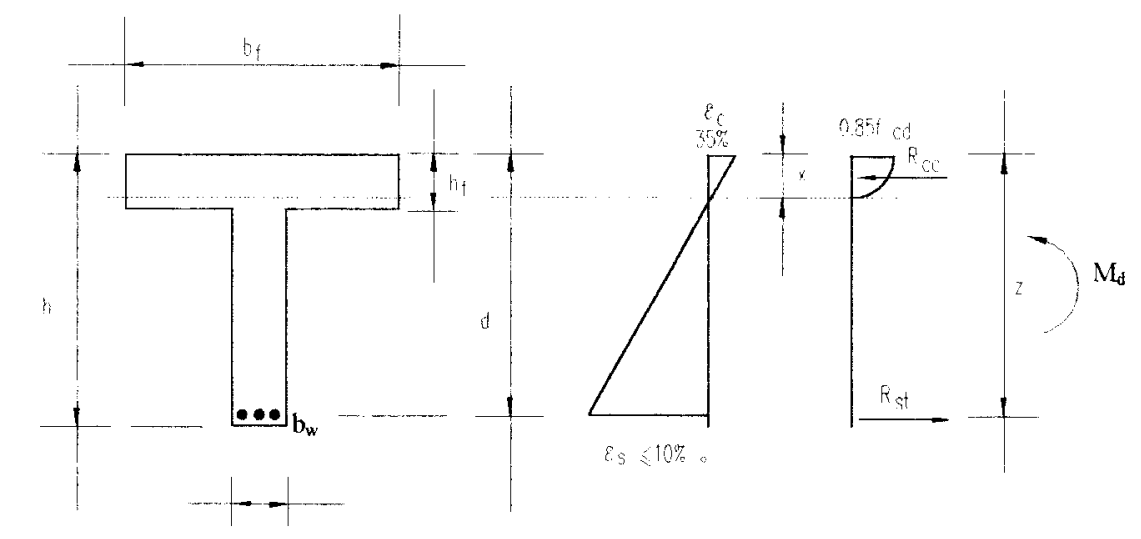

FIGURA 3.2 - LINHA NEUTRA NA MESA DA LAJE NERVURADA

Quando a mesa é toda comprimida, ou seja, a linha neutra recai na alma da seção $T$ e $b_{f} / b_{w} \geq 5$, pode-se adotar para as lajes nervuradas um dimensionamento simplificado, desprezando-se as tensões de compressão atuantes na alma oriundas da flexão, e desde que nas fibras inferiores da mesa comprimida, tenhase $\varepsilon_{c} \geq 0,2 \%$ (figura 3.3 )

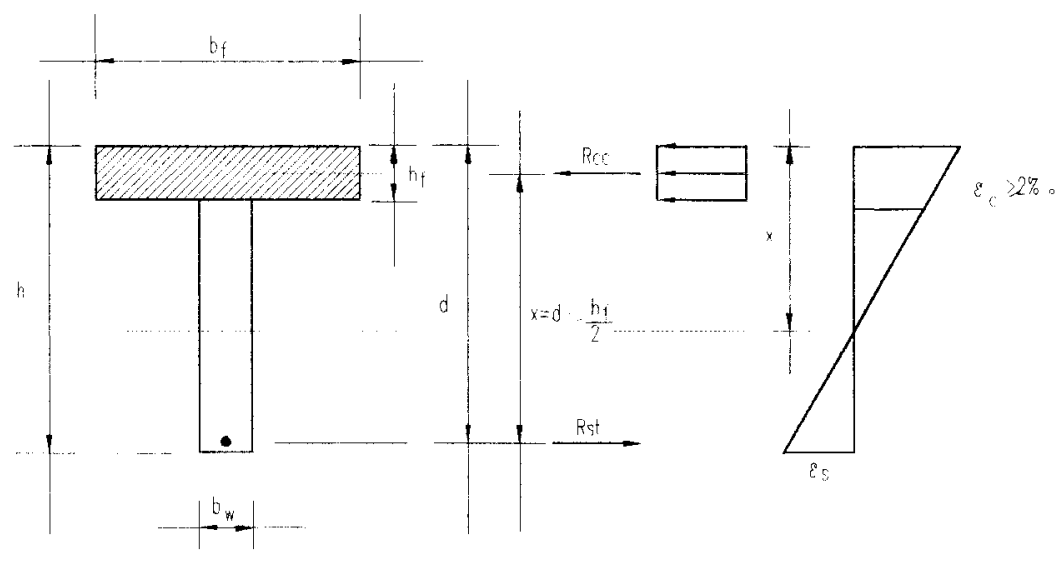

\section{FIGURA 3.3 - LINHA NEUTRA NA ALMA DA LAJE NERVURADA (PROCESSO SIMPLIFICADO)}

Deve-se considerar que este processo simplificado de dimensionamento está à favor da segurança, tornando-se anti-econômico para os casos em que se tenha $b_{f} / b_{w}<5$, devendo-se, então considerar-se a colaboração da porção comprimida da alma. 
Nas lajes nervuradas a situação mais comum e viável economicamente ocorre com a mesa comprimida, em que na região onde atuam os esforços de compressão encontra-se a maior área de concreto, material que apresenta elevada resistência à compressão, e na região onde atuam os esforços de tração a seção de concreto é desprezada, tendo apenas o papel de elemento de ligação e proteção para as armaduras, sendo que estas apresentam elevada resistência aos esforços de tração. E esta é a razão que inviabiliza em muitos casos a adoção da continuidade nas lajes nervuradas, visto que, com a continuidade têm-se nas regiões próximas dos apoios uma inversão dos momentos fletores originando-se esforços de tração na face superior onde predomina o concreto com baixa resistência a este tipo de solicitação e compressão na face inferior da seção.

Nos casos em que adota-se a continuidade das lajes nervuradas pode-se, nas regiões próximas aos apoios, optar-se pela inversão da mesa, ou a utilização de duas mesas, conforme a figura 3.4. Esta situação apresenta algumas desvantagens como aumento do consumo de concreto e consequentemente do peso próprio da construção, refletindo-se principalmente, nas estruturas de fundação, dificuldades na execução da mesa inferior, além do aumento do uso das fôrmas. Podese, então, concluir que a melhor distribuição de esforços ao longo da peça proveniente da hiperasticidade torna-se pouco interessante nas lajes nervuras de concreto armado, devido às propriedades do concreto e a forma da seção transversal da laje nervurada.

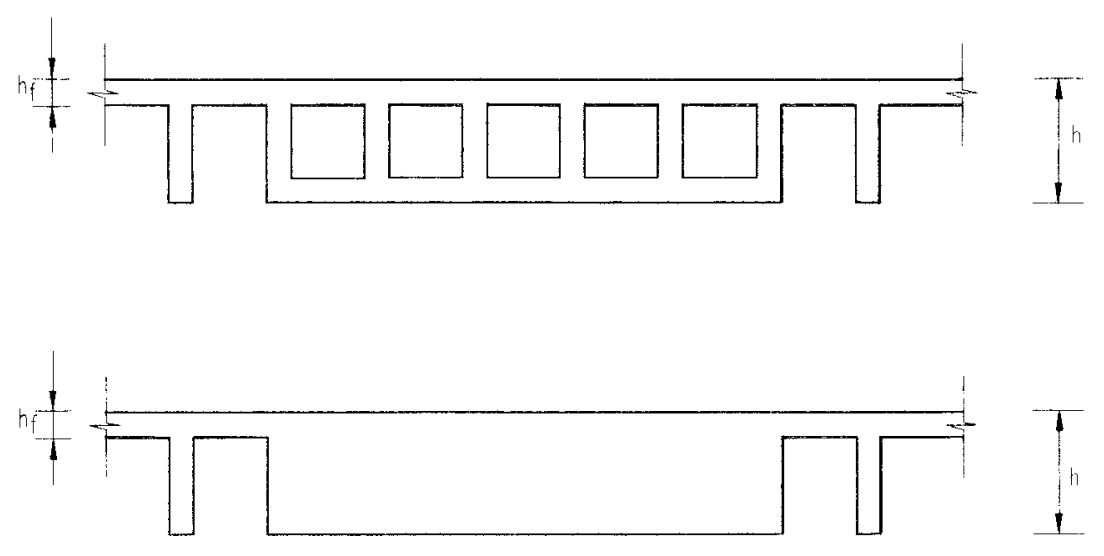

FIGURA 3.4 - LAJES NERVURADAS COM MESA INVERTIDA 
A verificação da resistência das nervuras à flexão deve ser feita no estado limite último, considerando-se o diagrama retangular de tensões no concreto.

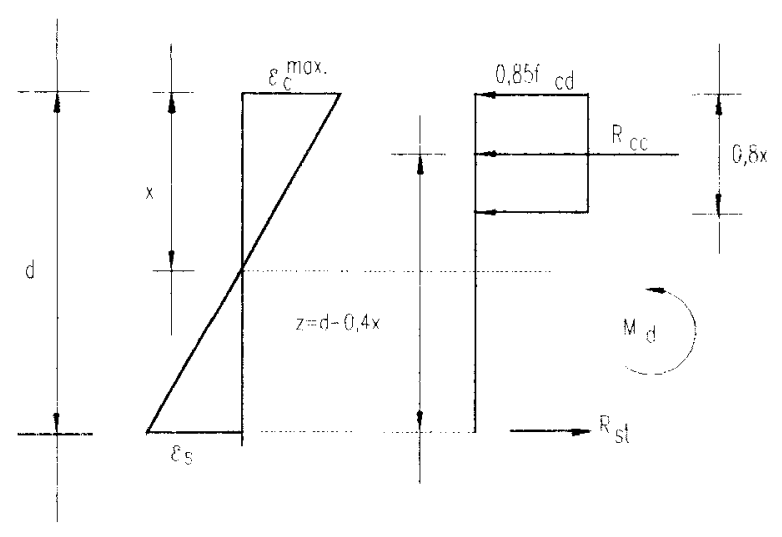

\section{FIGURA 3.5 - VERIFICAÇÃO DAS NERVURAS À FLEXÃO \\ (DIAGRAMA RETANGULAR DE TENSÕES NO CONCRETO)}

Apresenta-se a seguir a dedução das equações para o cálculo da armadura destinada a absorver os esforços de tração provenientes da flexão das nervuras. Considerou-se nesta dedução armadura somente na face inferior da nervura, ou seja, armadura tracionada, visto que, esta é a situação predominante nas lajes nervuras de concreto armado.

Para os casos em que se têm armadura na face superior (mesa) a determinação desta armadura é simples, bastando-se incluir no equilíbrio das tensões a resultante de compressão na armadura.

Do diagrama de tensões (figura 3.5) tem-se que:

$\mathrm{R}_{\mathrm{cc}}-\mathrm{R}_{\mathrm{st}}=0$

onde

$\mathbf{R}_{\mathrm{cc}}=$ força resultante de compressão no concreto

$\mathrm{R}_{\mathrm{cc}}=\mathrm{b}_{\mathrm{f}} \mathrm{y} \sigma_{\mathrm{cc}}$

Com $\sigma_{\mathrm{cc}}=$ tensão de compressão no concreto

$\mathrm{y}=0,8 \mathrm{x}$

$\mathrm{R}_{\mathrm{st}}=$ força resultante de tração na armadura 
$\mathrm{R}_{\mathrm{st}}=\mathrm{A}_{\mathrm{s}} \sigma_{\mathrm{s}}$

Com $\sigma_{\mathrm{s}}=$ tensão de tração na armadura

$\mathrm{A}_{\mathrm{s}}=$ área da seção transversal da armadura

Do diagrama retangular de tensões no concreto:

$R_{\mathrm{cc}}=b_{\mathrm{f}} 0,8 \times 0,85 \mathrm{f}_{\mathrm{cd}}$

$R_{c c}=0,68 b_{f} \times f_{c d}$

$\operatorname{Com} f_{c d}=f_{c k} / \gamma_{f}$ e $\gamma_{f}=1,4$

Como $\beta_{x}=x / d$, então tem-se

$R_{c c}=0,68 b_{f} d \beta_{x} f_{c d}$

De (3.3) e (3.5) em (3.1), tem-se

$0,68 b_{\mathrm{f}} d f_{c d}-\sigma_{\mathrm{s}} A_{s}=0$

Fazendo-se o equilíbrio de momentos fletores, obtém-se

$\mathrm{M}_{\mathrm{d}}=\mathrm{R}_{\mathrm{cc}}(\mathrm{d}-\mathrm{y} / 2)$

Com $\mathrm{M}_{\mathrm{d}}=$ momento fletor de cálculo

$\mathbf{M}_{\mathrm{d}}=1,4 \mathrm{M}_{\mathrm{k}}$ para os casos correntes, devendo-se consultar a Norma brasileira de ações e segurança nas estruturas (NB-5/80) para os outros casos.

De (3.5) em (3.7), obtém-se

$M_{d}=0,68 b_{f} d \beta_{x} f_{c d}(d-0,4 x)$

$M_{d}=0,68 b_{f} d^{2} \beta_{x} f_{c d}\left(1-0,4 \beta_{x}\right)$

Equações de compatibilidade

$$
\frac{\varepsilon_{\mathrm{c}}}{\mathrm{x}}=\frac{\varepsilon_{\mathrm{s}}}{\mathrm{d}-\mathrm{x}}
$$

Com $\varepsilon_{\mathrm{c}}$ e $\varepsilon_{\mathrm{s}}$ sendo a deformação no concreto e no aço respectivamente 
De (3.9) obtém-se

$$
\begin{aligned}
& \beta_{\mathrm{x}}=\varepsilon_{\mathrm{c}} /\left(\varepsilon_{\mathrm{c}}+\varepsilon_{\mathrm{s}}\right) \\
& \varepsilon_{\mathrm{s}}=\left[\left(1-\beta_{\mathrm{x}}\right) / \beta_{\mathrm{x}}\right]
\end{aligned}
$$

O procedimento descrito para o cálculo da armadura destinada a observar os esforços de tração provenientes da flexão da laje nervurada, também pode ser encontrado na forma de tabelas $\left(k_{c}\right.$ e $\left.k_{s}\right)$, inclusive para armadura na face superior da laje. Estas tabelas facilitam e agilizam os cálculos e podem ser encontradas em vasta bibliografia técnica relativa ao assunto. A seguir apresenta-se as tabelas para flexão simples em seção retangular extraídas de PINHEIRO (1993). 
TABELA 3.1 - FLEXÃO SIMPLES EM SEÇÃO RETANGULAR

\begin{tabular}{|c|c|c|c|c|c|c|c|c|c|c|c|c|c|c|}
\hline \multirow[t]{2}{*}{$\beta_{x}=\frac{x}{d}$} & \multicolumn{4}{|c|}{$\mathrm{k}_{\mathrm{c}}=\frac{\mathrm{bd}^{2}}{\mathrm{M}_{\mathrm{d}}}$} & \multicolumn{5}{|c|}{$\left(\mathrm{cm}^{2} / \mathrm{kN}\right)$} & \multicolumn{4}{|c|}{$\mathrm{k}_{\mathrm{s}}=\frac{\mathrm{A}_{\mathrm{s}} \mathrm{d}}{\mathrm{M}_{\mathrm{d}}}\left(\mathrm{cm}^{2} / \mathrm{kN}\right)$} & \multirow{2}{*}{$\begin{array}{l}\text { DOM } \\
\text { ÍNIO }\end{array}$} \\
\hline & \begin{tabular}{|l|}
$C-10$ \\
\end{tabular} & C-15 & C-20 & \begin{tabular}{|l|}
$\mathrm{C}-25$ \\
\end{tabular} & \begin{tabular}{|l|}
$C-30$ \\
\end{tabular} & \begin{tabular}{|l|} 
\\
\end{tabular}$-35$ & $C-40$ & \begin{tabular}{|l|}
$\mathrm{C}-45$ \\
\end{tabular} & C-50 & CA-25 & $50 \mathrm{~A}$ & $50 \mathrm{~B}$ & $60 \mathrm{~B}$ & \\
\hline 0,02 & 103 & 69,2 & 51,9 & 41,5 & 34,6 & 29,6 & 25,9 & 23,1 & 20,8 & 0,046 & 0,023 & 0,023 & 0,019 & \multirow{13}{*}{2} \\
\hline 0,04 & 52,3 & 34,9 & 26,2 & 20,9 & 17,4 & \begin{tabular}{|l|}
14,9 \\
\end{tabular} & 13,1 & 11,6 & 10,5 & 0,047 & 0,023 & 0,023 & 0,019 & \\
\hline 0,06 & 35,2 & 23,4 & 17,6 & 14,1 & 11,7 & 10,0 & 8,8 & 7,8 & 7,0 & 0,047 & 0,024 & 0,024 & 0,020 & \\
\hline 0,08 & 26,6 & 17,7 & 13,3 & 10,6 & 8,9 & 7,6 & 6,6 & 5,9 & 5,3 & 0,048 & 0,024 & 0,024 & 0,020 & \\
\hline 0,10 & 21,4 & 14,3 & 10,7 & 8,6 & 7,1 & 6,1 & 5,4 & $\overline{4,8}$ & 4,3 & 0,048 & 0,024 & 0,024 & 0,020 & \\
\hline 0,12 & 18,0 & 12,0 & 9,0 & 7,2 & 6,0 & 5,1 & 4,5 & 4,0 & 3,6 & 0,048 & 0,024 & 0.024 & 0,020 & \\
\hline 0,14 & $\mid 15,6$ & 10,4 & 7,8 & $\overline{6,2}$ & 5,2 & 4,5 & 3,9 & 3,5 & 3,1 & 0,049 & 0,024 & 0,024 & 0,020 & \\
\hline 0,16 & 13,7 & 9,2 & 6,9 & 5,5 & 4,6 & 3,9 & 3,4 & 3,1 & 2,7 & 0,049 & 0,025 & 0,025 & 0,020 & \\
\hline 0,18 & 12,3 & 8,2 & 6,2 & 4,9 & 4,1 & 3,5 & 3,1 & 2,7 & 2,5 & 0,050 & 0,025 & 0,025 & 0,021 & \\
\hline 0,20 & 11,2 & 7,5 & 5,6 & 4,5 & 4,7 & 3,2 & 2,8 & 2,5 & 2,2 & 0,050 & 0,025 & 0,025 & 0,021 & \\
\hline 0,22 & 10,3 & 6,8 & 5,1 & 4,1 & 3,4 & 2,9 & 2.6 & 2,3 & 2,1 & 0,050 & 0,025 & 0,025 & 0,021 & \\
\hline 0,24 & 9,5 & 6,3 & 4,7 & 3,8 & 3,2 & 2,7 & 2,4 & 2,1 & 1,9 & 0,051 & 0,025 & 0,025 & 0,021 & \\
\hline 0,26 & 8,8 & 5,9 & 4,4 & 3,5 & 2,9 & 2,5 & 2,2 & 2,0 & 1,8 & 0,051 & 0,026 & 0,026 & 0.021 & \\
\hline 0,28 & 8,3 & 5,5 & 4,1 & 3,3 & 2,8 & 2,4 & 2.1 & 1,8 & 1,7 & 0,052 & 0,026 & 0,026 & 0,022 & \multirow{8}{*}{3} \\
\hline 0,30 & 7,8 & 5,2 & 3,9 & 3,1 & 2,6 & 2,2 & 1,9 & 1,7 & $\overline{1,6}$ & 0,052 & 0,026 & 0,026 & 0,022 & \\
\hline 0,32 & 7,4 & 4,9 & 3,7 & 3,0 & 2,5 & 2,1 & 1.8 & 1,6 & 1,5 & 0,053 & 0,026 & 0,026 & 0,022 & \\
\hline 0,34 & 7,0 & 4,7 & 3,5 & 2,8 & 2,3 & 2,0 & 1,8 & 1,6 & 1,4 & 0,053 & 0,027 & 0,027 & 0.022 & \\
\hline 0,36 & 6,7 & 4,5 & 3,3 & 2,7 & 2,2 & 1,9 & 1,7 & 1,5 & 1,3 & 0,054 & 0,027 & 0,027 & 0,022 & \\
\hline 0,38 & 6,4 & 4,3 & 3,2 & 2,6 & 2,1 & 1,8 & 1,6 & 1,4 & 1,3 & 0,054 & 0,027 & 0,027 & 0,023 & \\
\hline 0,40 & 6,1 & 4,1 & 3,1 & 2,5 & 2,0 & 1,8 & 1,5 & 1,4 & 1.2 & 0,055 & 0,027 & 0,027 & 0,023 & \\
\hline 0,438 & 5,7 & 3,8 & 2,8 & 2,3 & 1,9 & 1,6 & 1,4 & 1,3 & 1,1 & 0,056 & 0,028 & 0,028 & 0,023 & \\
\hline 0,44 & 5,7 & 3,8 & 2,8 & 2,3 & 1,9 & 1,6 & 1,4 & 1,3 & 1,1 & 0,056 & 0,028 & 0,028 & 0,023 & \multirow{12}{*}{4} \\
\hline \begin{tabular}{|l|}
0,462 \\
\end{tabular} & 5,5 & 3,6 & 2,7 & 2,2 & 1,8 & 1,6 & 1,4 & 1,2 & 1,1 & 0,056 & 0,028 & 0,028 & 0,024 & \\
\hline 0,48 & 5,3 & 3,5 & 2,7 & 2,1 & 1,8 & 1,5 & 1,3 & 1,2 & 1,1 & 0,057 & 0,028 & 0,029 & 0,025 & \\
\hline 0,52 & 5,0 & 3,3 & 2,5 & 2,0 & 1,7 & 1,4 & 1,2 & 1,1 & 1,0 & 0,058 & 0,029 & 0,031 & 0,027 & \\
\hline 0,56 & $\overline{4,7}$ & 3,2 & 2,4 & 1,9 & 1,6 & 1,4 & 1,2 & 1,1 & 1,0 & 0,059 & 0,030 & 0,033 & 0,029 & \\
\hline 0,60 & 4,5 & 3,0 & 2,3 & 1,8 & 1,5 & 1,3 & 1,1 & 1,0 & 0,9 & 0,061 & 0,030 & 0,035 & - & \\
\hline \begin{tabular}{|l|}
0.628 \\
\end{tabular} & 4,4 & 2,9 & 2,2 & 1,8 & 1,5 & 1,3 & 1,1 & 1,0 & 0,9 & 0,061 & 0,031 & 0,037 & - & \\
\hline 0,64 & 4,3 & 2,9 & 2,2 & 1,7 & 1,4 & 1,2 & 1,1 & 1,0 & 0,9 & 0,062 & - & - & - & \\
\hline 0,68 & 4,2 & 2,8 & 2,1 & 1,7 & 1,4 & 1,2 & 1,0 & 0,9 & 0,8 & 0,063 & - & - & - & \\
\hline 0,72 & 4,0 & 2,7 & 2,0 & 1,6 & 1,3 & 1,2 & 1,0 & 0,9 & 0,8 & 0,065 & - & - & - & \\
\hline 0,76 & 3,9 & 2,6 & 2,0 & 1,6 & 1,3 & 1,1 & 1,0 & 0,9 & 0,8 & 0,066 & - & - & $=$ & \\
\hline 0,772 & 3,9 & 2,6 & 1,9 & 1,5 & 1,3 & 1,1 & 1,0 & 0,9 & 0,8 & 0,067 & - & - & - & \\
\hline
\end{tabular}


A armadura de flexão das nervuras deve ter a seção transversal com área mínima de $0,15 \% \mathrm{~b}_{\mathrm{w}} \mathrm{h}$, valor este indicado pela NB-1/78. Deve-se, também, dispor de uma armadura de distribuição com seção transversal de área mínima igual a $1 / 5$ da armadura principal, não inferior a $0,9 \mathrm{~cm}^{2} / \mathrm{m}$ no caso de lajes armadas em uma direção.

\subsubsection{VERIFICAÇÃO DO CISALHAMENTO NAS NERVURAS}

Para a verificação do cisalhamento nas nervuras das lajes nervuradas faz-se necessário dividir estas em dois grupos distintos, de acôrdo com a distância (a) entre nervuras.

A - Verificação do cisalhamento nas nervuras das lajes nervuradas com a $\leq 50 \mathrm{~cm}$.

Neste caso a NB-1/78, permite a verificação do cisalhamento nas nervuras considerando a laje nervurada como uma laje maciça, isto é, dispensa-se a armadura transversal (estribos nas nervuras) sempre que $\tau_{\mathrm{wd}} \leq \tau_{\mathrm{wu} 1}$, conforme anexo da NB-116/89 e tomando-se como seção resistente, aquela altura h e largura $b_{w}$.

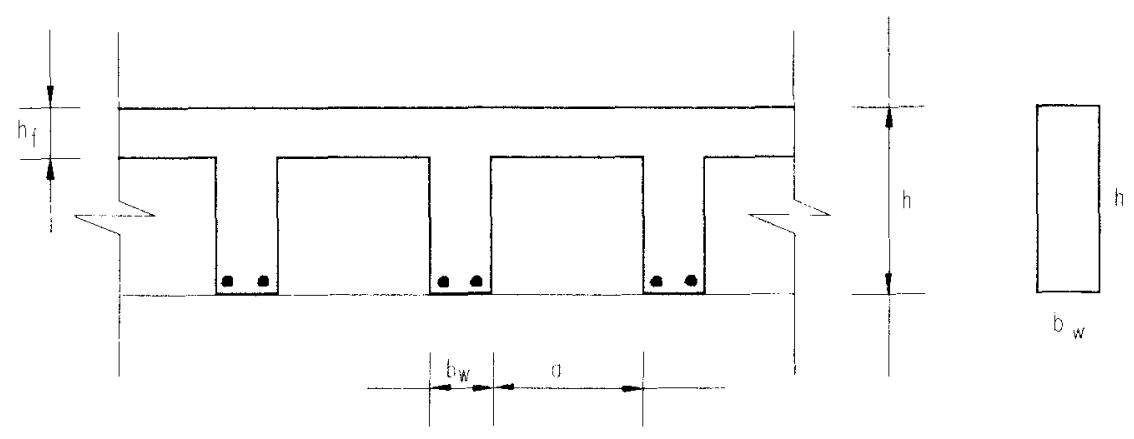

FIGURA 3.6 - CISALHAMENTO NAS NERVURAS DAS LAJES NERVURADAS 
O valor de cálculo da tensão convencional de cisalhamento no concreto é determinado por:

$$
\tau_{\mathrm{wd}}=\frac{\mathrm{V}_{\mathrm{d}}}{\mathrm{b}_{\mathrm{w}} \mathrm{d}}
$$

Para as lajes nervuradas submetidas à flexão simples e sem armadura de cisalhamento deve-se ter $\tau_{\mathrm{wd}} \leq \tau_{\text {wul }}$, onde

$$
\tau_{w u 1}=\psi_{4} \sqrt{f_{c k}}<1,0 \quad(\text { em MPa })
$$

Com $\psi_{4}$ assumindo um dos seguintes valores:

I) $\psi_{4}=0,12 \frac{\alpha \mathrm{k}}{1-3 \mathrm{~d} / \ell}$, para as cargas distribuídas, quando $\mathrm{d}>\ell / 20 \mathrm{e}$,

$\psi_{4}=0,14 \alpha \mathrm{k}$, quando $\mathrm{d} \leq \ell / 20$, sendo $\ell$ o menor vão teórico das lajes apoiadas ou o dobro do comprimento teórico das lajes em balanço;

II) $\psi_{4}=0,08 \alpha \mathrm{k}$, para ações lineares paralelas ao apoio (por exemplo paredes), permitindo-se a redução na proporção $a / 2 d$, da parcela da força cortante decorrente de ações cujo afastamento a do eixo do apoio seja inferior ao dobro da altura útil d;

III) quando há ações distribuídas e ações lineares paralelas ao apoio, $\psi_{4}$ é obtido por interpolação proporcionalmente às parcelas da força cortante, decorrentes desses dois tipos de carregamento.

Os coeficientes k e $\alpha$ são dados pelas expressões:

$k=1,6-d \geq 1$, com $d$ em metros;

$\alpha=1+50 \rho_{1} \leq 1,5$, limitando-se o produto $\alpha \mathrm{k}$ ao valor 1,75

sendo $\rho_{1}$ a taxa de armadura longitudinal de tração na seção afastada de $2 \mathrm{~h}$ da face interna do apoio, considerando-se apenas as barras de aço prolongadas até o apoio e devidamente ancoradas. 

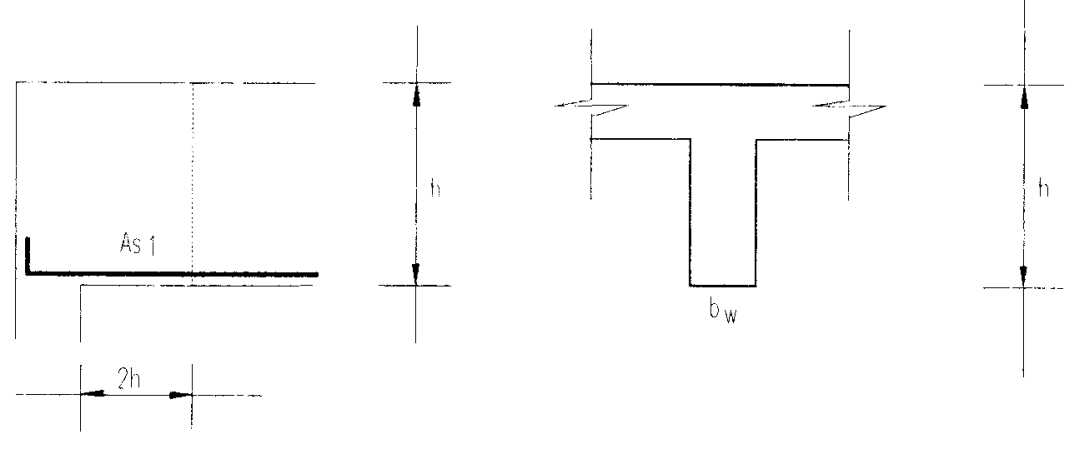

$$
\rho_{1}=\frac{\mathrm{A}_{\mathrm{s}}}{\mathrm{A}_{\mathrm{c}}}
$$

FIGURA 3.7 - DETERMINAÇÃO DE $\rho_{1}$

$B$ - Verificação do cisalhamento nas nervuras para lajes nervuradas com a $>50 \mathrm{~cm}$

A verificação do cisalhamento nas nervuras para as lajes nervuradas com $a>50 \mathrm{~cm}$ deve obedecer as recomendações aplicáveis às vigas usuais, isto é, qualquer que seja o valor da solicitação deve haver armadura transversal, respeitando-se a taxa mínima estabelecida pela NB-1/78. Neste caso a largura das nervuras não deve ser inferior a $8 \mathrm{~cm}$, na mesa deve haver armadura perpendicular à nervura por toda sua largura útil, com seção transversal mínima de $1,5 \mathrm{~cm}^{2}$, esta armadura deverá existir ao longo do comprimento da nervura.

Deve-se dispor de armadura transversal nos trechos onde ela é necessária, para resistir a força cortante, a fim de evitar-se a ruptura do concreto respeitando-se $\tau_{\mathrm{wd}} \leq \tau_{\mathrm{wu}}$, com $\tau_{\mathrm{wu}}$ igual a:

a) para peças lineares e lajes com $b_{w}<5 h$, se toda armadura transversal calculada (barras dobradas e estribos) for inclinada a $45^{\circ}$ sobre o eixo da peça:

$$
\tau_{\mathrm{wu}}=0,35 \mathrm{f}_{\mathrm{cd}} \leq 5,5 \mathrm{MPa}
$$

b) para peças lineares e lajes com $b_{w}<5 \mathrm{~h}$, para armadura transversal perpendicular $\left(90^{\circ}\right)$

$$
\tau_{\mathrm{uu}}=0,30 \mathrm{f}_{\mathrm{cd}} \leq 4,5 \mathrm{MPa}
$$


Para as lajes maciças e nervuradas e peças lineares com $b_{w}$ $>5 \mathrm{~h}$, os coeficientes 0,35 e 0,30 devem ser multiplicados por um dos seguintes fatores, mantidos os limites absolutos.

$$
\begin{array}{lll}
0,5 & \text { se } & h \leq 15 \mathrm{~cm}, \\
1 / 3+h / 90 & \text { se } & 15<\mathrm{h}<60, \\
1 & \text { se } & h \geq 60 \mathrm{~cm}
\end{array}
$$

A armadura transversal das peças lineares e das lajes nervuradas, para resistir aos esforços oriundos da força cortante, deve ser calculada pela teoria clássica de Morsch com base na seguinte tensão (MPa):

$$
\begin{aligned}
& \tau_{\mathrm{d}}=1,15 \tau_{\mathrm{wd}}-\tau_{\mathrm{c}}>0 \\
& \text { com } \\
& \tau_{\mathrm{c}}=\psi_{1} \sqrt{f_{\mathrm{ck}}} \\
& \text { sendo } \\
& \psi_{1}=0,15 \text { na flexão simples e na flexo-tração com a linha }
\end{aligned}
$$
neutra passando pela seção.

A armadura transversal composta por estribos verticais deve ser dimensionada com sua resistência de cálculo $f_{y d}$, não sendo tomados valores superiores a $435 \mathrm{MPa}$. Para o dimensionamento da área da seção da armadura transversal, tem-se:

$$
\frac{\mathrm{A}_{\mathrm{sw}}}{\mathrm{sn}}=\frac{\tau_{\mathrm{d}}}{\mathrm{f}_{\mathrm{yd}}} \mathrm{b}_{\mathrm{w}} \frac{100}{\mathrm{n}}
$$

onde

$\mathrm{A}_{\mathrm{sw}}$ = área da seção de armadura transversal,

$\mathrm{s}=$ espaçamento dos estribos,

$\mathrm{n}=$ número de ramos dos estribos

De $A_{\mathrm{sw}} / \mathrm{s} \mathrm{n}$, tem-se a área de armadura transversal $\left(\mathrm{cm}^{2}\right)$, por unidade de comprimento $(\mathrm{m})$. Esta não pode ser menor que a taxa mínima de armadura estabelecida pela NB-1/78, de $0,25 \% \mathrm{~b}_{w} / \mathrm{n}\left(\mathrm{cm}^{2} / \mathrm{m}\right)$ para os aços CA-25 e $0,14 \% \mathrm{~b}_{\mathrm{w}} / \mathrm{n}\left(\mathrm{cm}^{2} / \mathrm{m}\right)$ para os aços CA-50 e CA-60. 
Atenção especial deve-se ter para o cálculo da armadura transversal nas seções próximas aos apoios, se a ação e reação de apoio forem aplicadas em faces opostas da peça, comprimindo-a, a NB-1/78 traz as seguintes prescrições:

a) a força cortante oriunda de ação uniformemente distribuída pode ser considerada, no trecho entre o apoio e a seção situada à distância $h / 2$ da face do apoio, constante e igual à desta seção;

b) a força cortante devida a uma ação concentrada aplicada a uma distância $\mathrm{a} \leq 2 \mathrm{~h}$ do eixo teórico do apoio pode, nesse trecho de comprimento a, ser reduzida multiplicando-a por a / $2 \mathrm{~h}$, o eixo teórico do apoio é determinado pelo vão teórico;

c) para a verificação da tensão no concreto, feita pela comparação de $\tau_{\mathrm{wd}} \operatorname{com} \tau_{\mathrm{w}, \text {, não }}$ pode ser feita a redução do valor da força cortante:

A Norma Brasileira NB-1/78 estabelece, ainda, no item 6.3.2.2 que o espaçamento dos estribos, medido paralelamente ao eixo da peça, deve ser no máximo igual a $0,5 \mathrm{~d}$, não podendo ser maior que $30 \mathrm{~cm}$. Se houver armadura longitudinal de compressão exigida pelo cálculo, o espaçamento dos estribos, medido ao longo daquela armadura, não pode, também, ser maior que 21 vezes o diâmetro das barras longitudinais no caso do aço CA-25 ou CA-32 e 12 vezes esse diâmetro no caso do aço CA-40, CA-50 ou CA-60. Esta recomendação na maioria dos casos faz. com que as lajes nervuradas, em virtude da sua pequena altura, tenham grande quantidade de estribos, dificultando a execução e elevando os custos da laje, muitas vezes inviabilizando a execução das lajes nervuradas com distância livre entre nervuras maior que $50 \mathrm{~cm}$, optando-se, então, para lajes com distância livre entre nervuras menor que $50 \mathrm{~cm}$, evitando-se, assim, a colocação de armadura transversal (estribos) nas nervuras. 


\subsection{VERIFICAÇÃO DA RESISTÊNCIA DA MESA}

\subsubsection{VERIFICAÇÃO DA FLEXÃO DA MESA}

A Norma Brasileira NB-1/78 dispensa a verificação da mesa das lajes nervuradas quando a distância entre as nervuras for inferior a $50 \mathrm{~cm}$, esta verificação faz-se necessária quando houver ações concentradas ou linearmente distribuídas aplicadas na mesa entre as nervuras e quando a distância entre elas for maior que $50 \mathrm{~cm}$.

A laje nervurada quando carregada deforma-se podendo imaginar-se uma elástica conforme a figura 3.8. Como as nervuras de deformam de maneira diferente, a mesa apresenta uma elástica semelhante a da figura 3.9.

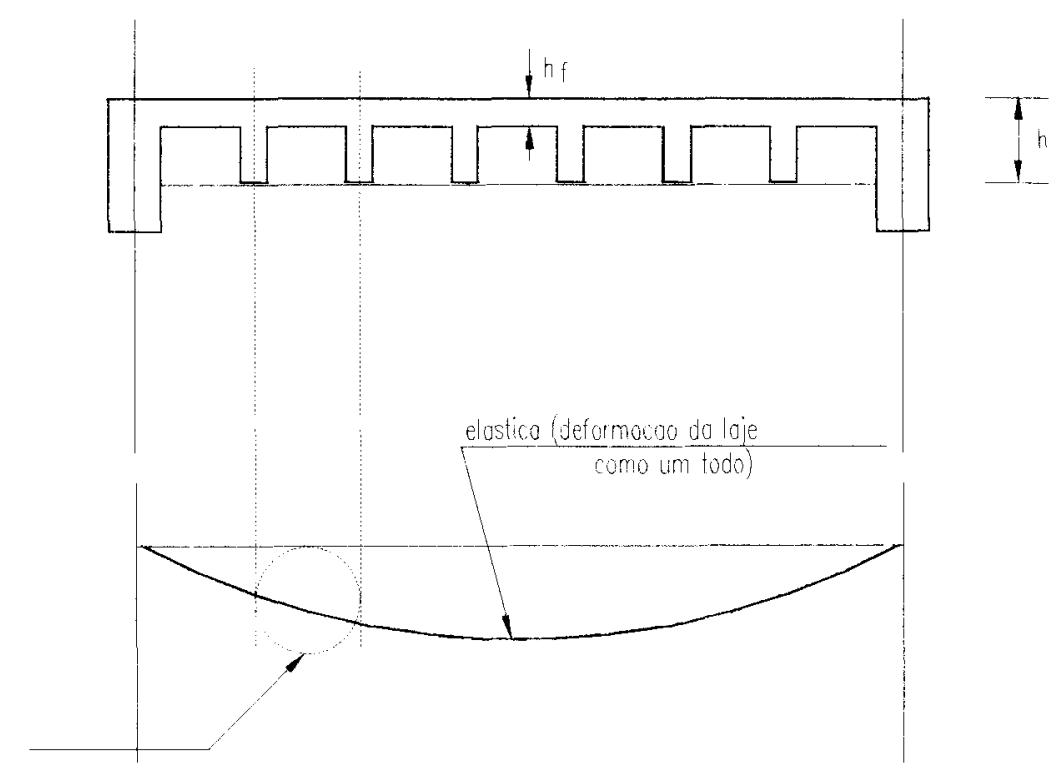

FIGURA 3.8 - ELÁSTICA DA LAJE NERVURADA, ANDRADE (1977) 


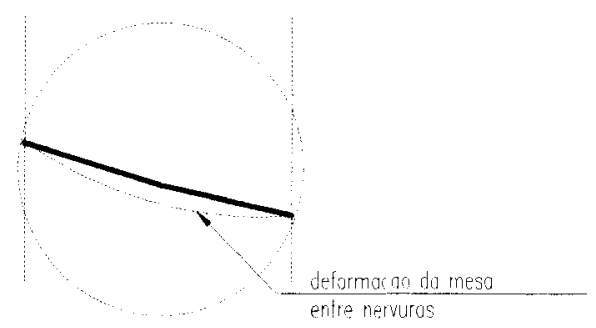

FIGURA 3.9 - ELÁSTICA DA MESA, ANDRADE (1977)

Pode-se, então, considerar a mesa como um conjunto de lajes maciças, contínuas, apoiadas elasticamente nas nervuras. Nesta condição a determinação dos esforços solicitantes torna-se muito complexa, principalmente quando os painéis têm grandes dimensões. Admitindo-se a continuidade dos painéis, passa-se a considerar um momento fletor negativo nos respectivos apoios, e consequentemente armadura para absorver as tensões de tração provocadas pela flexão. Admitir-se a continuidade não é condição de equilibrio para os painéis, portanto pode-se desprezá-la, em face da ordem de grandeza dos momentos fletores, permitindo-se com isto o aparecimento de fissuras, as quais não prejudicam a utilização e durabilidade das lajes nervuradas.

Contudo, os momentos fletores positivos atuantes nos painéis devem ser absorvidos por armadura adequada posicionada na mesa. Esta armadura deve ser calculada considerando os painéis como lajes maciças, com os lados apoiados nas nervuras.

\subsection{2. - VERIFICAÇÃO DO CISALHAMENTO DA MESA}

O critério para a verificação das tensões tangenciais na mesa segue a mesma rotina adotada para as lajes maciças. 
Para não se dispor de armadura transversal na mesa, deve-se, portanto ter:

$$
\begin{aligned}
& \tau_{\mathrm{wd}} \leq \tau_{\mathrm{wud}} \\
& \tau_{\mathrm{wd}}=\frac{\mathrm{V}_{\mathrm{d}}}{\mathrm{b}_{\mathrm{wd}}} \\
& \tau_{\mathrm{wud}}=\psi_{4} \sqrt{f_{\mathrm{ck}}} \\
& \text { onde: } \\
& \mathrm{V}_{\mathrm{d}}=\text { força cortante de cálculo } \\
& \mathrm{b}_{\mathrm{w}}=\text { largura da seção transversal } \\
& \mathrm{d}=\text { altura útil } \\
& \psi_{4}=\text { calculado conforme descrito no item } 3.1 .2 \\
& \mathrm{f}_{\mathrm{ck}}=\text { resistência característica à compressão do concreto aos } 28
\end{aligned}
$$

dias.

O efeito do cisalhamento na mesa das lajes nervuradas na maioria dos casos é desprezado, não necessitando verificação, apenas quando existirem ações concentradas aplicadas entre as nervuras esta verificação deverá ser feita. A colocação de armadura com a finalidade de absorver os esforços oriundos do cisalhamento nos painéis das lajes nervuradas não é recomendada, assim como nas lajes maciças, visto que sua pequena espessura dificulta e até inviabiliza a execução da mesma. Recomenda-se sempre que possível fazer com que as ações concentradas atuem diretamente nas nervuras, evitando-se assim a necessidade da armadura para o cisalhamento.

\subsection{VERIFICAÇÃO DAS TENSÕES DE CISALHAMENTO NAS LIGAÇÕES MESA-NERVURA}

A verificação das tensões de cisalhamento na ligação da mesa com as nervuras nas lajes nervuradas pode ser desprezada apenas quando a $\leq 50 \mathrm{~cm}$, 
com $\tau_{\mathrm{wd}} \leq \tau_{\mathrm{wu} 1}$, e a altura da mesa $\left(\mathrm{h}_{\mathrm{f}}\right)$ for maior ou igual a 0,5 da largura da nervura $\left(b_{w}\right)$. Para os demais casos esta verificação faz-se necessária, tanto para a mesa comprimida, situação mais freqüente e econômica, como para a mesa tracionada, conforme exposto a seguir.

\subsubsection{VERIFICAÇÃO DAS TENSÕES DE CISALHAMENTO NAS LIGAÇÕES MESA-NERVURA COM A MESA COMPRIMIDA}

Inicialmente, considera-se na viga de seção $\mathrm{T}$, solicitada à flexão e cisalhamento, um elemento com comprimento $\mathrm{dx}$, localizado entre fissuras, conforme mostra a figura 3.10 .
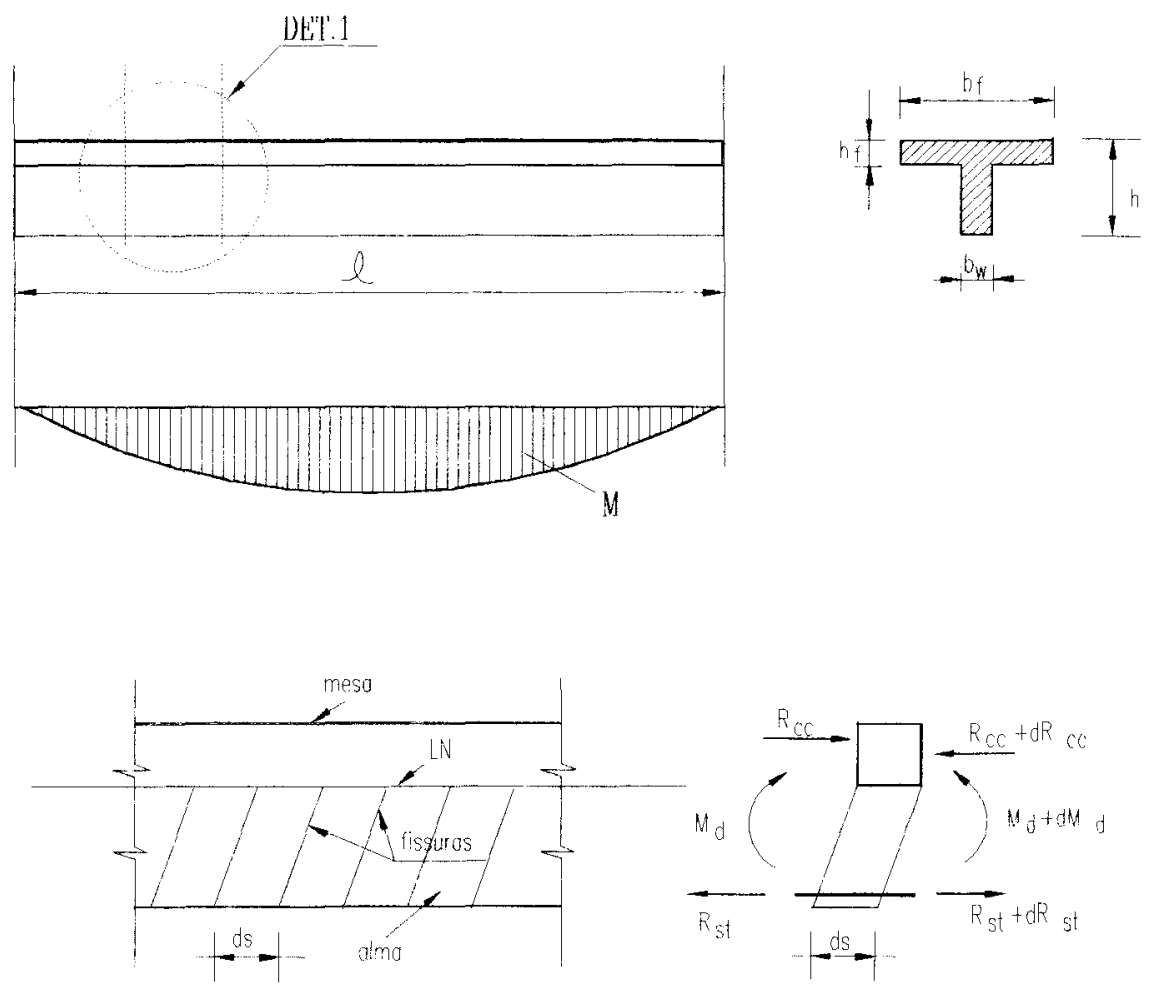

DET. 1

FIGURA 3.10 - ELEMENTO DE LARGURA dx DE UMA VIGA DE SEÇÃO T SOLICITADA À FLEXÃO E CISALHAMENTO, ANDRADE (1977) 
Considerando o equilíbrio do elemento em face das forças aplicadas, tem-se:

$$
\begin{aligned}
& \mathrm{zdR}_{\mathrm{cc}}=\mathrm{zdR_{ \textrm {st } }}=\mathrm{dM}_{\mathrm{d}} \\
& \mathrm{dR}_{\mathrm{cc}}=\frac{\mathrm{dM}_{\mathrm{d}}}{\mathrm{z}}
\end{aligned}
$$

$A$ variação de $R_{c c}$ na unidade de comprimento será:

$$
\frac{\mathrm{dR}_{\mathrm{cc}}}{\mathrm{dx}}=\frac{d M_{d}}{z d x}=\frac{V_{d}}{z}
$$

A força $R_{c c}$, como resultante das tensões de compressão no concreto pode ser considerada como soma das parcelas na figura 3.11. Como $R_{c c}$ varia com a variação de $M_{d}, R_{c c}$ também possui um diferencial em $d x$, o qual precisa ser transferido para a nervura, surgindo assim tensões cisalhamento na ligação da aba (parte da mesa) com a nervura.

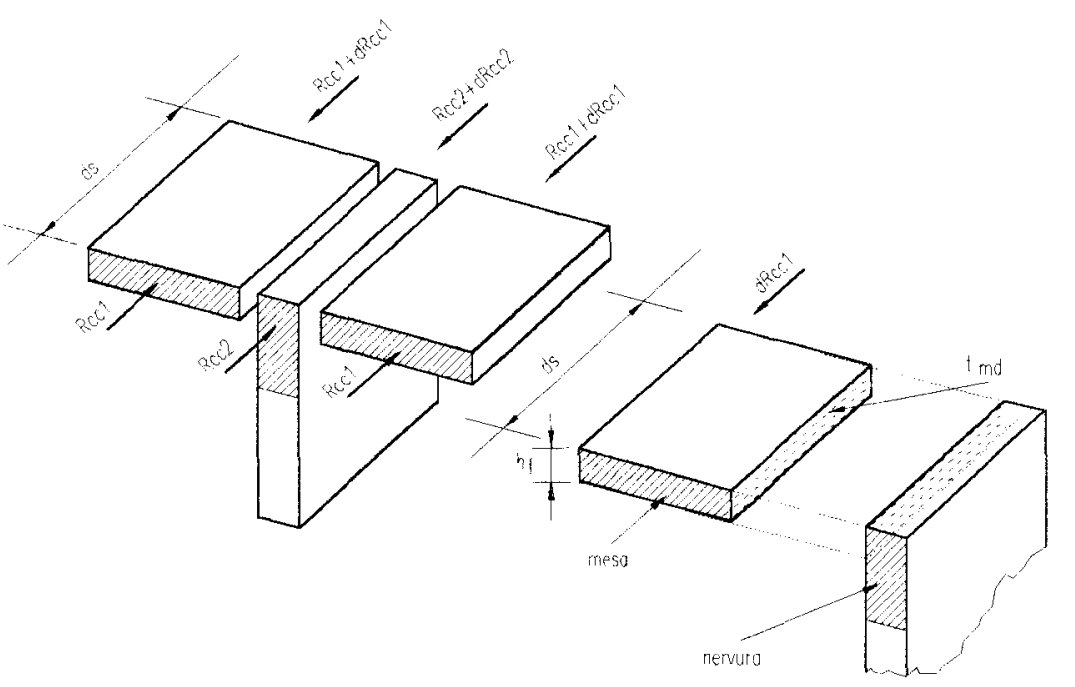

FIGURA 3.11 - REPRESENTAÇÃO DAS FORÇAS DE COMPRESSÃO ATUANTES NO CONCRETO, ANDRADE (1977)

Para o equilibrio do elemento da mesa tem-se

$\mathrm{dR}_{\mathrm{cc} 1}=\tau_{\mathrm{md}} \mathrm{h}_{\mathrm{f}} \mathrm{dx}$

como: 
$\mathrm{dR}_{\mathrm{ccl}}=\frac{\mathrm{R}_{\mathrm{ccl}}}{\mathrm{R}_{\mathrm{cc}}} \mathrm{dR}$

ou na unidade de comprimento

$\frac{\mathrm{dR}_{\mathrm{ccl}}}{\mathrm{dx}}=\frac{\mathrm{R}_{\mathrm{ccl}}}{\mathrm{R}_{\mathrm{cc}}} \frac{\mathrm{dR}_{\mathrm{cc}}}{\mathrm{dx}}$

De (3.16) em (3.14) e considerando-se a expressão de $\mathrm{dR}_{\mathrm{cc}}$ dada por (3.13), tem se que:

$$
\tau_{m d}=\frac{V_{d}}{h_{f}} \frac{R_{c c 1}}{z R_{c c}}
$$

Para resistir aos esforços de tração provenientes de $\tau_{\mathrm{md}}$, necessita-se dispor uma armadura transversal. Esta armadura pode ser calculada partindo-se da figura 3.12.

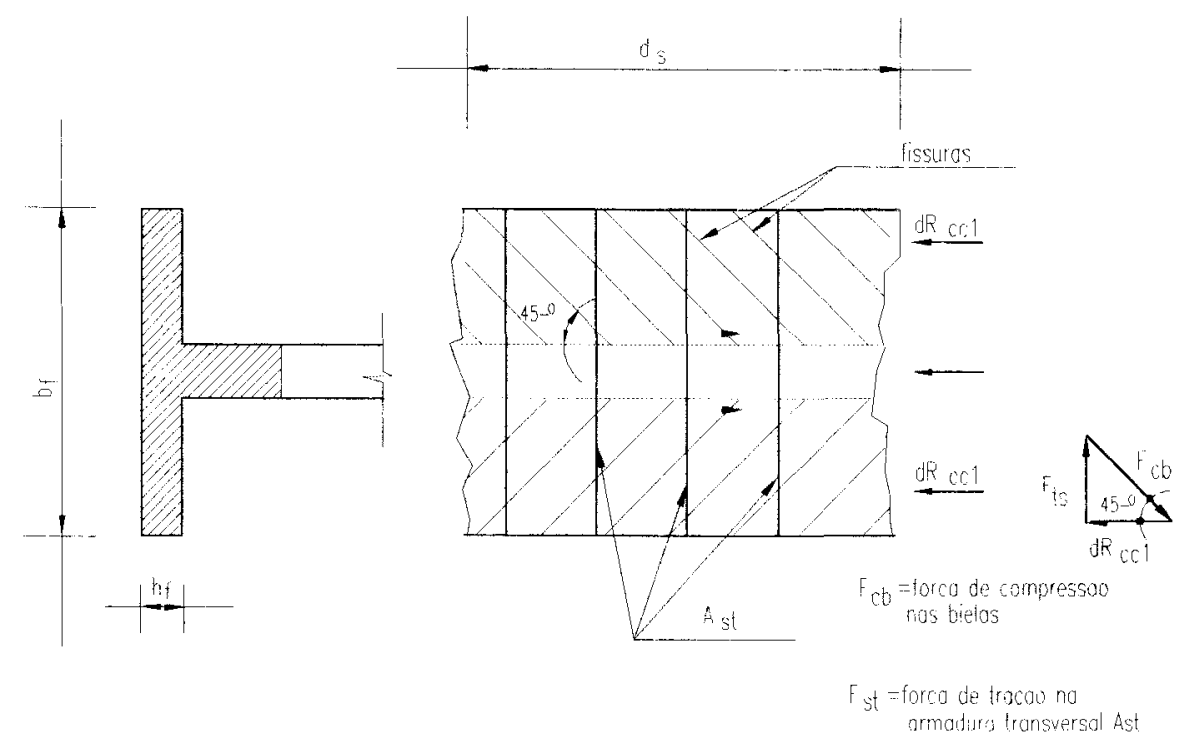

FIGURA 3.12 - ARMADURA PARA ABSORVER OS ESFORÇOS DE TRAÇÃO PROVOCADOS POR $\tau_{\mathrm{md}}$, ANDRADE (1977)

Supondo-se que as fissuras sejam inclinadas a $45^{\circ}$ para o equilíbrio:

$$
F_{s t}=d R_{\text {ccl }}
$$


Então:

$$
A_{s t}=\frac{F_{s t}}{f_{y d}}=\frac{d}{f_{y d}}
$$

De (3.16) e (3.14) em (3.20) obtém-se:

$$
A_{s t}=\frac{V_{d}}{z f_{y d}} \frac{R_{c c 1}}{R_{c c}}
$$

A relação $R_{c c} / R_{c c}$ pode ser representada como a relação entre as áreas comprimidas do concreto, $\mathrm{A}_{\mathrm{cI}}$ e $\mathrm{A}_{\mathrm{c}}$, portanto:

$$
\frac{\mathrm{R}_{\mathrm{cc1}}}{\mathrm{R}_{\mathrm{cc}}}=\frac{\mathrm{A}_{\mathrm{c} 1}}{\mathrm{~A}_{\mathrm{c}}}
$$

Para utilizar-se a expressão (3.22), que é geral, tem-se que determinar a posição de linha neutra.

Quando a linha neutra passa pela mesa tem-se, então que:

$$
\begin{aligned}
& \frac{\mathrm{A}_{\mathrm{c} 1}}{\mathrm{~A}_{\mathrm{c}}}=\frac{0,5\left(\mathrm{~b}_{\mathrm{f}}-\mathrm{b}_{\mathrm{w}}\right) \mathrm{h}_{\mathrm{f}}}{\mathrm{b}_{\mathrm{f}} \mathrm{h}_{\mathrm{f}}}=0,5\left(1-\mathrm{b}_{\mathrm{w}} / \mathrm{b}_{\mathrm{f}}\right) \\
& \operatorname{De}(3.23) \mathrm{em}(3.18) \text { e }(3.21): \\
& \tau_{m d}=\frac{V_{d}}{h_{f} z}=0,5\left(1-b_{w} / b_{f}\right) \\
& A_{s t}=\frac{V_{d}}{z f_{y d}}=0,5\left(1-b_{w} / b_{f}\right)
\end{aligned}
$$

Quando a linha neutra passa pela nervura, as expressões anteriores são válidas estando a favor da segurança. Neste caso, pode-se adotar $z=d-1 / 2 h_{f}$ 


\subsubsection{VERIFICAÇÃO DAS TENSÕES DE CISALHAMENTO NAS LIGAÇÕES MESA-NERVURA COM A MESA TRACIONADA}

Para o caso da mesa tracionada, o raciocínio é análogo ao anterior. Considerando uma viga de seção $T$, solicitada à flexão e cisalhamento em um elemento com largura dx, localizado entre fissuras de acôrdo com a figura 3.13.

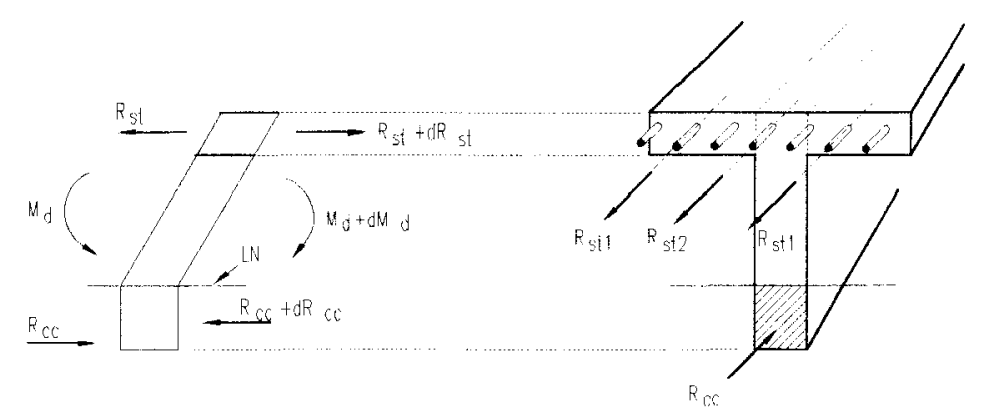

FIGURA 3.13 - ELEMENTO DE LARGURA dx DE UMA VIGA DE SEÇÃO T SOLICITADA À FLEXÃO E CISALHAMENTO, ANDRADE (1977)

Por equilibrio tem-se:

$\mathrm{dR}_{\mathrm{st}}=\frac{\mathrm{dM} \mathrm{d}_{\mathrm{d}}}{\mathrm{z}}$

ou com a variação de $\mathrm{R}_{\mathrm{st}}$ na unidade de comprimento:

$\frac{d R_{s t}}{d x}=\frac{V_{d}}{z}$

Para equilíbrio do elemento da mesa, tem-se:

$\mathrm{dR}_{\mathrm{st} 1}=\tau_{\mathrm{md}} \mathrm{h}_{\mathrm{f}} \mathrm{dx}$

como

$\mathrm{dR}_{\mathrm{st1}}=\frac{\mathrm{R}_{\mathrm{st1}}}{\mathrm{R}_{\mathrm{st}}} \mathrm{dR}_{\mathrm{st}}$

ou, na unidade de comprimento:

$\frac{\mathrm{dR}_{\mathrm{st1}}}{\mathrm{dx}}=\frac{\mathrm{R}_{\mathrm{st1}}}{\mathrm{R}_{\mathrm{st}}} \frac{\mathrm{dR}_{\mathrm{st}}}{\mathrm{dx}}$ 
De (3.30) em (3.28) considerando-se a expressão de $\mathrm{dR}_{\mathrm{cc}}$ dada por (3.27), tem-se que:

$$
\tau_{m d}=\frac{V_{d}}{h_{f} z} \frac{R_{s t 1}}{R_{s t}}
$$

Como no caso anterior para resistir aos esforços de tração oriundos de $\tau_{\mathrm{md}}$, tem-se que dispor de armadura transversal de acôrdo com a figura 3.14 .
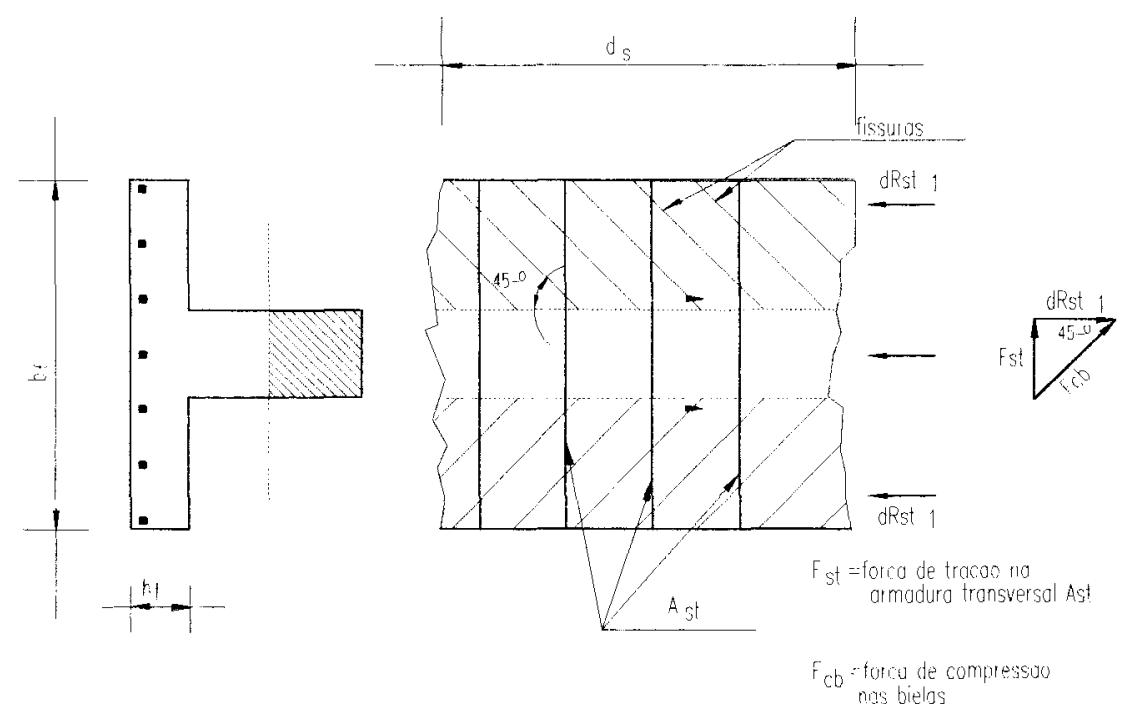

FIGURA 3.14 - ARMADURA PARA ABSORVER AOS ESFORÇOS DE TRAÇÃO PROVOCADOS POR $\tau_{\mathrm{md}}$, ANDRADE (1977)

Supondo-se, novamente que as fissuras sejam inclinadas a $45^{\circ}$ para o equilíbrio.

$$
\mathrm{F}_{\mathrm{st}}=\mathrm{dR}_{\mathrm{st} 1}
$$

então:

$$
A_{s t}=\frac{F_{s t}}{f_{y d}}=\frac{d}{f_{y d}}
$$

De (3.27) e (3.29) em (3.33), obtém-se: 


$$
A_{s t}=\frac{V_{d}}{z f_{y d}} \frac{R_{s t 1}}{R_{s t}}
$$

Como a relação $R_{s t 1} / R_{s t}$, é a própria relação entre áreas de armadura tracionada $A_{s 1}$ e $A_{s}$, tem-se finalmente

$$
\begin{gathered}
\tau_{m d}=\frac{V_{d}}{z h_{f}} \frac{A_{s t 1}}{A_{s}} \\
A_{s t}=\frac{V_{d}}{z f_{y d}} \frac{A_{s 1}}{A_{s}}
\end{gathered}
$$

Para o caso de mesas solicitadas alternadamente à tensão e à compressão, deve-se respeitar simultaneamente as condições impostas para cada situação, de maneira isolada.

Como as mesas também são solicitadas à flexão com plano de ação perpendicular às nervuras, as tensões de compressão resultantes têm efeito favorável. Pode-se, neste caso, considerar a armadura de flexão da mesa como armadura necessária para verificar a ligação da mesa. Assim, adota-se a maior das duas armaduras calculadas.

Neste caso pode-se adotar $\mathrm{z}=0,90 \mathrm{~d}$.

\subsection{VERIFICAÇÃO DO ESTADO LIMITE DE DEFORMAÇÃO EXCESSIVA}

A verificação do estado de deformação excessiva é um tanto contraditório, com divergências entre a NB-1/78 e alguns autores da bibliografia nacional. Além disso a Norma Brasileira neste assunto é incompleta. A seguir apresentam-se as recomendações da NB-1/78 e da NB-116/89, no que se refere à verificação das deformações e posteriormente é apresentado o procedimento teórico do cálculo das deformações. 


\subsubsection{DEFINIÇÕES E RECOMENDAÇÕES DA NORMA BRASILEIRA DE PROJETO E EXECUÇÃO DE OBRAS DE CONCRETO ARMADO (NB-1/78)}

\section{Estado de Deformação Excessiva}

"No projeto, especial atenção deverá ser dada a verificação da possibilidade de ser atingido o estado de deformação excessiva, a fim de que as deformações não possam ser prejudiciais à estrutura ou outras partes da construção.

Deverão ser estudadas as possíveis conseqüências indesejáveis das deformações e previstos os dispositivos necessários para evitá-las, adotando-se contra-flechas quando conveniente.

No cálculo das deformações deverão ser levadas em conta a retração e deformação lenta."

Flexão

"Salvo cálculo rigoroso a determinação das deformações das peças fletidas deverá ser feita considerando apenas o estádio II para barras, permitindo-se o estádio I para lajes, podendo proceder-se de acordo com os itens seguintes A e B.

\section{A - AÇÕES DE CURTA DURAÇÃO}

Quando a deformação lenta for nula ou desprezível, por serem as ações de curta duração, o módulo de deformação $E_{c}$ a adotar é o módulo secante do concreto, suposto igual a 0,9 do módulo na origem.

\section{B - AÇÕES DE LONGA DURAÇÃO}

Para levar em conta o efeito da deformação lenta, permite-se avaliar a flecha final devida às ações de longa duração, aplicadas logo após o término da construção, como o produto do valor da flecha imediata respectiva pela relação das curvaturas final e inicial na seção de maior momento em valor absoluto, calculadas através de $1 / \mathrm{r}=\left(\left|\varepsilon_{\mathrm{c}}\right|+\varepsilon_{\mathrm{s}}\right) / \mathrm{d}$ fazendo $\varepsilon_{\mathrm{c}}$ final igual a três vezes o valor de 
$\varepsilon_{\mathrm{c}}$ inicial e $\varepsilon_{\mathrm{s}}$ constante e igual ao valor inicial. No caso de ações de longa duração aplicadas 6 meses após a concretagem, $\varepsilon_{\mathrm{c}}$ final pode ser tomada igual a duas vezes $o$ valor inicial.

\section{C - EM ESTRUTURAS DE EDIFÍCIOS}

a) as flechas medidas a partir do plano que contém os apoios, quando atuarem todas as ações, não ultrapassarão 1/300 do vão teórico, exceto no caso balanços para os quais não ultrapassarão 1/150 do seu comprimento teórico.

b) o deslocamento causado pelas ações acidentais não será superior a $1 / 500$ do vão teórico e $1 / 250$ do comprimento teórico dos balanços.

Os deslocamentos transversais não poderão atingir o valor do qual possam resultar danos a elementos da construção apoiados na estrutura ou situados sob peças desta, prevendo-se, nestes casos, quando necessário, os dispositivos adequados para evitar as conseqüências indesejáveis.

No cálculo das flechas das lajes deve ser considerado, se for o caso, o efeito da rotação das vigas perimetrais."

Além das recomendações da NB-1/78 a NB-116/89 apresenta recomendações, as quais alteram dispositivos da NB-1/78.

\subsubsection{RECOMENDAÇÕES DA NORMA BRASILEIRA DE PROJETO DE ESTRUTURAS DE CONCRETO PROTENDIDO (NB-116/89)}

\section{A - ESTADO LIMITE DE DEFORMAÇÕES EXCESSIVAS}

As ações a considerar para esta verificação são dadas por:

$$
F_{\text {d.uti }}=\sum_{i=1}^{m} F_{g i, k}+\sum_{j=2}^{n} \psi_{2 j} F_{q, k}
$$


Os valores de $\psi_{2}$ são definidos pela NB-5/80 conforme exposto

à seguir:

\section{AÇÕES EM GERAL}

Variações uniformes de temperatura em relação à media anual local. 0,3

Pressão dinâmica do vento nas estruturas em geral.

Pressão dinâmica do vento nas estruturas em que a ação variável principal tem pequena variabilidade durante grandes intervalos de tempo (exemplo: edifícios de habitação)

CARGAS ACIDENTAIS DOS EDIFÍCIOS

Locais em que não há predominância de pesos de equipamentos que permanecem fixos por longos períodos de tempo, nem de elevadas concentrações de pessoas. 0,2

Locais em que há predominância de pesos de equipamentos que permanecem fixos por longos períodos de tempo, ou de levadas concentrações de pessoas. 0,4

Bibliotecas, arquivos, oficinas e garagens 0,6

\section{CARGAS MÓVEIS E SEUS EFEITOS DINÂMICOS}

Pontes de pedestres. $0,2 *$

Pontes rodoviárias. $0,2^{*}$

Pontes ferroviárias (ferrovias não especializadas). $0,4 *$

(*) Admite-se $\psi_{2}=0$ quando a ação variável principal corresponde a um efeito sísmico.

\section{B - CONDIÇÕES DE VERIFICAÇÃO}

A verificação da segurança, em relação ao estado limite de deformação excessiva, pode ser no estádio I ou no estádio II, admitindo-se para a razão entre os módulos de deformação do aço e do concreto o valor $\alpha_{\mathrm{e}}=15 \mathrm{e}$ considerada a fluência do concreto para os carregamentos de longa duração. 


\subsubsection{CÁlCULO DAS DEFORMAÇÕES}

A equação (3.37) fornece o valor dos deslocamentos em função da curvatura.

$$
\frac{d^{2} y}{d x^{2}}=\frac{1}{R}=-M_{d} E_{c} I
$$

Integrando-se duas vezes a equação acima e obtendo-se as constantes em função das condições de contorno, tem-se que a equação (3.38) que fornece o valor do deslocamento no meio do vão, para lajes com nervuras em uma direção e carregamento uniformemente distribuído.

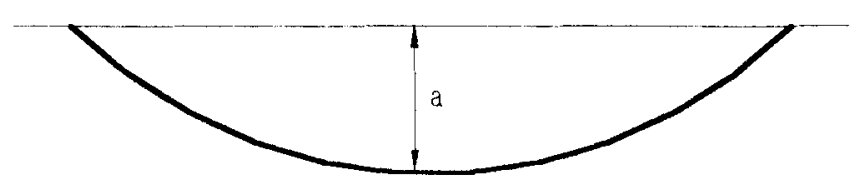

FIGURA 3.15 - DESLOCAMENTO PARA LAJE ARMADA EM UMA DIREÇÃO, BI-APOIADA, COM CARREGAMENTO UNIFORMEMENTE DISTRIBUIDO.

$$
\begin{aligned}
& \mathrm{a}=5 \mathrm{p} \ell^{4} / 384 \mathrm{E}_{\mathrm{c}} \mathrm{I} \\
& \text { onde } \\
& \mathrm{p}=\text { carregamento uniformemente distribuído; } \\
& \ell=\text { menor vão; } \\
& \mathrm{E}_{\mathrm{c}}=\text { módulo secante do concreto; } \\
& \mathrm{I}=\text { momento de inércia no estádio I ou II; }
\end{aligned}
$$

Para as lajes com nervuras nas duas direções as deformações iniciais (a) foram determinadas através do programa GPLAN3.

No caso de ações de longa duração, deve-se levar em conta o efeito da deformação lenta da seguinte forma.

$$
\begin{aligned}
& \mathrm{a}_{\mathrm{o}}=\mathrm{a}\left[\left(1+\varphi_{\mathrm{t}}\right)\left|\varepsilon_{\mathrm{c}}\right|_{\mathrm{f}}+\varepsilon_{\mathrm{s}}\right] /\left(\varepsilon_{\mathrm{ci}}+\varepsilon_{\mathrm{s}}\right) \\
& \text { onde: }
\end{aligned}
$$


$\left(1+\varphi_{t}\right)=3$ para ações de longa duração aplicadas logo após o término da construção.

$\left(1+\varphi_{t}\right)=2$ para ações de longa duração aplicadas 6 meses após a concretagem.

No cálculo das deformações a maior dificuldade está em se definir o valor da rigidez a ser considerada. Para a verificação no estádio II puro o concreto é desprezado na região tracionada, levando-se em conta apenas o aço. $\mathrm{O}$ valor da rigidez está vinculado à posição da linha neutra.

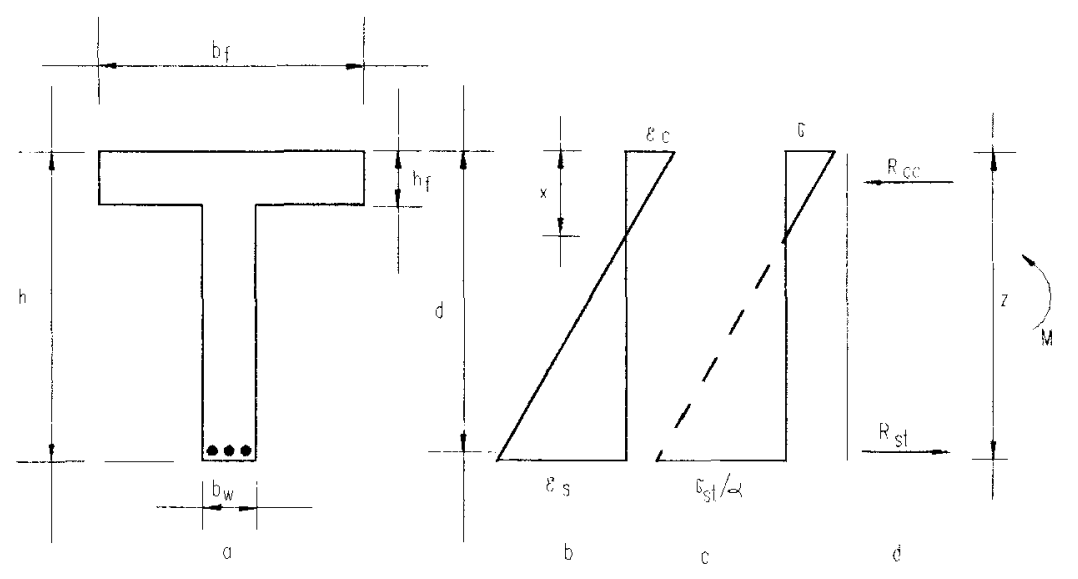

FIGURA 3.16 - CÁLCULO DAS DEFORMAÇÕES

A relação entre os módulos de deformações do aço e do concreto é dado por:

$\alpha_{\mathrm{e}}=\mathrm{E}_{\mathrm{s}} / \mathrm{E}_{\mathrm{c}}\left(\mathrm{NB}-116 / 89, \alpha_{\mathrm{e}}=15\right)$

Impondo-se $\sum \mathrm{x}=0$ e $\Sigma \mathrm{M}=0$ como condições de equilíbrio:

$\sum \mathrm{x}=0$

$R_{\mathrm{st}}=\mathrm{R}_{\mathrm{cc}}=0,5 \sigma_{\mathrm{cc}} \quad \mathrm{b}_{\mathrm{f}} \mathrm{x}=\mathrm{A}_{\mathrm{s}} \sigma_{\mathrm{st}}$

$\Sigma M=0$

$R_{c c}(d-x / 3)=0,5 \quad \sigma_{c c} b_{f} \times(d-x / 3)=M$

Da figura $b$ :

$\varepsilon_{\mathrm{c}} / \mathrm{x}=\varepsilon_{\mathrm{s}} /(\mathrm{d}-\mathrm{x})$ ou 
$\sigma_{\mathrm{cc}} / \mathrm{x}=\sigma_{\mathrm{st}} / \alpha_{\mathrm{c}}(\mathrm{d}-\mathrm{x})=>\sigma_{\mathrm{st}}=\alpha_{\mathrm{e}} \sigma_{\mathrm{cc}}(\mathrm{d}-\mathrm{x}) / \mathrm{x}$

Introduzindo-se (3.43) em (3.41):

$0,5 \sigma_{c c} \quad b_{f} x=A_{s} \alpha_{e} \sigma_{c c}(d-x) / x$

$b_{f} x^{2} / 2-\alpha_{e} A_{s}(d-x)=0$

Sabendo-se que:

$\varepsilon_{\mathrm{c}}=\mathrm{Mx} / \mathrm{E}_{\mathrm{c}} \mathrm{I}$

$\varepsilon_{\mathrm{s}}=M(\mathrm{~d}-\mathrm{x}) / \mathrm{E}_{\mathrm{c}} \mathrm{I}$

Para determinar-se a posição da linha neutra, tem-se:

Na mesa:

$$
x=\alpha_{e} A_{s} / b_{f}\left[-1+\left(1+2 b_{f} d / \alpha_{e} A_{s}\right)^{1 / 2}\right]
$$

$\mathrm{Na}$ alma:

$x^{2}+2\left[\frac{\left(b_{f}-b_{w}\right) h_{f}+\alpha_{e} A_{s}}{b_{w}}\right] x-\left[\frac{\left(b_{f}-b_{w}\right) h_{f}^{2}+2 \alpha_{e} A s d}{b_{w}}\right]=0$

A rigidez é dada pela expressão:

$E I=E_{c} b_{f} x^{3} / 3+E_{s} A_{s}(d-x)^{2}$

Segundo a NB-1/78 o módulo de deformação longitudinal secante é dado por:

$\mathrm{E}_{\mathrm{c}}=0,96600\left(\mathrm{f}_{\mathrm{ck}}+3,5\right)^{1 / 2}(\mathrm{MPa})$

O momento de inércia no estádio II é obtido pela expressão:

Para linha neutra na mesa

$I_{I I}=b_{\mathrm{f}} x^{3} / 3+\alpha_{e} A_{s}(d-x)^{2}$

Para linha neutra na alma

$$
I_{I I}=b_{f} x^{3} / 3-\left[\left(b_{f}-b_{w}\right)\left(x-h_{f}\right)^{3}\right] / 3+\alpha_{e} A_{s}(d-x)^{2}
$$


Para se considerar a variação da rigidez ao longo do eixo de uma peça fletida, pode-se adotar um momento de inércia equivalente dado pela Fórmula de Bränson, ACI 348F, calculado com:

$$
I_{e}=\left(M_{r} / M_{t o t}\right)^{3} I_{I}+\left[1-\left(M_{r} / M_{t o t}\right)^{3}\right] I_{I I} \leq I_{I}
$$

onde

$\mathrm{M}_{\mathrm{tot}}=$ momento fletor total das ações de curta e de longa

duração

$\mathrm{M}_{\mathrm{r}}=$ momento fletor de fissuração

$O$ momento fletor de fissuração deve ser calculado para o estádio $I_{b}$, para seção $T$, através da seguinte expressão:

$$
\begin{aligned}
& M_{r}=R_{c t}[2 x / 3+(h-x) / 2] \\
& \text { com }
\end{aligned}
$$$$
R_{c t}=0,751,2 f_{t k}\left[b_{w}\left(h-h_{f}\right)+b_{f}\left(h_{f}-x\right)\right] \text {, para linha neutra na }
$$

mesa

$$
R_{c t}=0,751,2 f_{t k}\left[b_{w}(h-x)\right] \text {, para linha neutra na alma }
$$

A Norma Brasileira NB-116/89 estabelece que a resistêcia característica à tração do concreto para peças sujeitas à flexão deverá ter seu valor majorado em 1,2 para seções transversais $\mathrm{T}$ ou duplo $\mathrm{T}$ e 1,5 para seções transversais retangulares.

$$
\begin{aligned}
& \mathrm{f}_{\mathrm{tk}}=\mathrm{f}_{\mathrm{ck}} / 10 \text { para } \mathrm{f}_{\mathrm{ck}} \leq 18 \mathrm{MPa} \\
& \mathrm{f}_{\mathrm{tk}}=0,06 \mathrm{f}_{\mathrm{ck}}+0,7 \text { para } \mathrm{f}_{\mathrm{ck}}>18 \mathrm{MPa}
\end{aligned}
$$

A posição da linha neutra no estádio $\mathrm{I}_{\mathrm{b}}$ pode ser dada:

$$
\text { A - LINHA NEUTRA NA MESA }
$$




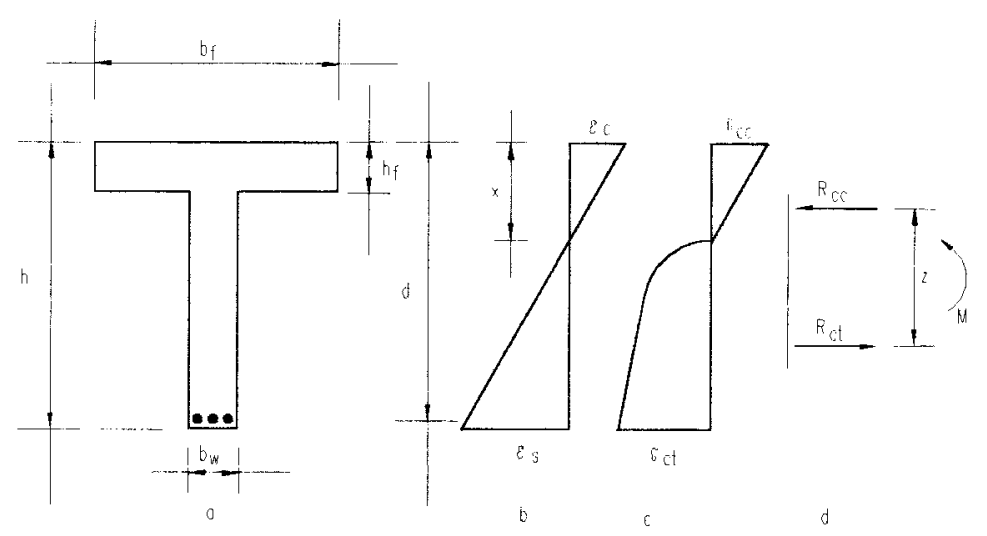

FIGURA 3.17 - LINHA NEUTRA NA MESA

A resultante de compressão no concreto é dada por:

$\mathrm{R}_{\mathrm{cc}}=0,5 \mathrm{~b}_{\mathrm{f}} \times \sigma_{\mathrm{cc}}$

A resultante de tensão na armadura é dada por:

$R_{s t}=\left[b_{f}\left(h_{f}-x\right)+\left(h-h_{f}\right) b_{w}\right] \sigma_{c t}$

Para o equilíbrio tem-se

$\mathrm{R}_{\mathrm{cc}}=\mathrm{R}_{\mathrm{st}}$

Da figura 3.18, tem-se:

$\varepsilon_{\mathrm{cc}} / \mathrm{x}=\varepsilon_{\mathrm{cr}} /(\mathrm{h}-\mathrm{x})$

onde

$$
\begin{aligned}
& \varepsilon_{\mathrm{cr}}=1,5_{\mathrm{x}} 2,7_{\mathrm{x}} 0,25_{\mathrm{x}} \mathrm{f}_{\mathrm{tk}} / \mathrm{E}_{\mathrm{c}} \\
& \varepsilon_{\mathrm{cc}}=1,5_{\mathrm{x}} 2,7_{\mathrm{x}} 0,75_{\mathrm{x}} \mathrm{f}_{\mathrm{tk}} / \mathrm{E}_{\mathrm{c} \times \mathrm{x}}[\mathrm{x} /(\mathrm{h}-\mathrm{x})] \\
& \sigma_{\mathrm{ct}}=0,75 \mathrm{f}_{\mathrm{tk}} \\
& \sigma_{\mathrm{ct}}=1,5_{\mathrm{x}} 2,7_{\mathrm{x}} 0,75_{\mathrm{x}} \mathrm{f}_{\mathrm{tk} \times} \mathrm{x} /(\mathrm{h}-\mathrm{x})
\end{aligned}
$$

Substituindo-se na equação (3.58), tem-se

$1,025 b_{f} x^{2}+\left[b_{f} h+b_{f} h_{f}+h b_{w}-h_{f} b_{w}\right] x-\left[b_{f} h_{f} h+h^{2} b_{w}+h h_{f} b_{w}\right]=0$ 
B - LINHA NEUTRA NA ALMA

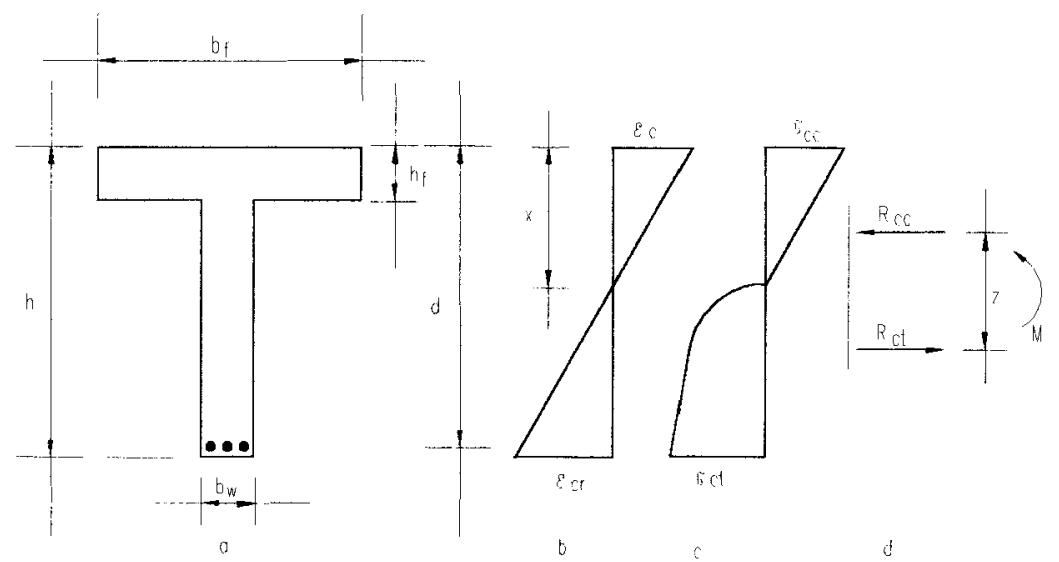

FIGURA 3.18 - LINHA NEUTRA NA ALMA

A resultante de compressão no concreto é dada por:

$R_{\mathrm{cc}}=0,5\left[\mathrm{~b}_{\mathrm{f}} \mathrm{h}_{\mathrm{f}}+\left(\mathrm{x}-\mathrm{h}_{\mathrm{f}}\right) \mathrm{b}_{\mathrm{w}}\right] \sigma_{\mathrm{cc}}$

A resultante de tração na armadura é dada por:

$\mathrm{R}_{\mathrm{st}}=\mathrm{b}_{\mathrm{w}}(\mathrm{h}-\mathrm{x}) \sigma_{\mathrm{ct}}$

No equilibrio tem-se

$\mathrm{R}_{\mathrm{cc}}=\mathrm{R}_{\mathrm{st}}$

Substituindo-se na equação (3.67), tem-se:

$1,025 b_{w} x^{2}+\left[2,025 b_{f} h_{f}-2,025 b_{w} h_{f}+2 h b_{w}\right] x-b_{w} h^{2}=0$

$\mathrm{I}_{\mathrm{I}}=$ momento de inércia no estádio $\mathrm{I}$, pode ser adotado igual a

$I_{x}$

$\mathrm{O}$ momento de inércia para a seção $\mathrm{T}$ é determinada pela expressão: 


$$
\mathrm{I}_{\mathrm{I}}=\frac{b_{f} h^{3}}{12}+b_{f} h\left(y_{c g}-\frac{h}{2}\right)^{2}-2\left\{\frac{\left(b_{f}-b_{w}\right)\left(h-h_{f}\right)^{3}}{24}+\frac{\left(b_{f}-b_{w}\right)\left(h-h_{f}\right)}{2}\left[y_{c g}-\frac{\left(h+h_{f}\right)^{2}}{2}\right]\right\}
$$

onde:

$\mathrm{y}_{\mathrm{cg}}=$ coordenada y do centro de gravidade da seção $\mathrm{T}$;

$$
\begin{aligned}
& y_{c g}=\frac{\frac{b_{f} h^{2}}{2}-\left[\frac{\left(h-h_{f}\right)\left(b_{f}-b_{w}\right)\left(h+h_{f}\right)}{2}\right]}{b_{f} h-\left(h-h_{f}\right)\left(b_{f}-b_{w}\right)} \\
& \mathrm{I}_{\text {II }}=\text { momento de inércia no estádio II (conforme equação }
\end{aligned}
$$
$3.50)$.

Determinado o momento de inércia da seção substitui-se na equação 3.38 e com 3.39 determina-se, assim o valor do deslocamento, este deve ser comparado com os limites especificados pela NB-1/78. Caso a flecha calculada for maior que o limite, permite-se ainda adotar uma contra-flecha de valor igual a diferença entre a flecha calculada e o limite permitido.

Para as lajes nervuradas com nervuras nas duas direções a deformação inicial poderá ser determinada através do programa GPLAN3, considerando-se as variáveis já descritas anteriormente, enquanto que a deformação final, considerando-se a deformação lenta para ações de longa duração será obtida através da equação 3.39 .

As ações provenientes do contrapiso das lajes nervuradas deverão ser incorporadas ao peso próprio das mesmas, tendo em vista que atuarão durante toda a vida útil da laje, e consequentemente contribuirão para o aumento da deformação lenta. 


\section{LAJES NERVURADAS MOLDADAS "IN LOCO"}

Denominam-se lajes nervuradas moldadas "in loco" aquelas executadas na própria obra, com as nervuras e mesas fundidas no local onde permanecerão por toda vida útil da edificação.

\subsection{MATERIAIS}

Os materiais empregados na execução das lajes nervuradas moldadas "in loco" são basicamente os constituintes do concreto armado: fôrmas, escoramentos, concreto, aço, além da mão de obra.

\subsubsection{CONCRETO}

O concreto é um material resultante da adição do cimento, no caso material ligante, com materiais inertes como o agregado graúdo e miúdo, além da água a qual promove as reações químicas no cimento, com eventual emprêgo de aditivos. 
$\mathrm{Na}$ execução das lajes nervuradas vários tipos de cimento podem ser utilizados, sendo o cimento Portland Comum o mais empregado comercialmente. Os agregados resumem-se basicamente a pedra britada número 1 $(9,5 \mathrm{~mm}$ a $19 \mathrm{~mm})$ e número $2(19 \mathrm{~mm}$ a $38 \mathrm{~mm})$, o agregado miúdo é composto pela areia. A água a ser adicionada aos agregados secos deve ser livre de impurezas. Em função das dimensões das seções transversais das lajes nervuradas, usualmente utilizase a pedra britada número 1 .

Para o cálculo de estruturas de concreto armado segundo a NB-1/78, o diagrama tensão-deformação à compressão do concreto é suposto como sendo o diagrama simplificado, composto de uma parábola de segundo grau, que passa pela origem, tem seu vértice no ponto de abscissa $0,2 \%$, ordenada a $0,85 \mathrm{f}_{c d} \mathrm{e}$ uma reta entre as deformações $0,2 \%$ e $0,35 \%$, tangente à parábola e paralela ao eixo das abscissas. Este diagrama é dito diagrama parábola-retângulo do concreto e está representado na figura 4.1 .

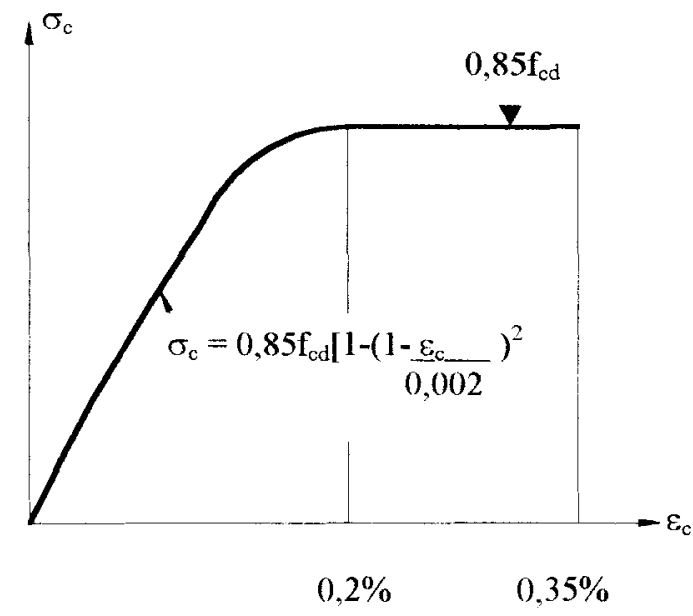

FIGURA 4.1 - DIAGRAMA TENSÃO-DEFORMAÇÃO DO CONCRETO

O módulo de deformação longitudinal à compressão, no início da deformação efetiva, corresponde ao primeiro carregamento é dado por:

$$
6600 \sqrt{f_{c j}}(\mathrm{MPa}), \text { com } f_{c j}=f_{c k}+35 \mathrm{MPa} \text {, sendo } f_{c k} \text { a resistência }
$$
característica à compressão do concreto aos 28 dias. 
O coeficiente de Poisson (v) relativo às deformações elásticas é igual a 0,2 , e o coeficiente de minoração do concreto $\gamma_{c}$ deve ser igual a 1,4 .

\subsubsection{AÇO}

$\mathrm{O}$ aço empregado deve ser aquele destinado exclusivamente ao concreto armado, recebendo sua denominação em função da resistência de escoamento $\mathrm{f}_{\mathrm{y}} \mathrm{em} \mathrm{kgf} / \mathrm{mm}^{2}$. Assim os aços mais utilizados comercialmente são: CA 25, CA 50 e CA 60, encontrados em barras de 12 metros de comprimento, sendo padronizados os seguintes diâmetros em milímetros: $5 ; 6,3 ; 8 ; 10 ; 12,5 ; 16 ; 20 ; 22,5$; 25 e 32 .

Os aços ainda são divididos em duas classes conforme o processo de fabricação empregado. Os aços classe A tem nas suas ligas de ferro com carbono adicionadas outros elementos (manganês, silício, alumínio, enxofre, fósforo e cromo), após a laminação à quente, o resfriamento ao ar livre. Enquanto que nos aços classe $B$ não utilizam-se ligas especiais e após a laminação à quente as barras são encruadas a frio (torção, tração, trefilação, entre outros). A figura 4.2 ilustra o aço destinado às estruturas de concreto armado.

O diagrama tensão-deformação para os aços apresentado pela NB-1/78, objetivando cálculo de estruturas de concreto armado é simplificado, conforme apresenta-se nas figuras 4.3 e 4.4, para os aços classe A e B, respectivamente. 

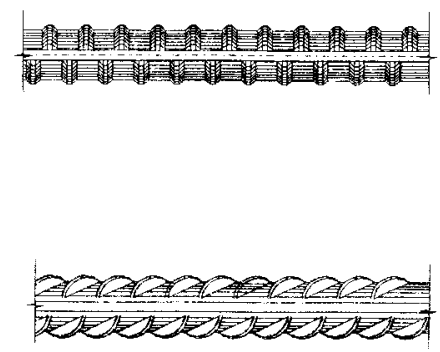

FIGURA 4.2 - AÇOS EMPREGADOS NA EXECUÇÃO DE ESTRUTURAS DE CONCRETO ARMADO

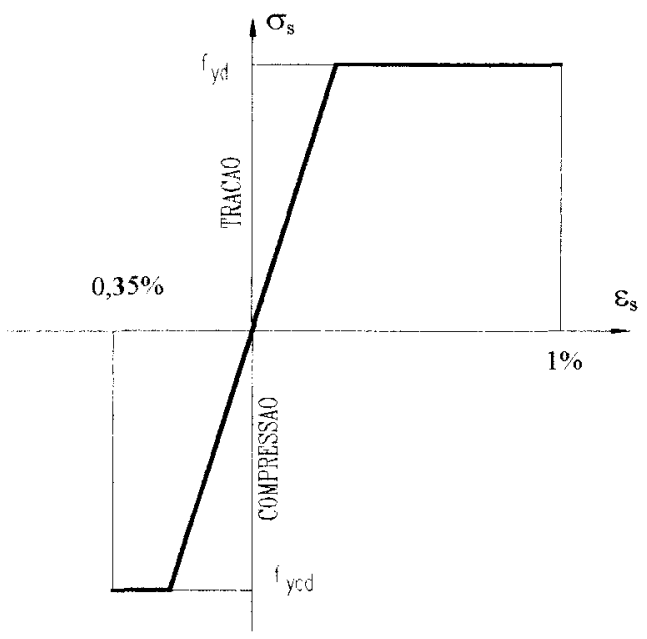

FIGURA 4.3 - DIAGRAMA TENSÃO-DEFORMAÇÃO SIMPLIFICADO PARA OS AÇOS CLASSE A, SEGUNDO A NB-1/78

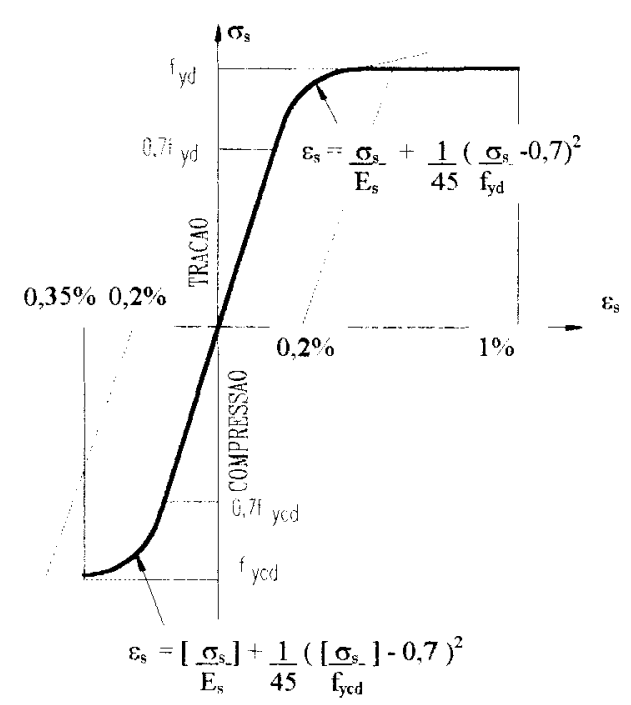

FIGURA 4.4 - DIAGRAMA TENSĀO-DEFORMAÇĀO SIMPLIFICADO PARA OS AÇOS CLASSE B, SEGUNDO A NB-1/78 
O módulo de elasticidade para o aço deve ser considerado igual a $210.000 \mathrm{MPa}$ e as resistências de escoramento de cálculo $f_{\mathrm{yd}}=\mathrm{f}_{\mathrm{yk}} / \gamma_{\mathrm{s}}$ e $\mathrm{f}_{\mathrm{ycd}}=\mathrm{f}_{\mathrm{yck}} / \gamma_{\mathrm{s}}$ são fixadas com as resistências características determinadas em ensaios, supondo-se $\mathrm{f}_{\mathrm{yck}}=\mathrm{f}_{\mathrm{yk}}$ caso não haja ensaio de compressão. Para os aços comumente utilizados o coeficiente de minoração da resistência do aço $\gamma_{\mathrm{s}}$ é admitido igual a 1,15, nos casos de haver controle da resistência por ocasião do recebimento do material na obra, caso contrário admite-se $\gamma_{\mathrm{s}}$ igual a 1,25 .

\subsubsection{ADITIVOS}

Os aditivos são produtos químicos, não indispensáveis à composição e à finalidade do concreto. Estes tem por objetivo apresentar ou melhorar certas características; entre as várias aplicações dos aditivos pode-se destacar; o acelerador de pega, os plastificantes e os superfluidificantes. Na utilização dos aditivos deve-se observar cuidadosamente as quantidades, as quais são geralmente pequenas, homogeneizar a mistura, verificar a validade do produto, e certificar-se que a composição química do mesmo não danificará nenhum material constituinte do concreto armado, como por exemplo, as armaduras. Os cuidados a serem tomados devem ser prescritos pelo fabricante do produto na própria embalagem. $\mathrm{O}$ uso indiscriminado dos aditivos, sem controle e em desacordo com as recomendações do fabricante prejudica a qualidade do concreto, e consequentemente da estrutura a qual este será incorporado.

Nas lajes nervuradas é recomendado a utilização de aditivos que melhorem a plasticidade do concreto, tendo em vista as dimensões reduzidas das seções transversais das nervuras (largura), o que dificulta o adensamento do concreto. 


\subsubsection{OUTROS MATERIAIS}

Pode-se entender como outros materiais envolvidos na produção do concreto armado, aqueles que não fazem parte da mistura em si, como as fôrmas e os escoramentos. As fồrmas tem por finalidade dar a moldagem desejada à laje enquanto o concreto ainda está fresco, os escoramentos dão sustentação à laje até que o concreto tenha resistência suficiente para absorver os esforços solicitantes provenientes de seu peso próprio e ações em função da continuidade e uso da obra.

As fôrmas e os escoramentos são geralmente confeccionados em madeira, sendo que o alto custo da mesma na composição final do custo do concreto armado possibilitou nos últimos anos a pesquisa e desenvolvimento de materiais e técnicas alternativas na substituição da madeira por outros materiais, tanto nas fồrmas como nos escoramentos, como será comentado no item 4.4 .

\subsection{DISPOSIÇÕES CONSTRUTIVAS}

Além das recomendações expostas nos capítulos 2 e 3 deste trabalho, a norma NB-1/78, faz algumas considerações quanto às taxas mínimas e a disposição das armaduras, conforme apresenta-se a seguir:

a) nas lajes com armaduras em uma única direção, a armadura mínima de distribuição, por metro de largura da laje, não deve ser menor que $0,9 \mathrm{~cm}^{2}$ ou $1 / 5$ da armadura principal.

b) os estribos, quando necessários não devem ter espaçamentos maiores que $20 \mathrm{~cm}$, nem diâmetro maior que $1 / 8$ da largura das nervuras. Estes devem possuir área mínima de 0,14\% (aço CA-50) e 0,25\% (aço CA-25), e serão distribuídos em toda extensão do vão, cobrindo-se o diagrama dos esforços cortantes; 
c) a armadura transversal da mesa decorrente da verificação ao cisalhamento da ligação mesa-nervura, quando necessária, deve ser disposta em toda extensão do vão da laje, cobrindo-se o diagrama de solicitações, observando-se a norma NB-1/78 que estabelece o mínimo, de $1,5 \mathrm{~cm}^{2} / \mathrm{m}$, ou $0,14 \%$ para o aço CA-50 e $0,25 \%$ para o aço CA-25. Por tratar-se de uma laje, nos casos onde a distância livre entre nervuras for menor ou igual a $50 \mathrm{~cm}$ pode-se desprezar-se esta disposição, considerando-se apenas armadura de distribuição, conforme determina o item a.

\subsection{DETALHAMENTO DO PROJETO}

Os desenhos que constituem o projeto de estrutura são o elo de ligação entre o cálculo (dimensionamento) estrutural e a execução da obra propriamente dita. Através dos desenhos e especificações o engenheiro de estruturas transmite aos encarregados pela execução da obra todas as informações necessárias ao bom desempenho e a segurança da estrutura a ser executada.

Os desenhos do projeto devem ser claros, em escala conveniente ao detalhe que se pretende ressaltar; as recomendações devem ser legíveis, colocadas em papel de destaque, a fim de não passarem despercebidas. Nos projetos procura-se enfatizar a apresentação gráfica, ou seja, os desenhos com todos os detalhes e cortes pertinentes à boa compreensão do conjunto, visto que, na execução da obra o baixo grau de instrução e especialização da mão de obra, faz com que muitas frases escritas nos projetos fiquem sem a devida atenção, podendo assim, comprometer a qualidade, durabilidade e até a segurança da estrutura de concreto armado.

A seguir a figura 4.5 apresenta os desenhos para o detalhamento de um projeto de uma laje nervurada de concreto armado, no exemplo de dimensionamento apresentado no item 4.5, tratar-se-á novamente do assunto. 
P1

P2

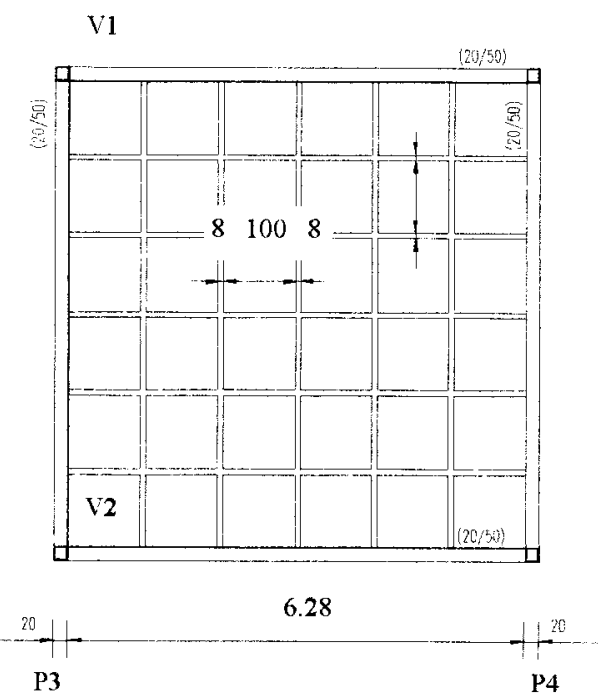

6.28

PLANTA DE FORMA
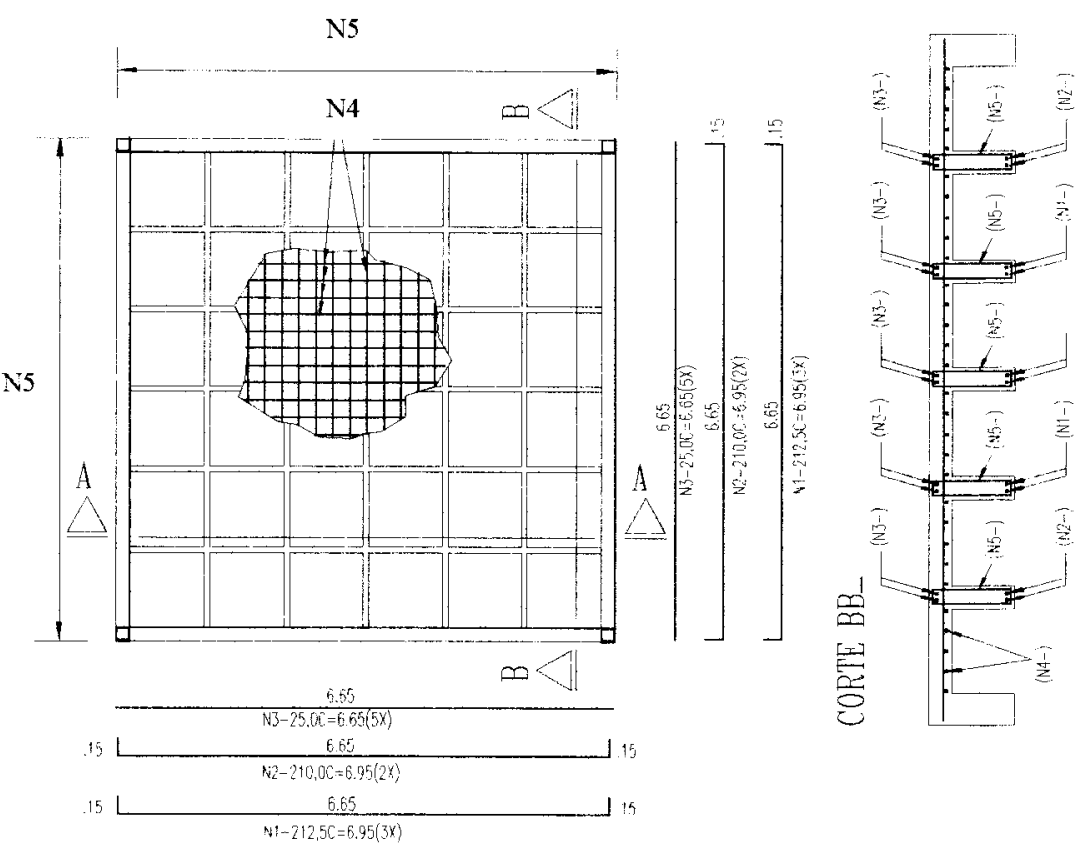

CORTE AA

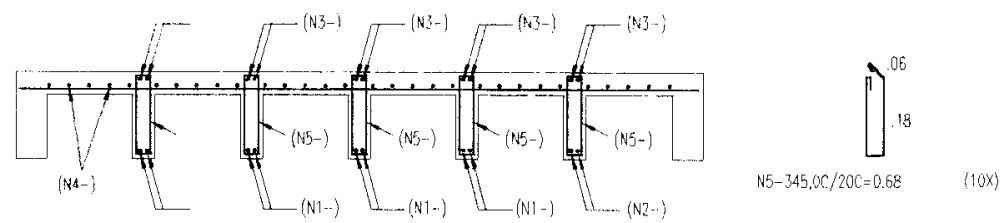

ARMAÇÕES

FIGURA 4.5 - DETALHAMENTO DE UMA LAJE NERVURADA DE CONCRETO ARMADO 


\subsection{EXECUÇÃO}

A execução das lajes nervuradas de concreto armado moldadas "in loco" requer alguns cuidados, além de várias etapas como as descritas sucintamente à seguir:

\subsubsection{FôRMAS}

As fôrmas utilizadas no concreto armado têm por finalidade dar forma e sustentação ao concreto armado antes que este atinja resistência suficiente para se auto suportar. Estas podem ser de diversos materiais, entre eles destacam-se: madeira, chapa de aço, fibra de vidro e blocos de concreto ou cerâmicos.

O material a ser empregado nas fồmas depende de uma análise econômica que deve levar em consideração: o tamanho da obra, o planejamento da obra com o prazo disponível para a execução, a quantidade de reaproveitamento das fồmas, a qualidade do material a ser empregada nas fôrmas, a mão-de-obra disponível para execução, além do custo do material propriamente dito.

Atualmente nas construções de edifícios convencionais a solução mais rápida e econômica adotada tem sido os blocos de concreto, comum ou leve, sendo que o bloco leve tem como vantagens o reduzido peso específico, ocorrendo assim uma redução no peso próprio da laje acabada e por conseqüente a redução das ações atuantes na estrutura. $\mathrm{Na}$ realidade os blocos servem como uma fồma perdida na laje, sem função de resistir a esforços, visto que, de modo geral sua resistência é muito baixa se comparada com o concreto da mesa e nervuras. Os blocos de concreto leve, são assim chamados, pois durante a sua moldagem é usado um 
aditivo incorporador de ar de tal modo a aumentar o volume de vazios com conseqüente redução de massa.

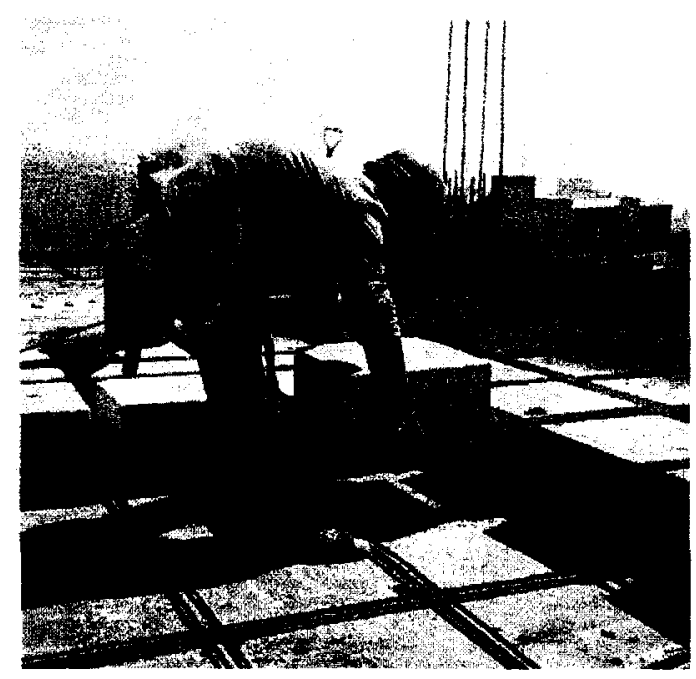

FIGURA 4.6 - COLOCAÇÃO DOS BLOCOS PARA AS LAJES NERVURADAS "MOLDADAS IN LOCO"

Os blocos são colocados sobre plataformas, as quais são sustentadas pelos cimbramentos, devidamente contraventados e apoiados em base firme. As plataformas e cimbramentos podem ser de madeira ou aço.

\subsubsection{ARMADURAS}

Após a colocação dos blocos obedecendo-se os espaçamentos especificados em projeto, colocam-se as armaduras das nervuras com seus respectivos espaçadores, a fim de garantir-se o cobrimento necessário à boa proteção das armaduras contra corrosão. Caso a laje possua armadura transversal (estribos) esta deve ser posicionada com seu devido espaçamento e fixada através de arames à armadura das nervuras evitando-se assim, que saiam de posição, quando da 
concretagem da laje. A armadura da mesa deve ser posicionada sobre os blocos, com os espaçamentos e cobrimentos convenientemente especificados no projeto.

\subsubsection{PREPARAÇÃO E LANÇAMENTO DO CONCRETO}

$\mathrm{O}$ concreto das lajes nervuradas deve possuir resistência característica mínima $\left(f_{c k}\right)$ estabelecida no projeto da laje. Nos casos correntes esta resistência é da ordem de $20,0 \mathrm{MPa}$, mas há uma tendência crescente de aumentar-se esta resistência,principalmente com a adição de micro-sílica ao concreto, o que permite uma redução nas dimensões das lajes e um conseqüente alívio das ações sobre a estrutura e as fundações. Além disso o aumento da resistência, como a redução do fator água cimento com trabalhabilidade e consumo de cimento adequados atendem a tendência atual de se prever maior durabilidade às estruturas de concreto armado.

Deve-se lançar o concreto após o amassamento, não sendo permitido entre o fim deste e o lançamento, intervalo superior a uma hora, sendo que este prazo deve ser contado a partir do fim da agitação. $O$ uso de retardadores de pega faz com que se possa dilatar este prazo, de acordo com as características do aditivo e as recomendações do fabricante.

A concretagem de uma laje nervurada deve sempre que possível ser executada uma única etapa, evitando-se as juntas de concretagem. Quando isto não for possível deve-se garantir a solidarização na ligação entre o concreto já endurecido com o novo, para isto deve-se na ligação remover a nata do concreto endurecido e proceder a limpeza do local antes da nova concretagem garantindo-se assim a boa aderência entre os concretos. As juntas de concretagem devem localizarse em regiões onde os esforços de flexão e cisalhamento são menores. 


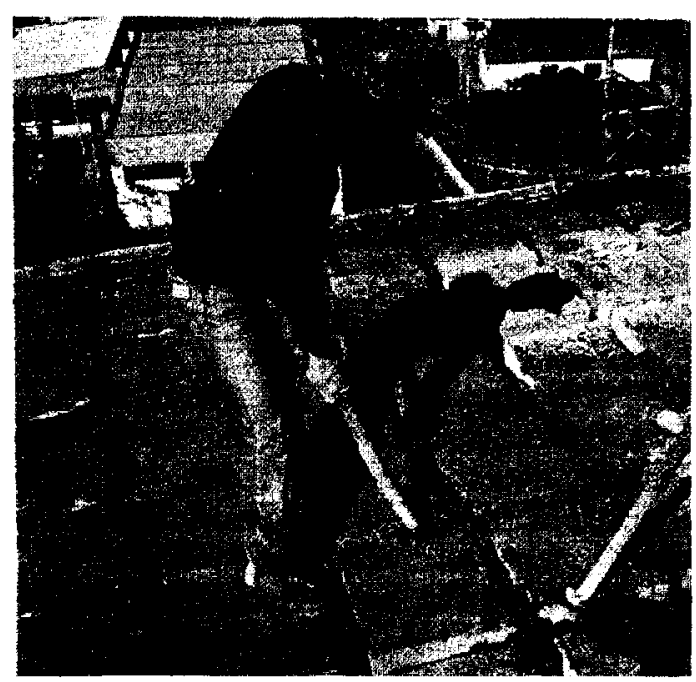

FIGURA 4.7 - CONCRETAGEM DA LAJE NERVURADA

Recomenda-se a utilização de cruzetas de concreto, no caso de lajes nervuradas com blocos, sendo que estas tem por finalidade manter o espaçamento dos blocos, garantido, assim, as dimensões das seções transversais das nervuras.

\subsubsection{ADENSAMENTO DO CONCRETO}

O concreto das lajes nervuradas deve sempre ser vibrado, a fim de garantir maior homogeneidade e redução do número de vazios, permitindo-se assim, que atinja-se a resistência mínima prevista em projeto. A vibração é feita com vibradores de imersão, manuseados por operários capacitados evitando-se a desagregação do material, e com dimensões compatíveis com a espessura das nervuras da laje (figura 4.7). 


\subsubsection{CURA DO CONCRETO}

Enquanto o concreto não atingir o endurecimento satisfatório, este deve ser protegido de agentes prejudiciais como: mudanças bruscas de temperatura, secagem rápida, chuva forte, água torrencial, agentes químicos, bem como contra choques e vibrações que possam produzir fissuração na massa do concreto ou prejudicar sua aderência à armadura.

A reação química de endurecimento do concreto necessita de água; como parte da água presente no concreto perde-se por evaporação no ambiente, para que a reação se processe de maneira completa, garantindo-se assim, a resistência desejada, deve-se manter o concreto permanentemente umedecido durante o período da cura, daí a necessidade de proteção contra a secagem prematura, no mínimo pelos 7 primeiros dias após o lançamento do concreto, aumentando-se este mínimo quando a natureza do cimento assim exigir. Além de manter-se a superficie do concreto umedecida pode-se protegê-la com uma película impermeável evitando-se a evaporação.

\subsubsection{RETIRADA DAS FÔRMAS E DOS ESCORAMENTOS}

A retiradadas fồrmas e escoramentos das lajes nervuradas deve ser feita quando o concreto se achar suficientemente endurecido para resistir às ações atuantes sobre a laje, e que estas não produzam deformações inaceitáveis, tendo em vista que o baixo módulo de deformação longitudinal do concreto $\left(\mathrm{E}_{\mathrm{c}}\right)$ nas primeiras idades, torna maior a probabilidade de deformação para o concreto solicitado com pouca idade.

A Norma NB-1/78 recomenda que a retirada das fồrmas seja realizada, no mínimo 48 horas e os escoramentos 21 dias após a concretagem. No 
caso de edificios de múltiplos pavimentos não deve-se concretar uma laje enquanto a laje do pavimento imediatamente inferior não estiver sem os escoramentos (no mínimo 21 dias), caso contrário a laje do pavimento inferior estaria sujeita à ações elevadas. Como o concreto possui pouca idade, este pode sofrer elevadas deformações, e causar danos à estrutura, caso haja a necessidade de concretar-se a laje do pavimento superior antes dos 21 dias, o engenheiro de estruturas deverá levar em conta esta situação na verificação dos estados limites para esta laje

A retirada das fôrmas e escoramentos deve ser efetuada sem choques à estrutura. No caso do emprêgo do cimento ARI ( alta resistência inicial ) a retirada das fôrmas e escoramentos pode ser antecipada, em função da elevação da resistência inicial do concreto, propiciada por este cimento.

\subsection{EXEMPLOS DE APLICAÇÃO}

EXEMPLO 1 - Laje de 6,48 x 6,48 m com nervuras nas duas direções, apoiadas nas vigas de borda. Neste exemplo será adotada distância livre entre nervuras (a) maior que $50 \mathrm{~cm}$, conforme a figura abaixo:

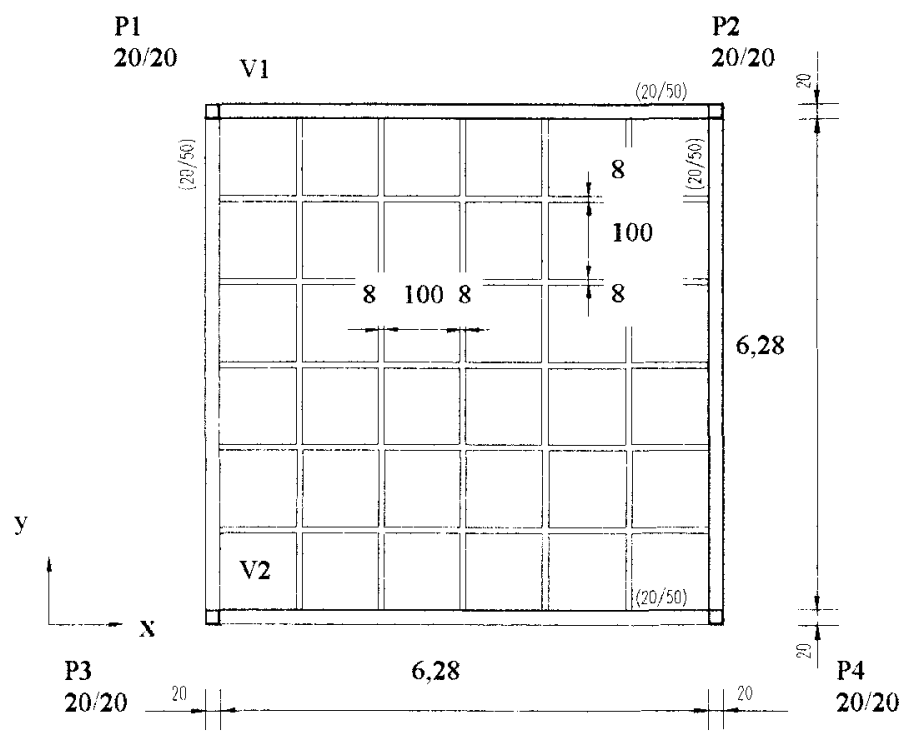

FIGURA 4.8 - LAJE COM NERVURAS NAS DUAS DIREÇÕES $(a>50 \mathrm{~cm})$, ANDRADE (1978) 
O concreto utilizado deverá ter resistência característica à compressão aos 28 dias $\left(f_{c k}\right)$ de $20 \mathrm{MPa}$. A sobrecarga de utilização adotada será de $2,00 \mathrm{kN} / \mathrm{m}^{2}$.

O pré-dimensionamento pode ser feito conforme a NB-1/78:

$$
d \geq \frac{\ell_{x}}{\psi_{2} \psi_{3}}=\frac{648}{1,5 \times 17}=25,41 \mathrm{~cm}(\mathrm{~h} \cong 26 \mathrm{~cm}) ; \text { ou ainda segundo }
$$

MACHADO (1983):

$$
\begin{aligned}
& \mathrm{d} \cong 1,5(2,5-0,1 \mathrm{n}) \ell^{*}, \operatorname{com} \ell^{*} \leq\left\{\begin{array}{l}
\ell_{x} \\
0,7 \ell_{y}
\end{array} ; \ell_{x} \leq \ell_{y}\right. \\
& \mathrm{d} \cong 1,5 \times(2,5-0,1 \times 0) \times 4,54 \\
& \mathrm{~d} \cong 17,03 \mathrm{~cm}(\mathrm{~h}=18 \mathrm{~cm})
\end{aligned}
$$

Adota-se por fim $\mathrm{h}=20 \mathrm{~cm}$

A altura da mesa $\left(\mathrm{h}_{\mathrm{f}}\right)$, segundo a NB-1/78, deverá ser igual a a 15 , não inferior a $4 \mathrm{~cm}$, adotando-se $h_{f}$ igual a $7 \mathrm{~cm}$. A largura $\left(b_{w}\right)$ das nervuras será adotada igual a $8 \mathrm{~cm}$.

As ações atuantes são:

Peso próprio da mesa $=0,07 \times 25=1,75 \mathrm{kN} / \mathrm{m}^{2}$

Piso + revestimento $=1,00 \mathrm{kN} / \mathrm{m}^{2}$

Peso próprio das nervuras $=\frac{\left[2\left(0,04 x_{x} 0,13_{x} 100\right)+2\left(0,04 x 0,13_{x} 1,08\right)\right] \times 25}{1,08 x 1,08}=0,47 \mathrm{kN} / \mathrm{m}^{2}$

Sobrecarga de utilização $=2,00 \mathrm{kN} / \mathrm{m}^{2}$

Total das ações atuantes $=5,22 \mathrm{kN} / \mathrm{m}^{2}$

A seção à ser considerada será um $\mathrm{T}$, conforme figura 4.9.

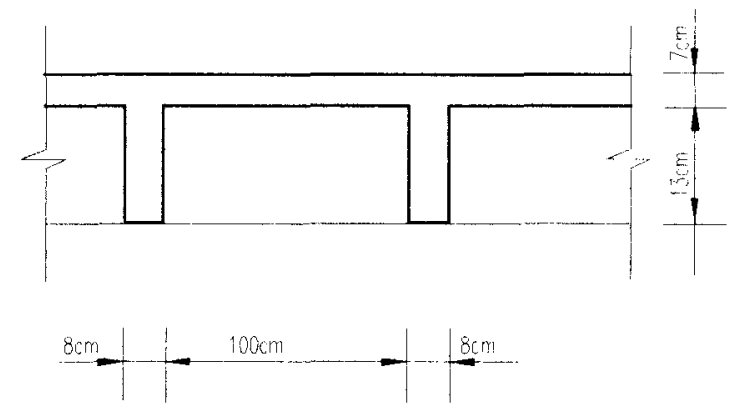

FIGURA 4.9 - SEÇÃO À SER CONSIDERADA PARA AS DIREÇÕES X E Y 
Da geometria da seção determinam-se para o Estádio I:

Coordenada y do centro de gravidade da seção $=4,71 \mathrm{~cm}$

Momento de inércia à flexão da seção $\mathrm{T}=13.693,99 \mathrm{~cm}^{4}$

Momento de inércia à torção da seção $T=14.566,67 \mathrm{~cm}^{4}$

Para o concreto adotado tem-se:

Módulo de deformação longitudinal (E)

$E=0,9 E_{c}$, com $E_{c}=6600 \sqrt{f_{c j}}$ e $f_{c j}=f_{c k}+3,5 \mathrm{MPa}$

$\mathrm{f}_{\mathrm{ck}}=20 \mathrm{MPa}(\mathrm{C} 20)$

$\mathrm{f}_{\mathrm{cj}}=20+3,5=23,5 \mathrm{MPa}$

$E_{c}=6600 \sqrt{23,5}=31.994,69 \mathrm{MPa}$

$\mathrm{E}=0,9 \times 31.994,69=28.795,22 \mathrm{MPa}$

Módulo de deformação transversal $\left(\mathrm{G}_{\mathrm{C}}\right)$

$\mathrm{G}_{\mathrm{c}}=0,40 \times \mathrm{Ec}=0,40 \times 31.994,69=12.797,88 \mathrm{MPa}=1,28 \times 10^{7} \mathrm{kN} / \mathrm{m}^{2}$

Com a finalidade de considerar-se a fissuração do concreto o módulo de deformação longitudinal será reduzido:

$$
\mathrm{E}^{*}=0,7 \mathrm{E}=0,7 \times 28.795,22=20.156,65 \mathrm{MPa} \text { ou } 2,01 \times 10^{7} \mathrm{kN} / \mathrm{m}^{2}
$$

Enquanto que o momento de inércia à torção será tomado igual $0,2\left(\mathrm{I}_{\mathrm{T}}\right)_{\mathrm{I}}$, ou seja, $\mathrm{I}_{\mathrm{T}}=0,2 \times 14.566,67=2.913,33 \mathrm{~cm}^{4}$.

Os esforços solicitantes serão determinados considerando-se a grelha da figura 4.10, com o emprego do programa GPLAN3 para análise de grelhas.

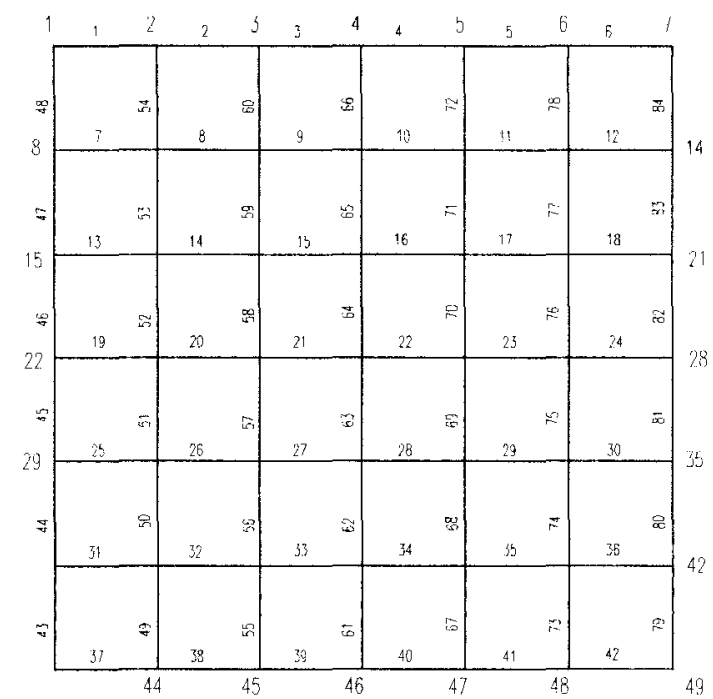

FIGURA 4.10 - GRELHA À SER CONSIDERADA $(a>50 \mathrm{~cm})$ 


\section{Verificação das nervuras}

\section{Verificação da flexão}

A verificação quanto aos esforços provenientes da flexão será feita considerando-se a seção resistente como uma seção $T$, para esta verificação empregou-se a tabela 2.1

O máximo momento fletor obtido foi de $11,76 \mathrm{kNm} /$ nervura, portanto, tem-se:

$$
\begin{aligned}
& k_{c}=\frac{b d^{2}}{M_{d}}=\frac{108_{x}(19)^{2}}{1,4 x 1176}=23,68, \log 0 \mathrm{k}_{\mathrm{s}}=0,024 \\
& A_{s x}=A_{s y}=k_{s} \frac{M_{d}}{d}=0,024_{x} \frac{1,4 x 1176}{19,0}=2,08 \mathrm{~cm}^{2} / \text { nervura }
\end{aligned}
$$

Adota-se $2 \phi 12,5 \mathrm{~mm}$

Esta armadura será adotada para as nervuras centrais com maior momento fletor, para as demais pode-se reduzir a armadura, conforme verificase à seguir:

Para o momento fletor de $10,41 \mathrm{kN} . \mathrm{m} /$ nervura tem-se:

$\mathrm{A}_{\mathrm{sx}}=\mathrm{A}_{\mathrm{sy}}=1,76 \mathrm{~cm}^{2} /$ nervura, podendo-se adotar a mesma armadura das nervuras centrais, ou seja, $2 \phi 12,5 \mathrm{~mm}$.

Para o momento fletor de $686 \mathrm{kN}$.m/nervura tem-se $A_{\mathrm{sx}}=\mathrm{A}_{\mathrm{sy}}=$ $1,16 \mathrm{~cm}^{2} /$ nervura, adotando-se $2 \phi 10,0 \mathrm{~mm}$.

As armaduras das nervuras foram determinadas para os máximos momentos fletores atuantes, ou seja, para a região do meio do vão da laje, podendo-se portanto reduzir a armadura de cada nervura nas regiões próximas do apoio. Em face da exigência da NB-1/78 de que pelo menos duas barras prossigam até o apoio, e as dificuldades de execução, caso as armaduras variem ao longo da nervura; fez com que se optasse por manter, à favor da segurança, a mesma armadura determinada para o meio do vão, em toda a extensão da nervura.

Ainda no tocante à flexão das nervuras, o momento fletor atuante pode ser determinado também, de acôrdo com as recomendações da NB-1/78, seguindo a teoria das placas. A fim de comparar-se os resultados obtidos, determinou- 
se o momento fletor máximo atuante na placa, através de tabelas, como por exemplo, as encontradas em PINHEIRO (1993), neste caso tem-se que:

$M=\mu \frac{p \ell^{2}}{100}$, sendo:

$\mathrm{p}=5,22 \mathrm{kN} / \mathrm{m}^{2}$

$\ell=6,48 \mathrm{~m}$

$\mu=4,23$ (para lajes do tipo $1, \operatorname{com} \lambda=\frac{\ell_{\mathrm{y}}}{\ell_{\mathrm{x}}}=1$ )

Logo, $M=9,27 \mathrm{kN} \cdot \mathrm{m} / \mathrm{m}$, ou $\mathrm{M}=10,01 \mathrm{kN} \cdot \mathrm{m} /$ nervura.

Obtém-se, então $A_{\mathrm{sx}}=\mathrm{A}_{\mathrm{sy}}=1,70 \mathrm{~cm}^{2} /$ nervura, adotam-se $2 \phi 12,5 \mathrm{~mm}$. Usualmente no emprego da teoria das placas para a determinação dos momentos fletores das lajes nervuradas, não se faz a variação da armadura de flexão, adotando-se a armadura obtida com o máximo momento fletor para toda a laje, embora a variação da armadura seja possível, desde que a determinação dos esforços solicitantes possibilite a obtenção não apenas dos valores máximos, mas também de valores intermediários.

\section{Verificação do cisalhamento}

Como a distância livre entre as nervuras (a) é maior que $50 \mathrm{~cm}$, a verificação quanto ao cisalhamento das nervuras deve obedecer às recomendações aplicáveis às vigas usuais.

A tensão convencional de cálculo do cisalhamento no concreto é determinada através da expressão:

$$
\tau_{w d}=\frac{V_{d}}{b_{w} d}=\frac{1,4 \times 11,25}{8 \times 19}=0,104 \mathrm{kN} / \mathrm{cm}^{2}=1,036 \mathrm{MPa}
$$

Esta tensão $\tau_{\mathrm{wd}}$ não deve ser maior que a tensão $\tau_{\mathrm{wu}}$, a fim de evitar-se a ruptura do concreto $\operatorname{com} \tau_{\mathrm{wu}}=0,30 \mathrm{f}_{\mathrm{cd}} \leq 4,5 \mathrm{MPa}$.

$$
\begin{aligned}
& \tau_{\text {wu }}=0,30 \times \frac{20}{1,4}=4,29 \mathrm{MPa} \\
& \therefore \tau_{\mathrm{wd}}<\tau_{\mathrm{wu}}
\end{aligned}
$$


A armadura transversal é determinada com a tensão $\tau_{d}$, com $\tau_{d}=1,15 \tau_{\mathrm{wu}}-\tau_{\mathrm{c}}$ e $\tau_{\mathrm{c}}=\psi_{1} \sqrt{\mathrm{f}_{\mathrm{ck}}}$.

Tem-se então:

$$
\begin{aligned}
\tau_{\mathrm{c}} & =0,15 \sqrt{20}=0,671 \mathrm{MPa} \\
\tau_{d} & =1,15 x 1,036-0,671=0,521 \mathrm{MPa}
\end{aligned}
$$

A armadura transversal é determinada pela expressão:

$$
\frac{\mathrm{A}_{\mathrm{sw}}}{\mathrm{sn}}=\frac{\tau_{\mathrm{d}}}{\mathrm{f}_{\mathrm{ywd}}} \mathrm{b}_{\mathrm{w}} \frac{100}{\mathrm{n}}, \mathrm{f}_{\mathrm{ywd}}=\frac{\mathrm{f}_{\mathrm{yk}}}{1,15}=435 \mathrm{MPa}
$$

$\mathrm{n}=2$ (estribo com dois ramos)

$$
\frac{A_{s w}}{s n}=\frac{0,521}{435} \times 8 \times \frac{100}{2}=0,48 \mathrm{~cm}^{2} / m
$$

A armadura mínima é obtida pela expressão:

$$
\frac{A_{s w, \min }}{s}=0,14 x \frac{b_{w}}{n}=0,14 \times \frac{8}{2}=0,56 \mathrm{~cm}^{2} / \mathrm{m}
$$

Adota-se para a armadura transversal, estribos de $\phi 5,0 \mathrm{~mm}$ a cada $10 \mathrm{~cm}$.

\section{Verificação da resistência da mesa.}

Verificação da flexão.

Esta verificação é feita considerando-se a mesa composta por vários painéis apoiados nas nervuras, conforme a figura 4.11 .

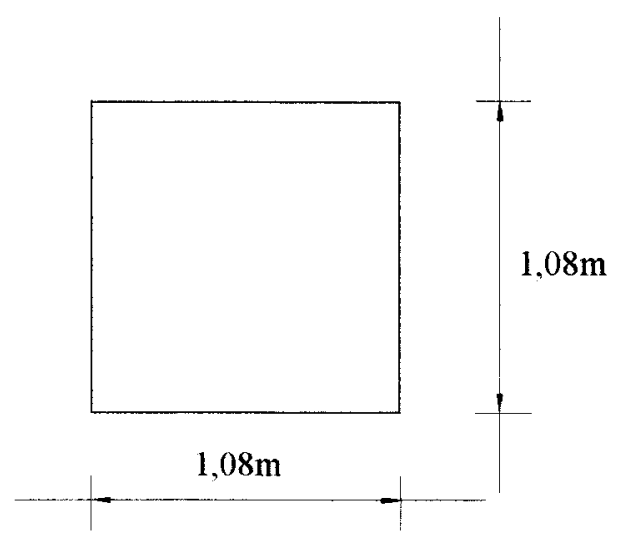

FIGURA 4.11 - LAJE APOIADA NAS NERVURAS 
Através das tabelas de PINHEIRO (1993), determina-se o máximo momento fletor atuante:

$$
\begin{aligned}
& M=\mu \frac{p \ell^{2}}{100}=4,23 x \frac{4,75 x(1,08)^{2}}{100}=0,23 \mathrm{kN} \cdot \mathrm{m} / \mathrm{m} \\
& v=\nu \frac{p \ell}{10}=2,5 x \frac{4,75 x 1,08}{10}=1,28 \mathrm{kN} / \mathrm{m} \\
& \text { Tem-se } \\
& k_{c}=\frac{b d^{2}}{M_{d}}=\frac{100 x 6^{2}}{1,4 x 23,44}=109,70, \mathrm{k}_{\mathrm{s}}=0,023 \\
& A_{s x}=A_{s y}=0,023 x \frac{1,4 x 23,44}{6}=0,13 \mathrm{~cm}^{2} / \mathrm{m} \\
& \mathrm{A}_{\mathrm{s} \min }=0,15 \% \mathrm{~b}_{\mathrm{w}} \mathrm{h}=0,15 \% \times 100 \times 7=1,05 \mathrm{~cm}^{2} / \mathrm{m}
\end{aligned}
$$

Adota-se, então, $\phi 5,0$ a cada $20 \mathrm{~cm}$.

\section{Verificação do cisalhamento}

A verificação do cisalhamento das tensões de cisalhamento na mesa é feita tomando-se:

$$
\begin{aligned}
& \tau_{w i d}=\frac{V_{d}}{b_{w} d}=\frac{1,4 x 1,28}{100 x 6}=0,003 \mathrm{kN} / \mathrm{cm}^{2}=0,03 \mathrm{MPa} \\
& \tau_{\text {wud }}=\psi_{4} \sqrt{f_{c k}} \triangleleft, 0, \mathrm{com} \psi_{4}=0,14 \alpha k \\
& \alpha=1+50 \rho_{1} \leq 1,5 ; \mathrm{k}=1,6-\mathrm{d} \geq 1 \\
& \alpha=1+50 \times \frac{1,05}{700}=1,07 \\
& k=1,6-0,07=1,53 \\
& \psi_{4}=0,14 x 1,07 x 1,53=0,236 \\
& \tau_{\text {wud }}=0,236 \sqrt{20}=1,05 \mathrm{MPa}
\end{aligned}
$$

Como: $\tau_{\mathrm{wd}}<\tau_{\mathrm{wud}}$ dispensa-se armadura de cisalhamento na mesa.

Verificação das tensões de cisalhamento na ligação mesanervura com mesa comprimida.

A tensão de cisalhamento $\tau_{\text {md }}$, que ocorre na ligação mesa nervura é dada pela equação: 


$$
\begin{aligned}
& \tau_{\mathrm{md}}=\frac{\mathrm{vd}}{\mathrm{zh}_{\mathrm{f}}} \frac{1}{2}\left(1-\frac{\mathrm{b}_{\mathrm{w}}}{\mathrm{b}_{\mathrm{f}}}\right) \\
& \tau_{m d}=\frac{1,4 \times 11,25}{19 \times 7} \times \frac{1}{2}\left(1-\frac{8}{108}\right) \\
& \tau_{\mathrm{md}}=0,110 \mathrm{kN} / \mathrm{cm}^{2}=1,10 \mathrm{MPa} \\
& \tau_{\mathrm{md}} \text { é menor que } 0,25 \mathrm{f}_{\mathrm{cd}}=3,57 \mathrm{MPa} .
\end{aligned}
$$

A armadura $A_{\text {st }}$ é determinada pela expressão:

$$
\begin{aligned}
& A_{s t}=\frac{V_{d}}{z f_{y d}} \frac{1}{2}\left(1-\frac{b_{w}}{b_{f}}\right) \\
& A_{s t}=\frac{1,4 \times 11,25}{19 x 435} \times \frac{1}{2}\left(1 \frac{8}{100}\right) 00 \\
& \mathrm{~A}_{\mathrm{st}}=0,88 \mathrm{~cm}^{2} / \mathrm{m}
\end{aligned}
$$

Como $\mathrm{A}_{\mathrm{st}} \geq 1,5 \mathrm{~cm}^{2} / \mathrm{m}$

Adota-se $\phi 6,3 \mathrm{~mm}$ a cada $20 \mathrm{~cm}$ nas duas direções.

\section{Verificação da Estado limite de deformação excessiva.}

$\mathrm{Na}$ verificação das deformações as ações a serem consideradas são:

$$
\begin{aligned}
& F_{d, u t i l}=\sum_{i=1}^{m} F_{G i ; k}+\sum_{j=2}^{n} \psi_{2 j} F_{Q k} \\
& F_{d, u t i l}=3,22+0,2 \times 2,00=3,62 \mathrm{kN} / \mathrm{m}^{2}
\end{aligned}
$$

A relação entre os módulos de deformações longitudinal do aço e do concreto, segundo a NB-116/89, deve ser tomado $\alpha_{\mathrm{e}}=15$.

Ainda segundo a NB-116/89 o estado limite de deformações excessiva pode ser verificado no Estádio I ou Estádio II, neste exemplo será adotado o momento de inércia equivalente $\left(\mathrm{I}_{\mathrm{e}}\right)$, dado pela fórmula de Bränson.

$$
I_{e}=\left(\frac{M_{r}}{M_{\text {tot }}}\right)^{3} I_{I}+\left[1-\left(\frac{M_{r}}{M_{\text {tot }}}\right)^{\beta}\right] I_{I I} \leq I_{I}
$$

Cálculo do momento de inércia para o Estádio I.

A coordenada y do centro de gravidade é: 


$$
\begin{gathered}
y_{c g}=\frac{\frac{b_{f} h^{2}}{2}-\left[\left(h-h_{f}\left(b_{f}-b_{w}\right)\left[\begin{array}{c}
h+h_{f} \\
2
\end{array}\right]\right]\right.}{b_{f} h-\left(h-h_{f}\right)\left(b_{f}-b_{w}\right)} \\
y_{c g}=\frac{\frac{108_{x} 20^{2}}{2}-\left[(20-7)(108-8)\left(\frac{20+7}{2}\right)\right]}{108 \times 20-(20-7)(108-8)}=4,71 \mathrm{~cm} \\
I_{I}=\frac{b_{f} h^{3}}{12}+b_{f} h\left[y_{C G}-\frac{h}{2}\right]^{2}-2\left[\frac{\left(b_{f}-b_{w}\right)\left(h-h_{f}\right)^{3}}{24}+\frac{\left(b_{f}-b_{w}\right)\left(h-h_{f}\right)}{2}\left[y_{C G} \frac{\left(h+h_{f}\right)}{2}\right]^{2}\right] \\
I_{I}=\frac{108_{x} 20^{3}}{12}+108_{x} 20\left[4,71-\frac{20}{2}\right]^{2}-2\left[\frac{(108-8)(20-7)^{3}}{24}+\frac{(108-8)(20-7)}{2}\left[4,71-\frac{(20+7)}{2}\right)^{2}\right] \\
I_{I}=13.693,99 \mathrm{~cm}^{4}
\end{gathered}
$$

Cálculo do momento de fissuração (Estádio $\mathrm{I}_{\mathrm{b}}$ )

1a. Hipótese Linha neutra na mesa

$$
\begin{aligned}
& 1,025 b_{f} x^{2}+\left(b_{f} h+b_{f} h_{f}+h b_{w}-h_{f} b_{w}\right) x-\left(b_{f} h_{f} h+h^{2} b_{w}-h h_{f} b_{w}\right)=0 \\
& 1,025 x 108 x^{2}+\left(108_{x} 20+108 x 7+20 x 8-7 x 8\right) x-\left(108_{x} 7 x 20+20^{2}{ }_{x} 8-20 x 7 x 8\right)=0 \\
& 110,70 x^{2}+3020 x-17.200=0
\end{aligned}
$$

Resolvendo a equação do 2o. Grau, tem-se:

$\mathrm{x}=4,85 \mathrm{~cm}<\mathrm{h}_{\mathrm{f}}=7,0 \mathrm{~cm}$, a linha neutra está na mesa.

A resultante de tração no concreto $R_{c t}$ é dada pela expressão:

$$
\begin{aligned}
& R_{c t}=0,75 x 1,2 f_{t k}\left[b_{w}\left(h-h_{f}\right)+b_{f}\left(h_{f}-x\right)\right] \text { sendo } \mathrm{f}_{\mathrm{tk}}=0,06 f_{c k}+0,7 \\
& f_{t k}=0,06 \times 20+0,7=1,90 \mathrm{MPa} \text { ou } 0,19 \mathrm{kN} / \mathrm{cm}^{2} \\
& R_{c t}=0,75 x 1,2 \times 0,19[8(20-7)+108(7-4,85)] \\
& R_{c t}=57,49 \mathrm{kN}
\end{aligned}
$$

O momento de fissuração é determinado através da equação:

$$
\begin{aligned}
& M_{r}=R_{c t}\left[\frac{2 x}{3}+\frac{(h-x)}{2}\right] \\
& M_{r}=57,49\left[\frac{2 x 4,85}{3}+\frac{(20-4,85)}{2}\right] \\
& M_{r}=621,37 \mathrm{kN} . \mathrm{cm}, \text { ou } \mathrm{M}_{\mathrm{r}}=6,21 \mathrm{kNm}
\end{aligned}
$$

Cálculo do momento de inércia para o Estádio II admitindo-se, incialmente, a linha neutra na mesa, tem-se: 


$$
\begin{aligned}
& x=\alpha_{e} \frac{A_{s}}{b_{f}}\left[-1+\left(1+\frac{2 b_{f} d}{\alpha_{e} A_{s}}\right)^{\frac{1}{2}}\right] \\
& x=15 x \frac{2,50}{108}\left[-1+\left(1+\frac{2 x 108_{x} 19}{15 \times 2,50}\right)^{\frac{1}{2}}\right]
\end{aligned}
$$

$\mathrm{x}=3,62 \mathrm{~cm}<\mathrm{h}_{\mathrm{f}}=7 \mathrm{~cm}$, logo a linha neutra está na mesa.

O momento de inércia no Estádio II é dado pela expressão:

$$
\begin{aligned}
& I_{I I}=\frac{b_{f} x^{3}}{3}+\alpha_{e} A_{s}(d-x)^{2} \\
& I_{I I}=\frac{108_{x} 3,62^{3}}{3}+15 \times 2,50(19-3,62)^{2} \\
& I_{I I}=11.769,18 \mathrm{~cm}^{4}
\end{aligned}
$$

Aplicando-se a fórmula de Bränson, tem-se:

$$
\begin{aligned}
& I_{e}=\left(\frac{M_{r}}{M_{\text {tot }}}\right)^{3} I_{I}+\left[1-\left(\frac{M_{r}}{M_{\text {tot }}}\right)^{3}\right] \mathrm{I}_{\mathrm{II}} \mathrm{I}_{\mathrm{I}} \\
& I_{e}=\left(\frac{6,21}{11,76}\right)^{3} x 13.693,99+\left[1-\left(\frac{6,21}{11,76}\right)^{3}\right] 11.769,18 \mathrm{I}_{\mathrm{I}}=13.693,99 \\
& I_{e}=12.053,05 \mathrm{~cm}^{4}
\end{aligned}
$$

A deformação inicial será determinada com o emprego do programa GPLAN3, com os parâmetros determinados anteriormente.

Tem-se, então a deformação incial, $a=1,72 \mathrm{~cm}$.

A deformação final (ou flecha final) será determinada pela equação:

$$
\mathrm{a}_{\infty}=\mathrm{a} \frac{\left(1+\varphi_{t}\right)\left|\varepsilon_{c}\right|+\varepsilon_{s}}{\varepsilon_{c}+\varepsilon_{s}},
$$

Adota-se: $\left(1+\varphi_{t}\right)=3, \mathrm{E}_{\mathrm{c}}=14.000 \mathrm{MPa}$

$$
\begin{aligned}
\varepsilon_{\mathrm{c}} & =\frac{M_{x}}{E_{c} I_{e}}=\frac{1176 x 3,62}{1400 \times 12053,05}=2,52 \times 10^{-4} \\
\varepsilon_{s} & =\frac{M(d-x)}{E_{c} I_{e}}=\frac{1176(19-3,62)}{1400 \times 12053,05}=1,07 \times 10^{-3}
\end{aligned}
$$




$$
\begin{aligned}
& a_{\infty}=a \frac{3 \times\left(2,52 \times 10^{-4}\right)+1,07 \times 10^{-3}}{2,52 \times 10^{-4}+1,07 \times 10^{-3}} \\
& a_{\infty}=1,72 \times 1,38 \\
& a_{\infty}=2,37 \mathrm{~cm}
\end{aligned}
$$

A determinação da deformação final também pode ser feita empregando-se as tabelas para o cálculo de deformações em lajes maciças, como, por exemplo, aquelas apresentadas por SANTOS (1983). Segundo estas tabelas a deformação final nesta laje é de $a_{\infty}=1,96 \mathrm{~cm}$. A defomação limite $a_{\text {lim }}=2,16 \mathrm{~cm}$, portanto, a deformação é aceitável. 

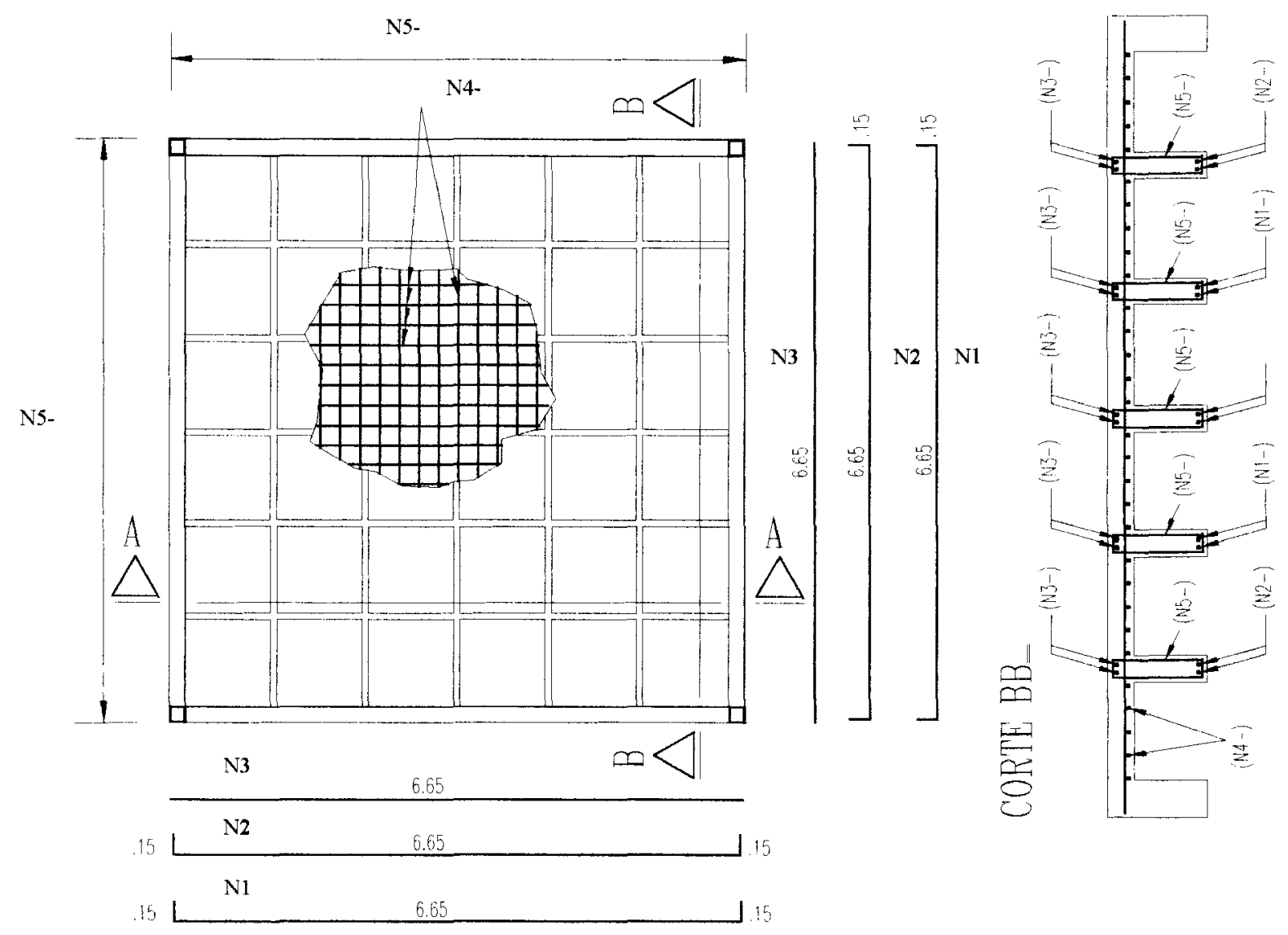

CORT'E AA_
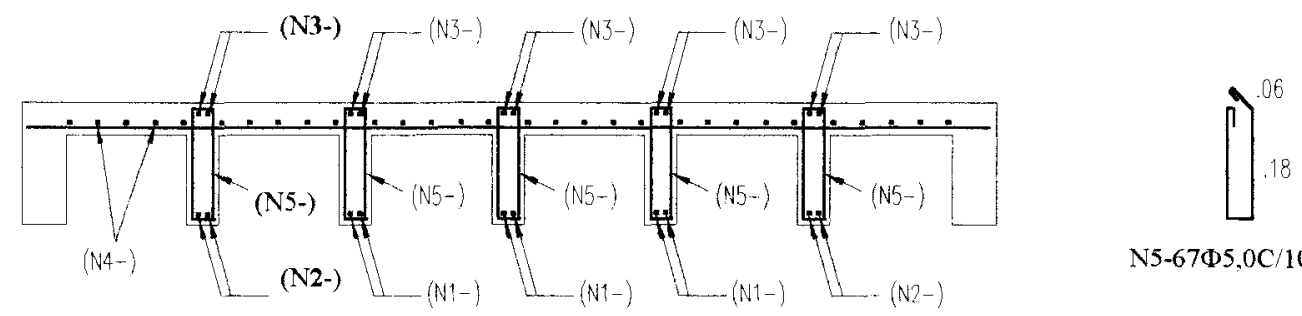

$\mathrm{N} 5-67 \Phi 5,0 \mathrm{C} / 10 \mathrm{C}=0,68(10 \mathrm{X})$

$\mathrm{N} 1-2 \Phi 12,5 \mathrm{C}=6,95(6 \mathrm{X})$

$\mathrm{N} 2-2 \Phi 10,0 \mathrm{C}=6,95(4 \mathrm{X})$

$\mathrm{N} 3-2 \Phi 5,0 \mathrm{C}=6,65(10 \mathrm{X})$

$\mathrm{N} 4-32 \Phi 6,3 \mathrm{C} / 20 \mathrm{C}=6,65(2 \mathrm{X})$

FIGURA 4.12 - DETALHAMENTO DA LAJE NERVURADA 
EXEMPLO 2 - A laje do exemplo 1 será dimensionada novamente, adotando-se a distância livre entre nervuras (a) igual a $50 \mathrm{~cm}$, conforme a figura abaixo:

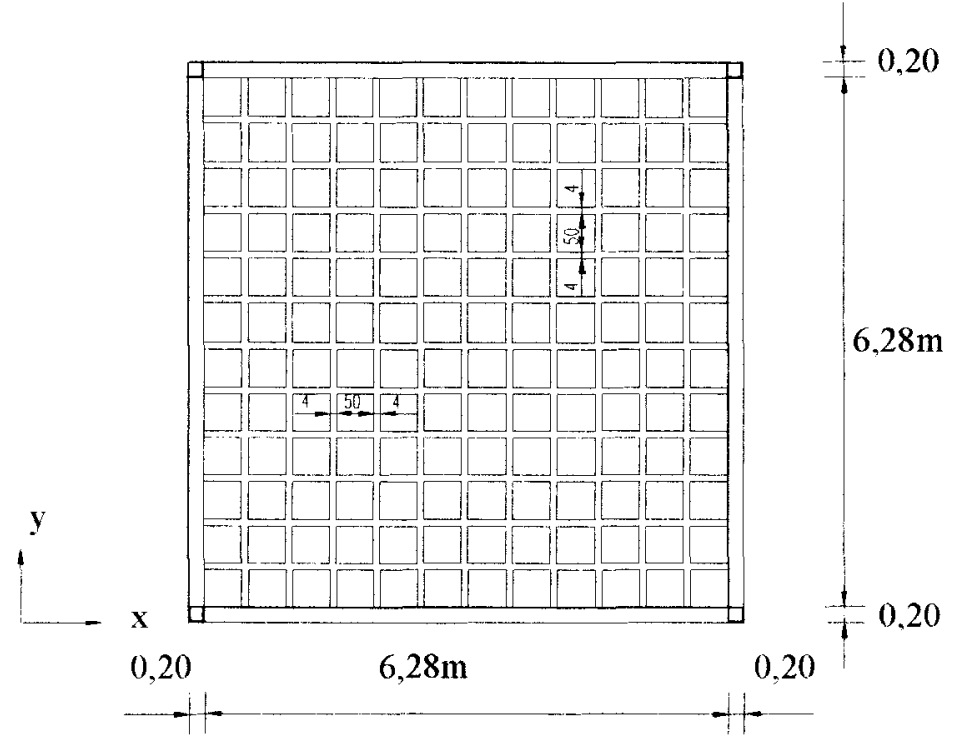

FIGURA 4.13 - LAJE COM NERVURAS NAS DUAS DIREÇÕES $(a \leq 50 \mathrm{~cm})$

O concreto utilizado será o mesmo do exemplo anterior, bem como a sobrecarga de utilização.

O pré-dimensionamento é o mesmo do exemplo 1, adotando-se $\mathrm{h}=20 \mathrm{~cm}$.

A altura da mesa será:

$h_{f} \geq \frac{a}{15}=\frac{50}{15}=3,33 \mathrm{~cm}$, como $\mathrm{h}_{\mathrm{f}} \geq 4 \mathrm{~cm}$, adota-se $\mathrm{h}_{\mathrm{f}}=4 \mathrm{~cm}$.

A largura das nervuras $b_{w}$ será tomada igual a $4 \mathrm{~cm}$.

As seções atuantes são:

Peso próprio da mesa $=0,04 \times 25=1,00 \mathrm{kN} / \mathrm{m}^{2}$

Piso + revestimento $=1,00 \mathrm{kN} / \mathrm{m}^{2}$

Peso próprio das nervuras =

$\frac{\left[2\left(0,02 x_{x} 0,16 x 0,50\right)+2\left(0,02 x_{x} 0,16 x 0,54\right)\right]_{x} 25}{0,54 x 0,54}=0,57 \mathrm{kN} / \mathrm{cm}^{2}$

Sobrecarga de utilização $=2,00 \mathrm{kN} / \mathrm{m}^{2}$

Total da ações atuantes $=4,57 \mathrm{kN} / \mathrm{m}^{2}$

A seção considerada será um $T$, conforme a figura 4.14 . 


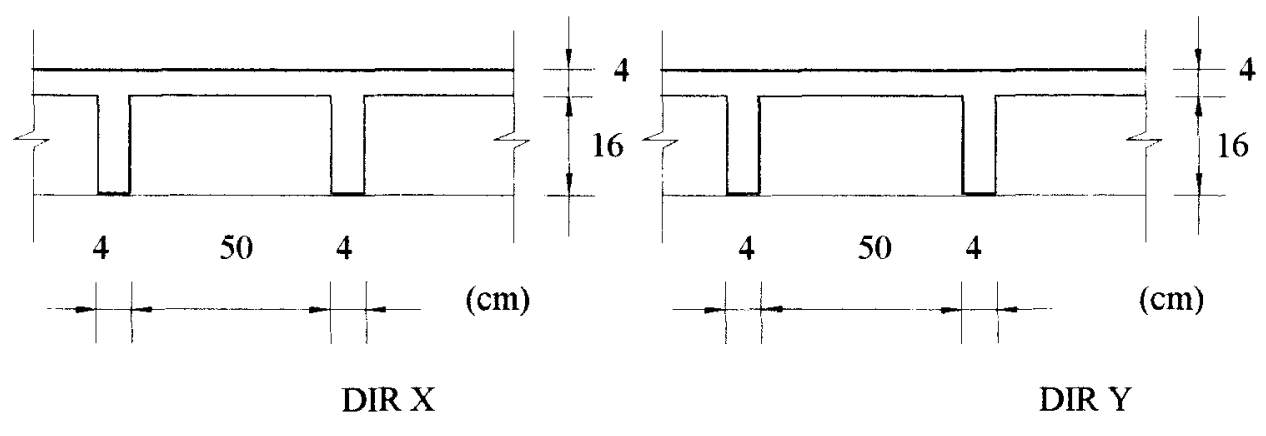

FIGURA 4.14 - SEÇÃO À SER CONSIDERADA

Determina-se para o Estádio I:

Coordenada y do centro de gravidade da seção $=4,29 \mathrm{~cm}$

Momento de inércia à flexão da seção $=6.590,48 \mathrm{~cm}^{4}$

Momento de inércia à torção da seção $=1493,33 \mathrm{~cm}^{4}$

Tem-se para o concreto adotado:

$$
\begin{aligned}
& \mathrm{G}_{\mathrm{c}}=1,28 \times 10^{7} \mathrm{kN} / \mathrm{m}^{2} \\
& \mathrm{E}^{*}=2,01 \times 10^{7} \mathrm{kN} / \mathrm{m}^{2}
\end{aligned}
$$

O momento de inércia à torção será reduzido a fim de levar-se em conta a fissuração do concreto:

$$
\mathrm{I}_{\mathrm{T}}=0,2 \times 1493,33=298,67 \mathrm{~cm}^{4}
$$

Os esforços solicitantes serão determinados através do programa GPLAN3, considerando-se a grelha da figura 4.15.

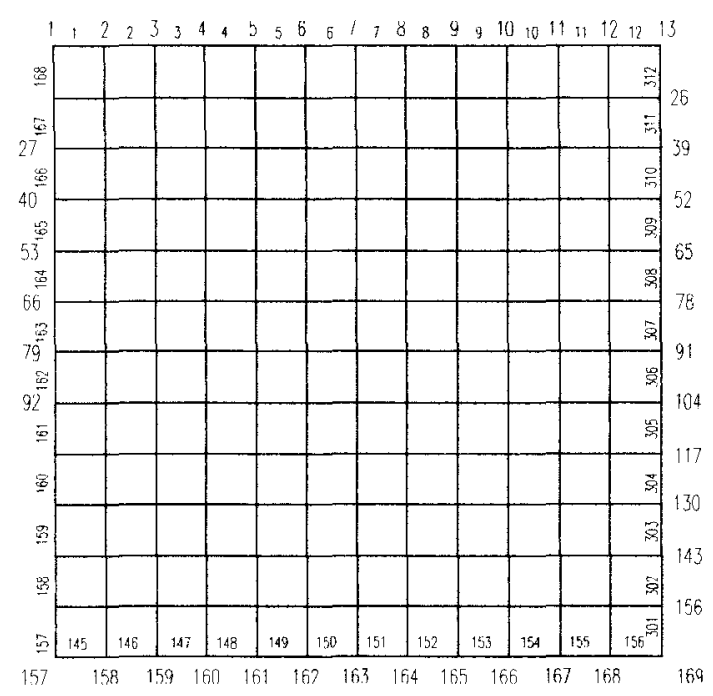

FIGURA 4.15 - GRELHA A SER CONSIDERADA $(a \leq 50 \mathrm{~cm})$ 


\section{Verificação das nervuras.}

\section{Verificação da flexão.}

O momento fletor máximo nas nervuras é de $5,32 \mathrm{kNm} /$ nervura, logo tem-se:

$$
\begin{aligned}
& k_{c}=\frac{b d^{2}}{M_{d}}=\frac{54_{x}(19)^{2}}{1,4 \times 532}=26,17, \log 0 \mathrm{k}_{\mathrm{s}}=0,023 \\
& A_{s x}=A_{s y}=k_{s} \frac{M_{d}}{d}=0,023 x \frac{532}{19}=0,64 \mathrm{~cm}^{2} / \text { nervura } \\
& \mathrm{A}_{\mathrm{s} \min }=0,15 \% \mathrm{~b}_{\mathrm{w}} \mathrm{h}=0,15 \% \times 4 \times 20=0,12 \mathrm{~cm}^{2} / \text { nervura }
\end{aligned}
$$

Adota-se $1 \phi 10 \mathrm{~mm}$ por nervura. Esta armadura será distribuída igualmente por todas as nervuras, embora sabendo-se que para as demais nervuras esta armadura está além do necessário, ou seja, à favor da segurança.

\section{Verificação do cisalhamento.}

A distância livre entre as nervuras (a) é igual a $50 \mathrm{~cm}$, a NB1/78 permite a verificação quanto aos esforços provenientes ao cisalhamento na laje nervurada como laje maciça, ou seja, é dispensada a colocação de armadura transversal nas nervuras, sempre que $\tau_{\mathrm{wd}} \leq \tau_{\mathrm{wu} 1}$.

A força cortante máxima atuante nas nervuras é $5,16 \mathrm{kN}$.

A tensão de cálculo do cisalhamento no concreto é:

$$
\begin{aligned}
& \tau_{w d}=\frac{V_{d}}{b_{w} d}=\frac{1,4 x 5,16}{4 x 19}=0,095 \mathrm{kN} / \mathrm{cm}^{2}=0,951 \mathrm{MPa} \\
& \tau_{w u 1}=\psi_{4} \sqrt{f_{c k}}<1,0 \mathrm{MPa}, \text { com } \psi_{4}=0,14 \alpha k, \mathrm{k}=1,6-\mathrm{d} \geq \mathrm{e} \\
& \alpha=1+50 \rho_{1} \leq 1,5 \\
& \alpha=1+50 \frac{0,8}{280}=1,143<1,5 \\
& k=1,6-0,19=1,41>1 \\
& \psi_{4}=0,14 x 1,1431 \times 410=0,226 \\
& \tau_{w u 1}=0,226 \sqrt{20}=1,019 \mathrm{MPa}, \text { adota }-\mathrm{se} \tau_{\text {wu1 }}=1,00 \mathrm{MPa} \\
& \quad \text { Como } \tau_{\mathrm{wd}}<\tau_{\mathrm{wu} 1} \text { não é necessário colocar-se armadura }
\end{aligned}
$$

transversal (estribos) 


\section{Verificação da resistência da mesa.}

A NB-1/78 dispensa a verificação na resistência da mesa quanto à distância livre entre nervuras (a) for menor ou igual a $50 \mathrm{~cm}$.

Verificação das tensões de cisalhamento na ligação mesanervura.

Também pode ser omitida já que a distância livre entre nervuras (a) é igual a $50 \mathrm{~cm} \mathrm{e} \tau_{\mathrm{wd}} \leq \tau_{\mathrm{wu1}}$.

\section{Verificação da Estado limite de deformação excessiva.}

A combinação das ações é dada pela equação:

$$
\begin{aligned}
& F_{d, u t i l}=\sum_{i=1}^{m} F_{G i ; k}+\sum_{j=2}^{n} \psi_{2 j} F_{Q k} \\
& F_{d, u t i l}=2,84+0,2 x 2,00=3,24 \mathrm{kN} / \mathrm{m}^{2}, \text { ou } \\
& F_{d, u t i l}=3,24 x 0,50=1,62 \mathrm{kN} / \text { nervura }
\end{aligned}
$$

A relação $\left(\alpha_{\mathrm{e}}\right)$ entre os módulos de deformação longitudinal do aço e do concreto, será tomado igual a 15 e a verificação do estado de deformação excessiva será feito no Estádio II.

Posição da linha neutra (x) para o Estádio II.

1a. Hipótese: Linha Neutra na mesa

$$
\begin{aligned}
& x=\alpha_{e} \frac{A_{s}}{b_{f}}\left[-1+\left(1+\frac{2 b_{f} d}{\alpha_{e} A_{s}}\right)^{\frac{1}{2}}\right] \\
& x=15_{x} \frac{0,80}{50}\left[-1+\left(1+\frac{2 \times 50 x 19}{15 x^{2} 0,80}\right)^{\frac{1}{2}}\right] \\
& \mathrm{x}=2,79 \mathrm{~cm}<\mathrm{h}_{\mathrm{f}}=4 \mathrm{~cm}, \log \text { a linha neutra está na alma. }
\end{aligned}
$$

O momento de inércia no Estádio II é dado: 


$$
\begin{aligned}
& I_{I I}=\frac{b_{f} x^{3}}{3}+\alpha_{e} A_{s}(d-x)^{2} \\
& I_{I l}=\frac{50 x 2,79^{3}}{3}+15 x 0,80 x(19-2,79)^{2} \\
& I_{I I}=3515,13 \mathrm{~cm}^{4}
\end{aligned}
$$

A deformação inicial será determinada através do programa GPLAN3, com os parâmetros já determinados.

A máxima deformação inicial é de $1,99 \mathrm{~cm}$.

A deformação final será determinada considerando-se a equação abaixo:

$$
\begin{aligned}
& \mathrm{a}_{\infty}=\mathrm{a} \frac{\left(1+\varphi_{t}\right)\left|\varepsilon_{c}\right|+\varepsilon_{s}}{\varepsilon_{c}+\varepsilon_{s}} \\
& \text { Adota-se }\left(1+\varphi_{\mathrm{t}}\right)=3, \mathrm{E}_{\mathrm{c}}=14.000 \mathrm{MPa}
\end{aligned}
$$

$$
\begin{aligned}
& \varepsilon_{c}=\frac{M_{x}}{E_{c} I_{I I}}=\frac{532 \times 2,79}{1400 \times 3515,13}=3,02 \times 10^{-4} \\
& \varepsilon_{s}=\frac{M(d-x)}{E_{c} I_{I I}}=\frac{532 x(19-2,79)}{1400 \times 3515,13}=1,75 \times 10^{-3}
\end{aligned}
$$

$$
\begin{aligned}
& a_{\infty}=a \times \frac{3 \times\left(3,02 \times 10^{-4}\right)+1,75 \times 10^{-3}}{3,02 \times 10^{-4}+1,75 \times 10^{-3}} \\
& a_{\infty}=1,99 \times 1,29 \\
& a_{\infty}=2,58 \mathrm{~cm}, a_{\text {lim }}=2,16 \mathrm{~cm}
\end{aligned}
$$

Deve-se, portanto, adotar-se uma contra flecha de 2,58-2,16= $0,42 \mathrm{~cm}$ (aproximadamente $0,5 \mathrm{~cm}$ ). 


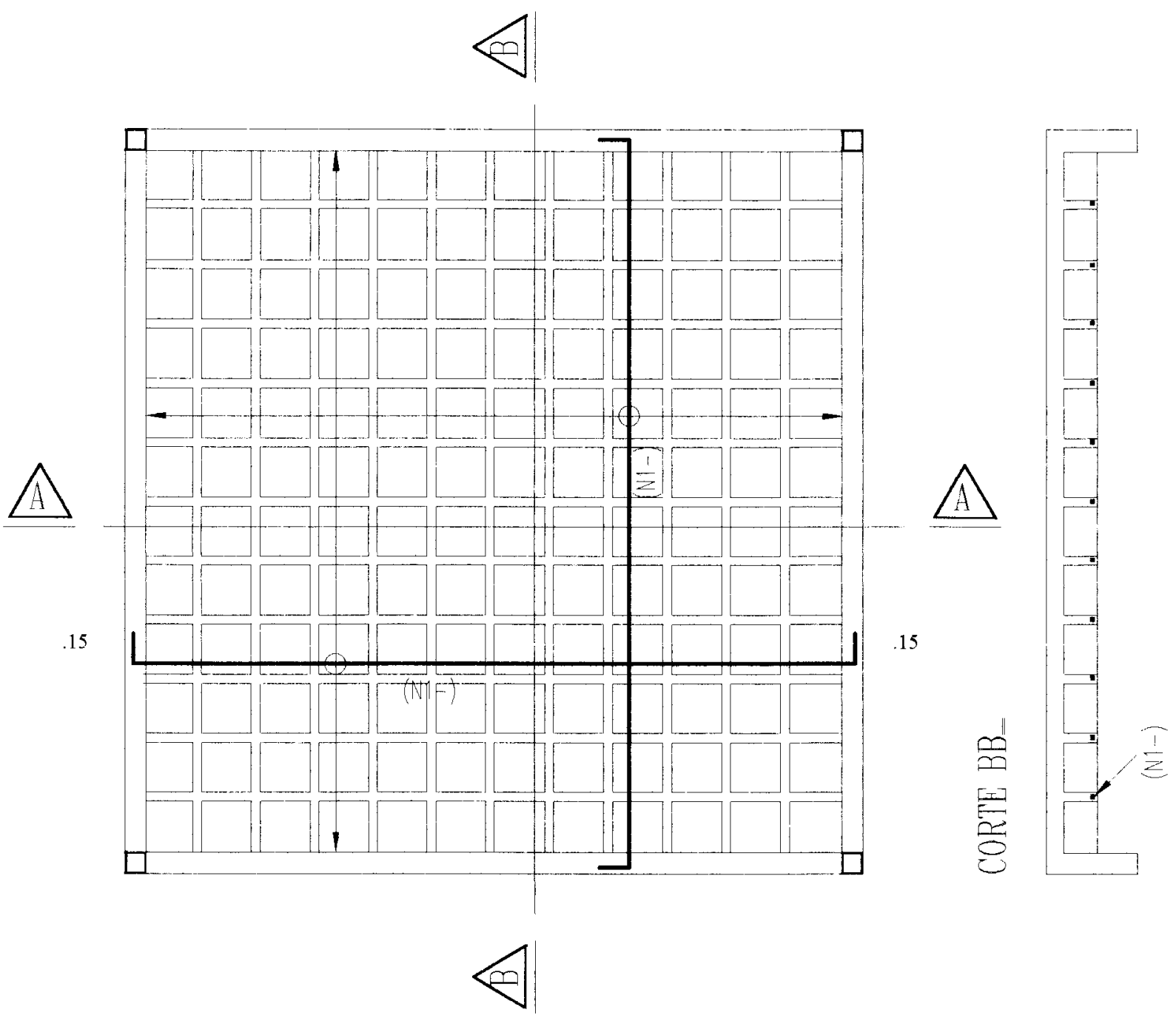

COR'E AA

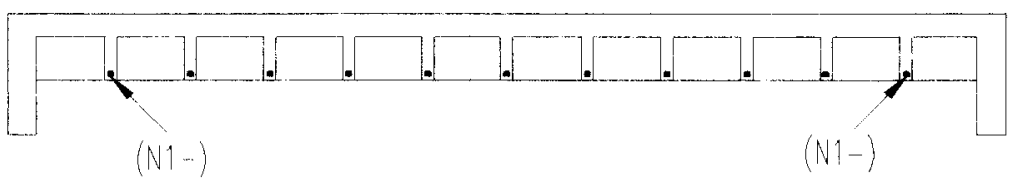

$\mathrm{N} 1-11 \Phi 10,0 \mathrm{C} / 54 \mathrm{C}=6,95(2 \mathrm{X})$

FIGURA 4.16 - DETALHAMENTO DA LAJE NERVURADA 
EXEMPLO 3 - Laje do exemplo 1, com um lado engastado em outra laje de mesmas dimensões. Adotar-se-á distância livre entre as nervuras (a) maior que $50 \mathrm{~cm}$, conforme a figura 4.17 .

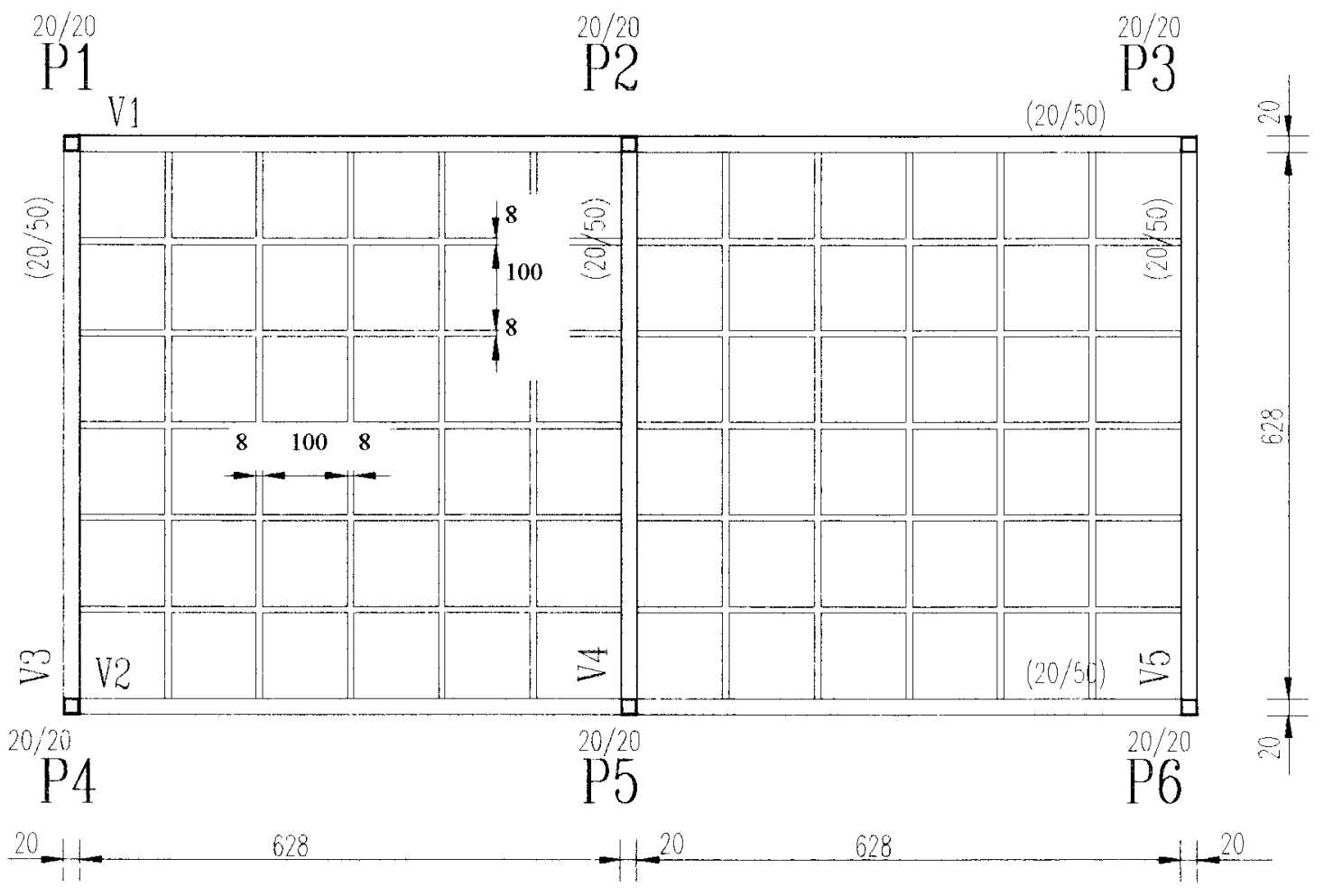

FIGURA 4.17 - LAJES NERVURADAS CONTÍNUAS $(a>50 \mathrm{~cm})$

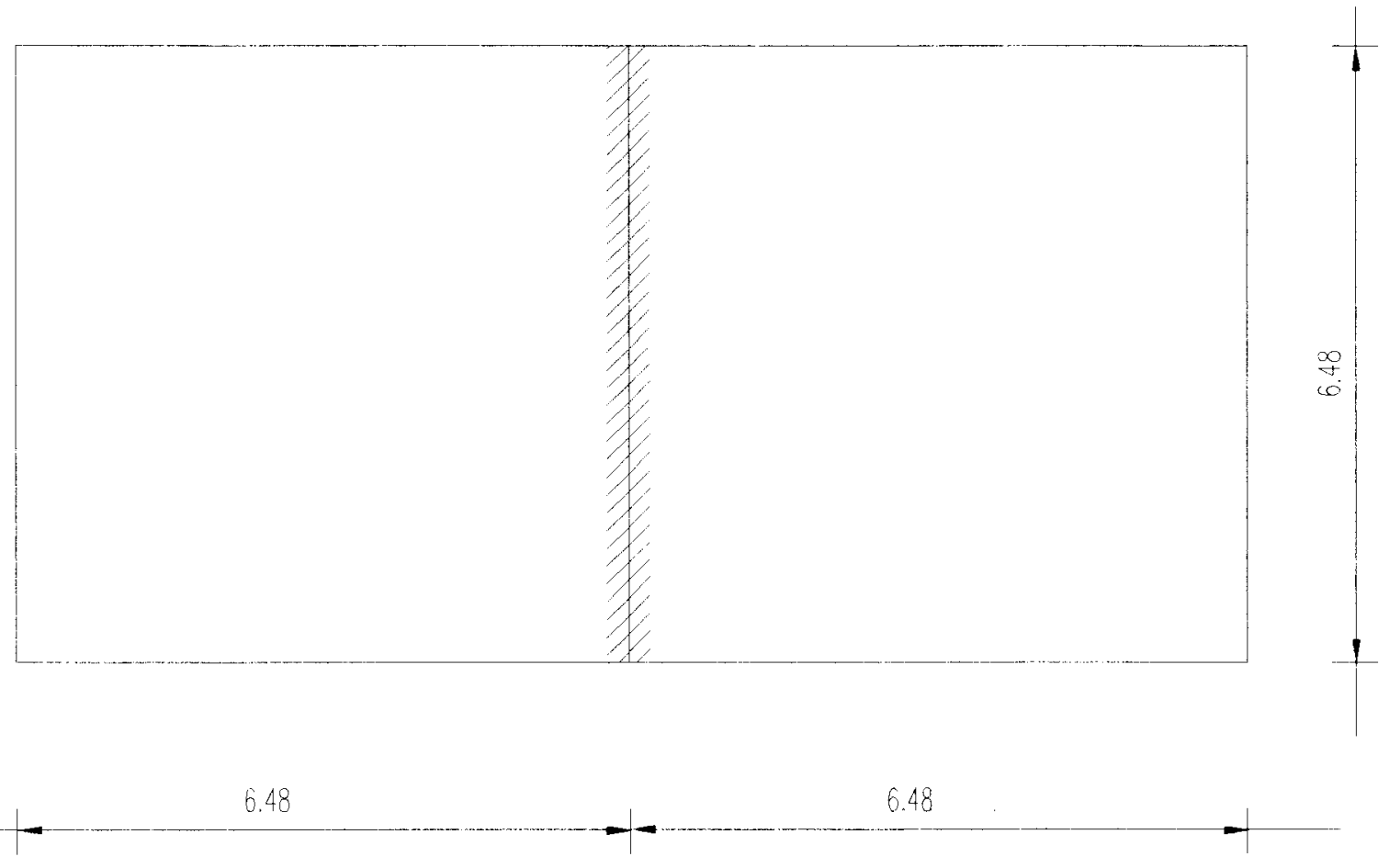


A seção a ser considerada, as ações atuantes e as propriedades do concreto são as mesmas do exemplo 1 .

\section{Verificação da resistência das nervuras. \\ Verificação da flexão.}

A verificação da flexão das nervuras deverá ser feita para:

a) Região do engaste entre as lajes, máximo momento fletor negativo;

b) Região próxima ao meio do vão na direção $\mathrm{x}$, máximo momento fletor $\mathrm{em} \mathrm{x}$;

c) Região próxima ao meio do vão na direção y, máximo momento fletor em y.

A - Região do engaste

O máximo momento fletor nesta região é de 18,77

kN.m/nervura, logo tem-se:

$$
k_{c}=\frac{b d^{2}}{M_{d}}=\frac{8 x(19)^{2}}{1,4 \times 1877}=1,10>k_{c_{\text {lim }}} \text {, esta seção é insuficiente. }
$$

Pode-se adotar na região do engaste uma mesa inferior, com $h_{f}$

$=4 \mathrm{~cm}$, tem-se então:

$$
\begin{aligned}
& k_{c}=\frac{108 x(19)^{2}}{1,4 x 1877}=14,84, \log 0 \mathrm{k}_{\mathrm{s}}=0,024 \\
& A_{s x^{\prime}}=k_{s} \frac{M_{d}}{d}=0,024 x \frac{1,4 x 1877}{19}=3,32 \mathrm{~cm}^{2} / \text { nervura }
\end{aligned}
$$

$$
\text { Adota-se } 2 \phi 12,5+2 \phi 10,0 \text { (2.camada), } \quad\left(\mathrm{A}_{\mathrm{sx}}{ }_{\text {adot }}=4,10\right.
$$

$\mathrm{cm}^{2} /$ nervura), os quais serão distribuídos na mesa superior na região do engaste. Embora a colocação da mesa inferior tenha elevado o peso próprio da laje nervura, esta não foi levada em conta na determinação dos esforços solicitantes, haja visto que, pouco acrescentaria às ações atuantes da estrutura.

Utilizando-se as tabelas para a determinação dos momentos fletores considerando-se a laje nervurada como placa, obteve-se o momento fletor máximo no engaste igual a $27,4 \mathrm{kN} . \mathrm{m} / \mathrm{m}$, ou $\mathbf{M}=29,59 \mathrm{kN} . \mathrm{m} /$ nervura, superior, portanto, ao obtido através do programa GPLAN3. 
B - Região próxima ao meio do vão na direção $\mathrm{x}$.

O momento fletor máximo nas nervuras é de 9,70

kN.m/nervura, tem-se, então:

$$
\begin{aligned}
& k_{c}=\frac{b d^{2}}{M_{d}}=\frac{54 x(19)^{2}}{1,4 x 970}=14,35, \text { logo } \mathrm{k}_{\mathrm{s}}=0,024 \\
& A_{s x}=k_{s} \frac{M_{d}}{d}=0,024 x \frac{1,4 x 970}{19}=1,72 \mathrm{~cm}^{2} / \text { nervura }
\end{aligned}
$$

Adota-se $2 \phi 12,5 \mathrm{~mm}$ por nervura $\left(A_{\mathrm{sx} \text { adot }}=2,50 \mathrm{~cm}^{2} /\right.$ nervura $)$.

C - Região próxima ao meio do vão na direção y.

O momento fletor máximo nas nervuras é de 9,33

kN.m/nervura, tem-se:

$$
\begin{aligned}
& k_{c}=\frac{b d^{2}}{M_{d}}=\frac{54_{x}(19)^{2}}{1,4 x 933}=14,92, \log 0 \mathrm{k}_{\mathrm{s}}=0,024 \\
& A_{s y}=k_{s} \frac{M_{d}}{d}=0,024 x \frac{1,4 x 933}{19}=1,65 \mathrm{~cm}^{2} / \text { nervura }
\end{aligned}
$$

Adota-se $2 \phi 10,0 \mathrm{~mm}$ por nervura $\left(\mathrm{A}_{\mathrm{sy} \text { adot }}=1,60 \mathrm{~cm}^{2} /\right.$ nervura $)$

A verificação da flexão, neste exemplo, já é suficiente para concluir-se que a opção do engastamento de uma das bordas nas lajes nervuradas não é viável, tendo em vista, o aumento do consumo de concreto e aço, além de dificultar a execução das lajes. 
EXEMPLO 4 - Laje de 6,0 m x 12,0 m apoiada nas vigas da borda e com distância livre entre nervuras (a) igual a $44 \mathrm{~cm}$, conforme figura 4.19 , observa-se que as nervuras distribuídas em uma única direção, no menor vão, tendo em vista que um dos lados tem o dobro do comprimento do outro. A nervura na outra direção (maior vão) atende às recomendações da NB-1/78.
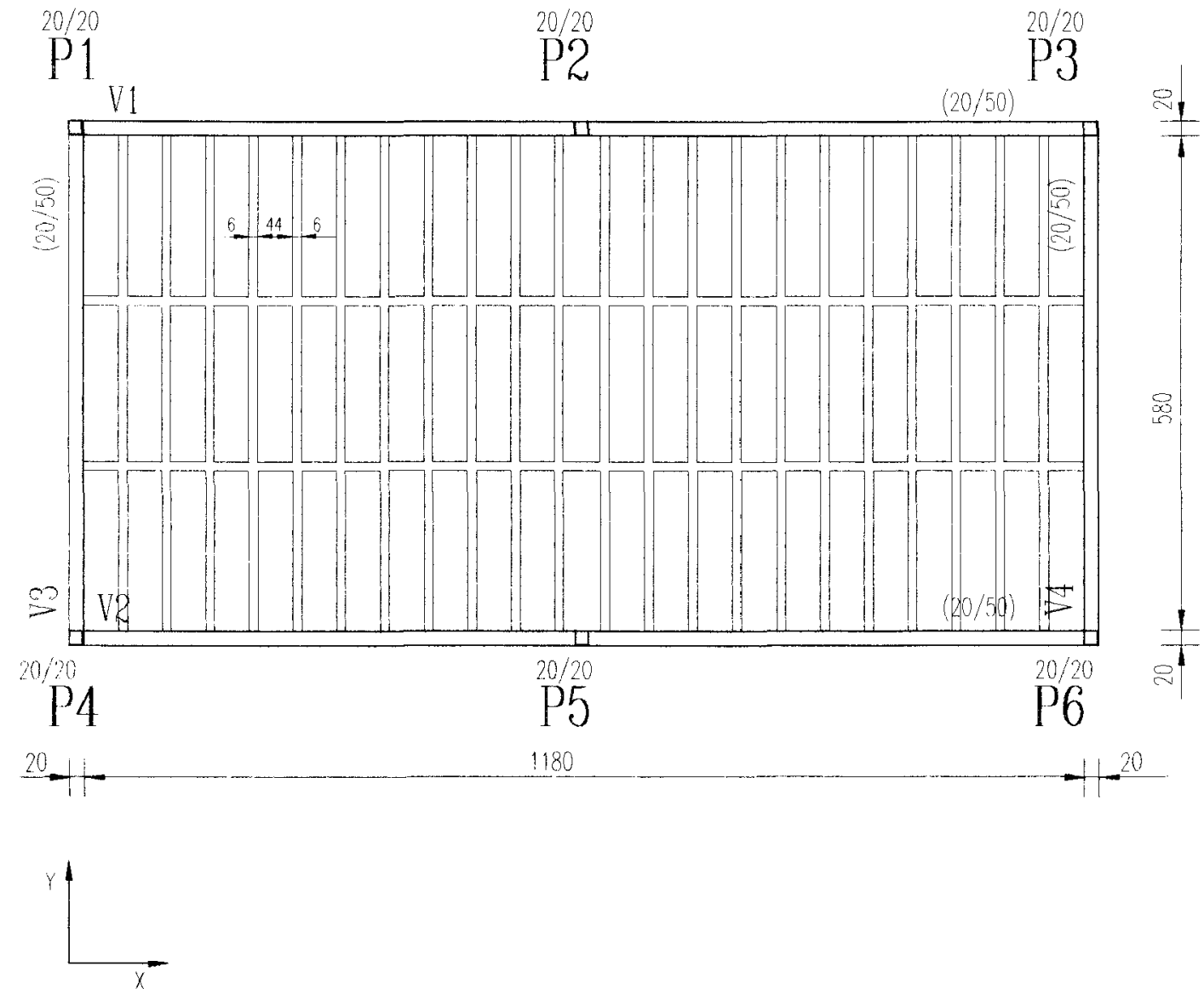

FIGURA 4.19 - LAJE COM NERVURAS EM UMA DIREÇÃO ( $a \leq 50 \mathrm{~cm})$

\section{Pré-dimensionamento:}

a) Segundo a NB-1/78:

$$
\mathrm{d} \geq \frac{\ell_{\mathrm{x}}}{\psi_{2} \psi_{3}}=\frac{600}{1,0 \times 17}=35,29 \mathrm{~cm}
$$

b) Segundo MACHAD0 (1983):

$$
\begin{aligned}
& \mathrm{d} \cong 1,5(2,5-0,1 \mathrm{n}) \ell^{*} \\
& \mathrm{~d} \cong 1,5 \times(2,5-0,1 \times 0) \times 6,00=22,5 \mathrm{~cm}
\end{aligned}
$$

Adota-se $\mathrm{h}=25 \mathrm{~cm}$ 
A altura da mesa $\left(\mathrm{h}_{\mathrm{f}}\right)$ deve ser maior ou igual a $\frac{a}{15}=\frac{44}{15}=2,93 \mathrm{~cm}$, adota $-\mathrm{se} \mathrm{h}_{\mathrm{f}}=4 \mathrm{~cm}$. A largura $\left(\mathrm{b}_{\mathrm{w}}\right)$ das nervuras será tomada igual a $6 \mathrm{~cm}$.

As ações atuantes são:

Peso próprio da mesa $=0,04 \times 25=1,00 \mathrm{kN} / \mathrm{m}^{2}$

Piso + revestimento $=1,00 \mathrm{kN} / \mathrm{m}^{2}$

Peso Próprio das nervuras $=\frac{(6,06 \times 0,21) 25}{0,50}+0,05=0,68 \mathrm{kN} / \mathrm{m}^{2}$

Sobrecarga de utilização $=2,00 \mathrm{kN} / \mathrm{m}^{2}$

Total das ações atuantes $=4,68 \mathrm{kN} / \mathrm{m}^{2}$

A seção considerada é aquela da figura 4.20 .
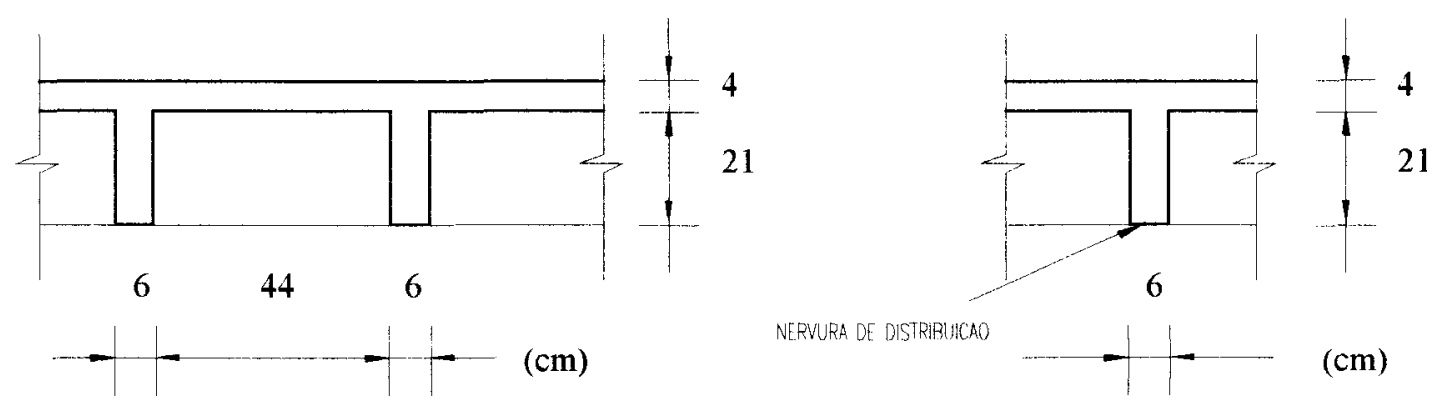

FIGURA 4.20 - SEÇÃO T CONSIDERADA

Os esforços solicitantes serão determinados considerando-se as nervuras como vigas de largura unitária, conforme o esquema estático da figura 4.21.

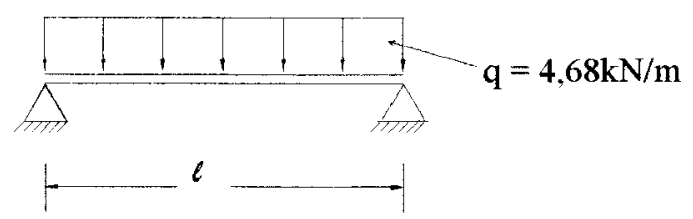

FIGURA 4.21 - ESQUEMA ESTÁTICO DA LAJE NERVURADA COM NERVURA EM UMA DIREÇÃO 
As propriedades do concreto são as mesmas adotadas para pelos exemplos anteriores.

\section{Verificação da resistência da nervura.}

\section{Verificação da flexão.}

A verificação quanto aos esforços oriundos da flexão será feita considerando-se a seção $\mathrm{T}$, como seção resistente.

O máximo momento fletor é determinado pela expressão:

$$
\mathrm{M}=\frac{\mathrm{p} \ell^{2}}{8}=\frac{4,68 \mathrm{x} 6^{2}}{8}=21,06 \mathrm{kN} . \mathrm{m} / \mathrm{m}
$$

Tem-se, então, $M=21,06 \times 0,50=10,53 \mathrm{kN} \cdot \mathrm{m} / \mathrm{n}$ ervura, ou $\mathrm{M}=1053 \mathrm{kN} . \mathrm{cm} /$ nervura .

Logo:

$$
\begin{aligned}
& k_{c}=\frac{b d^{2}}{M_{d}}=\frac{50_{x}(24)^{2}}{1,4 \times 1053}=19,54, \text { então } \mathrm{k}_{\mathrm{s}}=0,024 \\
& A_{\mathrm{sx}}=k_{s} \frac{M_{d}}{d}=0,024_{x} \frac{1,4 \times 1053}{24}=1,47 \mathrm{~cm}^{2} / \text { nervura, ou } 2,94 \mathrm{~cm}^{2} / \mathrm{m}
\end{aligned}
$$

Adota-se $2 \phi 10,0 \mathrm{~mm}\left(\mathrm{~A}_{\mathrm{sx} \text { adot. }}=1,60 \mathrm{~cm}^{2} /\right.$ nervura $)$, em função disto deve-se aumentar a largura $\left(b_{w}\right)$ da nervura, haja visto, a necessidade de arranjo das armaduras e vibração do concreto quando da execução da laje. A largura $b_{w}$ das nervuras inicialmente com $6 \mathrm{~cm}$ deverá passar para $8 \mathrm{~cm}$, em face disto, o peso próprio das nervuras passará para $0,84 \mathrm{kN} / \mathrm{m}^{2}$, consequentemente o total das ações será de $4,84 \mathrm{kN} / \mathrm{m}^{2}$.

$\mathrm{O}$ momento fletor máximo será de $1089 \mathrm{kN} . \mathrm{cm}$, a armadura $\mathrm{A}_{\mathrm{s}}$ de $1,53 \mathrm{~cm}^{2} /$ nervura, mantendo-se os $2 \phi 10,0 \mathrm{~mm}$ adotados anteriormente.

A armadura na direção y tem a função de distribuição, devendo-se ter $A_{s y}=\frac{1}{5} A_{s x}$, então:

$$
A_{s y}=\frac{1}{5} \times 2,94=0,59 \mathrm{~cm}^{2} / m, \text { ou } \mathrm{A}_{\mathrm{sy}}=0,90 \mathrm{~cm}^{2} / \mathrm{m}=1,80 \mathrm{~cm}^{2} / \text { nervura. }
$$


Adota-se para a direção $\mathrm{y}, 2 \phi 12,5 \mathrm{~mm} \quad\left(\mathrm{~A}_{\mathrm{sy}, \text { adot. }}=\right.$ $2,50 \mathrm{~cm}^{2} /$ nervura), deve-se dispor de duas nervuras de distribuição perpendiculares às nervuras principais.

\section{Verificação do cisalhamento.}

A distância livre entre as nervuras é menor que $50 \mathrm{~cm}$ $(a=42 \mathrm{~cm})$, a NB-1/78 permite a verificação como laje maciça, dispensando-se colocação de armadura transversal (estribos) quando $\tau_{\mathrm{wd}} \leq \tau_{\mathrm{wu} 1}$.

A força cortante máxima nas nervuras é dada pela expressão:

$$
\mathrm{V}=\frac{\mathrm{p} \ell}{2}=\frac{4,86 \times 6}{2}=14,52 \mathrm{kN} / \mathrm{m}, \text { ou } \mathrm{V}=14,52 \times 0,50=7,26 \mathrm{kN} / \text { nervura }
$$

A tensão de cálculo do cisalhamento no concreto é:

$$
\begin{aligned}
& \tau_{w d}=\frac{V_{d}}{b_{w} d}=\frac{1,4 x 7,26}{8 \times 24}=0,053 \mathrm{kN} / \mathrm{cm}^{2}=0,529 \mathrm{MPa} \\
& \tau_{w u 1}=\psi_{4} \sqrt{f_{c k}}<1,0(\mathrm{MPa}), \operatorname{com} \psi_{4}=0,14 \alpha k ; \mathrm{k}=1,6-\mathrm{d} \geq 1 \mathrm{e} \\
& \alpha=1+50 \rho_{1} \leq 1,5 \\
& \alpha=1+50 x \frac{160}{368}=1,217<1,5 \\
& k=1,6-0,24=1,360>1 \\
& \psi_{4}=0,14 x 1,217 \times 1,360=0,232 \\
& \tau_{w u 1}=0,232 \sqrt{20}=1,036 \mathrm{MPa}, \log \tau_{\text {wu1 }}=1,00 \mathrm{MPa}
\end{aligned}
$$

Como $\tau_{\mathrm{wd}}<\tau_{\mathrm{wu} 1}$ não é necessário a colocação de armadura transversal (estribos)

\section{Verificação da resistência da mesa.}

Esta verificação não é necessária $a<50 \mathrm{~cm}$.

\section{Verificação das tensões de cisalhamento na ligação mesa-}

nervura.

Também não é necessária esta verificação, já que a $<50 \mathrm{~cm} \mathrm{e}$ $\tau_{\mathrm{wd}}<\tau_{\mathrm{wu}]}$ 


\section{Verificação da Estado limite de deformação excessiva.}

Para a verificação das deformações as ações à serem

consideradas são:

$$
\begin{aligned}
& F_{d, \text { utl }}=\sum_{i=1}^{m} F_{G i, k}+\sum_{j=2}^{n} \psi_{2 j} F_{Q k} \\
& F_{d, \text { util }}=2,84+0,2 \times 2,00=3,24 \mathrm{kN} / \mathrm{m}^{2}, \text { ou } \\
& F_{d, u t i l}=1,62 \mathrm{kN} / \mathrm{m}
\end{aligned}
$$

A relação entre os módulos de deformação longitudinal do aço e do concreto, será adotado igual a $15\left(\alpha_{\mathrm{e}}=15\right)$, neste exemplo, a verificação do estado de deformação excessiva será feito no Estádio II.

Cálculo do momento de inércia no Estádio II.

Posição da linha neutra (x).

1a. Hipótese: Linha Neutra na mesa

$$
\begin{aligned}
& x=\alpha_{e} \frac{A_{s}}{b_{f}}\left[-1+\left(1+\frac{2 b_{f} d}{\alpha_{e} A_{s}}\right)^{\frac{1}{2}}\right] \\
& x=15 x \frac{1,60}{50}\left[-1+\left(1+\frac{2 x 50 \times 24}{15 \times 1,60}\right)^{\frac{1}{2}}\right] \\
& \mathrm{x}=4,34 \mathrm{~cm}>\mathrm{h}_{\mathrm{f}}=4 \mathrm{~cm} .
\end{aligned}
$$

2a. Hipótese: Linha neutra na alma.

$$
\begin{aligned}
& x^{2}+2\left[\frac{\left(b_{f}-b_{w}\right) h_{f}+\alpha_{e} A_{s}}{b_{w}}\right] x-\left[\frac{\left(b_{f}-b_{w}\right) h_{f}{ }^{2}+2 \alpha_{e} A_{s} d}{b_{w}}\right]=0 \\
& x^{2}+2\left[\frac{(50-8)_{x} 4+15 x 1,60}{8}\right] x-\left[\frac{(50-8)_{x} 4^{2}+2 x 15 x 1,60 x 24}{8}\right]=0 \\
& x^{2}+48 x-228=0 \\
& x=4,36 \mathrm{~cm} \therefore \text { linha neutra na alma }
\end{aligned}
$$




$$
\begin{aligned}
& I_{I I}=\frac{b_{f} x^{3}}{3} \frac{\left(b_{f}-b_{w}\right)\left(x-h_{f}\right)^{3}}{3}+\alpha_{e} A_{s}(d-x)^{2} \\
& I_{I I}=\frac{50 x 4,36^{3}}{3} \frac{(50-8)(4,36-4)^{3}}{3}+15 x 1,60 x(24-4,36)^{2} \\
& I_{I I}=10.638,22 \mathrm{~cm}^{4}
\end{aligned}
$$

A deformação inicial para laje com nervuras em uma direção e ações uniformemente distribuídas, é dada por:

$$
\mathrm{a}=\frac{5 p \ell^{4}}{384 E_{c} I}
$$

Para o módulo de deformação longitudinal do concreto $\left(\mathrm{E}_{\mathrm{c}}\right)$ limitado em 14.000 $\mathrm{MPa}\left(\alpha_{\mathrm{e}}=15\right)$ tem-se:

$$
\begin{aligned}
& a=\frac{5 \times 0,0162 \times 600^{4}}{384 x 1400 \times 10638,22} \\
& a=1,84 \mathrm{~cm}
\end{aligned}
$$

A deformação final é dada por:

$\mathrm{a}_{\infty}=\mathrm{a} \frac{\left(1+\varphi_{t}\right)\left|\varepsilon_{c}\right|+\varepsilon_{s}}{\varepsilon_{c}+\varepsilon_{s}}$

Adota-se: $\left(1+\varphi_{\mathrm{t}}\right)=3$

As deformações no concreto $\left(\varepsilon_{\mathrm{c}}\right)$ e no aço são dadas por:

$$
\begin{aligned}
& \varepsilon_{\mathrm{c}}=\frac{M_{x}}{E_{c} I}=\frac{729 \times 4,36}{1400 \times 10638,22}=2,13 \times 10^{-4} \\
& \varepsilon_{s}=\frac{M(d-x)}{E_{c} I}=\frac{729(24-4,36)}{1400_{x} 10638,22}=9,61 \times 10^{-4} \\
& \mathrm{a}_{\infty}=1,84 \times \frac{3 \times\left(2,13 \times 10^{-4}\right)+9,61 \times 10^{-4}}{2,13 \times 10^{-4}+9,61 \times 10^{-4}} \\
& \mathrm{a}_{\infty}=1,84 \times 1,36 \\
& \mathrm{a}_{\infty}=2,51 \mathrm{~cm}
\end{aligned}
$$

A deformação limite $\mathrm{a}_{\mathrm{lim}}=\frac{\ell}{300}=\frac{600}{300}=2,0 \mathrm{~cm}$.

Adota-se, portanto, uma contra-flecha de $2,50-2,00=0,50 \mathrm{~cm}$ 


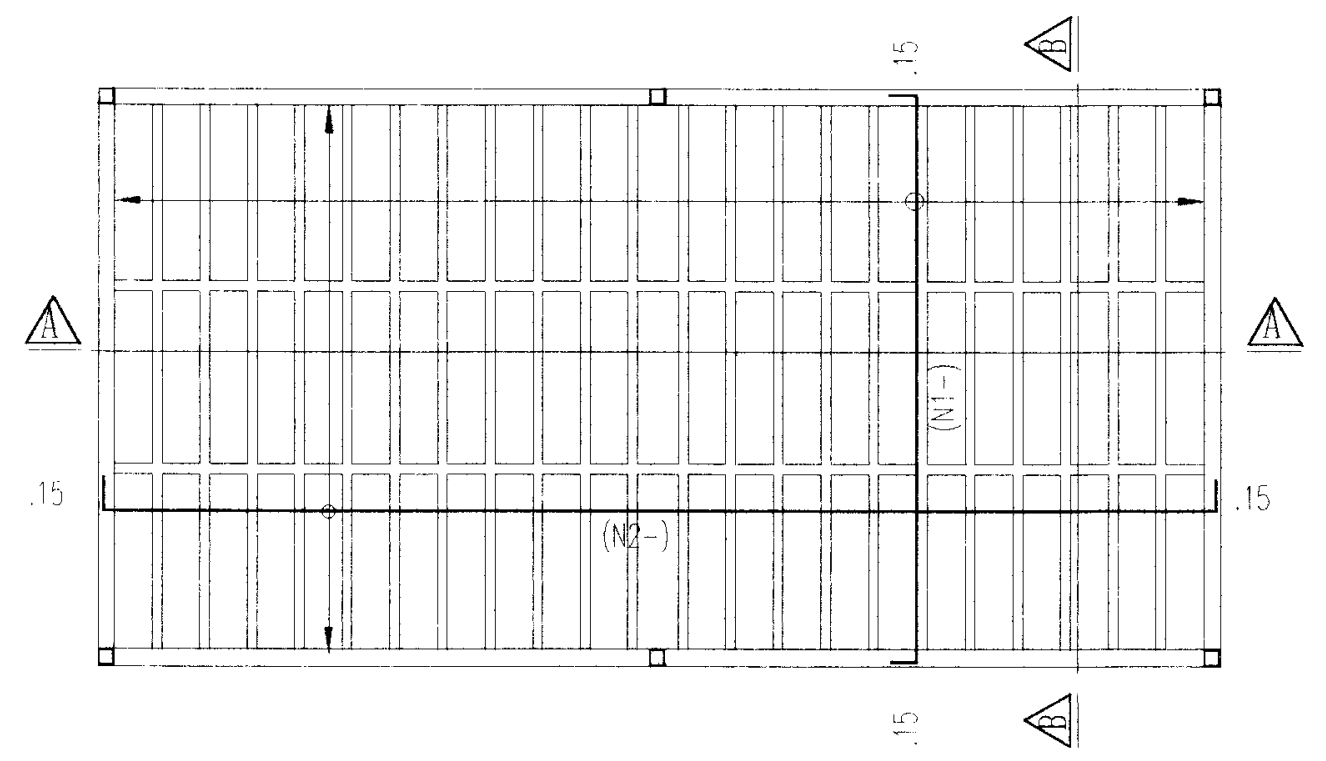

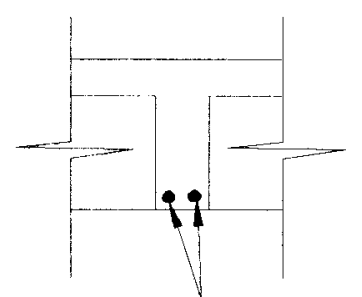

(N1-)

CORTE AA-

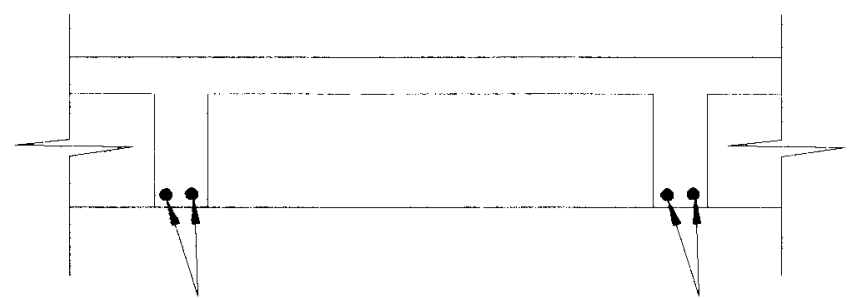

(N2-)
$\left(\mathrm{N}^{2-}\right)$

CORTE BB-

$\mathrm{N} 1-2 \Phi 10,0 \mathrm{C} / 50 \mathrm{C}=6,47(2 \mathrm{X})$

$\mathrm{N} 2-2 \Phi 12,5 \mathrm{C}=12,47(2 \mathrm{X})$

FIGURA 4.22 - DETALHAMENTO DA LAJE NERVURADA 
EXEMPLO 5 - Laje do exemplo 4, com paredes de tijolo furado apoiadas sobre a laje conforme a figura 4.23 .

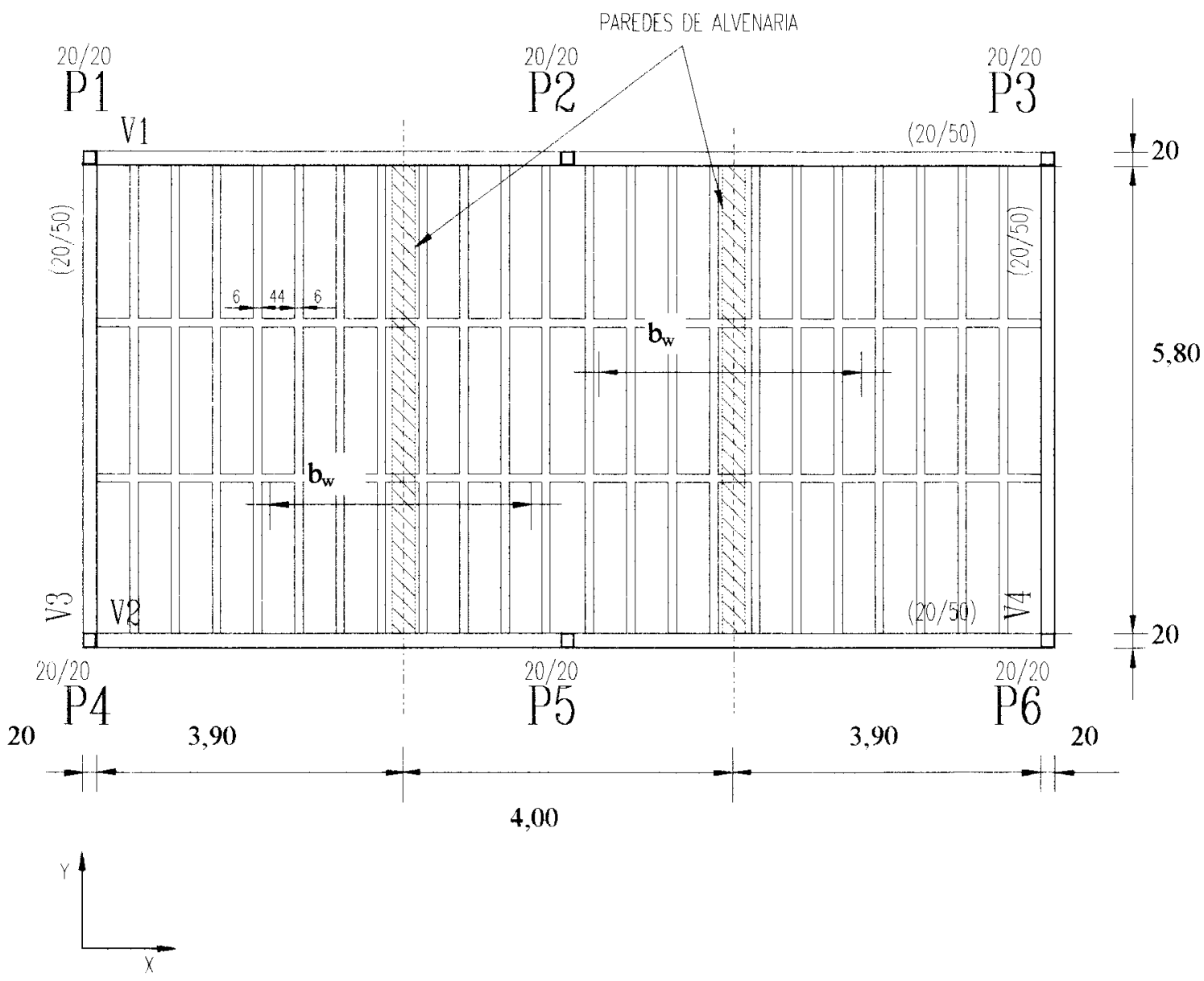

FIGURA 4.23 - LAJE COM NERVURAS EM UMA DIREÇÃO ( $a<50 \mathrm{~cm})$, COM PAREDES APOIADAS SOBRE A MESMA

As dimensões adotadas, serão inicialmente as mesmas do exemplo anterior, devendo-se entretanto determinar largura útil $b_{\mathrm{w}}$ para as cargas das paredes.

O peso próprio das alvenarias será $2,80 \times 3,00=8,40 \mathrm{kN} / \mathrm{m}$.

Para momento fletor positivo a largura útil $b_{w}{ }^{*}$ deverá ser:

$$
\begin{aligned}
& b_{w}=b+\frac{2 a_{1}\left(\ell-a_{1}\right)}{\ell}\left(1-\frac{b}{\ell}\right) \operatorname{com} \mathrm{b}=\mathrm{a}+\mathrm{h} \\
& \mathrm{b}=25+25=50 \mathrm{~cm} \\
& \mathrm{~b}_{\mathrm{w}}{ }^{*}=50+\frac{2 \times 300 x(600-300)}{600}\left(1-\frac{50}{600}\right)=325 \mathrm{~cm}
\end{aligned}
$$


Para força cortante $b_{\mathrm{w}}{ }^{*}$ é:

$$
\begin{aligned}
& b_{w}{ }^{*}=b+a_{1}\left(1-\frac{b}{\ell}\right) \\
& b_{w}{ }^{*}=50+300 x\left(1-\frac{50}{600}\right)=325 \mathrm{~cm}
\end{aligned}
$$

As ações atuantes são as mesmas do exemplo 4 acrescidas da parede de alvenaria.

Ações atuantes $=4,84 \mathrm{kN} / \mathrm{m}^{2}$

Peso próprio da alvenaria $=\frac{8,4}{3,25}=2,59 \mathrm{kN} / \mathrm{m}^{2}$

Total das ações atuantes $=7,43 \mathrm{kN} / \mathrm{m}^{2}$.

As nervuras compreendidas dentro da largura útil $b_{w}{ }^{*}$ serão denominadas tipo B com o total das ações atuantes de $7,43 \mathrm{kN} / \mathrm{m}^{2}$, enquanto que, as demais nervuras serão denominadas tipo $\mathrm{A}$, com total das ações atuantes de $4,84 \mathrm{kN} / \mathrm{m}^{2}$.

A verificação das nervuras do tipo A são as mesmas do exemplo anterior. Apresenta-se, a seguir, as verificações para as nervuras do tipo B.

Os esforços solicitantes serão determinados, considerando-se a laje como uma viga de largura unitária.

\section{Verificação da flexão.}

O máximo momento fletor é:

$$
\begin{aligned}
& M=\frac{p \ell^{2}}{8}= \frac{7,43 \times 6^{2}}{8}=33,44 \mathrm{kN} \cdot \mathrm{m} / \mathrm{m} \\
& \text { Tem-se, então, } \mathrm{M}=33,44 \times 0,50=16,72 \mathrm{kN} \cdot \mathrm{m} / \text { nervura }
\end{aligned}
$$

Logo:

$$
\begin{aligned}
& k_{c}=\frac{b d^{2}}{M_{d}}=\frac{50 x(24)^{2}}{1,4 x 1672}=12,30, \text { então } \mathrm{k}_{\mathrm{s}}=0,024 \\
& A_{s x}=k_{s} \frac{M_{d}}{d}=0,024 x \frac{1,4 x 1672}{24}=2,34 \mathrm{~cm}^{2} / \text { nervura }, \text { ou } 4,68 \mathrm{~cm}^{2} / \mathrm{m}
\end{aligned}
$$

Adota-se $2 \phi 12,5 \mathrm{~mm}\left(\mathrm{~A}_{\mathrm{sx} \text { adot. }}=2,50 \mathrm{~cm}^{2} /\right.$ nervura $)$ na direção $\mathrm{x}$. 
O cálculo da armadura para direção y $\left(A_{\text {sy }}\right)$ será feito considerando-se apenas as ações provenientes das alvenarias (ações concentradas).

$$
\begin{aligned}
& \mathrm{A}_{\mathrm{sy}}=\mathrm{A}_{\mathrm{sy}_{1}}+\mathrm{A}_{\mathrm{sy}_{2}}, \mathrm{com} \\
& \mathrm{A}_{\mathrm{sy}_{1}}=\left(1-0,8 \frac{\mathrm{b}}{\mathrm{b}_{\mathrm{w}}}\right) \mathrm{A}_{\mathrm{sx}_{1}} \mathrm{e} \\
& \mathrm{A}_{\mathrm{sy}_{2}}=\frac{1}{5} \mathrm{~A}_{\mathrm{sx}_{2}}
\end{aligned}
$$

Tem-se:

$$
\begin{aligned}
& A_{s x_{1}}=\frac{q_{c o n c}}{q_{t o t a l}} A_{s x} \text { e } \mathrm{A}_{\mathrm{sx}}=A_{\mathrm{sx}_{1}}+A_{\mathrm{sx}_{2}} \\
& A_{s x_{1}}=\frac{2,59}{7,43} \times 4,68=1,63 \mathrm{~cm}^{2} / m, \mathrm{~A}_{\mathrm{sx}_{2}}=3,26 \mathrm{~cm}^{2} / \mathrm{m}
\end{aligned}
$$

Logo:

$$
\begin{aligned}
& A_{s y_{1}}=\left\{1-0,8 x \frac{50}{325}\right\}, 63=1,43 \mathrm{~cm}^{2} / m \mathrm{e} \\
& \mathrm{A}_{\mathrm{sy}_{2}}=\frac{1}{5} \times 4,68=0,94 \mathrm{~cm}^{2} / m, \text { então } \\
& \mathrm{A}_{\mathrm{sy}}=2,37 \mathrm{~cm}^{2} / m=4,74 \mathrm{~cm}^{2} / \text { nervura }
\end{aligned}
$$

Adota-se então, para a direção y, $4 \phi 12,5 \mathrm{~mm}$ por nervura $\left(A_{\text {sy. }}=5,00 \mathrm{~cm}^{2} /\right.$ nervura $)$, com duas nervuras de distribuição.

\section{Verificação do cisalhamento.}

Verificação como laje maciça, distância livre entre nervuras (a) é menor que $50 \mathrm{~cm}$.

Nas nervuras do tipo A a verificação é idêntica ao exemplo anterior, enquanto que, para as nervuras do tipo B toma-se:

Força cortante máxima nas nervuras:

$$
\begin{gathered}
V=\frac{p \ell}{2}=\frac{7,43 x 6}{2}=22,29 \mathrm{kN} / \mathrm{m}, \text { ou } \mathrm{V}=22,29 \times 0,50=11,15 \mathrm{kN} / \text { nervura } \\
\text { A tensão de cálculo do cisalhamento no concreto é: } \\
\tau_{w d}=\frac{V_{d}}{b_{w} d}=\frac{1,4 \times 11,15}{8 \times 24}=0,081 \mathrm{kN} / \mathrm{cm}^{2}, \text { ou } \tau_{w d}=0,813 \mathrm{MPa}
\end{gathered}
$$

A tensão $\tau_{\mathrm{wu} 1}$ é dada pela expressão: 


$$
\begin{aligned}
& \tau_{w u 1}=\psi_{4} \sqrt{f_{c k}}<1,0(\mathrm{MPa}), \text { com } \psi_{4}=0,14 \alpha k ; \mathrm{k}=1,6-\mathrm{d} \geq \mathrm{e} \\
& \alpha=1+50 \rho_{1} \leq 1,5 \\
& \alpha=1+50_{x} \frac{250}{368}=1,34<1,5 \\
& k=1,36>1 \\
& \alpha k \leq 1,75 ; 1,34 \times 1,36=1,82 \\
& \psi_{4}=0,14 x 1,75=0,245 \\
& \tau_{w u 1}=0,245 \sqrt{20}=1,096 \mathrm{MPa}, \log \tau_{\text {wu1 }}=1,00 \mathrm{MPa} \\
& \text { Como } \tau_{\mathrm{wd}}<\tau_{\mathrm{w} 11} \text { não é necessário a colocação de armadura }
\end{aligned}
$$
transversal (estribos).

\section{Verificação da resistência da mesa.}

\section{Verificação da flexão da mesa.}

As paredes estão apoiadas fora do eixo das nervuras, ou seja, as ações provenientes das mesmas é aplicada diretamente sobre as mesas, portanto torna-se necessária a verificação à flexão das mesas, mesmo que a distância livre entre as nervuras (a) seja menor que $50 \mathrm{~cm}$.

O espaçamento das nervuras na direção y é muito maior que o espaçamento das nervuras na direção $\mathrm{x}, \mathrm{a}_{\mathrm{y}}>2 \mathrm{a}_{\mathrm{x}}$, pode-se concluir que as mesas serão consideradas como lajes armadas em uma direção, apoiadas nas nervuras.

O momento fletor máximo é dado por:

$$
\begin{aligned}
& \mathrm{M}=\frac{\mathrm{p} \ell}{4}=\frac{8,4 \times 0,50}{4}=1,05 \mathrm{kN} \cdot \mathrm{m} / \mathrm{m} \\
& k_{c}=\frac{b d^{2}}{M_{d}}=\frac{100 x(3)^{2}}{1,4105}=6,12, \log \mathrm{k}_{\mathrm{s}}=0,025 \\
& \text { A armadura na mesa é: } \\
& A_{s}=k_{s} \frac{M_{d}}{d}=0,025 x \frac{1,4 x 105}{3}=1,23 \mathrm{~cm}^{2} / \mathrm{m}
\end{aligned}
$$

Adota-se na direção y armadura de distribuição de $\phi 5,0 \mathrm{~mm}$ $\operatorname{com} 10 \mathrm{~cm}$ 


\section{Verificação do cisalhamento.}

A força cortante máxima é:

$$
V=\frac{p}{2}=\frac{8,40}{2}=4,20 \mathrm{kN} / \mathrm{m}
$$

A máxima tensão de cisalhamento no concreto:

$$
\tau_{w d}=\frac{V_{d}}{b_{w} d}=\frac{1,4 \times 4,2}{8 \times 24}=0,31 \mathrm{kN} / \mathrm{cm}^{2}, \text { ou } \tau_{\mathrm{wd}}=0,306 \mathrm{MPa}
$$

A tensão $\tau_{\text {wu1 }}$ é igual a $1,00 \mathrm{MPa}$, logo tem-se $\tau_{\text {wd }}<\tau_{\text {wul }}$ não há necessidade de colocação de armadura transversal.

Verificação das tensões de cisalhamento nas ligações mesanervura com a mesa comprimida.

A tensão de cisalhamento na ligação mesa-nervura é:

$$
\begin{aligned}
& \tau_{m d}=\frac{V_{d}}{h_{f} z} 0,5\left(1 \frac{b_{w}}{b_{f}}\right) \operatorname{com} \mathrm{z}=\mathrm{d}-0,5 \mathrm{~h}_{\mathrm{f}} \\
& z=24-0,5.4=22 \mathrm{~cm} \\
& \tau_{\mathrm{md}}=\frac{1,4 \times 11,15}{4 \times 22} \times 0,5 \times\left(1 \frac{8}{50}\right)=0,075 \mathrm{kN} / \mathrm{cm}^{2}, \text { ou } \tau_{\mathrm{md}}=0,745 \mathrm{MPa}
\end{aligned}
$$

A armadura necessária é dada por:

$$
\begin{aligned}
& A_{s t}=\frac{V_{d}}{z f_{y d}} \times 0,5 \times\left(1 \frac{b_{w}}{b_{f}}\right) \\
& A_{s t}=\frac{1,4 \times 11,15}{22 \times 434,8} \times 0,5 \times\left(1-\frac{8}{50}\right) 100=0,69 \mathrm{~cm}^{2} / m
\end{aligned}
$$

$$
A_{\text {stmin }}=1,50 \mathrm{~cm}^{2} / \mathrm{m}
$$

Adota-se $\phi 5,0 \mathrm{~mm}$ com $10 \mathrm{~cm}\left(A_{\text {st adot. }}=1,96 \mathrm{~cm}^{2} / \mathrm{m}\right)$.

\section{Verificação da Estado limite de deformação excessiva.}

A verificação das deformações será feito para as nervuras do tipo B, já que estas receberão as ações provenientes das paredes. 


$$
\begin{aligned}
& F_{d, u t i l}=\sum_{i=}^{m} F_{G i, k}+\sum_{j=2}^{n} \psi_{2 j} F_{Q k} \\
& F_{d, u t i l}=5,43+0,2 \times 2,00=5,83 \mathrm{kN} / \mathrm{m}^{2}, \text { ou } \\
& F_{d, u t i l}=2,92 \mathrm{kN} / \mathrm{m}
\end{aligned}
$$

A relação entre os módulos de deformação longitudinal do aço e do concreto será, novamente, tomado igual a $15\left(\alpha_{\mathrm{e}}=15\right)$. A verificação do estado limite de deformação excessiva será feito no Estádio II.

Cálculo do momento de inércia no Estádio II.

Posição da linha neutra $(\mathrm{x})$.

1a. Hipótese: Linha Neutra na mesa

$$
\begin{aligned}
& x=\alpha_{e} \frac{A_{s}}{b_{f}}\left[-1+\left(1+\frac{2 b_{f} d}{\alpha_{e} A_{s}}\right)^{\frac{1}{2}}\right] \\
& x=15 x \frac{2,50}{50}\left[-1+\left(1+\frac{2 \times 50 \times 24}{15 \times 2,50}\right)^{\frac{1}{2}}\right] \\
& \mathrm{x}=5,30 \mathrm{~cm}>\mathrm{h}_{\mathrm{f}}=4 \mathrm{~cm} .
\end{aligned}
$$

2a. Hipótese: Linha neutra na alma.

$$
\begin{aligned}
& x^{2}+2\left[\frac{\left(b_{f}-b_{w}\right) h_{f}+\alpha_{e} A_{s}}{b_{w}}\right] x-\left[\frac{\left(b_{f}-b_{w}\right) h_{f}{ }^{2}+2 \alpha_{e} A_{s} d}{b_{w}}\right]=0 \\
& x^{2}+2\left[\frac{(50-8) x 4+15 x 2,50}{8}\right] x-\left[\frac{(50-8) x 4^{2}+2 x 15 x 2,50 x 24}{8}\right]=0 \\
& x^{2}+51,38 x-309,00=0 \\
& x=5,44 \mathrm{~cm} \therefore \text { linha neutra na alma } \\
& I_{I I}=\frac{b_{f} x^{3}}{3} \frac{\left(b_{f}-b_{w}\right)\left(x-h_{f}\right)^{3}}{3}+\alpha_{e} A_{s}(d-x)^{2} \\
& I_{I I}=\frac{50 x 5,44^{3}}{3} \frac{(50-8)(5,44-4)^{3}}{3}+15 \times 2,50 x(24-5,44)^{2} \\
& I_{I I}=15.559,11 \mathrm{~cm}^{4}
\end{aligned}
$$

A deformação inicial para laje com nervuras em uma direção e ações uniformemente distribuídas, é dada por: 


$$
\mathrm{a}=\frac{5 p \ell^{4}}{384 E_{c} I}
$$

Para o módulo de deformação longitudinal do concreto igual a 14.000 MPa tem-se:

$$
\begin{aligned}
& a=\frac{5 x 0,0292{ }_{x} 600^{4}}{384 x 1400 x 15559,11} \\
& a=2,26 \mathrm{~cm}
\end{aligned}
$$

A deformação final é dada por:

$$
\begin{aligned}
& \mathrm{a}_{\infty}=\mathrm{a} \frac{\left(1+\varphi_{t}\right)\left|\varepsilon_{c}\right|+\varepsilon_{s}}{\varepsilon_{c}+\varepsilon_{s}}, \operatorname{com}\left(1+\varphi_{\mathfrak{t}}\right)=3 \\
& \varepsilon_{\mathrm{c}}=\frac{M_{x}}{E_{c} I}=\frac{1314 \times 5,44}{1400_{x} 15559,11}=3,28 \times 10^{-4} \\
& \varepsilon_{s}=\frac{M(d-x)}{E_{c} I}=\frac{1314(24-5,44)}{1400 \times 15559,11}=1,12 \times 10^{-3} \\
& \text { Então, } \mathrm{a}_{\infty}=2,26 x \frac{3\left|3,28 \times 10^{-4}\right|+1,12 \times 10^{-3}}{3,28 \times 10^{-4}+1,12 \times 10^{-3}} \\
& \mathrm{a}_{\infty}=2,26 \times 1,45 \\
& \mathrm{a}_{\infty}=3,28 \mathrm{~cm}
\end{aligned}
$$

A máxima deformação permitida $a_{\text {lim }}=2,00 \mathrm{~cm}$; adota-se, portanto, uma contra-flecha de $3,28-2,00=1,28 \mathrm{~cm}(\cong 1,00 \mathrm{~cm})$

Embora não haja a necessidade da colocação de estribos (armadura transversal) com função estrutural nas nervuras, estes foram empregados com a finalidade construtiva, a fim de posicionar as armaduras das nervuras do tipo B, e as nervuras de distribuição. 
$\mathrm{N} 7-2 \Phi 6,3 \mathrm{C}=12,17(2 \mathrm{X})$

.15

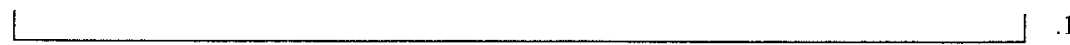

.15

$\mathrm{N} 5-4 \Phi 12,5 \mathrm{C}=12,47(2 \mathrm{X})$

$m<1$

$.15 \quad .15$

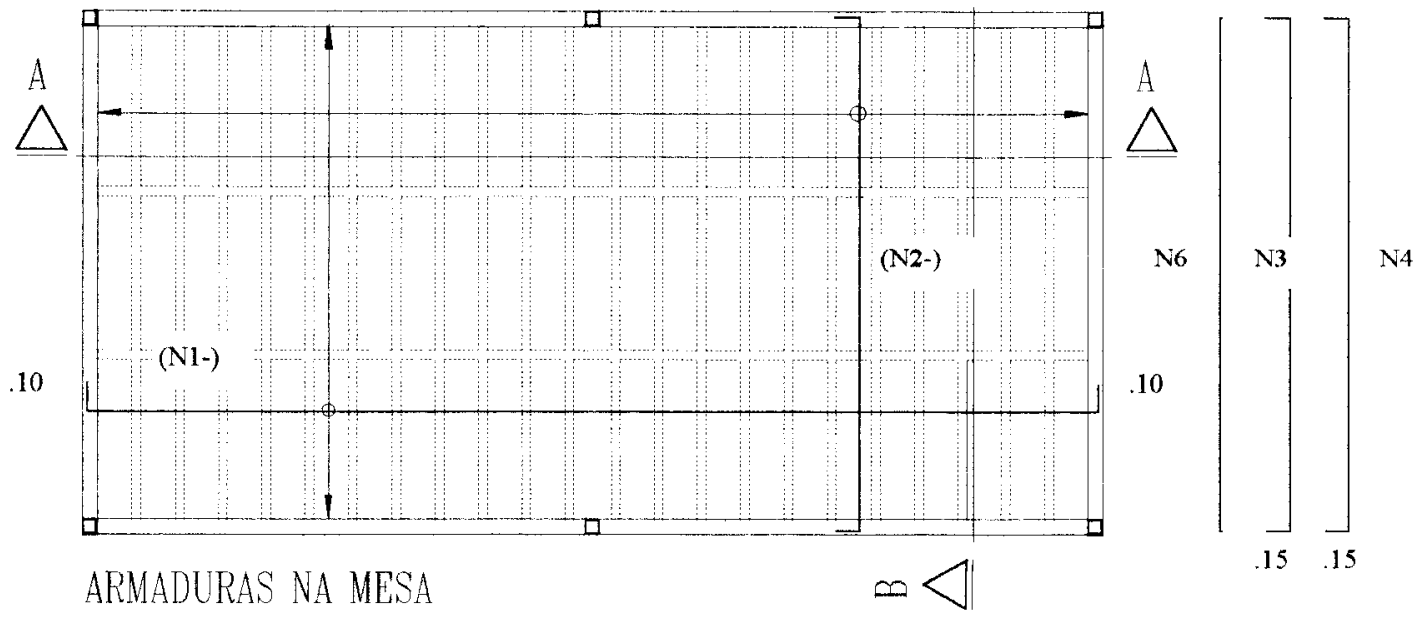

NERVIRAS

TIPO A (18X)

NERVURAS

$\operatorname{TIPO} B(22 X)$

NERVURAS DE

DISTRIBUICAO

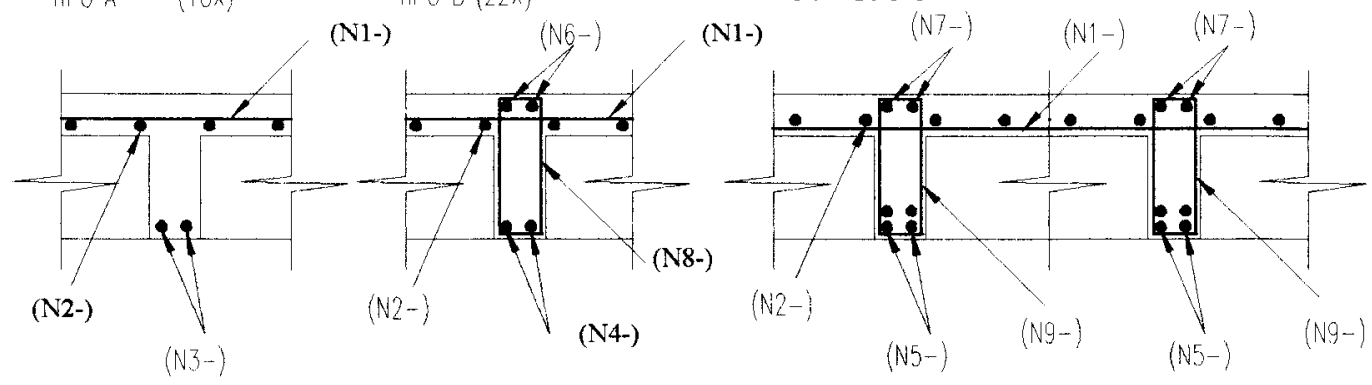

CORTE AA-

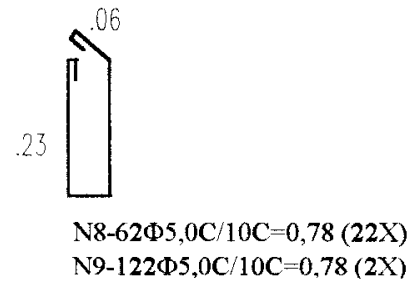

CORTE BB-

$\mathrm{N} 1-61 \Phi 5,0 \mathrm{C} / 10 \mathrm{C}=12,37$

$\mathrm{N} 2-121 \Phi 5,0 \mathrm{C} / 10 \mathrm{C}=6,37$

$\mathrm{N} 3-2 \Phi 10,0 \mathrm{C}=6,47(18 \mathrm{X})$

$\mathrm{N} 4-2 \Phi 12,5 \mathrm{C}=6,47(22 \mathrm{X})$

$\mathrm{N} 6-2 \Phi 6,3 \mathrm{C}=6,6,17(22 \mathrm{X})$

FIGURA 4.24 - DETALHAMENTO DA LAJE NERVURADA 
EXEMPLO 6 - Laje de 10,0 m x 12,0 m com nervuras em uma direção, apoiada nas vigas de borda, com balanços de $2,0 \mathrm{~m}$, conforme a figura 4.25 .

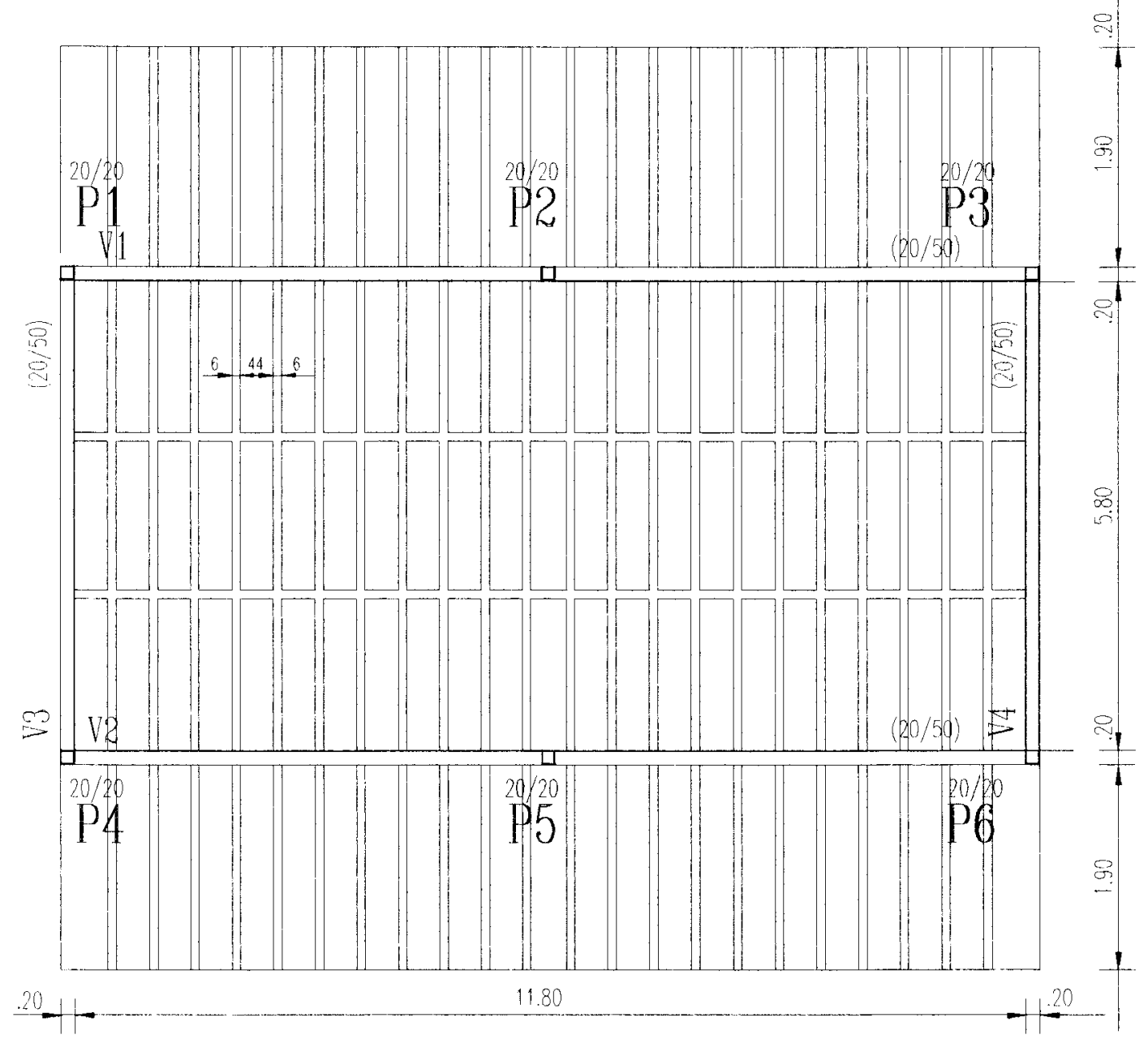

FIGURA 4.25 - LAJE COM NERVURAS EM UMA DIREÇÃO, SENDO PARTE EM BALANÇO

Pode-se observar na figura 4.25 que a distância livre (a) entre nervuras foi fixada em $44 \mathrm{~cm}$ e para largura $\left(b_{w}\right)$ das nervuras adotou-se $6 \mathrm{~cm}$, ou seja, tomou-se a mesma seção adotada para o exemplo 4 .

As ações atuantes totalizam $4,68 \mathrm{kN} / \mathrm{m}^{2}$ (ver exemplo 4), os esforços solicitantes são obtidos considerando-se as nervuras como vigas de largura unitária, conforme o esquema estático da figura 4.26 

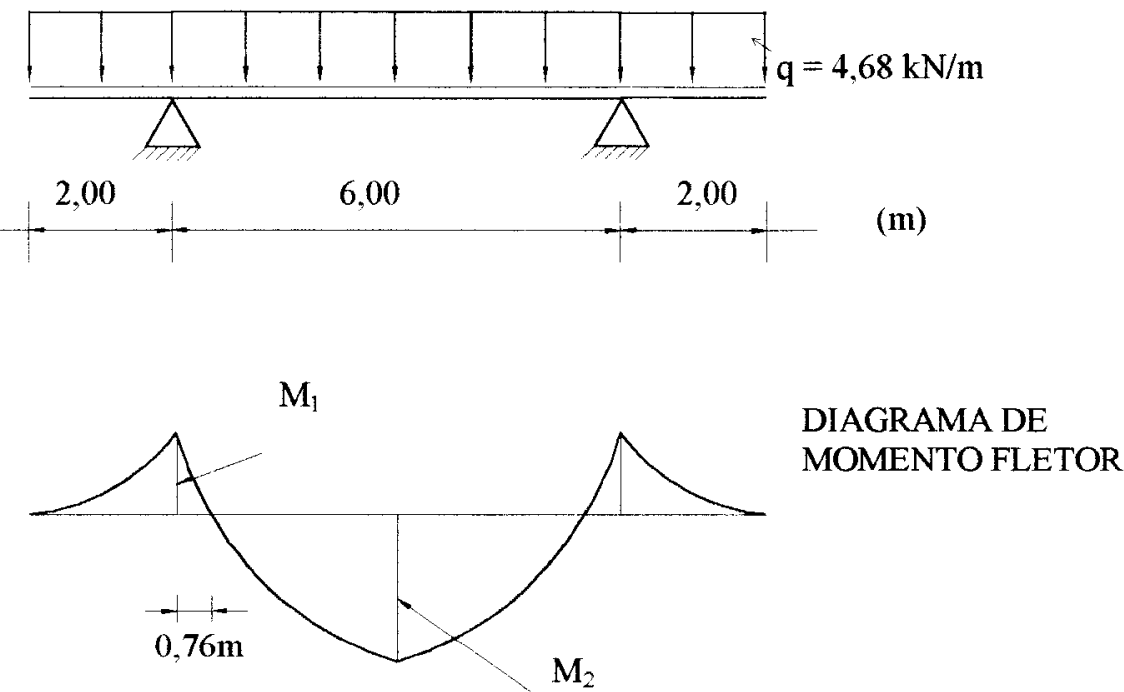

\section{FIGURA 4.26 - ESQUEMA ESTÁTICA DA LAJE COM NERVURAS EM UMA DIREÇÃO, SENDO PARTE EM BALANÇO}

As propriedades do concreto são as mesmas dos exemplos anteriores.

\section{Verificação da resistência da nervura}

Verificação da flexão.

A verificação da flexão das nervuras deverá ser feita para:

a) Região dos apoios;

b) Região central da laje.

A - Região dos apoios

O momento fletor máximo na região dos apoios $\left(\mathrm{M}_{1}\right)$ é:

$$
M_{1}=4,68 \times 2 \times 1=9,36 \mathrm{kN} / \mathrm{m} \text {, ou } M_{1}=4,68 \mathrm{kN} \cdot \mathrm{m} / \text { nervura } \text {. }
$$

Para o dimensionamento da armadura de flexão, nesta região, deve-se considerar como seção resistente, a seção retangular, dada pela figura 4.27. 


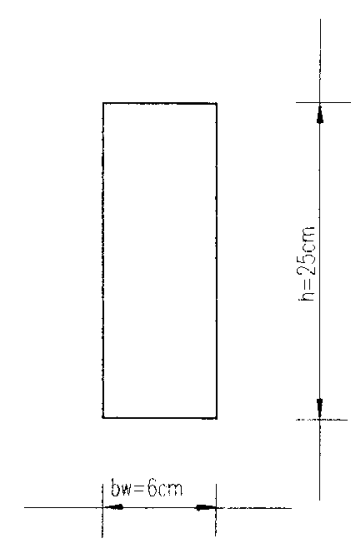

\section{FIGURA 4.27 - SEÇÃO RESISTENTE À FLEXÃO}

Tem-se:

$$
\begin{aligned}
& k_{c}=\frac{b d^{2}}{M_{d}}=\frac{6 x(24)^{2}}{1,4 x 468}=5,28, \text { então } \mathrm{k}_{\mathrm{s}}=0,025 \\
& A_{s x}=k_{s} \frac{M_{d}}{d}=0,025 x \frac{1,4 \times 468}{24}=0,68 \mathrm{~cm}^{2} / \text { nervura }
\end{aligned}
$$

Adota-se $2 \phi 8,0 \mathrm{~mm}$ por nervura $\left(\mathrm{A}_{\mathrm{sx} \text { adot }}=1,00 \mathrm{~cm}^{2} /\right.$ nervura $)$

\section{B - Região Central da Laje.}

Para a região central da laje nervurada o momento fletor máximo $\left(\mathrm{M}_{2}\right)$ é:

$$
\begin{aligned}
& \mathrm{M}_{2}=\frac{\mathrm{p} \ell^{2}}{8}-\mathrm{M}_{1}=\frac{4,68 \times 6^{2}}{8}-9,36=11,70 \mathrm{kN} \cdot \mathrm{m} / \mathrm{m} \text { ou } 5,85 \mathrm{kN} \cdot \mathrm{m} / \text { nervura } \\
& \text { Tem-se: } \\
& k_{c}=\frac{b d^{2}}{M_{d}}=\frac{50 \times(24)^{2}}{1,4 \times 585}=35,17, \text { então } \mathrm{k}_{\mathrm{s}}=0,023 \\
& A_{\mathrm{sx}}=k_{s} \frac{M_{d}}{d}=0,023 x \frac{1,4 \times 585}{24}=0,79 \mathrm{~cm}^{2} / \text { nervura }
\end{aligned}
$$

Adota-se, também para esta região, $2 \phi 8,0 \mathrm{~mm}$ por nervura $\left(A_{\text {sx,adot }}=1,0 \mathrm{~cm}^{2} /\right.$ nervura $)$.

A armadura de distribuição na direção y, deve ser:

$$
\begin{aligned}
& A_{s y}=\frac{1}{5} A_{\mathrm{sx}}=\frac{1}{5} \times 1,60=0,32 \mathrm{~cm}^{2} / m, \text { ou } \mathrm{A}_{\mathrm{sy}}=0,90 \mathrm{~cm}^{2} / m, \text { ou } \\
& \mathrm{A}_{\mathrm{sy}}=1,80 \mathrm{~cm}^{2} / \text { nervura. }
\end{aligned}
$$


Adota-se, então, para direção y, $2 \phi 12,5 \mathrm{~mm}$ por nervura de distribuição $\left(\mathrm{A}_{\mathrm{sy} \text { adot }}=2,50 \mathrm{~cm}^{2} /\right.$ nervura $)$, com duas nervuras perpendiculares às nervuras principais.

\section{Verificação do Cisalhamento}

Verificação quanto aos esforços provenientes do cisalhamento será feita como uma laje maciça, ou seja, quando $\tau_{\mathrm{wd}} \leq \tau_{\mathrm{wu} 1}$ dispensa-se a colocação de armadura transversal (estribos).

A força cortante máxima na região em balanço é de $9,36 \mathrm{kN} / \mathrm{m}$, enquanto que, entre os apoios é de $14,04 \mathrm{kN} / \mathrm{m}$, portanto $\mathrm{V}=14,04 \mathrm{x} 0,50=7,02$ $\mathrm{kN} /$ nervura.

A tensão de cálculo de cisalhamento no concreto é:

$$
\begin{aligned}
& \tau_{w d}=\frac{V_{d}}{b_{w} d}=\frac{1,4 \times 7,02}{6 \times 24}=0,068 \mathrm{kN} / \mathrm{cm}^{2}=0,683 \mathrm{MPa} \\
& \tau_{w u 1}=\psi_{4} \sqrt{f_{c k}}<1,0(\mathrm{MPa}), \mathrm{com} \psi_{4}=0,14 \alpha k ; \mathrm{k}=1,6-\mathrm{d} \geq 1 \mathrm{e} \\
& \alpha=1+50 \rho_{1} \leq 1 \\
& \alpha=1+50 x \frac{0,8}{326}=1,123<1,5 \\
& k=1,36>1 \\
& k=1,6-0,24=1,36>1 \\
& \psi_{4}=0,14 x 1,123 \times 1,36=0,214 \\
& \tau_{w u 1}=0,214 \sqrt{20}=0,956 \mathrm{MPa}
\end{aligned}
$$

Como $\tau_{\mathrm{wd}}<\tau_{\mathrm{wu} 1}$ não há necessidade de colocação de armadura transversal (estribos)

\section{Verificação da resistência da mesa}

Esta verificação é dispensada $a<50 \mathrm{~cm}$

\section{Verificação das tensões de cisalhamento na ligação mesa-}

nervura

Também pode ser dispensado, haja visto que, $a<50 \mathrm{~cm} \mathrm{e}$ $\tau_{\mathrm{wd}}<\tau_{\mathrm{wu} 1}$ 


\section{Verificação do Estado Limite de Deformação Excessiva.}

Neste exemplo não será feita a verificação do estado limite de deformação excessiva, já que os balanços contribuem para a redução da deformação entre os apoios, fazendo com que esta seja menor que a deformação verificada para o exemplo anterior.

Os estribos (armadura transversal), foram adotados apenas para fins construtivos. 

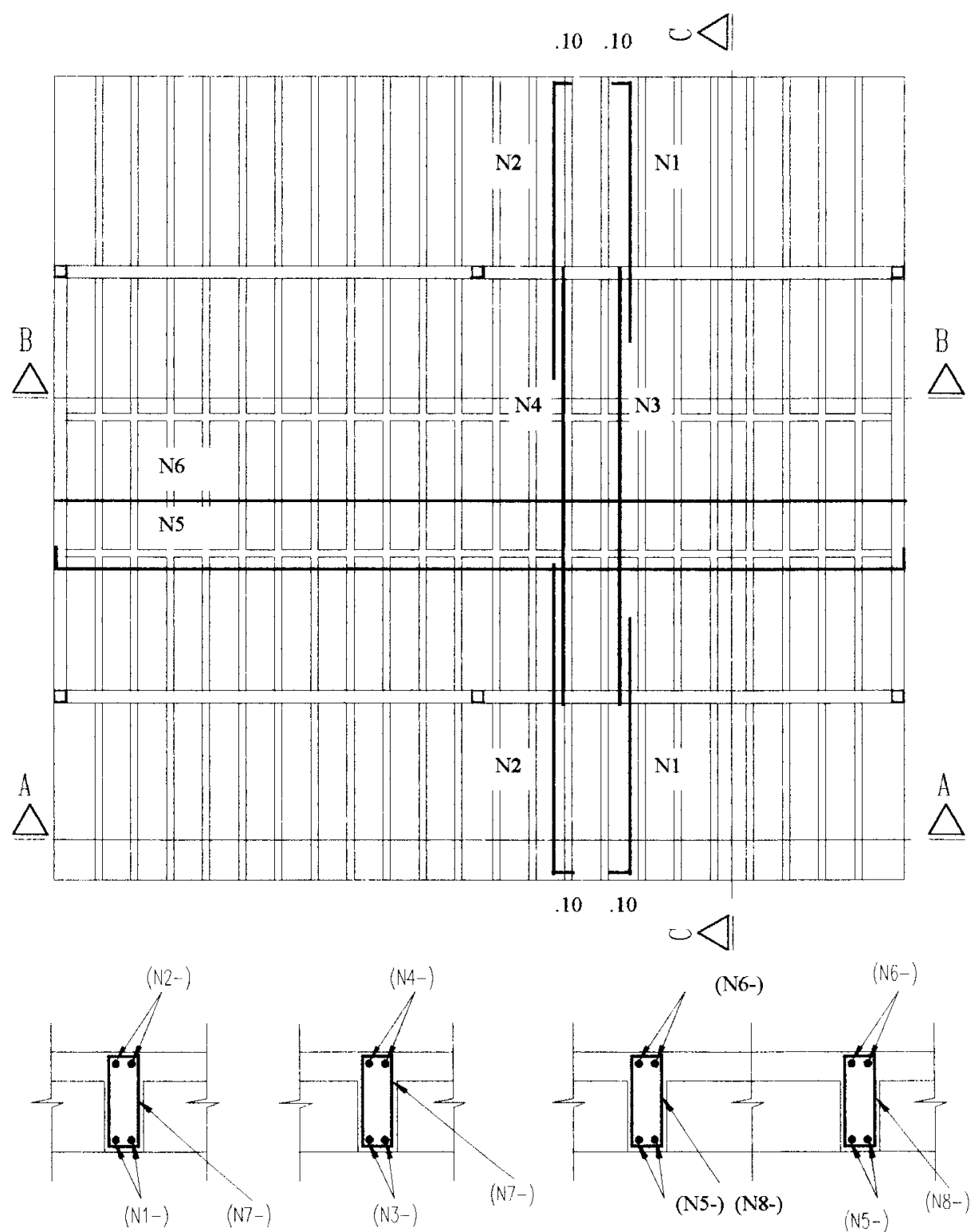

CORTE AACORTE BB_

CORTE CC_

$\mathrm{N} 1-2 \Phi 6,3 \mathrm{C}=2,60(48 \mathrm{X})$

$\mathrm{N} 2-2 \Phi 8,0 \mathrm{C}=3,60(48 \mathrm{X})$

$\mathrm{N} 3-2 \Phi 8,0 \mathrm{C}=6,00(24 \mathrm{X})$

$\mathrm{N} 4-2 \Phi 6,3 \mathrm{C}=6,00(24 \mathrm{X})$

$\mathrm{N} 5-2 \Phi 8,0 \mathrm{C}=12,37(2 \mathrm{X})$

$\mathrm{N} 6-2 \Phi 6,3 \mathrm{C}=12,17(2 \mathrm{X})$

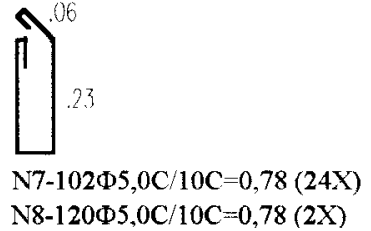

FIGURA 4.28 - DETALHAMENTO DA LAJE NERVURADA 


\section{LAJES NERVURADAS PRÉ-MOLDADAS}

Entende-se por lajes nervuradas pré-moldadas, aquelas em que parte das nervuras são executadas fora do local de utilização definitivo, com controle de qualidade. As lajes devem ser inspecionadas, individualmente ou em lotes através de inspetores do próprio construtor, da fiscalização do proprietário ou de organizações especializadas dispensando-se a existência de laboratório e de instalações congêneres próprias. As lajes são constituídas de vigas pré-moldadas de concreto armado e lajotas, as quais recebem uma capa (mesa) de concreto lançado na obra, solidarizando os elementos.

\subsection{MATERIAIS}

Os materiais empregados na execução das lajes nervuradas prémoldadas podem ser divididos em dois grupos, sendo um relativo à fabricação da viga pré-moldada e outro devido à concretagem de parte da nervura e da mesa na obra. 


\subsubsection{VIGAS PRÉ-MOLDADAS}

A fabricação das vigas pré-moldadas envolve o emprego dos seguintes materiais:

\subsubsection{CONCRETO}

$O$ concreto deve apresentar uma resistência característica $f_{c k}$ de no mínimo $15 \mathrm{MPa}$; o consumo mínimo de cimento de $350 \mathrm{~kg} / \mathrm{m}^{3}$; os agregados devem ser miúdos, com areia e pedra britada de diâmetro nominal máximo de $19 \mathrm{~mm}$, visando melhorar a plasticidade; a dosagem do concreto deve ser experimental. Quando emprega-se o processo de cura acelerada recomenda-se o cimento ARI (alta resistência inicial) com escórias, objetivando-se elevada resistência em poucas horas após a concretagem da peça, agilizando assim o processo produtivo e liberando as fồrmas metálicas para moldagem de novas peças.

\subsubsection{AÇO}

O aço empregado nas vigas é do tipo CA 50 ou CA 60, especificados pela NB-3/80. 


\subsubsection{ADITIVOS}

Podem ser utilizados aditivos no concreto, com o objetivo de acelerar a pega e o desenvolvimento da resistência da peça nas idades iniciais; redução do calor de hidratação; melhora da trabalhabilidade, redução da relação água / cimento; aumento da compacidade e impermeabilidade aumentando a resistência aos agentes agressivos e às variações climáticas.

\subsubsection{CAPA OU MESA DA LAJE NERVURADA PRÉ-MOLDADA}

Os materiais envolvidos na execução propriamente dita da laje nervurada pré-moldada são:

\subsubsection{CONCRETO}

O concreto destinado à capa ou mesa deve possuir uma resistência característica de no mínimo $15 \mathrm{MPa}$, o consumo mínimo de cimento deve ser de $300 \mathrm{~kg} / \mathrm{m}^{3}$. 
5.1.2.2. ACO

O aço empregado na execução da capa ou mesa é o CA 50 e o CA 60 .

\subsubsection{LAJOTAS}

As lajotas utilizadas nas lajes nervuradas pré-moldadas têm por finalidade servir de suporte (fồrma perdida) para o concreto da mesa, ao contrário do que imagina-se as lajotas não resistem aos esforços solicitantes atuantes na laje acabada. Estas lajotas podem ser cerâmicas (argila expandida), de concreto, ou de outros materiais como concreto celular, isopor, plásticos, etc.

\subsection{ARMAZENAMENTO}

O armazenamento dos materiais deve seguir determinadas recomendações, a fim de evitar-se que estes prejudiquem a qualidade e resistência da laje nervurada pré-moldada. 


\subsubsection{CIMENTO}

O cimento deve ser armazenado em local seco, por período máximo de três meses, depois do qual tem-se inicio a hidratação do cimento.

\subsubsection{AGREGADOS}

Os agregados não exigem condições especiais de armazenamento, mas recomenda-se conhecer o teor de umidade dos mesmos quando da dosagem do concreto.

\subsubsection{AÇO}

As barras de aço também não necessitam de condições especiais de armazenamento, aconselha-se, porém, que estas não permaneçam expostas por longos períodos à ação das intempéries climáticas, as quais podem causar a corrosão do material. 


\subsubsection{ADITIVOS}

Os aditivos devem ser armazenados em local protegido, dentro de sua própria embalagem. Estes devem ser utilizados dentro dos prazos de validade estabelecidas pelos fabricantes, visto que, perdem suas propriedades passado tal validade.

\subsection{FABRICAÇÃO DO ELEMENTO PRÉ-MOLDADO}

O processo de fabricação do elemento (viga) pré-moldado das lajes nervuradas pré-moldadas (tipo treliçada ou tipo volterrana) é constituído de várias etapas, as quais são descritas à seguir:

\subsubsection{FÔRMAS}

As fôrmas são feitas com chapas de aço laminado, visto que, estas apresentam algumas qualidades como: precisão nas formas e dimensões, facilidade de manuseio, resistência suficiente para suportar a pressão exercida pelo concreto fresco, inexistência de juntas, obtenção de várias peças ao longo do comprimento da fôrma, além da durabilidade do material que possibilita grande número de reaproveitamento das fồmas.

As fôrmas geralmente são confeccionadas em chapas de aço com espessura de $1 / 8^{\prime \prime}(3,2 \mathrm{~mm})$ e seu comprimento pode chegar a até 30 metros, sendo, agrupadas em conjuntos de até 10 unidades, formando leitos de fabricação. As 
figuras 5.1 e 5.2 ilustram algumas fôrmas para as vigas pré-moldadas encontradas comercialmente.

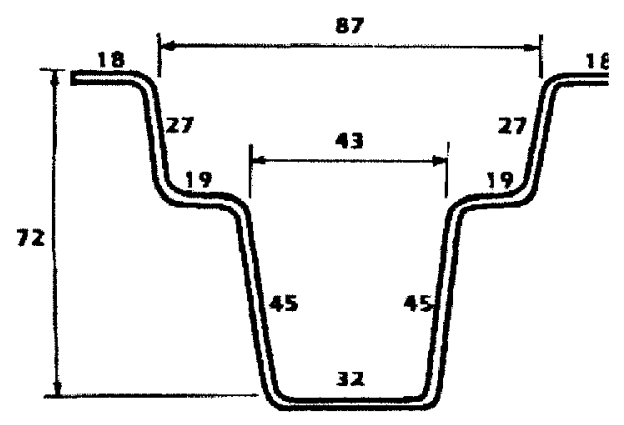

FIGURA 5.1 - FÔRMAS PARA VIGAS DAS LAJES TIPO VOLTERRANA

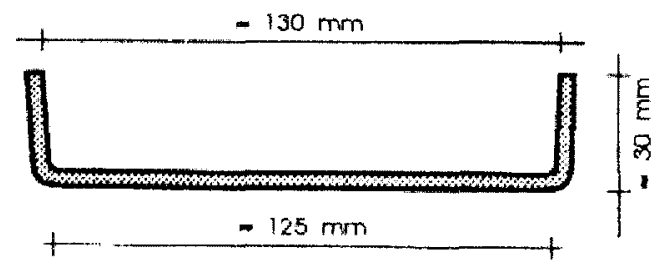

FIGURA 5.2 - FÔRMAS PARA VIGAS COM TRELIÇAS

\subsubsection{LIMPEZA E PREPARAÇÃO DAS FÔRMAS}

As fồrmas devem ser limpas utilizando-se uma espátula de metal, raspando-se as crostas de concreto que ficam após a desfôrma anterior. Para facilitar a desfôrma, após a limpeza aplica-se o desmoldante 


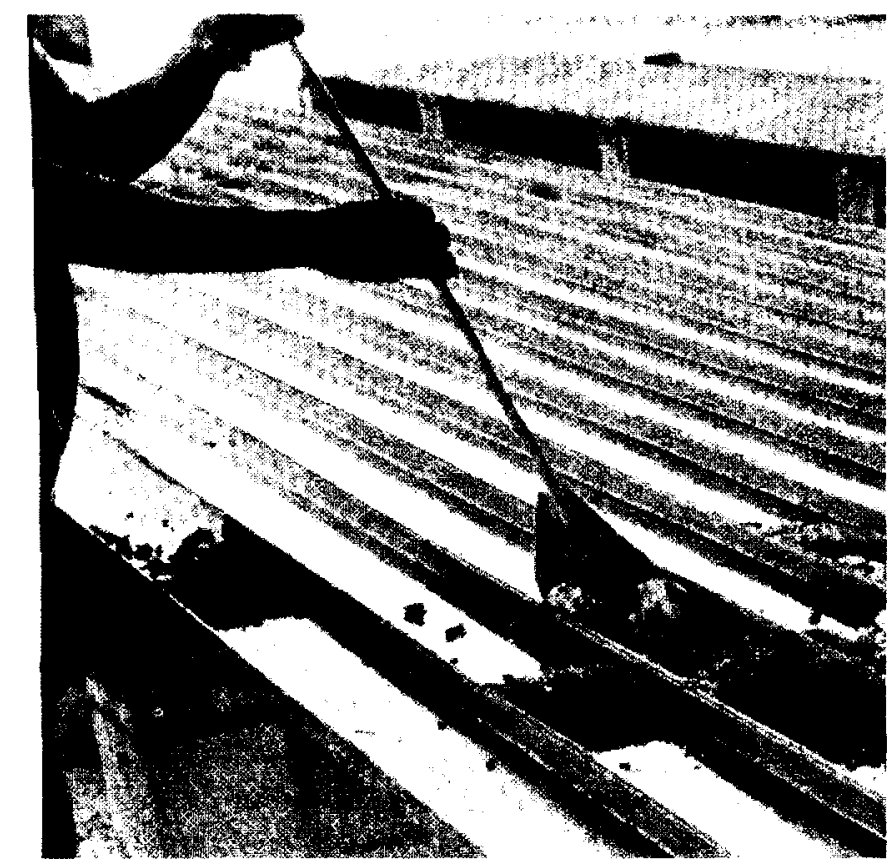

FIGURA 5.3. - LIMPEZA DAS FÔRMAS, LIMA (1991)

\subsubsection{PREPARAÇÃO DO CONCRETO}

O concreto deve ser preparado a fim de obter-se aos 28 dias a resistência característica à compressão estabelecida no projeto da viga, obedecendo as recomendações apresentadas no item 5.1.1.1 deste trabalho. O amassamento do concreto não deve ser manual, sendo feito em betoneiras.

\subsubsection{LANÇAMENTO DO CONCRETO}

O concreto deve ser lançado sobre as fôrmas com o auxílio de uma caçamba içada ou mesmo manualmente e espalhado uniformemente com réguas metálicas. 


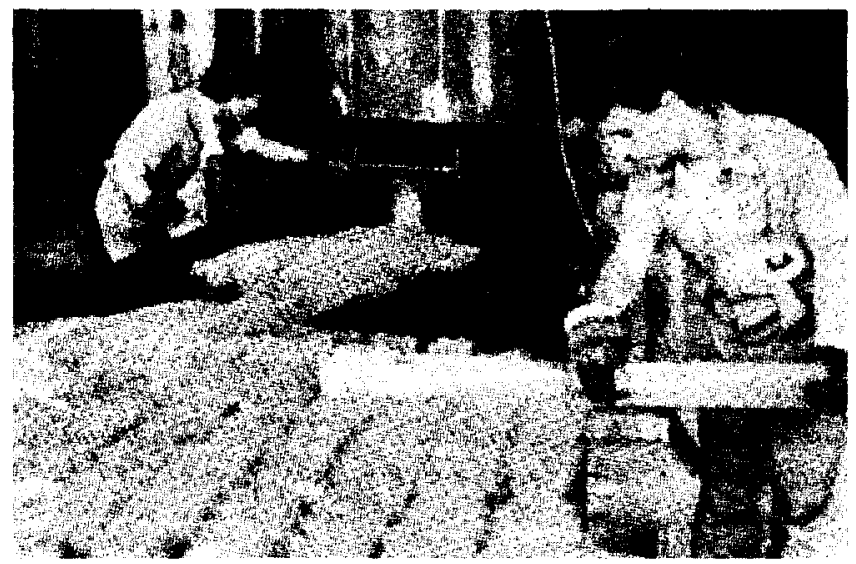

FIGURA 5.4. - LANÇAMENTO DO CONCRETO, LIMA (1991)

\subsection{5. - ARMADURAS}

As armaduras da vigas podem ser colocadas antes ou após o lançamento de parte do concreto dependendo do processo de fabricação adotado

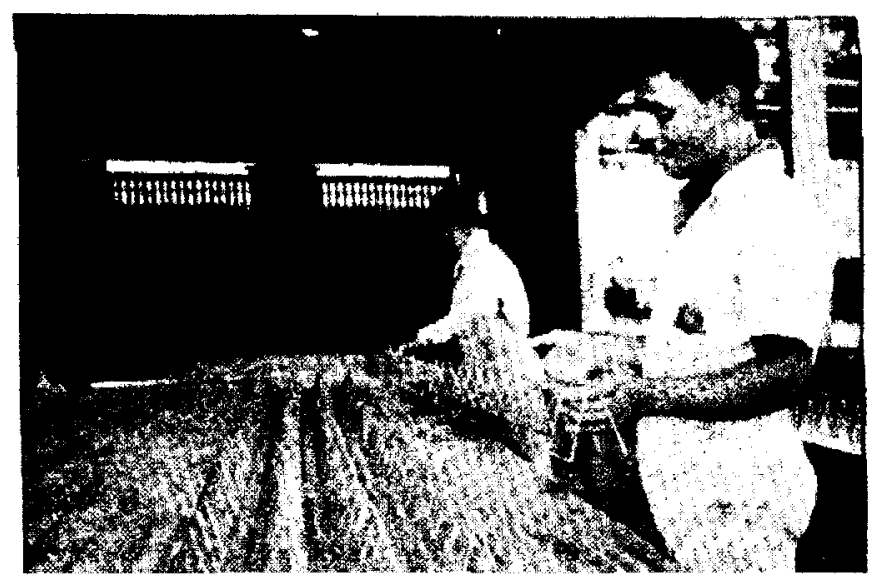

FIGURA 5.5. - COLOCAÇÃO DAS ARMADURAS, LIMA (1991) 


\subsubsection{VIBRAÇÃO}

Durante ou imediatamente após o lançamento do concreto este deve ser adensado, sendo a vibração o processo comumente empregado. Esta tem por finalidade garantir que o concreto preencha toda a fôrma, resultando em uma boa aderência entre concreto e aço, pode-se dizer que a vibração garante ao concreto plasticidade e diminuição de vazios. Nas vigas das lajes com nervuras pré-moldadas a vibração pode ser dispensada, quando o processo de fabricação utiliza concreto muito plástico, caso contrário, normalmente emprega-se mesas vibratórias, com freqüências que permitem curtos períodos de vibração com amplitudes reduzidas, a fim de que não haja desagregação do concreto.

\subsubsection{CURA DO CONCRETO}

A cura do concreto pode ser feita de duas maneiras: normal ou acelerada, sendo que a primeira embora menos eficiente é a mais utilizada, visto que não exige nenhum equipamento especial. A seguir apresenta-se os processos de cura do concreto.

\subsubsection{CURA NORMAL DO CONCRETO}

A cura normal do concreto consiste em proteger a peça concretada até que o concreto atinja o endurecimento satisfatório, para isto mantém- 
se as superficies da peça permanentemente umedecidas, durante o período necessário à hidratação do concreto.

\subsubsection{CURA ACELERADA DO CONCRETO}

Este processo consiste na cura à vapor, a qual tem por objetivo acelerar o endurecimento do concreto através do calor, sem que com isso tenha-se perda de água, o que viria a paralisar a hidratação do concreto. Mesmo eficiente a cura à vapor não é muito difundida, devido principalmente, à necessidade de equipamentos como câmara de vapor ou manta térmica, e de mão-de-obra especializada.

Na cura à vapor recomenda-se o emprego do cimento ARI com escórias e alguns cuidados devem ser tomados:

a) incremento máximo de temperatura: $20^{\circ} \mathrm{C} /$ hora;

b) temperatura máxima no elemento submetido a tratamento à vapor sob pressão atmosférica: $70^{\circ} \mathrm{C}$;

c) decréscimo de temperatura no resfriamento de no máximo $30^{\circ} /$ hora.

\subsubsection{CODIFICAÇÃO}

Antes de iniciar-se a desfôrma, as peças devem ser identificadas, recebendo etiquetas com códigos de fabricante. A codificação das vigas é essencial para a montagem da laje, visto que, no projeto de execução fornecido pelo fabricante, todo o posicionamento das vigas é definido com base na codificação das mesmas. 


\subsubsection{DESFÔRMA E ESTOCAGEM DAS VIGAS}

A desforma e estocagem das vigas podem ser feitas manualmente ou com o auxílio de pontes rolantes, dependendo das dimensões das peças, do porte e produtividade da empresa. A estocagem deve ser feita de maneira cuidadosa a fim de evitar-se que as peças danifiquem-se, sendo permitido o empilhamento, intercalando-se dispositivos de apoio, evitando-se assim o contato das superficies de concreto de duas peças superpostas.

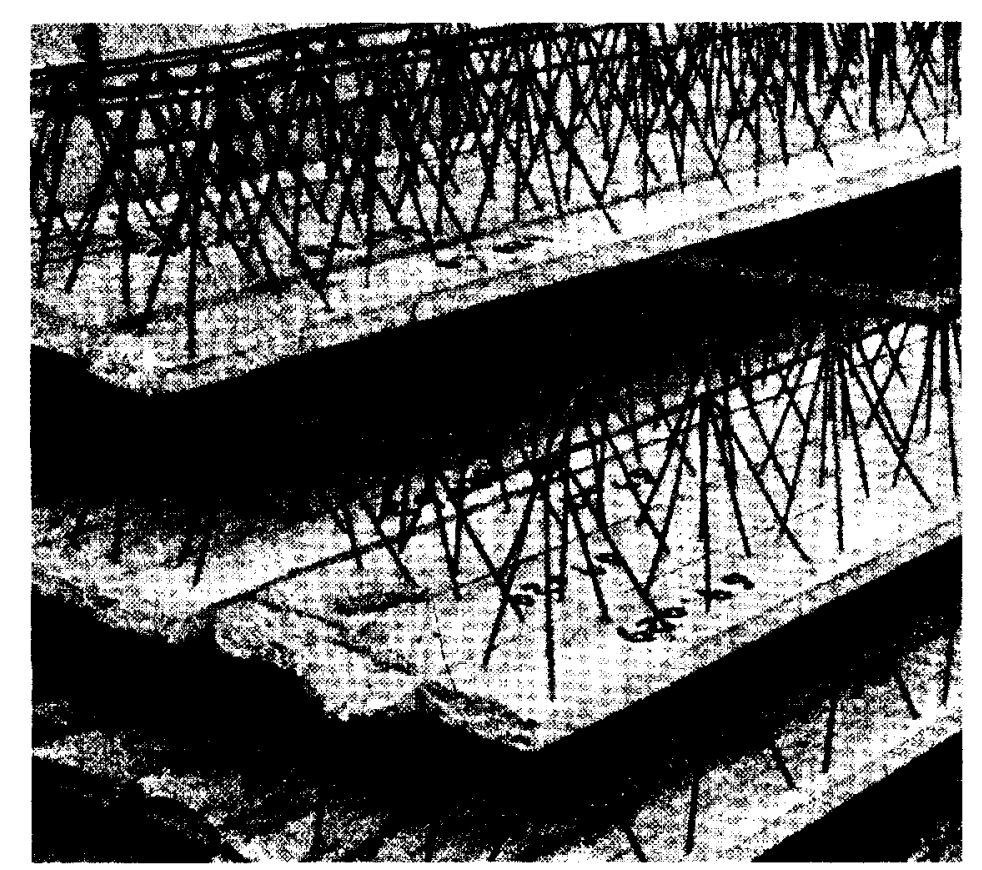

FIGURA 5.6. - ESTOCAGEM DAS VIGAS, LIMA (1991)

\subsubsection{TRANSPORTE DAS VIGAS}

O transporte das vigas deve ser realizado em veículos apropriados às dimensões e a massa das peças, também deve-se observar as recomendações quanto ao apoio das peças conforme comentou-se no item anterior. 


\subsection{TÉCNICAS DE EXECUÇÃO}

À seguir descreve-se sucintamente os processos envolvidos na execução das lajes nervuradas pré-moldadas.

\subsubsection{PLANTA DE EXECUÇÃO}

Antes de iniciar-se a execução de um laje nervurada prémoldada deve-se conhecer a planta de execução fornecida pelo fabricante da laje. Esta planta tem por objetivo fornecer a quem executa a laje, todas as informações pertinentes à execução, como: posicionamento das vigas, quantidade de lajotas, armaduras adicionais necessárias, espessura e resistência características à compressão do concreto aos 28 dias, da capa (mesa), entre outros, para permitir a correta execução de parte da nervura e da mesa moldada no local.
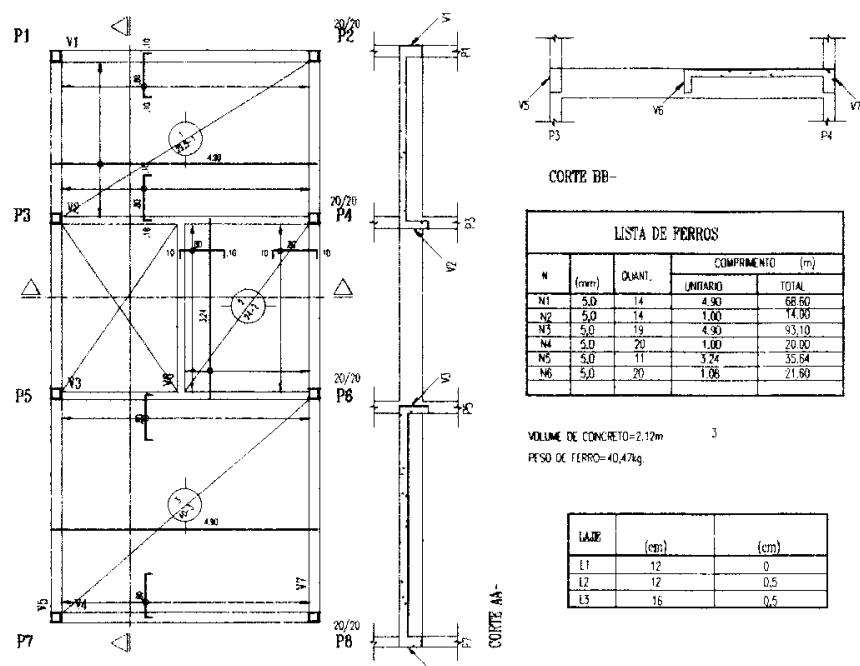

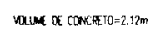

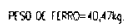

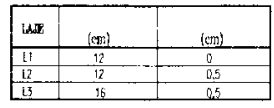

FIGURA 5.7 - PLANTA DE EXECUÇÃO 


\subsubsection{ESCORAMENTO DA LAJE}

Todos os vãos da laje devem ser escorados com tábuas colocadas em espelhos, exceto nos escoramentos destinados às nervuras de travamento, onde devem ser colocados horizontalmente, isto se não for fornecida pelo fabricante da laje a fôrma própria (cachimbo). $\mathrm{O}$ escoramento tem por finalidade dar sustentação a laje enquanto esta ainda não possui resistência suficiente para absorver os esforços solicitantes provenientes de seu peso próprio, portanto deve estar apoiado sobre base firme, bem contraventada e com altura necessária para possibilitar a contra-flecha da laje, quando necessária. Além disso, o escoramento deve ser posicionado de modo a diminuir os vãos das vigas para que estas, antes da concretagem, resistam às ações oriundas da montagem e concretagem.

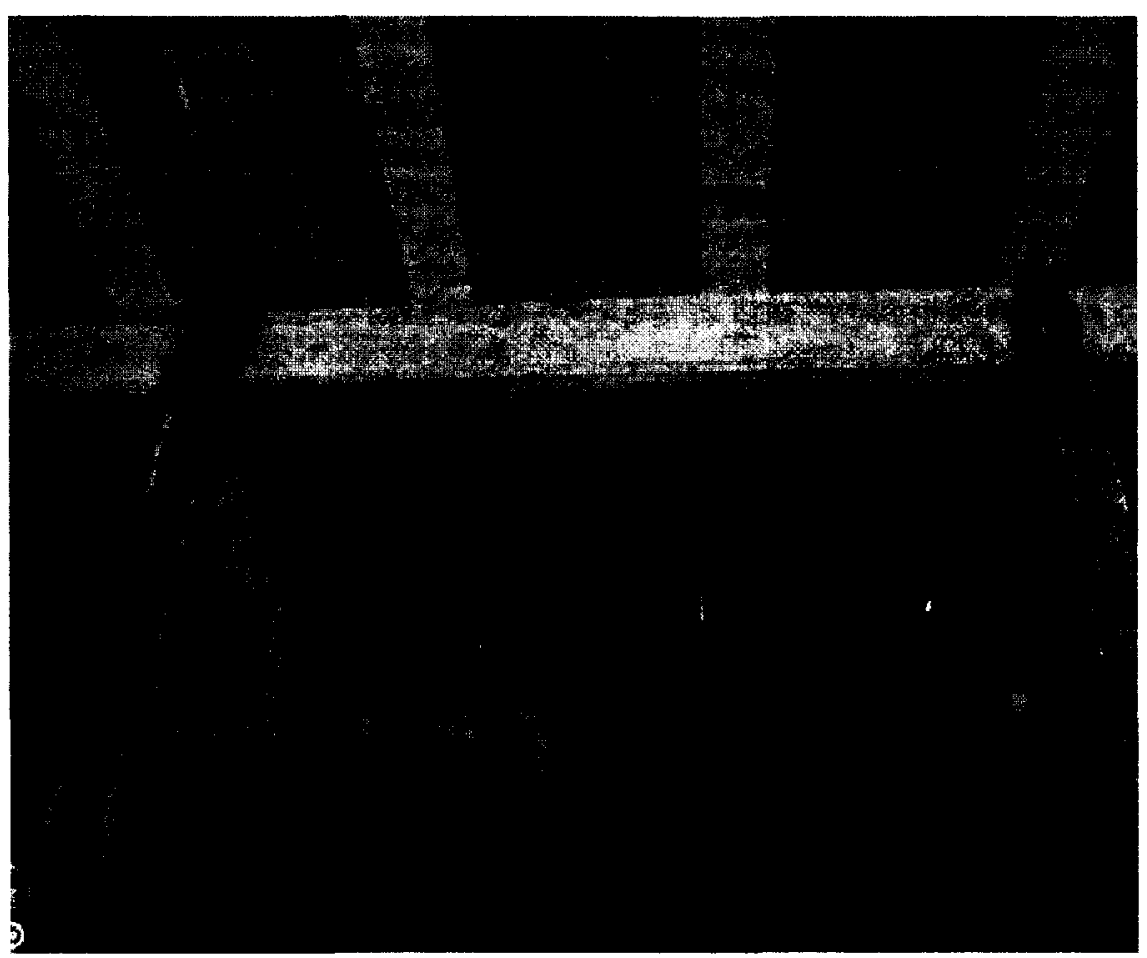

FIGURA 5.8. - ESCORAMENTO DA LAJE 


\subsubsection{COLOCAÇÃO dAS VIGAS}

As vigas das lajes nervuradas pré-moldadas devem ser colocadas empregando-se uma lajota em cada extremidade, para espaçá-las corretamente. A primeira carreira de lajotas deve ser apoiada de um lado sobre a parede ou a fôrma (tábua) e de outro sobre a primeira viga.

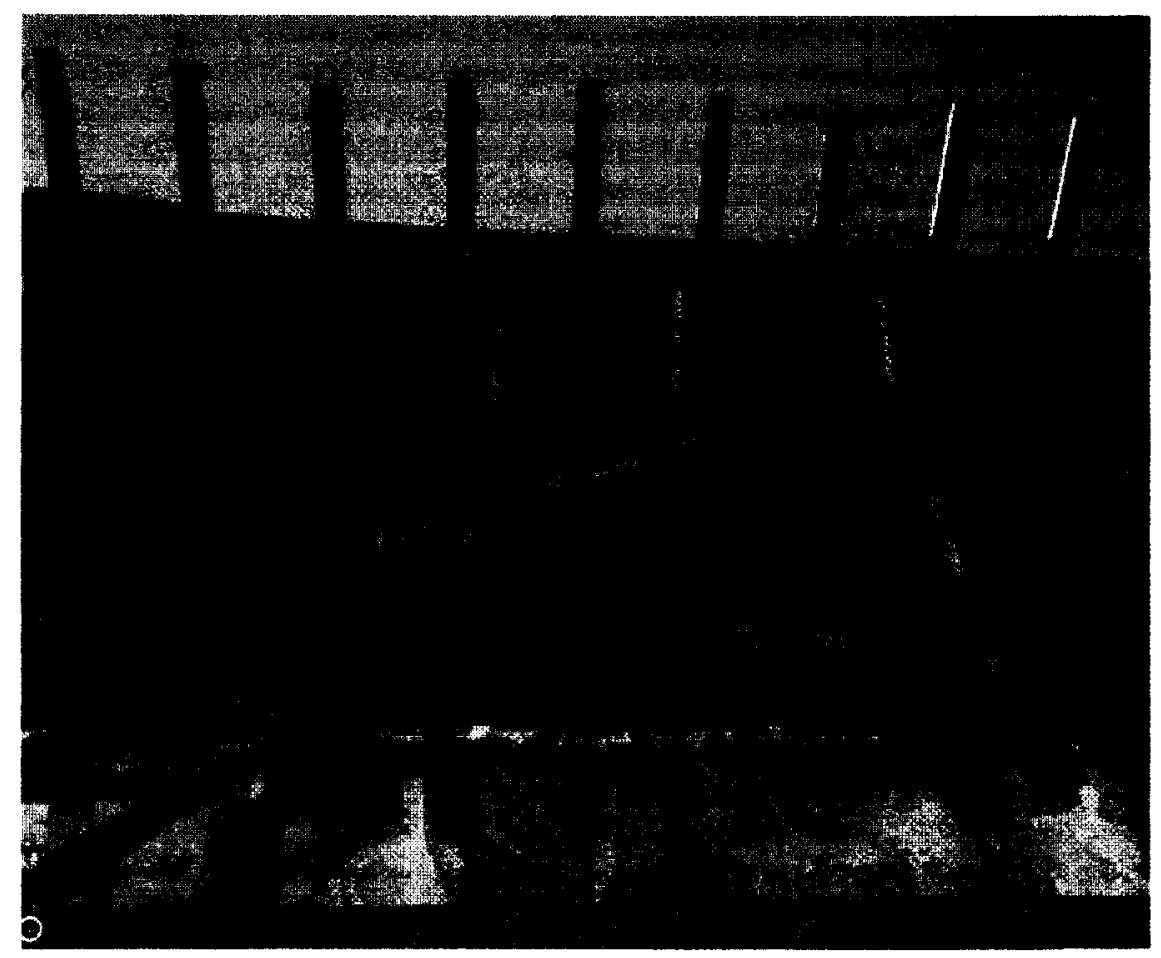

FIGURA 5.9 - COLOCAÇÃO DAS VIGAS

Para as lajes com nervuras em duas direções deve-se observar o alinhamento dos furos nos quais passarão as vigas. Deve-se colocar em correspondência aos furos, as canaletas, entre as canaletas colocar as lajotas; passamse nos furos as barras da armadura necessárias para as nervuras perpendicular às vigas pré-moldadas, conforme indicação do projeto fornecido pelo fabricante. 


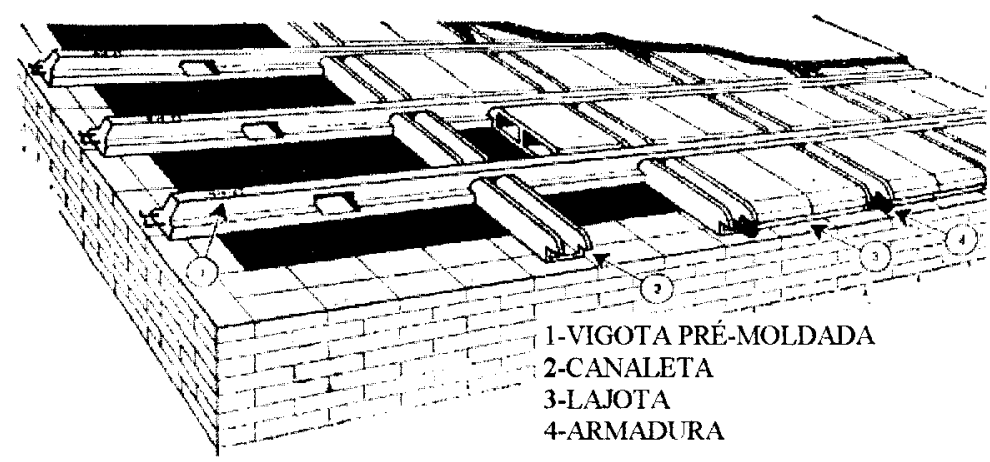

FIGURA 5.10 - LAJE COM NERVURAS NAS DUAS DIREÇÕES, BORGES (1972)

\subsubsection{COLOCAÇÃO dAS LAJOTAS}

As lajotas devem ser colocadas entre as vigas, cuidados devem ser tomados para que não hajam folgas, e o esquadro seja mantido. Nas nervuras de travamento e extremidades devem ser colocadas lajotas a fim de evitar consumo desnecessário de concreto. 


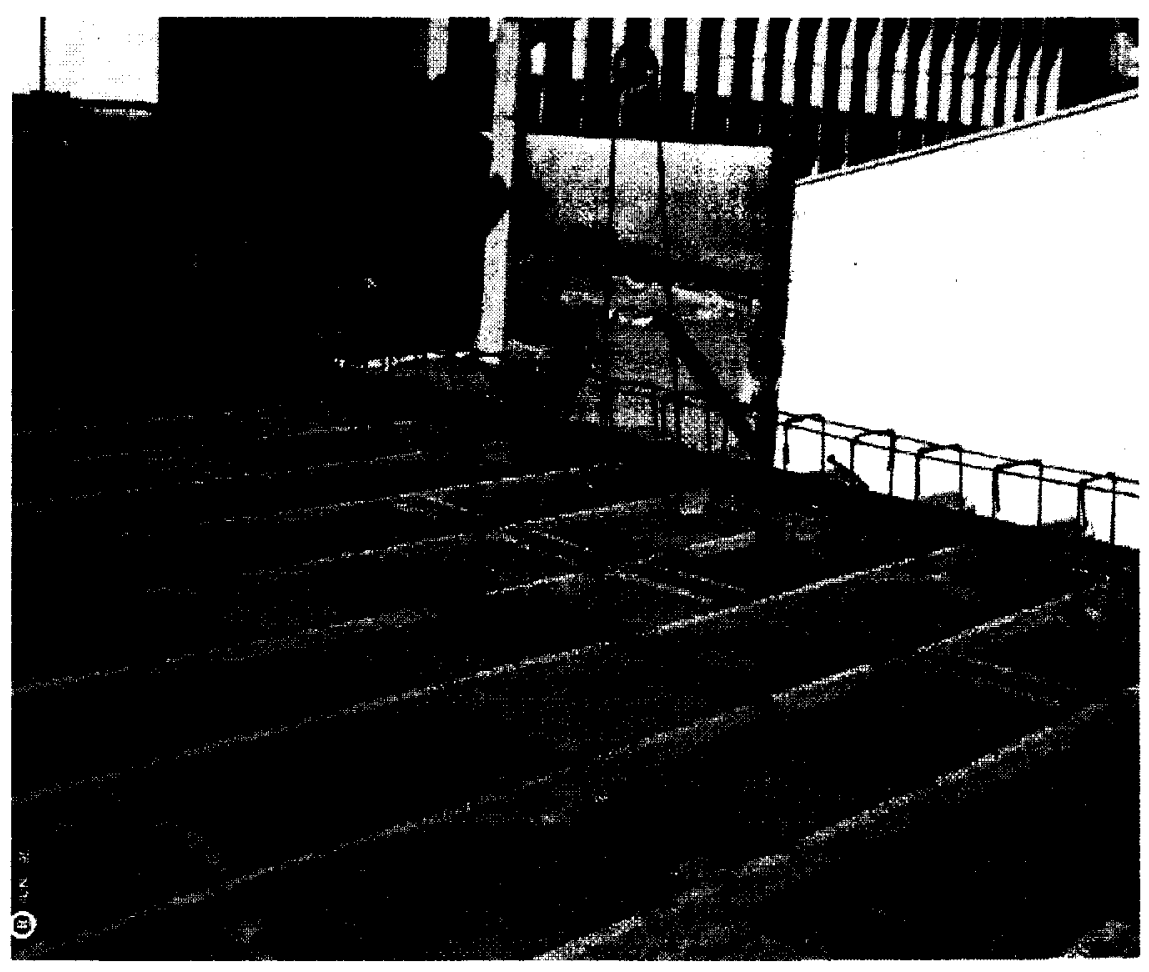

FIGURA 5.11 - COLOCAÇÃO DAS LAJOTAS

\subsubsection{DISTRIBUIÇÃO DA ARMADURA POSICIONADA JUNTO À FACE SUPERIOR}

As barras de armadura devem ser distribuídas conforme o projeto fornecido pelo fabricante, devem ser apoiados e amarrados sobre as barras de distribuição, que são colocados no sentido transversal ao das vigas. A armadura não deve entrar nas juntas entre as vigas, mas no meio da espessura da capa (mesa). 


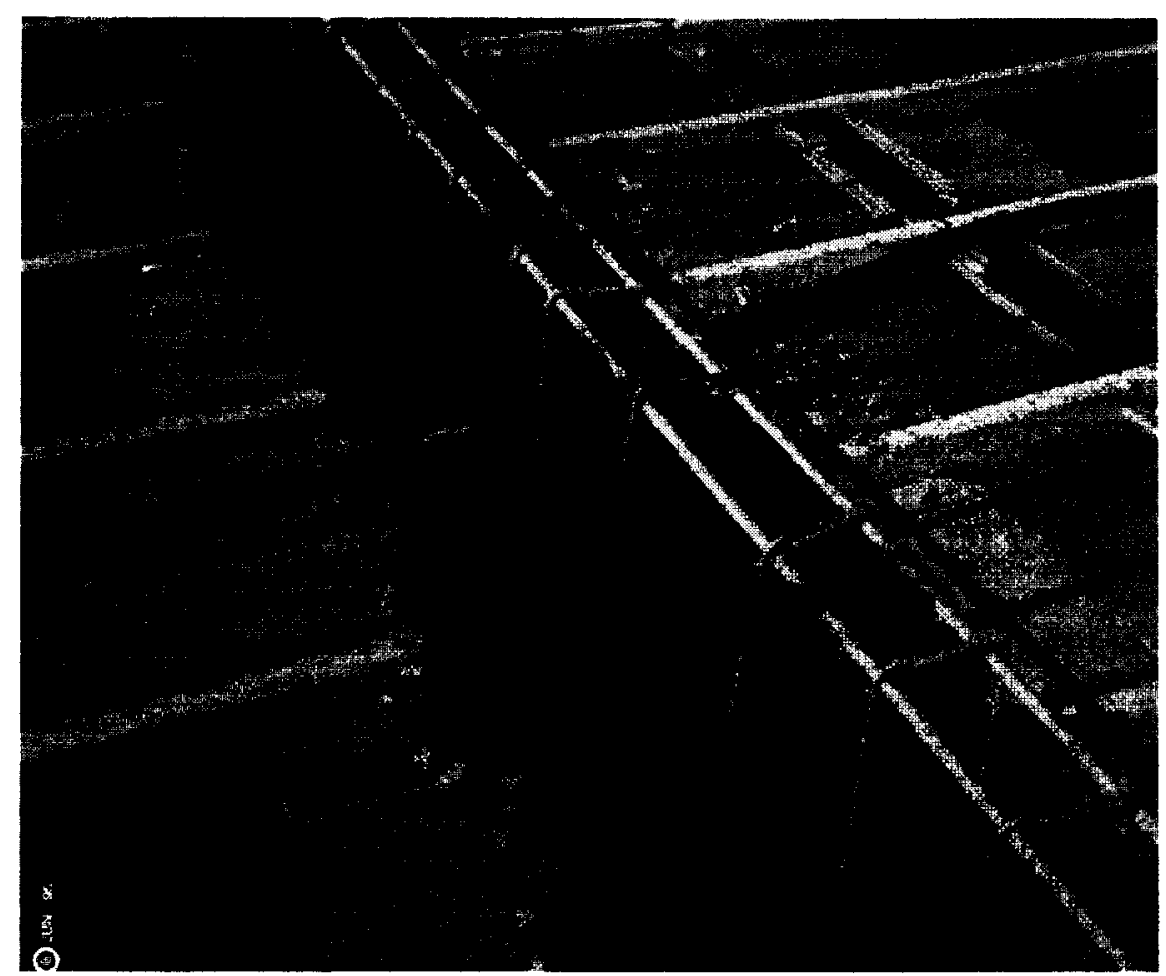

FIGURA 5.12 - DISTRIBUIÇÃO DA ARMADURA POSICIONADA JUNTO À FACE SUPERIOR DA MESA

\subsubsection{CONCRETAGEM DA CAPA OU MESA}

Antes de lançar-se o concreto sobre a laje deve-se molhar a superficie a ser concretada até sua saturação. Para o concreto da mesa deve-se seguir a recomendação da resistência característica $\left(f_{c k}\right)$ contida no projeto do fabricante, geralmente entre $15 \mathrm{MPa}$ e $20 \mathrm{MPa}$.

Para caminhar-se sobre a laje durante o lançamento do concreto, deve-se fazê-lo sobre tábuas apoiadas nas vigas. Durante os três primeiros dias após o lançamento do concreto, a superfície da capa (mesa) deve ser umedecida periodicamente.

A retirada do escoramento não deve ser feita antes de passados 18 dias do lançamento do concreto. Além disso, a retirada dos pontaletes deve ser 
feita do centro para as extremidades, a fim de não introduzir-se na laje esforços solicitantes (momentos fletores que provoquem tração na face superior da laje), para os quais estas não foram dimensionadas.

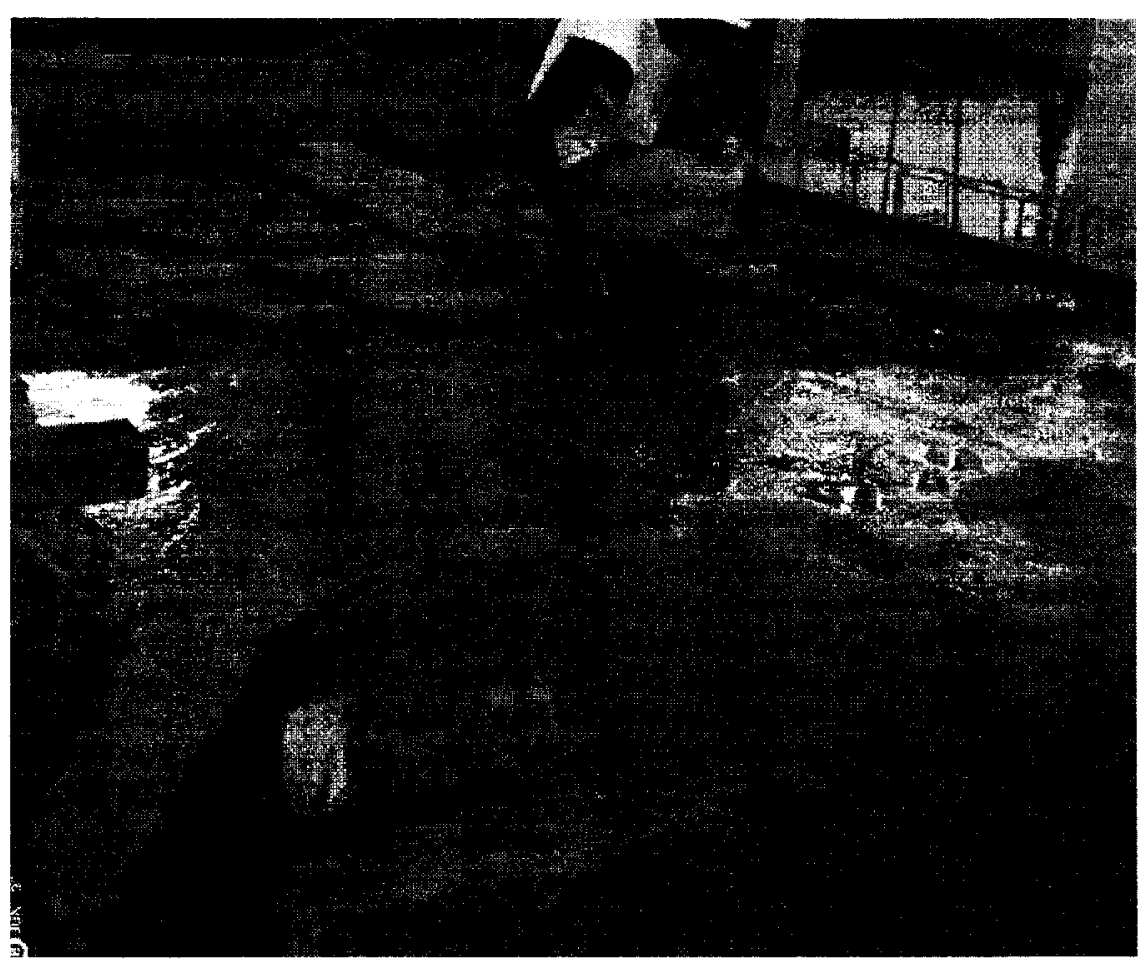

FIGURA 5.13 - CONCRETAGEM DA LAJE

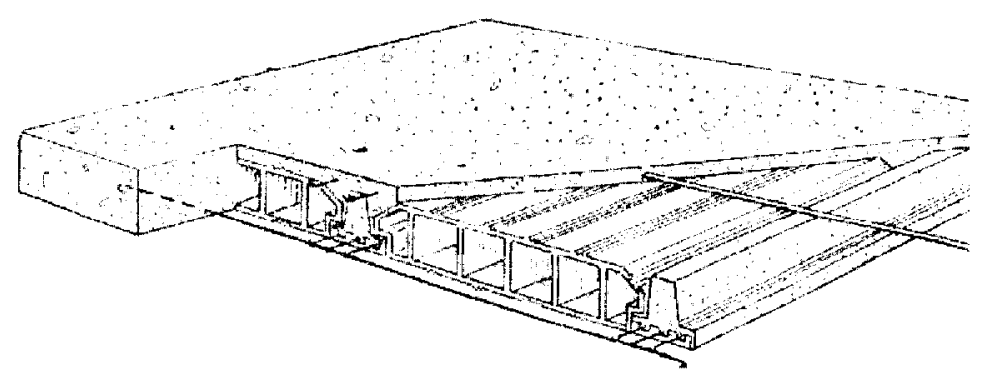

FIGURA 5.14 - CORTE DA LAJE ACABADA, BORGES (1972) 


\subsection{PRESENÇA DE FISSURAS NAS LAJES NERVURAdAS PRÉ- MOLDADAS}

As fissuras podem ser resultado de erros de dimensionamento da laje ou da estrutura, da má execução ou do uso indevido. Entre estas destacam-se as fissuras por falta de travamento transversal, por falta de armaduras posicionada junto à face superior na região dos apoios, deformação excessiva da laje, armadura posicionada junto à face inferior insuficiente, má aderência entre os materiais (lajotas e viga com o concreto lançado na obra). Outro fato importante, que pode prejudicar o bom desempenho das lajes consistem na utilização da laje para ações maiores que aquela para a qual esta foi projetada.

Além das condições expostas, muitos outros fatores podem interferir e prejudicar o bom desempenho das lajes nervuradas pré-moldadas, fatores que não estão ligados diretamente às lajes, como por exemplo: fundações mau projetadas e/ou mau executadas, vigas pouco rígidas, entre outros fatores.

\subsection{APRESENTAÇÃO DO PROJETO}

Um aspecto importante não só para as lajes nervuradas prémoldadas, mas para qualquer elemento de concreto armado é o detalhamento do projeto, ou seja, como o engenheiro projetista passa as informações para a execução de uma estrutura. Nas lajes nervuradas pré-moldadas cabe ao fabricante enviar à obra juntamente com os elementos que compõem a laje, uma planta (projeto) de execução, com as informações necessárias à execução das mesmas.

A planta de execução deve conter uma planta de forma com as lajes, cortes das lajes, detalhes necessários à execução, recomendações quanto ao escoramento, resistência característica do concreto, espessura da mesa ou capa, tabela 
com toda as armaduras necessárias e quantidades. Para interpretar-se a planta de execução deve-se conhecer a simbologia apresentada na figura 5.15.

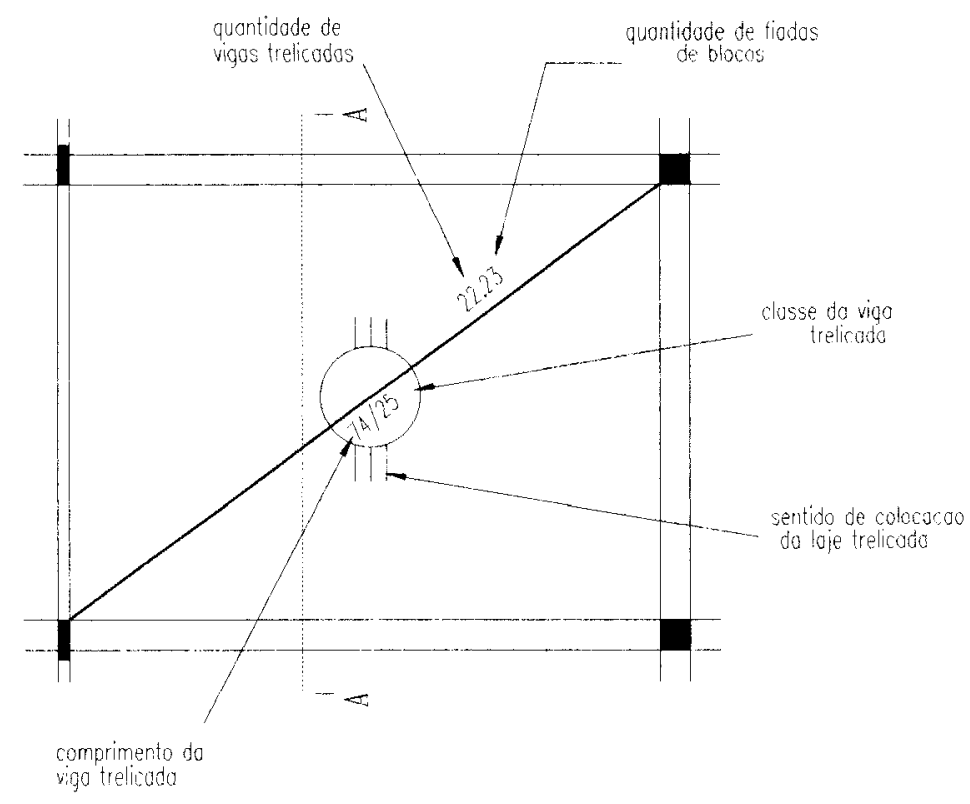

FIGURA 5.15 - SIMBOLOGIA EMPREGADA NA PLANTA DE EXECUÇÃO DAS LAJES NERVURADAS PRÉ-MOLDADAS

\subsection{OBSERVAÇÕES GERAIS QUANTO ÀS LAJES NERVURADAS PRÉ- MOLDADAS}

\subsubsection{SOBRECARGA DE UTILIZAÇÃO}

O conceito da sobrecarga de utilização para as lajes nervuradas pré-moldadas é entendido muitas vezes de forma errada, inclusive no meio técnico 
para as lajes com nervuras pré-moldadas. Entende-se por sobrecarga de utilização, como sendo a ação acidental somada ao revestimento da laje em questão.

\subsubsection{ALTURA DA MESA}

A altura da mesa ou capa da laje nervurada pré-moldada é muito questionada, a Norma Brasileira NB-1/78 estabelece que esta não deve ser menor que a/ 15 , onde a é a distância livre entre as nervuras, sempre maior que $4 \mathrm{~cm}$. Este número muitas vezes não é obedecido pelos fabricantes das lajes, os quais utilizam as recomendações da norma de lajes mistas (NB-4/78), visto que esta permite uma mesa de $3 \mathrm{~cm}$ de altura. Neste trabalho pesquisou-se a origem dos números apresentados pela NB-1/78 conforme apresenta-se abaixo. Este trabalho aborda no Capítulo 1 a diferença entre laje nervurada e laje mista, concluindo-se finalmente que, a laje pré-moldada não deve ser qualificada como laje mista e dependendo da sobrecarga de utilização a mesa pode possuir altura mínima de $3 \mathrm{~cm}$.

\subsubsection{VINCULAÇÃO}

A vinculação das lajes nervuradas pré-moldadas pode ser considerada como apoio, engaste elástico ou engaste. Usualmente opta-se por lajes apoiadas, visto que, a situação de engaste faz com que apareçam tensões de compressão na parte inferior da laje, estas muitas vezes não podem ser resistidas pela seção da laje, uma vez que a área de concreto resistente é insuficiente. Apresenta-se à seguir alguns detalhes das lajes nervuradas pré-moldadas, a fim de ilustrar algumas situações. 

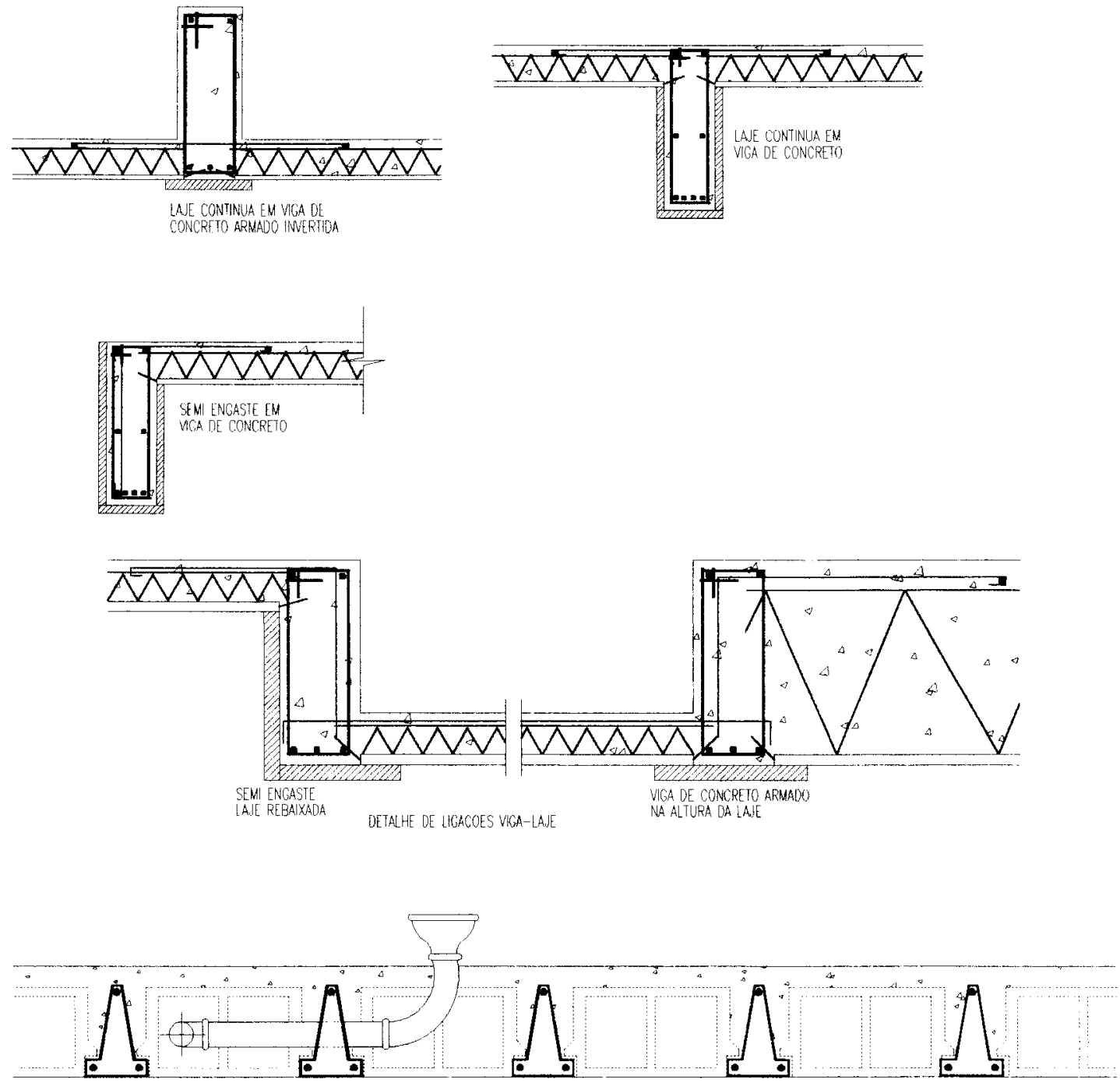

DETALHE Da COLOCACAO DE TUBULACOES NA LAJE

FIGURA 5.16 - ALGUNS DETALHES DAS LAJES NERVURADAS PRÉMOLDADAS

\subsubsection{VERIFICAÇÃO DA MESA DE CONCRETO}

A Norma Brasileira NB-1/78 dispensa a verificação e colocação de armadura na mesa, quando a distância livre entre nervuras (a) for menor ou igual à 
$50 \mathrm{~cm}$, a altura da mesa $\left(h_{f}\right)$ for maior ou igual a $4 \mathrm{~cm}$ e não se tenha ações concentradas entre as nervuras, caso em que se enquadram as lajes nervuradas prémoldadas. Em face à esta recomendação, da NB-1/78 partiu-se para o equacionamento da verificação da mesa, admitindo-se o concreto simples, sem armadura, no Estádio $I_{\mathrm{A}}$. A seguir apresenta-se esta verificação para:

a) Altura da mesa $h_{f}=3 \mathrm{~cm}$;

b) Altura da mesa $h_{f}=4 \mathrm{~cm}$.

a) Altura da mesa $h_{f}=3 \mathrm{~cm}$;

$$
\text { Adota-se: } \quad \begin{array}{ll}
a & =50 \mathrm{~cm} \\
& b_{w}=4 \mathrm{~cm} \\
& h=11 \mathrm{~cm} \\
& h_{\mathrm{f}}=3 \mathrm{~cm}
\end{array}
$$

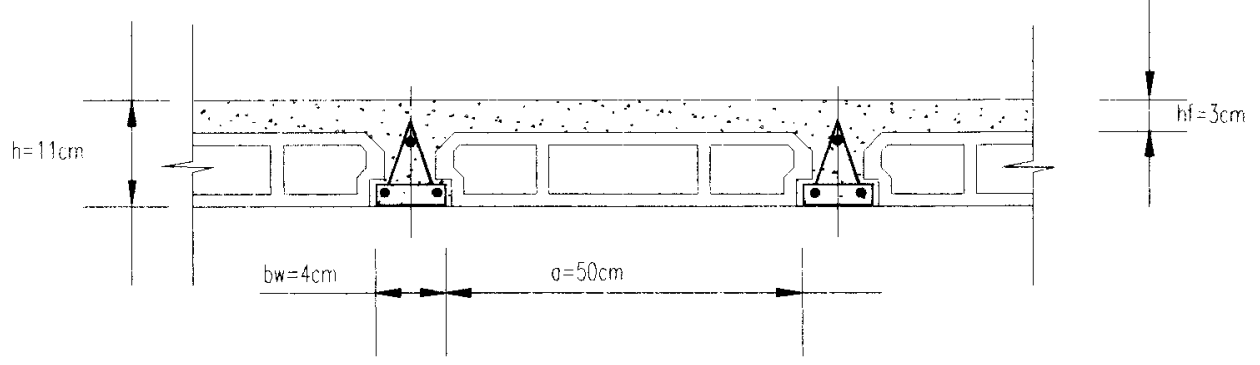

FIGURA 5.17 - DIMENSÕES ADOTADAS

As ações atuantes à serem consideradas são:

Peso próprio da mesa $=0,03 \times 25=0,75 \mathrm{kN} / \mathrm{m}^{2}$

Revestimento $=1,00 \mathrm{kN} / \mathrm{m}^{2}$

Total das ações permanentes $\mathrm{g}=1,75 \mathrm{kN} / \mathrm{m}^{2}$

Sobrecarga de utilização $=2,00 \mathrm{kN} / \mathrm{m}^{2}$

$$
\begin{aligned}
& F_{d, \dot{u} t i l}=\sum_{i=1}^{m} F_{G i, k}+F_{Q i, k}+\sum_{j=2}^{n} \psi_{2 j} F_{Q j, k} \\
& \mathrm{~F}_{\mathrm{d}, \text { útil }}=0,75+1,00+2,00=3,75 \mathrm{kN} / \mathrm{m}^{2}
\end{aligned}
$$

Obtém-se, então, os seguintes esforços solicitantes: 


$$
\begin{aligned}
& M_{k}=\left\{3,75 x \frac{0,54^{2}}{8}\right\} 00=13,67 \mathrm{kN} . \mathrm{cm} / \mathrm{m} \\
& V_{k}=\left\{3,75 x \frac{0,54}{2}\right)=1,02 \mathrm{kN} / \mathrm{m}
\end{aligned}
$$

\section{Verificação da flexão - Estádio $I_{A}$}
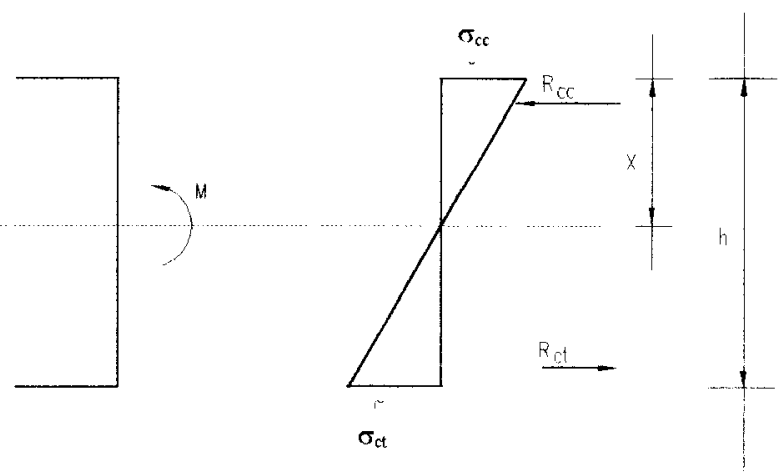

FIGURA 5.18 - FLEXÃO (ESTÁDIO $\mathrm{I}_{\mathrm{A}}$ )

Do equilibrio de forças:

$$
\mathrm{N}=\mathrm{R}_{\mathrm{cc}}-\mathrm{R}_{\mathrm{ct}}=0
$$

Do equilíbrio de momentos:

$$
\mathrm{M}=\mathrm{R}_{\mathrm{cc}} \frac{2 \mathrm{x}}{3}+\mathrm{R}_{\mathrm{ct}} \frac{2(\mathrm{~h}-\mathrm{x})}{3}
$$

Pelo diagrama de tensões:

$$
\frac{\sigma_{c c}}{x}=\frac{\sigma_{c t}}{h-x}
$$

Determinação da posição da linha neutra (x)

Momento estático em relação à linha neutra $=0$

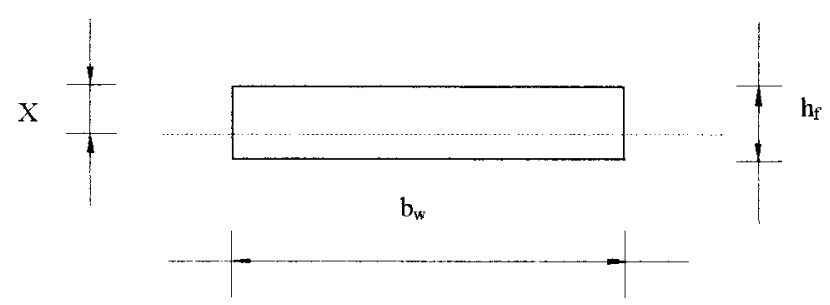

FIGURA 5.19 - SEÇÃO A SER CONSIDERADA 
$50 \mathrm{x}^{2}-50(3-\mathrm{x})^{2}=0$

Obtém-se: $x=1,5 \mathrm{~cm}$

Pelo diagrama de tensões: $\sigma_{\mathrm{cc}}=\sigma_{\mathrm{ct}}$

Pode-se adotar a tensão máxima resistente $\sigma_{\mathrm{ct}}=0,7 \mathrm{f}_{\mathrm{ctm}}$ (estado limite de formação de fissuras)

$$
\begin{aligned}
& \text { Com } f_{c t m}=0,30 f_{c k}^{2 / 3} \text { (em MPa) } \\
& \mathrm{f}_{\mathrm{ctm}}=0,30(15)^{2 / 3}=1,825 \mathrm{MPa} \\
& \sigma_{\mathrm{ct}}=0,70.1,825=1,277 \mathrm{MPa}
\end{aligned}
$$

O momento de inércia ideal é dado por:

$$
\begin{aligned}
& I_{\mathrm{I}}=\frac{b_{w} x^{3}}{3}+\frac{b_{w}(h-x)^{3}}{3} \\
& I_{\mathrm{I}}=\frac{100_{x}(1,5)^{3}}{3}+\frac{100_{x}(3-15)^{3}}{3}=225 \mathrm{~cm}^{4}
\end{aligned}
$$

A tensão atuante é dada por:

$$
\begin{aligned}
& \sigma_{c t}=\frac{M}{I_{\mathrm{I}}}(h-x) \\
& \sigma_{c t}=\frac{13,67}{225} \times(3-1,5)=0,09 \mathrm{kN} / \mathrm{cm}^{2}=0,911 \mathrm{MPa}
\end{aligned}
$$

Conclui-se que a tensão atuante $0,911 \mathrm{MPa}$ é menor que a tensão resistente $1,277 \mathrm{MPa}$, logo a seção resiste ao esforço de flexão.

\section{Verificação quanto ao cisalhamento.}

A tensão atuante $\tau_{\mathrm{wd}}$ é dada pela expressão:

$$
\tau_{\mathrm{wd}}=\mathrm{V}_{\mathrm{d}} / \mathrm{b}_{\mathrm{w}} \times \mathrm{d}=1,4 \times 1,02 / 100 \times 3=4,73 \times 10^{-3} \mathrm{kN} / \mathrm{cm}^{2}=0,047 \mathrm{MPa}
$$

Com a altura $h \leq 15 \mathrm{~cm}$, tem-se:

$$
\begin{aligned}
& \tau_{\mathrm{wu}}=0,50 \times 0,30 \mathrm{f}_{\mathrm{cd}}=1,607 \mathrm{MPa} \mathrm{e} \\
& \tau_{w u 1}=\psi_{4} \sqrt{f_{c k}}
\end{aligned}
$$

$$
\begin{gathered}
\operatorname{Com} \psi_{4}=0,12 \frac{\alpha \mathrm{k}}{1-3 \mathrm{~d} / \mathrm{L}}, \\
\mathrm{k}=1,6-\mathrm{d} \geq 1, \log \mathrm{k}=1,6-0,03=1,570 \\
\alpha=1+50 \rho_{1} \leq 1,5, \text { como } \rho_{1}=0\left(\mathrm{~A}_{\mathrm{s}}=0\right) \text {, então: } \alpha=1
\end{gathered}
$$




$$
\begin{aligned}
& \psi_{4}=0,12 x \frac{1.1,570}{1-3(0,03 / 0,54)}=0,226 \\
& \tau_{w u 1}=0,226 \sqrt{15}=0,876 \mathrm{MPa}
\end{aligned}
$$

Como $\tau_{\text {wd }}(0,047)<\tau_{\text {wu1 }}(0,876)$, a seção resiste às tensões oriundas do cisalhamento, sem a necessidade de colocação de armadura transversal (estribos).

b) Altura da mesa $h_{f}=4 \mathrm{~cm}$;

$$
\text { Adota-se: } \quad \begin{array}{ll}
a=50 \mathrm{~cm} \\
& \mathrm{~b}_{\mathrm{w}}=4 \mathrm{~cm} \\
& \mathrm{~h}=12 \mathrm{~cm} \\
& \mathrm{~h}_{\mathrm{f}}=4 \mathrm{~cm}
\end{array}
$$

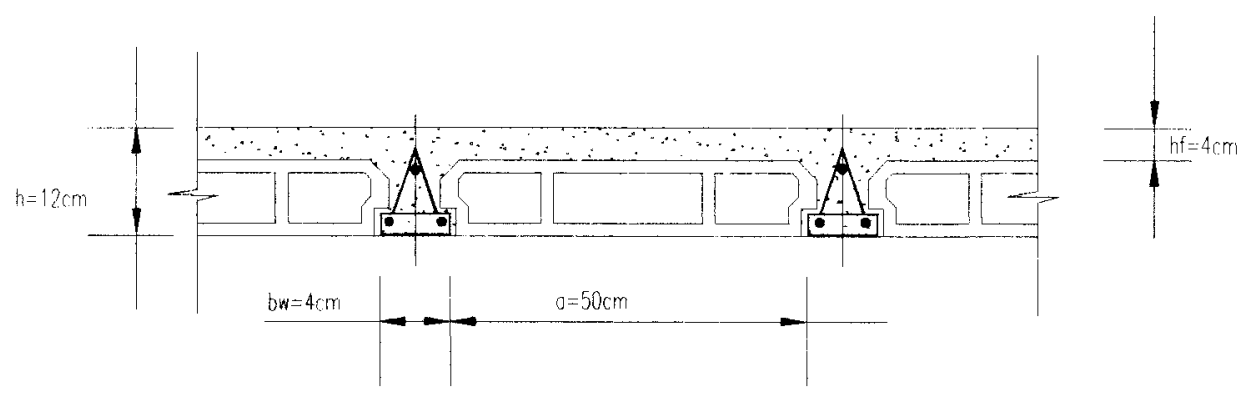

FIGURA 5.20 - DIMENSÕES ADOTADAS

As ações atuantes à serem consideradas são:

Peso próprio da mesa $=0,04 \times 25=1,00 \mathrm{kN} / \mathrm{m}^{2}$

Revestimento $=1,00 \mathrm{kN} / \mathrm{m}^{2}$

Total das ações permanentes $=2,00 \mathrm{kN} / \mathrm{m}^{2}$

Sobrecarga de utilização $=2,00 \mathrm{kN} / \mathrm{m}^{2}$

$F_{\mathrm{d}, \text { util }}=1,00+1,00+2,00=4,00 \mathrm{kN} / \mathrm{m}^{2}$

Obtém-se, então, os seguintes esforços solicitantes: 


$$
\begin{aligned}
& M_{k}=\left(4 \frac{0,54^{2}}{8}\right) 100=14,58 \mathrm{kNcm} / \mathrm{m} \\
& \begin{aligned}
& V_{k}=\left\{4_{x} \frac{0,54}{2}\right)=1,08 \mathrm{kN} / \mathrm{m} \\
& \text { Verificação da flexão - Estádio } \mathrm{I}_{\mathrm{A}} \\
& \text { Determinação da posição da linha neutra (x) } \\
& \mathrm{x}=2,0 \mathrm{~cm}
\end{aligned}
\end{aligned}
$$

A tensão de tração máxima resistente no concreto é de $\sigma_{\mathrm{ct}}=1,277 \mathrm{MPa}$, conforme já obtido no caso a).

$\mathrm{O}$ momento de inércia ideal é de $533,33 \mathrm{~cm}^{4}$ e a tensão de tração atuante no concreto é $\sigma_{\mathrm{ct}}=0,547 \mathrm{MPa}$.

Pode-se, então, concluir que a tensão atuante $(0,547)$ é menor que a tensão resistente $(1,277 \mathrm{MPa})$, a seção resiste ao esforço de flexão.

\section{Verificação quanto ao cisalhamento.}

A tensão atuante $\tau_{\text {wd }}$ é de $0,038 \mathrm{MPa}$, enquanto que a tensão $\tau_{\text {wul }}$ é $0,932 \mathrm{MPa}$. Logo como $\tau_{\mathrm{wd}}<\tau_{\mathrm{wu} 1}$ a seção resiste às tensões oriundas do cisalhamento, sem a necessidade da colocação da armadura.

A seguir apresenta-se dois quadros, onde varia-se a sobrecarga de utilização para lajes com altura da mesa de $3 \mathrm{~cm}$ e $4 \mathrm{~cm}$, respectivamente e comparou-se as tensões atuantes e resistentes. As tensões estão em $\mathrm{MPa}$ e as sobrecargas em $\mathrm{kN} / \mathrm{m}^{2}$.

TABELA 5.1 - VERIFICAÇÃO DAS TENSÕES ORIUNDAS DA FLEXÃO E DO CISALHAMENTO NA MESA DAS LAJES NERVURADAS, ALTURA DA MESA $\left(h_{f}\right)$ DE 3 CM

\begin{tabular}{|c|c|c|c|c|}
\hline \multirow{2}{*}{$\begin{array}{c}\text { Sobrecarga } \\
\text { de utilização }\end{array}$} & \multicolumn{2}{|c|}{ Flexão } & \multicolumn{2}{c|}{ Cisalhamento } \\
\cline { 2 - 5 } & Atuante & Resistente & Atuante & Resistente \\
\hline 2,50 & 1,033 & 1,277 & 0,054 & 0,876 \\
\hline 3,00 & 1,154 & 1,277 & 0,060 & 0,876 \\
\hline 3,50 & 1,276 & 1,277 & 0,066 & 0,876 \\
\hline 4,00 & 1,397 & 1,277 & 0,072 & 0,876 \\
\hline
\end{tabular}


TABELA 5.2 - VERIFICAÇÃO DAS TENSÕES ORIUNDAS DA FLEXÃO E DO CISALHAMENTO NA MESA DAS LAJES NERVURADAS, ALTURA DA MESA

$\left(h_{f}\right)$ DE 4 CM

\begin{tabular}{|c|c|c|c|c|}
\hline \multirow{2}{*}{$\begin{array}{c}\text { Sobrecarga } \\
\text { de utilização }\end{array}$} & \multicolumn{2}{|c|}{ Flexão } & \multicolumn{2}{c|}{ Cisalhamento } \\
\cline { 2 - 5 } & Atuante & Resistente & Atuante & Resistente \\
\hline 2,50 & 0,615 & 1,277 & 0,043 & 0,932 \\
\hline 3,00 & 0,683 & 1,277 & 0,047 & 0,932 \\
\hline 3,50 & 0,752 & 1,277 & 0,052 & 0,932 \\
\hline 4,00 & 0,820 & 1,277 & 0,057 & 0,932 \\
\hline 4,50 & 0,888 & 1,277 & 0,061 & 0,932 \\
\hline 5,00 & 0,957 & 1,277 & 0,066 & 0,932 \\
\hline 5,50 & 1,025 & 1,277 & 0,071 & 0,932 \\
\hline 6,00 & 1,094 & 1,277 & 0,076 & 0,932 \\
\hline 6,50 & 1,162 & 1,277 & 0,080 & 0,932 \\
\hline 7,00 & 1,230 & 1,277 & 0,085 & 0,932 \\
\hline 7,50 & 1,299 & 1,277 & 0,090 & 0,932 \\
\hline
\end{tabular}

Na tabela 5.1 pode-se verificar que as tensões normais atuantes, provenientes da flexão são menores que as tensões as quais a seção pode resistir, isto para sobrecargas de utilização menores que $4,00 \mathrm{kN} / \mathrm{m}^{2}$. Na tabela 5.2 verifica-se que para sobrecargas de utilização menores que $7,50 \mathrm{kN} / \mathrm{m}^{2}$ a seção resiste aos esforços provenientes da flexão. Já as tensões atuantes provenientes do cisalhamento são muito menores do que as tensões resistentes, das seções verificadas.

Conclui-se, então, que para as lajes nervuradas pré-moldadas usuais, com distância livre entre nervuras (a) menor ou igual a $50 \mathrm{~cm}$, com mesa de altura $\left(\mathrm{h}_{\mathrm{f}}\right)$ igual a $3 \mathrm{~cm}$ e sobrecargas de utilização menores que $4,00 \mathrm{kN} / \mathrm{m}^{2}$ não há necessidade de dispor-se de armadura de flexão e cisalhamento na mesa, enquanto que nas lajes nervuradas pré-moldadas com altura da mesa $\left(\mathrm{h}_{\mathrm{f}}\right)$ igual a $4 \mathrm{~cm}$ não há necessidade de dispor de tais armaduras, para sobrecargas de utilização menores que $7,50 \mathrm{kN} / \mathrm{m}^{2}$.

Nos cálculos apresentados considerou-se a distância livre entre nervuras de $50 \mathrm{~cm}$, sendo esta situação a mais desfavorável, haja visto que, na maior parte dos casos de lajes nervuradas pré-moldadas a distância livre entre nervuras é menor que $50 \mathrm{~cm}$. 


\subsubsection{VERIFICAÇÃO DO CISALHAMENTO NA LIGAÇÃO CONCRETO PRÉ-MOLDADO E CONCRETO MOLDADO IN LOCO}

A norma brasileira NB-949/85 permite o cálculo de uma peça composta por elementos pré-moldados e elementos moldados no local, como uma peça monolítica, desde que a tensão de aderência de cálculo satisfaça as seguintes condições:

$$
\tau_{s d} \leq \frac{\beta_{s} f_{y d} A_{s}}{b s}+\beta_{c} f_{t d}
$$

onde:

$\mathrm{A}_{\mathrm{s}}=$ área da armadura atravessando perpendicularmente a interface e totalmente ancorada nos elementos componentes,

$\mathrm{f}_{\mathrm{yd}}=$ resistência de cálculo da armadura,

$\mathrm{s}=$ espaçamento da armadura $\mathrm{A}_{\mathrm{s}}$,

$\mathrm{b}=$ largura da interface,

$f_{t d}=$ segundo a NB-1/78 para o concreto de menor resistência,

entre os que estão em contato,

$$
\tau_{s d}=\frac{F_{m d}}{\mathrm{a}_{\mathrm{v}} b}
$$

com:

$\mathrm{F}_{\mathrm{md}}=$ valor médio da força de compressão ou tração acima da ligação, ao longo do comprimento $\mathrm{a}_{\mathrm{v}}$,

$$
a_{v}=\text { distância entre os pontos de momento nulo e máximo, }
$$

respectivamente,

$$
\begin{aligned}
& \beta_{\mathrm{s}}=\text { coeficiente de minoração aplicado à armadura; } \\
& \beta_{\mathrm{c}}=\text { coeficiente de minoração aplicado ao concreto. }
\end{aligned}
$$


TABELA 5.3 - VALORES DOS COEFICIENTES $\beta_{\mathrm{s}}$ E $\beta_{\mathrm{c}}$

\begin{tabular}{|c|c|c|}
\hline $\mathrm{A}_{\mathrm{s}} / \mathrm{sb}(\%)$ & $\beta_{\mathrm{s}}$ & $\beta_{\mathrm{c}}$ \\
\hline$\leq 0,2$ & 0 & 0,3 \\
\hline$\geq 0,5$ & 0,9 & 0,6 \\
\hline
\end{tabular}

A tabela acima é válida para superficies de ligação intencionalmente ásperas com rugosidades entre $0,5 \mathrm{~cm}$ em $3,0 \mathrm{~cm}$.

Para valores intermediários interpolar linearmente, admite-se $\mathrm{A}_{\mathrm{s}}=0$ quando $\tau_{\mathrm{sd}} \leq \beta_{\mathrm{c}} f_{\mathrm{td}}$.

\subsection{EXEMPLO DE APLICAÇÃO}

Apresenta-se como ilustração o projeto das lajes nervuradas pré-moldadas de uma resistência de dois pavimentos, conforme a figura 5.21. Os cálculos para a laje do piso do dormitório 1 são descritos detalhadamente, passo a passo, enquanto que para as demais lajes, apresenta-se apenas os resultados, visto que o processo é repetitivo. 


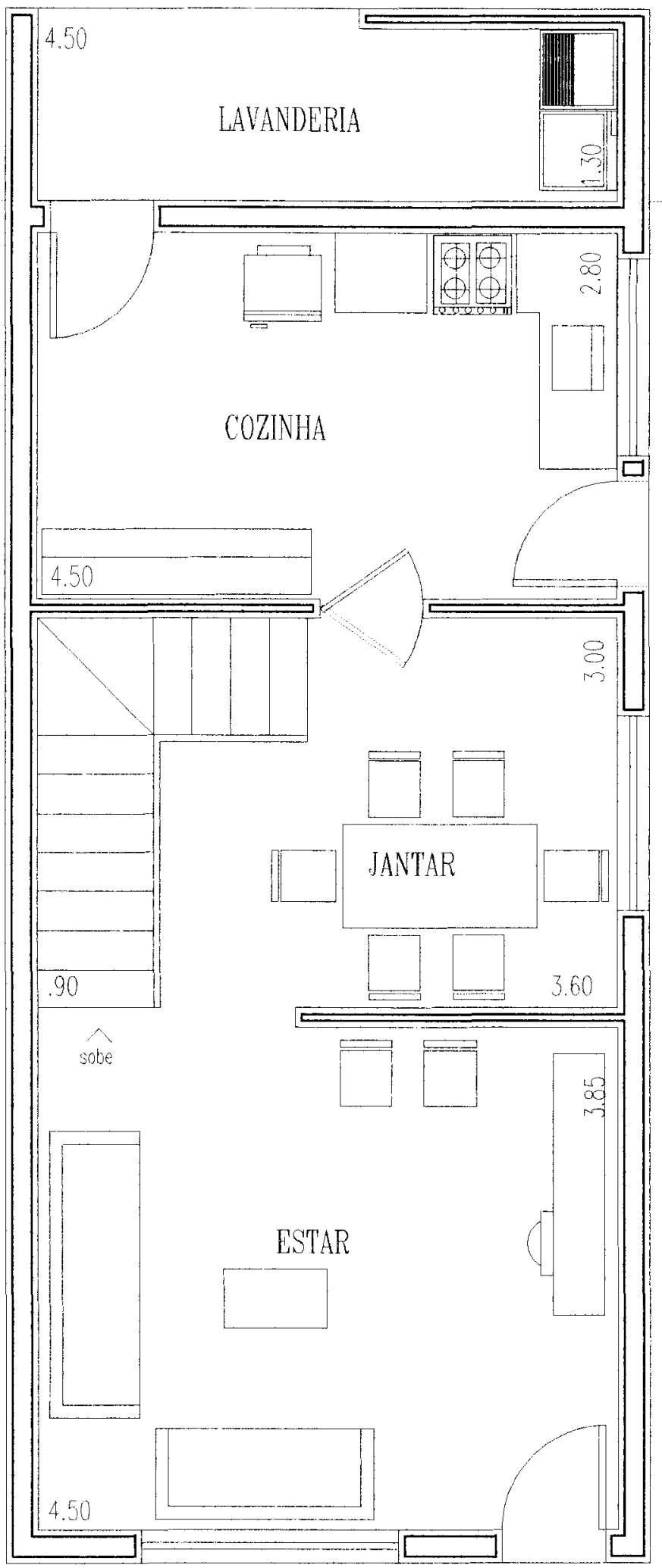




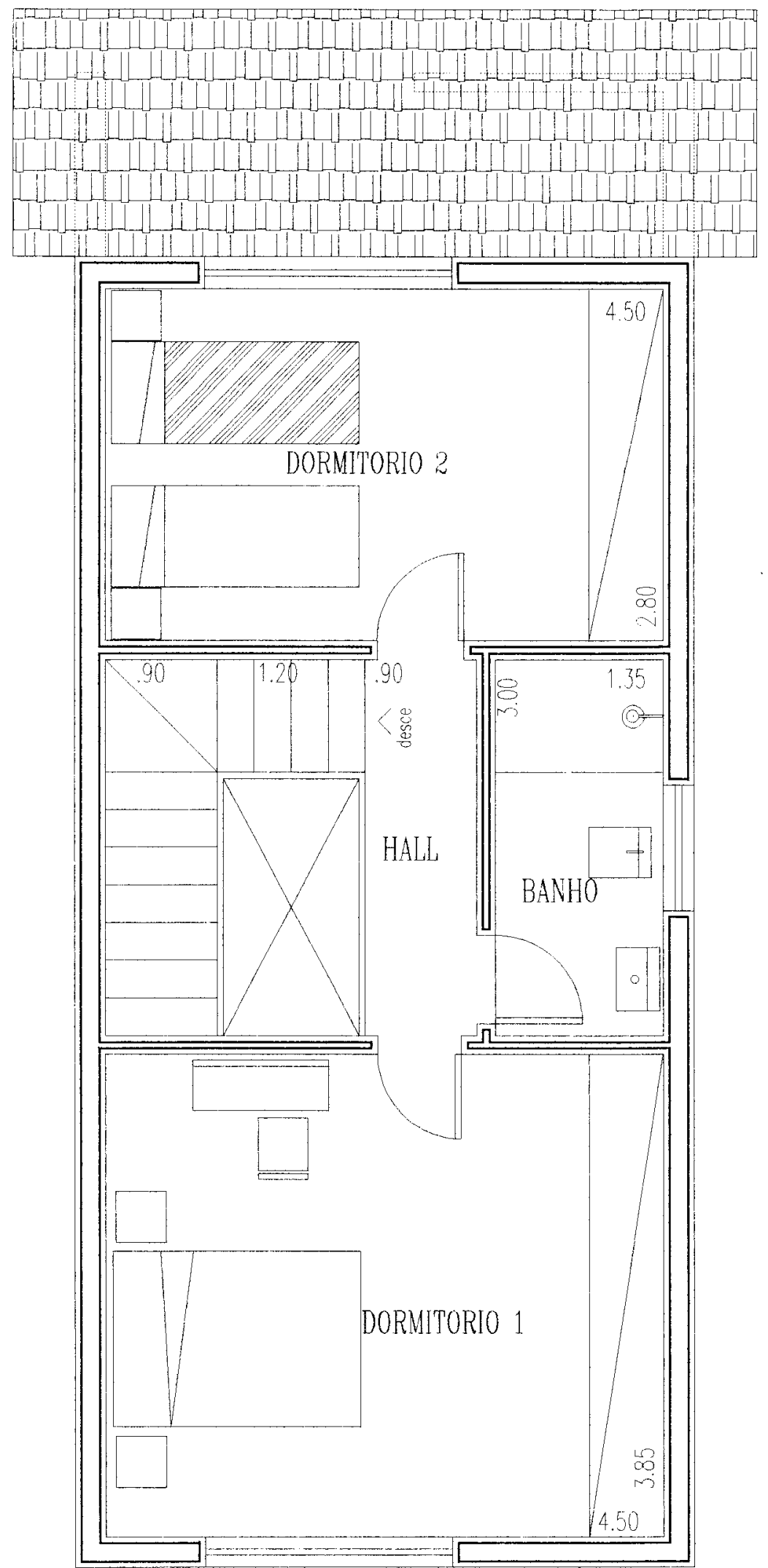

FIGURA 5.21 - PLANTA BAIXA DO PROJETO EXEMPLO 
Admite-se para o concreto das vigas e da mesa (capa) resistência característica à compressão aos 28 dias $\left(f_{c k}\right)$ igual a $15 \mathrm{MPa}$, o aço empregado é o CA 50A e o CA60. 


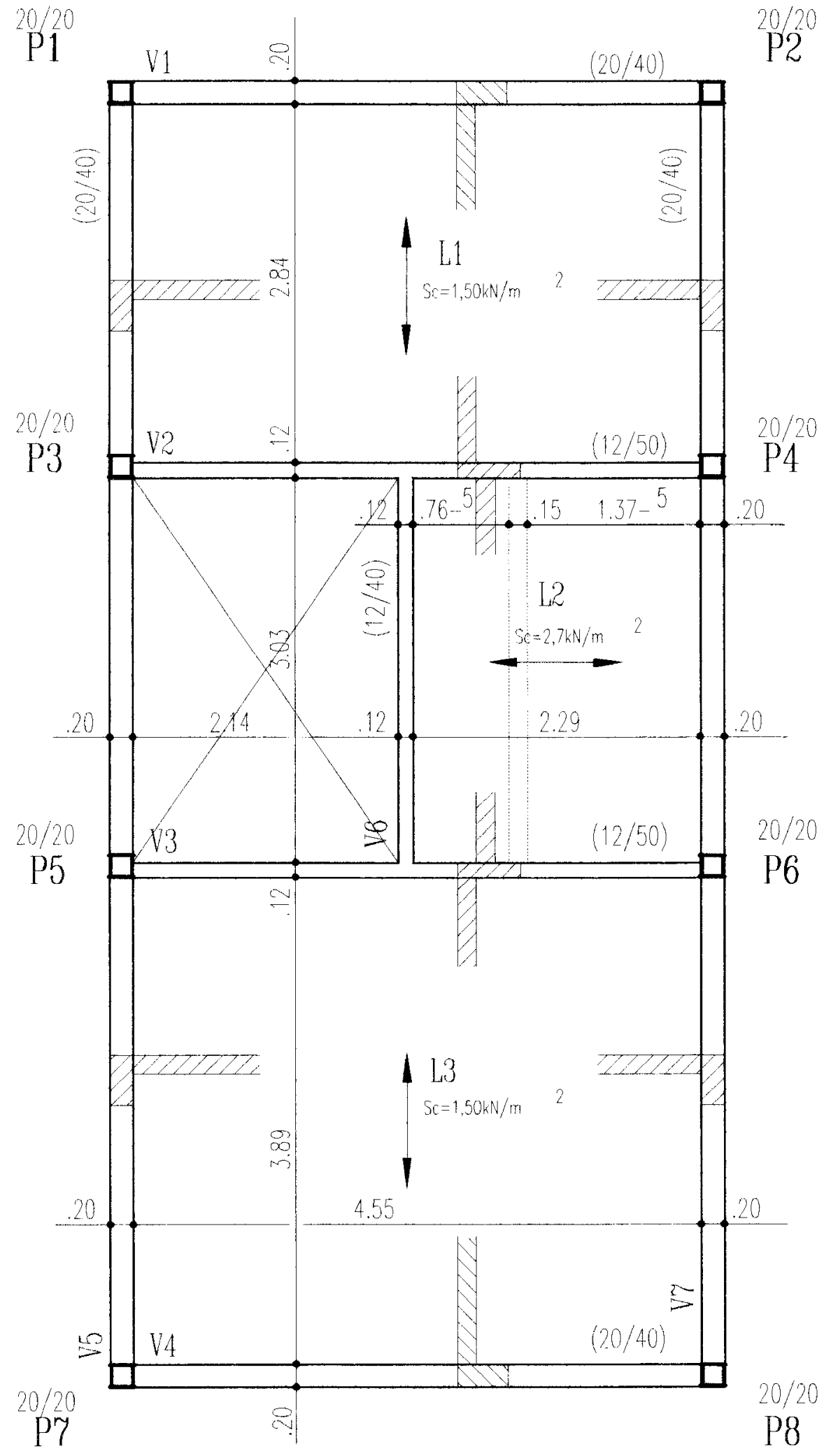

* L2 sobrecargo-cargo acidentoltentulho de enchimento. 


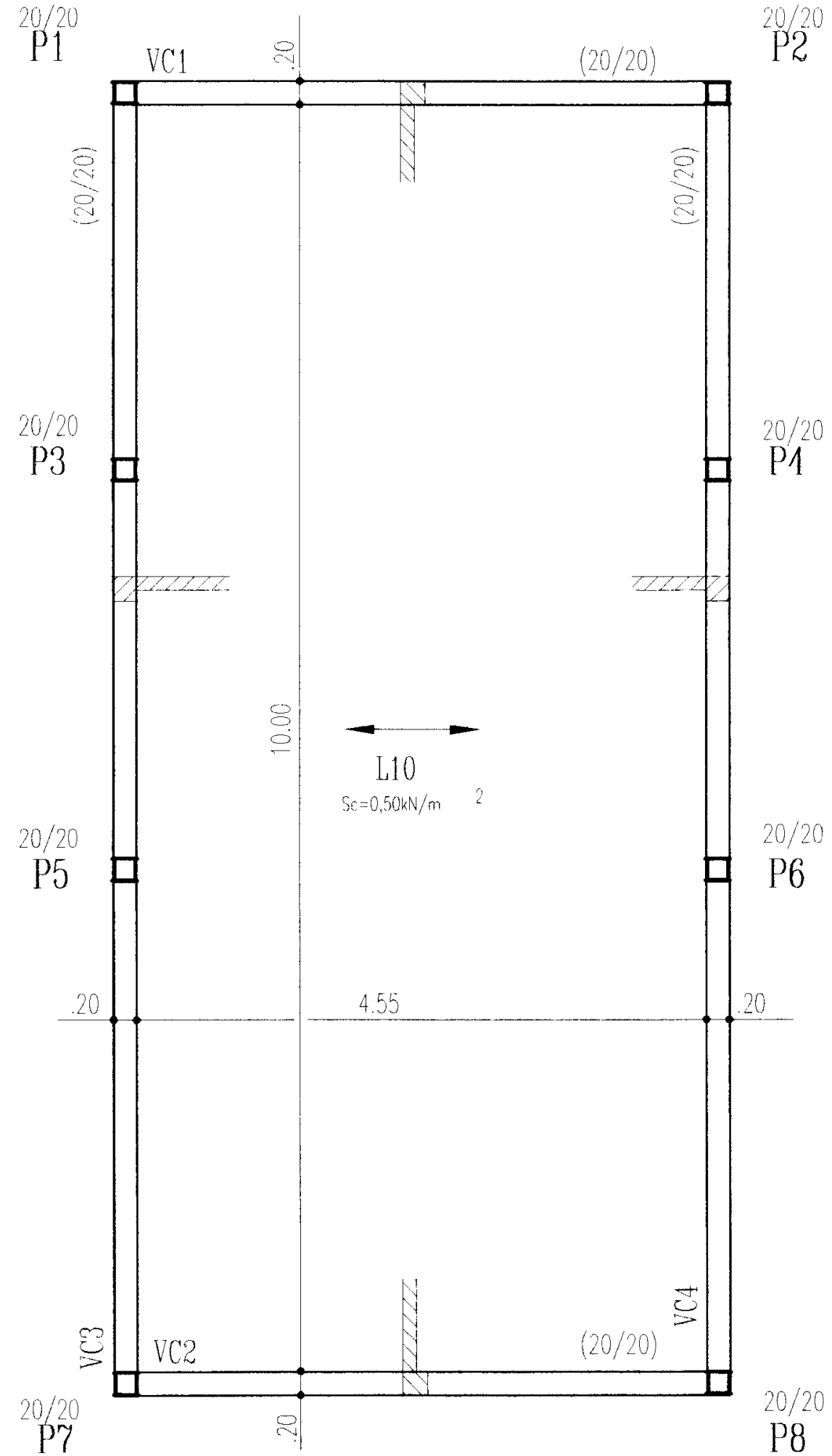

L.10 : sobrecargo=carga acidentalt tethodo

FIGURA 5.22 - PLANTA DE FORMA FORNECIDA PELO ENGENHEIRO DE ESTRUTURAS 


\section{Estimativa da altura da laje do piso do dormitório 1}

O pré-dimensionamento da altura $(\mathrm{h})$ das lajes nervuradas pode ser feito de várias maneiras, neste trabalho destacam-se duas delas:

a) Recomendações da NB-1/78

A Norma Brasileira NB-1/78 estabelece que a altura útil (d) das lajes deve ser menor ou igual ao lado menor dividido pelos coeficientes $\psi_{2}$ e $\psi_{3}$. Para a laje em questão admite-se que $\psi_{2}=1,0$ e $\psi_{3}=17$, obtendo-se para $1=405 \mathrm{~cm}$, altura útil igual a $23,82 \mathrm{~cm}$;

b) Equação proposta por MACHADO (1983)

Estabelece-se que a altura útil das lajes deve ser maior ou igual a $1,5(2,5-0, \ell \mathrm{n}) \ell^{*}$, com $\mathrm{n}=0$ (laje apoiada) e $\ell^{*}$ igual ao lado menor $(\ell=405 \mathrm{~cm})$, logo d é igual ou maior que $15,19 \mathrm{~cm}$.

Finalmente para a laje do dormitório 1 adota-se a altura $h=20$ $\mathrm{cm}$. A altura da mesa $\left(\mathrm{h}_{\mathrm{f}}\right)$ deve respeitar as recomendações da NB-1/78, ou seja, $\mathrm{h}_{\mathrm{f}} \geq$ a/ 15 , não menor que $4 \mathrm{~cm}$, adotando-se então $h_{\mathrm{f}}=4 \mathrm{~cm}$. A Norma Brasileira estabelece, ainda que parte da largura da mesa colabora para resistir aos esforços de flexão, assim a laje nervurada tem uma seção resistente na forma de $\mathrm{T}$, sendo que a largura da mesa deve ser:

$$
\begin{aligned}
& b_{f}=2 b_{1}+b_{w}, \text { com } \\
& b_{1} \leq\left\{\begin{array}{l}
0,1 \mathrm{a}=40 \mathrm{~cm} \\
0,8 h_{\mathrm{f}}=32 \mathrm{~cm}, \log 0 \text { tem }- \text { se } b_{1}=16 \mathrm{~cm} \\
0,5 b_{2}=16 \mathrm{~cm}
\end{array}\right.
\end{aligned}
$$


Para as nervuras das lajes nervuradas pré-moldadas, a largura $b_{w}$ tem-se geralmente $8 \mathrm{~cm}$, então $b_{f}=2 \times 16+8=40 \mathrm{~cm}$.

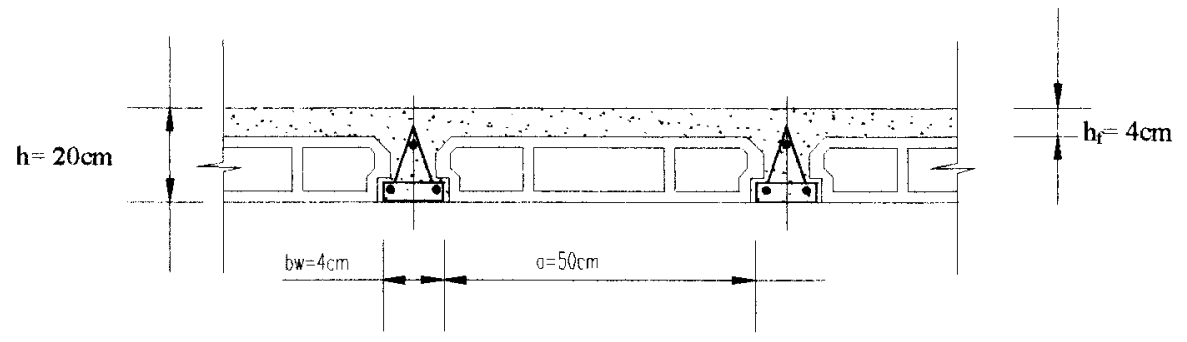

FIGURA 5.23 - SEÇÃO TRANSVERSAL DA LAJE NERVURADA PRÉMOLDADA

\section{Ações atuantes na laje}

a) Peso próprio

Para determinar-se o peso próprio da laje nervurada prémoldada encontra-se a altura equivalente a uma laje maciça.

$$
\begin{aligned}
& h_{e q}=\left[b_{f} h_{f}+\left(h-h_{f}\right) b_{w}\right] / b_{f} \\
& h_{e q}=[40 \times 4+(20-4) \times 8] / 40 \\
& h_{e q}=7,2 \mathrm{~cm}
\end{aligned}
$$

$\mathrm{O}$ peso próprio da laje nervurada distribuído na sua área é obtido multiplicando-se a $h_{\mathrm{eq}}$ pelo peso específico do concreto, $7,2 \times 0,25=1,80$ $\mathrm{kN} / \mathrm{m}^{2}$.

b) Peso da lajota

O peso próprio da lajota é determinado a partir do seu peso específico e de sua altura; o peso específico da lajota cerâmica é, em média de 6 
$\mathrm{kN} / \mathrm{m}^{3}$, a altura para a lajota da laje do dormitório 1 é de $16 \mathrm{~cm}$ ou $0,16 \mathrm{~m}$, obtendose então $0,96 \mathrm{kN} / \mathrm{m}^{2}$.

c) Sobrecarga de utilização

A sobrecarga de utilização é constituída da ação acidental obtida através da Norma Brasileira NB-5/80 de acôrdo com a ocupação a qual a laje será destinada, mais o peso próprio do revestimento da laje. No exemplo, a sobrecarga de utilização é de $1,50 \mathrm{kN} / \mathrm{m}^{2}$ e o peso próprio do revestimento é 0,5 $\mathrm{kN} / \mathrm{m}^{2}$. A resultante de todas as ações atuantes é de $4,76 \mathrm{kN} / \mathrm{m}^{2}$.

\section{Esforços solicitantes}

Para determinar os esforços solicitantes da laje em questão, admite-se que esta comporta-se como uma viga bi-apoiada de largura unitária.

a) Força cortante

A força cortante máxima atuante é determinada multiplicandose o carregamento pelo menor vão da laje, e dividindo-se esta por dois, obtendo-se então, para a laje em questão $\mathrm{V}=9,64 \mathrm{kN} / \mathrm{m}$ ou $3,86 \mathrm{kN} /$ nervura.

b) Momento fletor

O máximo momento fletor é determinado multiplicando-se a ação uniformemente distribuída pelo quadrado do menor vão da laje, e dividindo-se este por oito, obtendo-se assim $M=9,76 \mathrm{kNm} / \mathrm{m}$ ou $3,90 \mathrm{kNm} /$ nervura. 
Cabe lembrar neste item, conforme já comentado no capítulo deste trabalho, que o momento fletor máximo pode ser reduzido desde que se avalie o momento fletor como uma laje nervurada realmente, através do método dos elementos finitos, admitindo-se que a mesa absorve uma parcela do momento fletor atuante, prevendo-se armadura na mesa, além da armadura de distribuição, afim de resistir a tal momento.

\section{Determinação da armadura de flexão}

A armadura de flexão é aquela destinada a absorver os esforços de tração provenientes do momento fletor, portanto nesta laje esta armadura deve ser posicionada na porção inferior da nervura. $\mathrm{O}$ cálculo da armadura segue a teoria apresentada no capítulo 3 deste trabalho.

Admite-se que o momento de cálculo $\mathrm{M}_{d}$ é igual a $0,68 b d^{2} \beta_{x} f_{c d}\left(1-0,4 \beta_{x}\right)$ obtendo-se assim, o valor de $\beta_{x}$, o qual indica a posição da linha neutra. Para a laje em questão $\beta_{\mathrm{x}}=0,056$, observa-se que a mesma encontra-se no domínio 2, a linha neutra está na mesa $(x=1,04 \mathrm{~cm})$ e para efeito de verificação do estado limite último tem-se uma seção $\mathrm{T}$.

No domínio 2 tem-se que a deformação no aço é igual a 1,00\%, através da compatibilidade de deformações obtém-se a deformação no concreto $\varepsilon_{c}=0,059 \%$. Admitindo-se a tensão na armadura igual a $f_{y d}$, obtém-se $\sigma_{\mathrm{sd}}=43,48 \mathrm{kN} / \mathrm{cm}^{2}$, com este valor determina-se a área de armadura $A_{\mathrm{s}}$ igualando-se a $\left(0,68 \mathrm{bd} \beta_{\mathrm{x}} \mathrm{f}_{\mathrm{cd}}\right) / \sigma_{\mathrm{sd}}$.

Para a laje do dormitório 1, obtém-se $A_{s}=0,69 \mathrm{~cm}^{2} /$ nervura, a armadura mínima ( $\left.A_{\mathrm{s}} \mathrm{min}\right)$ deve ser $0,15 \% \mathrm{~b}_{\mathrm{w}} \mathrm{h}\left(0,24 \mathrm{~cm}^{2} /\right.$ nervura), adotando-se finalmente: $2 \phi 5,0 \mathrm{~mm}+1 \phi 6,3 \mathrm{~mm}\left(\mathrm{~A}_{\mathrm{s}}=0,72 \mathrm{~cm}^{2}\right)$ 


\section{Verificação da resistência da mesa}

A verificação da resistência da mesa pode ser dispensada conforme recomendação da NB-1/78, visto que, a distância livre entre as nervuras (a) é menor que $50 \mathrm{~cm}$. Deve-se dispor de armadura de distribuição perpendicular às nervuras com área de $0,90 \mathrm{~cm}^{2} / \mathrm{m}$, adota-se $1 \phi 5,0 \mathrm{~mm}$ cada $20 \mathrm{~cm}$.

\section{Verificação quanto às tensões de cisalhamento}

Segundo a NB-1/78 as lajes nervuradas em que as nervuras apresentam distância livre (a) menor que $50 \mathrm{~cm}$, a verificação das tensões de cisalhamento deve ser feita como uma laje propriamente dita.

A força cortante máxima é de $3,86 \mathrm{kN} /$ nervura e a tensão de cisalhamento de cálculo correspondente a esta força cortante é de $0,0365 \mathrm{kN} / \mathrm{cm}^{2}$ ou $0,365 \mathrm{MPa}$. A tensão última de cálculo do concreto é obtida pela expressão $\tau_{\mathrm{wu}}=0,30$ $\mathrm{f}_{\mathrm{cd}}$, obtendo-se para o exemplo $\tau_{\mathrm{wu}}=3,21 \mathrm{MPa}$ (concreto com $\mathrm{f}_{\mathrm{ck}}$ de $15 \mathrm{MPa}$ ), a tensão $\tau_{\mathrm{wu} 1}$ deve ser determinada considerando-se a taxa de armadura $\rho_{1}$, a resistência característica do concreto à compressão aos 28 dias $\left(f_{c k}\right)$, com a seguinte expressão: $\tau_{\mathrm{wul}}=\psi_{4} \sqrt{\mathrm{f}_{\mathrm{ck}}}$, sendo que este valor deve ser menor que $1,0 \mathrm{MPa}$; o coeficiente $\psi_{4}$ é determinado através da expressão $\psi_{4}=0,14 \alpha \mathrm{k}$, com $\mathrm{k}=1,6-\mathrm{d} \geq 1 \mathrm{e} \mathrm{d}=$ $1 / 20$. No exemplo tem-se $1 / 20=0,20 \mathrm{~m} \mathrm{e} k=1,4$. O coeficiente $\alpha=1+50 \rho_{1} \leq 1,5$, obtendo-se no exemplo $\rho_{1}=0,49 \%$ e $\alpha=1,25$.

Finalmente determina-se $\psi_{4}=0,245$ e $\tau_{\mathrm{wu} 1}=0,95 \mathrm{MPa}$, conclui-se que não há necessidade de colocar-se estribos na laje, visto que $\tau_{\mathrm{wd}}<\tau_{\mathrm{wul}}$. 


\section{Verificação do cisalhamento na ligação concreto pré-moldado concreto "in loco"}

Nesta verificação seguiu-se as recomendações da Norma Brasileira NB-949/85. A tensão de aderência de cálculo é dada pela expressão $\tau_{\mathrm{sd}}=$ $\mathrm{F}_{\mathrm{md}} /\left(\mathrm{a}_{\mathrm{v}} \mathrm{b}\right)$, com $\mathrm{F}_{\mathrm{md}}$ igual ao valor médio da força de compressão ou de tração acima da ligação ao longo da distância $\left(a_{v}\right)$ entre os pontos de momento nulo e máximo, pode-se concluir que $\mathrm{F}_{\mathrm{md}}$ é igual ao momento fletor máximo dividido por $2 \mathrm{z}$, obtendose neste exemplo $F_{m d}$ igual a $15,18 \mathrm{kN}$.

A distância $a_{v}$ para este exemplo é de $2,02 \mathrm{~m}$, a largura $b$ da interface é de $8 \mathrm{~cm}$, obtendo-se o valor de $\tau_{\mathrm{sd}}$ igual a $0,0094 \mathrm{kN} / \mathrm{cm}^{2}$ ou $0,094 \mathrm{MPa}$.

A tensão de aderência de cálculo deve satisfazer a seguinte condição:

$\tau_{\mathrm{sd}} \leq \beta_{\mathrm{s}} \mathrm{f}_{\mathrm{yd}} \mathrm{A}_{\mathrm{s}} /(\mathrm{b} \mathrm{s})+\beta_{\mathrm{c}} \mathrm{f}_{\mathrm{td}}$.

Para obter-se os coeficientes $\beta_{\mathrm{s}}$ e $\beta_{\mathrm{c}}$ através da tabela 5.4, devese determinar a relação $A_{s} /(s \quad b)$, sendo $A_{s}$ a área de armadura atravessando perpendicularmente a interface e totalmente ancorada nos elementos, e $\mathbf{s} 0$ espaçamento da mesma. Neste exemplo, bem como nos outros casos de lajes nervuradas com nervuras pré-moldadas, $A_{s}$ deve ser igual a zero, obtendo-se então, $\beta_{\mathrm{s}}$ $=0$ e $\beta_{\mathrm{c}}=0,3$. Daí conclui-se que $\tau_{\mathrm{sd}} \leq \beta_{\mathrm{s}} \mathrm{f}_{\mathrm{td}} \leq 0,3 \mathrm{f}_{\mathrm{td}}$, com $\mathrm{f}_{\mathrm{td}}$ para o concreto de menor resistência, dentre os que estão em contato. No exemplo, $f_{t d}=1,07 \mathrm{MPa}(\mathrm{C}$ 15), e $\tau_{\text {sd }}=0,094 \mathrm{MPa}<0,32 \mathrm{MPa}$, logo não necessita-se dispor de armadura transversal.

\section{Verificação do estado limite de deformação excessiva}

$\mathrm{Na}$ verificação do estado limite de deformação emprega-se a seguinte combinação de ações: 


$$
F_{d, \text { útil }}=\sum_{i=1}^{m} F_{G i, k}+\sum_{j=2}^{n} \psi_{2 j} \cdot F_{q k}
$$

Obtendo-se para o exemplo em questão, $F_{d, u ́ t i l}=1,42 \mathrm{kN} / \mathrm{m}$, sendo esta a ação de cálculo para este estado limite de utilização.

A Norma Brasileira NB-116/89 recomenda adotar na verificação do estado limite de deformação a relação entre os módulos de deformação do aço e do concreto, $\alpha_{\mathrm{e}}=15$. Adotando-se $E_{\mathrm{s}}=210.000 \mathrm{MPa}$, obtém-se 14.000 $\mathrm{MPa}$, a posição da linha neutra da seção $\mathrm{T}$ da laje nervurada de concreto armado pode ser determinada através da expressão:

$x=\alpha_{e} \frac{A_{s}}{b_{f}}\left[1+\left(1+\frac{2 b_{f} d}{\alpha_{e} A_{s}}\right)^{/ 2}\right]$

Obtendo-se para o exemplo $\mathrm{x}=2,90 \mathrm{~cm}$, logo a linha neutra está na mesa, pois $h_{\mathrm{f}}=4,0 \mathrm{~cm}$.

$\mathrm{Na}$ avaliação da rigidez da laje nervurada, para levar em conta a variação desta ao longo do eixo de uma peça fletida, pode-se adotar um momento de inércia equivalente, fornecido pela fórmula de Branson, determinado com a expressão:

$$
I_{\mathrm{e}}=\left(\mathrm{M}_{\mathrm{r}} / \mathrm{M}_{\mathrm{tot}}\right)^{3} \mathrm{I}_{\mathrm{I}}+\left[1-\left(\mathrm{M}_{\mathrm{r}} / \mathrm{M}_{\mathrm{tot}}\right)^{3}\right] \mathrm{I}_{\mathrm{II}} \leq \mathrm{I}_{\mathrm{I}}
$$

$\mathrm{O}$ momento de inércia no estádio $\mathrm{I}\left(\mathrm{I}_{\mathrm{I}}\right)$ é determinado pela

expressão:

$$
\begin{gathered}
I_{I}=\frac{b_{f} h^{2}}{12}+b_{f} h\left(y_{\text {cg }}-\frac{h}{2}\right)^{2}-2\left[\frac{\left(h-h_{f}\right)^{4}}{12}+\left(h-h_{f}\right)^{2}\left(y_{c g}-b_{w}\right)^{2}\right] \\
y_{\text {cg }}=\frac{\left[\frac{b_{f} h^{2}}{2}-\left(h-h_{f}\right)^{3}\right]}{b f h-2\left(h-h_{f}\right)^{2}}
\end{gathered}
$$

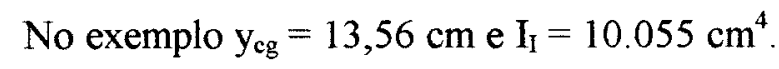

$\mathrm{O}$ momento de inércia no estádio II $\left(\mathrm{I}_{\mathrm{II}}\right)$ é determinado pela expressão:

$$
I_{I I}=\frac{b_{f} h^{2}}{3}+\alpha_{e} A_{s}(d-x)^{2}
$$


no exemplo $\mathrm{I}_{\mathrm{II}}=2.953,47 \mathrm{~cm}^{4}$

$\mathrm{O}$ momento de fissuração da seção $\mathrm{M}_{\mathrm{r}}$ deve ser determinado para o estádio $I_{b}$. Calcula-se a posição da linha neutra para este estádio, supondo-se inicialmente que ela encontra-se na mesa da laje nervurada, através da seguinte expressão:

$$
1,025 b_{f} x^{2}+\left(b_{f} h+b_{f} h_{f}+h b_{w}-h_{f} b_{w}\right) x-\left(b_{f} h_{f} h+h^{2} b_{w}-h h_{f}\right.
$$
$\left.b_{w}\right)=0$

No caso em questão, $x=4,52 \mathrm{~cm}$, como $x>h_{f}=4 \mathrm{~cm}$, a hipótese adotada não é válida, ou seja, a linha neutra não está na mesa conforme admitiu-se inicialmente, e pode ser determinado pela seguinte expressão:

$$
1,025 b_{w} x^{2}+\left(2,025 b_{f} h_{f}-2,025 b_{w} h_{f}+2 h b_{w}\right) x-b_{w} h^{2}=0
$$

Obtendo-se para o exemplo $\mathrm{x}=5,15 \mathrm{~cm}$, como $\mathrm{x}>\mathrm{h}_{\mathrm{f}}=4 \mathrm{~cm}$, confirma-se a hipótese assumida de que a linha neutra encontra-se na alma.

O momento de fissuração é obtido pela expressão:

$$
M_{r}=R_{c t}\left[\frac{2 x}{3}+\frac{(h-x)}{2}\right], \text { com } R_{c t}=0,75 x 1,2 f_{t k}\left[b_{w}(h-x)\right]
$$

Obtendo-se no exemplo $R_{\mathrm{ct}}=16,04 \mathrm{kN}$ e $\mathrm{M}_{\mathrm{r}}=1,74 \mathrm{kN} . \mathrm{m}$. $\mathrm{O}$ momento máximo na laje para a ação de utilização de cálculo $\left(\mathrm{M}_{\mathrm{tot}}\right)$ é igual a $2,91 \mathrm{kNm}$, então $\mathrm{I}_{\mathrm{e}}=4.471,64 \mathrm{~cm}^{4}\left(<\mathrm{I}_{\mathrm{I}}\right)$.

A deformação inicial (a) no meio do vão da laje bi-apoiada com nervuras em uma direção é dada por:

$$
\mathrm{a}=\frac{5 p e^{4}}{384 \mathrm{E}_{\mathrm{c}} \mathrm{Ie}_{\mathrm{e}}}, \text { no exemplo } \mathrm{a}=0,80 \mathrm{~cm}
$$

A deformação final $\left(\mathrm{a}_{\infty}\right)$ é dada por:

$$
\mathrm{a}_{\mathrm{oo}}=\mathrm{a} \frac{\left(1+\varphi_{\mathrm{t}}\right)\left|\varepsilon_{\mathrm{c}}\right|+\varepsilon_{\mathrm{s}},}{\varepsilon_{\mathrm{c}}+\varepsilon_{\mathrm{s}}}
$$

Neste caso, $\left(1+\varphi_{\mathrm{t}}\right)=3, \varepsilon_{\mathrm{c}}=1,35_{\times} \times 10^{-4}, \varepsilon_{\mathrm{s}}=7,25 \times 10^{-4}$, obtendose, finalmente, $a_{\infty}=1,05 \mathrm{~cm}$, como a deformação máxima permitida pela NB-1/78 é igual a $\ell 300=1,35 \mathrm{~cm}$, conclui-se que $\mathrm{a}_{\mathbf{0}}<\mathrm{a}_{\mathrm{lim}}$, assim sendo a deformação é aceitável, sem necessidade de contra-flecha. 
A seguir apresenta-se tabelas com os dados, dimensionamento e verificação de todas as lajes mostradas na figura 5.22. Cabe-se ressaltar que a laje $\mathrm{L} 3$ cujos cálculos foram detalhados, foi recalculada para $\mathrm{h}=16 \mathrm{~cm}$, objetivando-se um dimensionamento mais econômico.

TABELA 5.4 - DADOS DAS LAJES DO PROJETO

\begin{tabular}{|c|c|c|c|c|c|c|}
\hline \multirow{2}{*}{ Laje } & \multirow{2}{*}{$\begin{array}{c}\text { Altura } \\
(\mathrm{cm})\end{array}$} & \multirow{2}{*}{$\begin{array}{c}\text { Vão } \\
(\mathrm{m})\end{array}$} & $\begin{array}{c}\text { Sobrecarga } \\
\mathrm{kN} / \mathrm{m}^{2}\end{array}$ & $\begin{array}{c}\text { Peso Próprio } \\
\mathrm{kN} / \mathrm{m}^{2}\end{array}$ & $\begin{array}{c}\text { Revestimento } \\
\mathrm{kN} / \mathrm{m}^{2}\end{array}$ & $\begin{array}{c}\text { Alvenaria } \\
\mathrm{kN} / \mathrm{m}\end{array}$ \\
\hline L1 & 12 & 3,00 & 1,50 & 1,88 & 0,50 & $\cdots$ \\
\hline L2 & 12 & 2,45 & 2,70 & 1,88 & 0,50 & 6,60 \\
\hline L3 & 16 & 4,05 & 1,50 & 2,32 & 0,50 & $\cdots$ \\
\hline L10 & 11 & 4,75 & 0,50 & 1,63 & $-\cdots$ & $\cdots$ \\
\hline
\end{tabular}

TABELA 5.5 - VERIFICAÇÃO QUANTO AO ESTADO LIMITE ÚLTIMO

\begin{tabular}{|c|c|c|c|c|c|c|c|}
\hline \multirow[b]{2}{*}{ Laje } & \multicolumn{2}{|c|}{ Esforços } & \multicolumn{5}{|c|}{$\overline{A_{s}}$} \\
\hline & $\begin{array}{c}\text { Cortante } \\
\mathrm{kN}\end{array}$ & $\begin{array}{l}\text { Momento } \\
\mathrm{kN} . \mathrm{cm}\end{array}$ & $\begin{array}{l}\text { calculada } \\
\mathrm{cm}^{2} / \text { nerv. }\end{array}$ & $\begin{array}{l}\text { mínimo } \\
\mathrm{cm}^{2} / \text { nerv. }\end{array}$ & $\begin{array}{l}\text { distância } \\
\mathrm{cm}^{2} / \mathrm{m}\end{array}$ & $\begin{array}{l}\text { adotado } \\
\mathrm{cm}^{2} / \text { nerv. }\end{array}$ & $\begin{array}{l}\text { adotado } \\
\text { por nerv. }\end{array}$ \\
\hline L1 & 5,82 & 437 & 0,56 & 0,14 & 0,90 & 0,60 & $3 \phi 5,0$ \\
\hline $\mathrm{L} 2$ & 7,90 & 510 & 0,65 & 0,14 & 0,90 & 0,72 & $\begin{array}{l}2 \phi 5,0+ \\
1 \phi 6,3\end{array}$ \\
\hline L3 & 8,75 & 885 & 0,82 & 0,19 & 0,90 & 0,95 & $3 \phi 6,3$ \\
\hline $\mathrm{L} 10$ & 5,06 & 601 & 0,85 & 0,13 & 0,90 & 0,95 & $3 \phi 6,3$ \\
\hline
\end{tabular}

TABELA 5.6 - VERIFICAÇÃO QUANTO AO E.L. DEFORMAÇÃO

\begin{tabular}{|c|c|c|c|c|c|}
\hline Laje & $\mathrm{x}(\mathrm{cm})$ & $\mathrm{y}_{\mathrm{cg}}(\mathrm{cm})$ & $\mathrm{I}_{\mathrm{I}}\left(\mathrm{cm}^{4}\right)$ & $\mathrm{I}_{\mathrm{II}}\left(\mathrm{cm}^{4}\right)$ & $\mathrm{I}_{\mathrm{e}}\left(\mathrm{cm}^{4}\right)$ \\
\hline L1 & 1,96 & 6,73 & $5.126,67$ & 756,78 & $1.895,27$ \\
\hline L2 & 2,13 & 6,73 & $5.126,67$ & 885,46 & $1.227,44$ \\
\hline L3 & 2,88 & 9,64 & $11.144,07$ & $2.242,60$ & $3.199,63$ \\
\hline L10 & 2,27 & 6,12 & $3.470,73$ & 900,85 & $1.101,76$ \\
\hline
\end{tabular}


TABELA 5.7 - VERIFICAÇÃO QUANTO AO ESTADO LIMITE DEFORMAÇÃO

\begin{tabular}{|c|c|c|c|c|}
\hline Laje & $\mathbf{a}(\mathrm{cm})$ & $\mathrm{a}_{\mathrm{oo}}(\mathrm{cm})$ & $\mathrm{a}_{\mathrm{lim}}(\mathrm{cm})$ & OBS. \\
\hline $\mathrm{L} 1$ & 0,43 & 0,59 & 1,00 & OK! \\
\hline $\mathrm{L} 2$ & 0,76 & 1,07 & 0,82 & contra flecha $0,5 \mathrm{~cm}$ \\
\hline $\mathrm{L} 3$ & 0,98 & 1,37 & 1,35 & OK! \\
\hline $\mathrm{L} 10$ & 2,98 & 4,40 & 1,58 & $*$ \\
\hline
\end{tabular}

(*) Observa-se que a laje L10 apresenta grande deformação no meio do vão $(5,11 \mathrm{~cm})$, necessitando-se de contra-flecha de $3,0 \mathrm{~cm}$, optou-se então por novo dimensionamento, aumentando-se a altura da laje para $15 \mathrm{~cm}$. Obtém-se, então, para a laje L10:

Área de armadura calculada $\left(A_{s}\right.$, calculada $)=0,72 \mathrm{~cm}^{2} /$ nervura.

Armadura adotada $=1 \phi 6,3 \mathrm{~mm}+2 \phi 5,0 \mathrm{~mm}\left(\mathrm{~A}_{\mathrm{s}}\right.$ adotado $=0,72 \mathrm{~cm}^{2} /$ nervura)

A deformação calculada para a laje é de $2,71 \mathrm{~cm}$, como a máxima deformação permitida é de $1,58 \mathrm{~cm}$, adota-se uma contra-flecha de $1,50 \mathrm{~cm}$. 


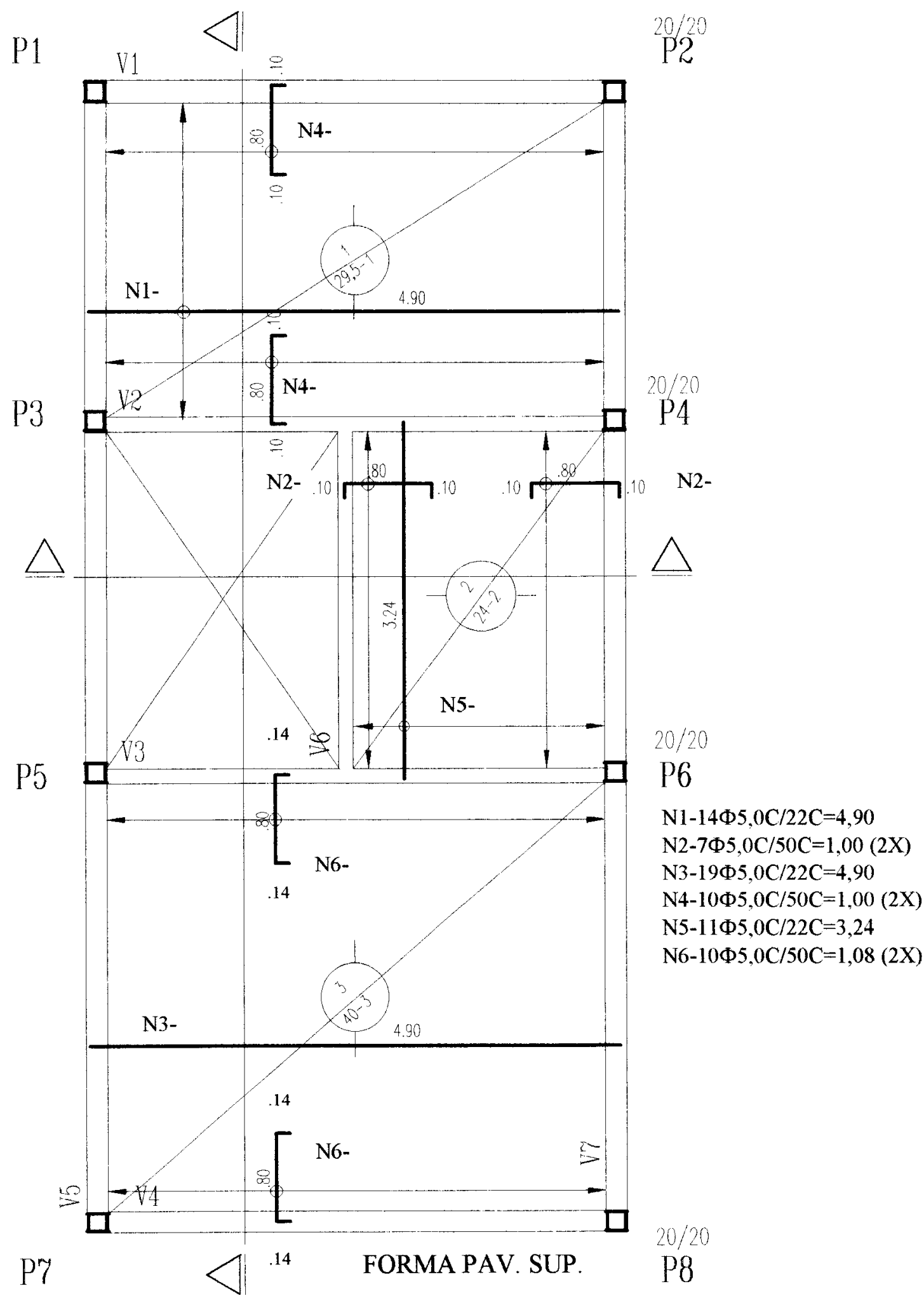



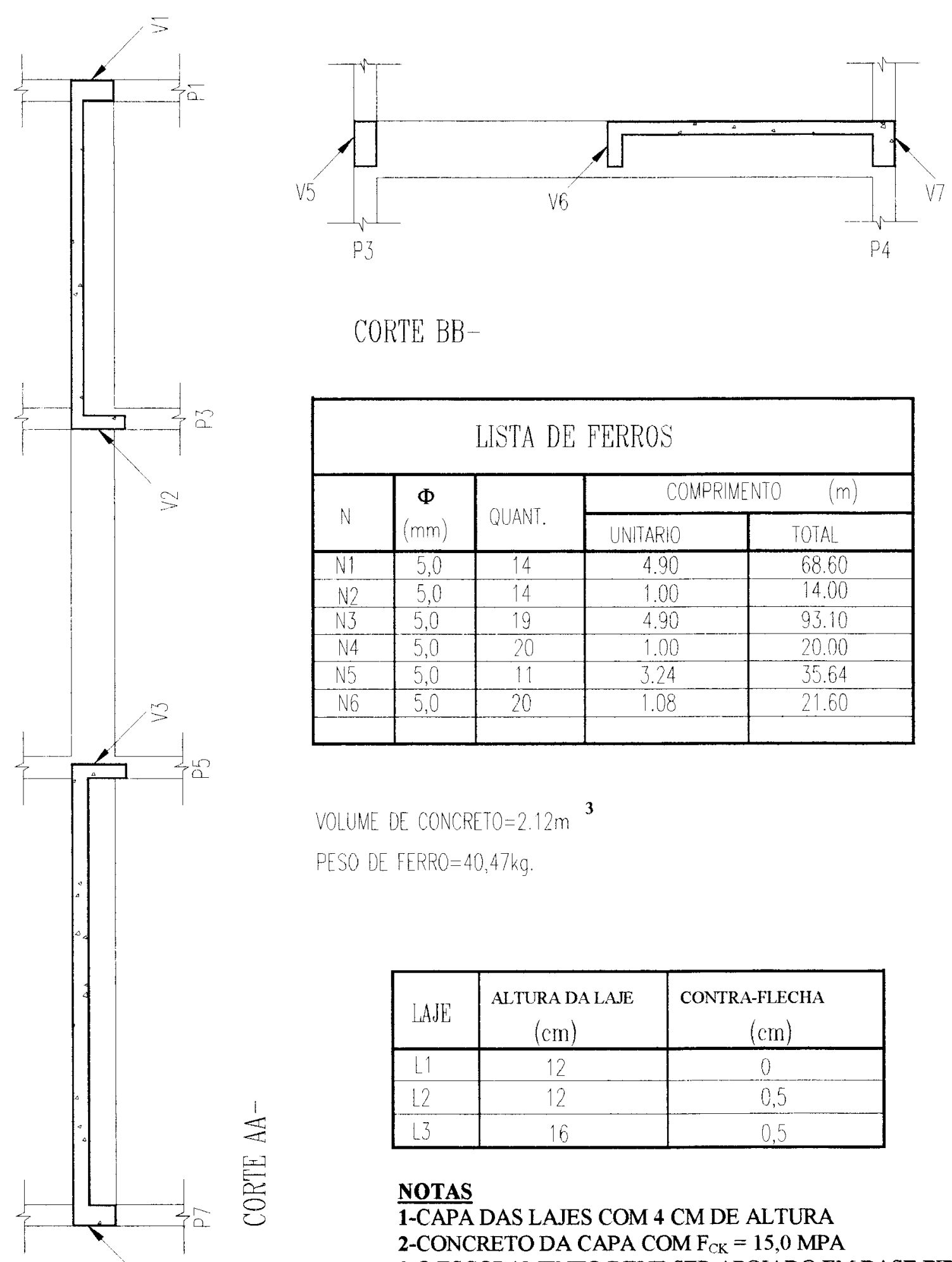

CORTE BB-

\begin{tabular}{|c|c|c|c|c|}
\hline \multicolumn{5}{|c|}{ LISTA DE FERROS } \\
\hline \multirow{2}{*}{ N } & \multirow{2}{*}{$\begin{array}{c}\Phi \\
(\mathrm{mm})\end{array}$} & \multirow{2}{*}{ QUANT. } & \multicolumn{2}{|c|}{ COMPRIMENTO } \\
\hline & & & UNITARIO & TOTAL \\
\hline$\overline{N 1}$ & $\overline{5,0}$ & 14 & 4.90 & 68.60 \\
\hline N2 & 5,0 & 14 & 1.00 & 14.00 \\
\hline $\mathrm{N3}$ & 5,0 & 19 & 4.90 & 93.10 \\
\hline N4 & 5,0 & 20 & 1.00 & 20.00 \\
\hline$N 5$ & 5,0 & 11 & 3.24 & 35.64 \\
\hline N6 & 5,0 & 20 & 1.08 & 21.60 \\
\hline
\end{tabular}

VOLUME DE CONCRETO $=2.12 \mathrm{~m}^{3}$

PESO DE FERRO $=40,47 \mathrm{~kg}$.

\begin{tabular}{|c|c|c|}
\hline LAJE & $\begin{array}{c}\text { ALTURA DA LAJE } \\
(\mathrm{cm})\end{array}$ & $\begin{array}{c}\text { CONTRA-FLECHA } \\
(\mathrm{cm})\end{array}$ \\
\hline$L 1$ & 12 & 0 \\
\hline$L 2$ & 12 & 0,5 \\
\hline$L 3$ & 16 & 0,5 \\
\hline
\end{tabular}

\section{NOTAS}

1-CAPA DAS LAJES COM 4 CM DE ALTURA

2-CONCRETO DA CAPA COM $F_{C K}=15,0 \mathrm{MPA}$

3-O ESCORAMENTO DEVE SER APOIADO EM BASE FIRME 4-DESFÔRMAR NO MÍNIMO APÓS 18 DIAS 


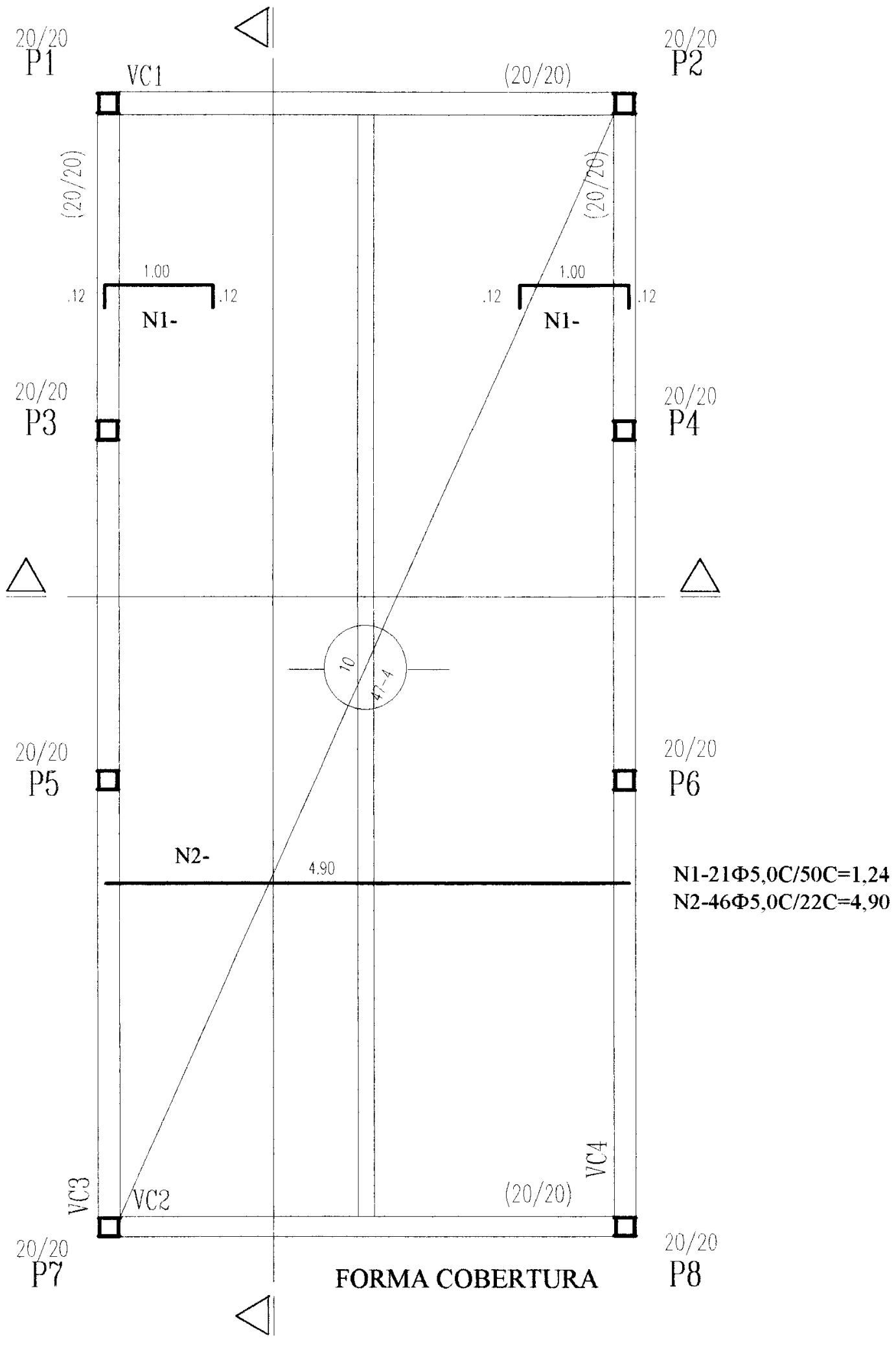




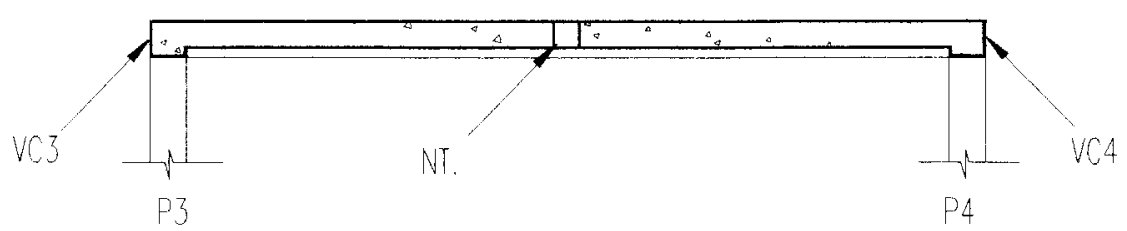

CORTE BB

\begin{tabular}{|c|c|c|c|c|}
\hline \multicolumn{2}{|c|}{ LISTA DF FERROS } \\
\hline \multirow{2}{*}{$N$} & $\Phi$ \\
& $(\mathrm{mm})$ & QUANT. & \multicolumn{2}{|c|}{ COMPRIMENTO $(\mathrm{m})$} \\
\cline { 4 - 5 } & & UNIARIO & TOTAL \\
\hline $\mathrm{N} 1$ & 5,0 & 42 & 1.24 & 52.08 \\
\hline $\mathrm{N} 2$ & 5,0 & 46 & 4.90 & 225.40 \\
\hline & & & & \\
\hline
\end{tabular}

3

VOLUME DE CONCRETO $=2,12 \mathrm{~m}$

PESO DE FERRO $=44,40 \mathrm{~kg}$.

\begin{tabular}{|c|c|c|}
\hline LAJE & $\begin{array}{c}\text { ALTURA DA LAJE } \\
(\mathrm{cm})\end{array}$ & $\begin{array}{c}\text { CONTRA-FLECHA } \\
(\mathrm{cm})\end{array}$ \\
\hline $\mathrm{L} 10$ & 15 & 1,50 \\
\hline
\end{tabular}

\section{NOTAS}

1-CAPA DE CONCRETO COM 3 CM DE ALTURA

$\frac{1}{4}$
$\frac{1}{9}$
$\frac{5}{8}$ 2-CONCRETO DA CAPA COM $F_{C K}=15,0$ MPA 3-O ESCORAMENTO DEVE SER APOIADO EM BASE FIRME 4-DESFÔRMA NO MÍNIMO APÓS 18 DIAS

FIGURA 5.24 - PLANTA DE EXECUÇÃO DAS LAJES PRÉ-MOLDADAS 


\section{6 - CONCLUSÕES FINAIS}

1

O pré dimensionamento das lajes nervuradas através da equação proposta pela NB-1/78 resultou em alturas elevadas para as mesmas, enquanto que, a equação proposta por MACHADO (1983) apresenta, alturas menores, que após as verificações pertinentes à segurança das lajes nervuradas tanto ao estado limite último, quanto ao estado limite de utilização, mostram-se mais econômicas e compatíveis a estas lajes.

2

Para a determinação dos esforços solicitantes das lajes com nervuras nas duas direções adotou-se para o concreto das mesmas a redução do módulo de deformação longitudinal em $0,7 \mathrm{E}_{\mathfrak{c}}$, a fim de admitir-se a fissuração do concreto.

No tocante aos esforços provenientes da torção, nos exemplos apresentados no capítulo 4 para as lajes com nervuras nas duas direções, tomou-se para o momento de inércia à torção 0,2 do $\left(\mathrm{I}_{\mathrm{T}}\right)_{\mathrm{I}}$ (momento de inércia à torção no estádio I, seção não fissurada. A redução do momento de inércia à torção vem do fato que as seções de concreto armado quando fissuradas têm pouca capacidade para absorver os esforços provenientes da torção. O multiplicador 0,2 é proposto por SUSSEKIND (1979), enquanto que outros autores como LEONHARDT (1978), indica no sentido de desprezar-se a rigidez à torção das lajes nervuradas, dividindo-se o módulo de deformação do concreto $\left(\mathrm{G}_{\mathrm{c}}\right)$ por 100 . 
O fato de desprezar-se os efeitos da torção, resulta momentos fletores elevados, enquanto que, adotando-se $0,2 \quad\left(\mathrm{I}_{\mathrm{T}}\right)_{\mathrm{I}}$ conforme proposto por SUSSEKIND (1979) os momentos fletores apresentados são menores, e os momentos torçores obtidos nas nervuras são pequenos.

Em face a estes resultados verificou-se a capacidade das nervuras resistirem aos momentos torçores obtidos, através da expressão:

$\frac{\tau_{t d}}{\tau_{t u}}+\frac{\tau_{w d}}{\tau_{w u}} \leq 1,0$, chegou-se, então, a conclusão que os esforços provenientes da torção nas nervuras são absorvidos pela seção resistente, sem a a necessidade de dispor-se de armaduras adicionais, caso estas fossem necessárias seriam determinadas segundo o ítem 4.1.3.3 da NB-1/78, através da seguinte expressão:

$\frac{A_{s 90}}{s}=\frac{A_{s l}}{u}=\frac{T_{d}}{2 A_{e} f_{y d}}$, onde:

$A_{90}=$ área da seção transversal de um estribo, simples ou múltiplo, normal ao eixo da peça;

$\mathrm{A}_{\mathrm{sl}}=$ soma das áreas das seções das barras longitudinais;

$\mathrm{A}_{\mathrm{c}}=$ área limitada pela linha média da parede, incluindo a parte vazada;

$\mathrm{u}=$ perímetro de $A_{\mathrm{e}}$;

$\mathrm{s}=$ afastamento entre os eixos dos estribos.

A determinação dos esforços solicitantes mediante a aplicação da teoria das placas, considera na realidade, a plenitude da capacidade da seção em resistir aos esforços oriundos da torção. Isto nas lajes com as bordas apoiadas faz com que ocorra uma redução dos momentos fletores máximos, e a conseqüente elevação dos momentos torçores, momentos estes que a seção da nervura não tem capacidade de absorver. Tem-se, então, a plastificação das regiões mais solicitadas e uma redistribuição dos esforços, sendo que estes são admitidos em regiões menos solicitadas, haja visto que normalmente no emprego da teoria das placas, a armadura determinada para a região com maiores esforços é repetida em toda a laje nervurada. Para as lajes combordas engastadas os momentos fletores na região do engaste, 
obtidos através da teoria das placas são maiores que aqueles obtidos através das grelhas.

Conclui-se, então, que o modelo mais indicado, em face às características do material, concreto armado, é aquele que leva em conta a fissuração do concreto, e a conseqüente redução da rigidez à flexão e à torção das nervuras. $\mathrm{O}$ dimensionamento das armaduras à flexão pode ser feito não só para o momento fletor máximo, mas também para momentos fletores menores em outras nervuras, variandose, assim, as armaduras das nervuras. Não é recomendável a variação das armaduras ao longo de uma mesma nervura, somente nos casos em que a economia material/mão-de-obra se faça evidente.

A verificação do estado limite de deformações excessivas nas lajes nervuradas deve ser feita considerando-se a relação entre os módulos de deformação do aço e do concreto $\left(\alpha_{e}\right)$ igual a 15 , conforme recomendação da Norma Brasileira NB-116/89.

Ainda, segundo a NB-116/89 a verificação das deformações pode ser feita no Estádio I ou Estádio II. A fórmula de Branson, fornece um valor intermediário para o momento de inércia à flexão, levando-se em conta, que nas regiões de maiores esforços de flexão, o concreto está fissurado (Estádio II) e nas regiões menos solicitadas tem-se o concreto não fissurado (Estádio I).

A verificação no Estádio II apresenta resultados mais conservativos (à favor da segurança), além da verificação, a nível de cálculo, ser mais simples e rápido do que aquela feita considerando-se a Fórmula de Bränson, embora esta última represente melhor o comportamento da estrutura.

Para a determinação da deformação inicial nas lajes com nervuras nas duas direções utilizou-se o programa GPLAN3, supondo-se a linearidade fisica.

Nas lajes nervuradas pré-moldadas não considerou-se a rigidez à torção das nervuras, tendo em vista que, estas lajes na sua maioria, possuem nervuras dispostas apenas em uma direção, além da existência de uma junta de 
concretagem, entre a viga pré-moldada e a mesa concretada "in loco", com concretos de idades diferentes.

Os exemplos apresentados no Capítulo 5 são de lajes nervuradas pré-moldadas com nervuras distribuídas em uma direção, as nervuras existentes na outra região são apenas nervuras de distribuição e travamento.

A Norma Brasileira NB-1/78 dispensa a verificação da flexão da mesa quando a distância livre entre nervuras (a) for menor que $50 \mathrm{~cm}$, e desde a altura da mesa $\left(h_{f}\right)$ seja maior ou igual a a 15 ou $4 \mathrm{~cm}$. Diante do exposto verificou-se a flexão da mesa, para as lajes nervuradas, haja visto que estas se enquadram nas condições previstas pela norma. A verificação da flexão da mesa foi feita no Estádio I, ou seja, considerou-se o concreto sem armadura e conclui-se que para a altura da mesa (capa) de $3 \mathrm{~cm}$ pode-se admitir sobrecargas de até $4,00 \mathrm{kN} / \mathrm{m}^{2}$, enquanto que para mesas com altura de $4 \mathrm{~cm}$ admite-se sobrecargas de até $7,50 \mathrm{kN} / \mathrm{m}^{2}$, conforme exposto no Capítulo 5 deste trabalho.

As dimensões mínimas recomendadas na norma NB-1/78 para as lajes nervuradas têm por objetivo permitir a obtenção dos esforços solicitantes mediante a teoria de placas. Caso a determinação destes esforços seja feita através de cálculo da grelha, estas dimensões poderão ser alteradas, desde que acompanhadas das verificações pertinentes.

Quanto à distância livre entre as nervuras (a) a tendência é de adotar-se, tanto para as lajes nervuradas moldadas "in loco", quando para as prémoldadas, esta distância é próxima aos $50 \mathrm{~cm}$. Esta modulação vem a facilitar a execução, além de possibilitar para as lajes moldadas "in loco" a utilização de fồmas de fibra, reaproveitáveis ou blocos de concreto celular (leve), como fồrma tipo caixão perdido. As fôrmas de madeira além de dificultar a execução, vêm elevando os custos das obras de concreto armado, em face ao alto custo da madeira e da mão-de-obra. 
Conforme demonstrado no exemplo 3 do capítulo 4 deste trabalho, a opção do engaste das lajes nervuradas na maioria dos casos é inviável, tendo em vista o aparecimento de tensões de compressão elevadas na região da seção transversal onde a área de concreto é reduzida. A execução da mesa também na porção inferior da laje, muitas vezes eleva o custo da obra, tornando-se inviável se comparada com a laje nervurada apoiada, com mesa superior (exemplo 2 do capítulo 4).

Neste trabalho não abordaram-se as lajes mistas, isto deve-se ao fato de que na grande maioria dos casos as lajes mistas na realidade não passam de lajes nervuradas. Entende-se por lajes mistas aquelas em que os blocos colados como caixão perdido para a concretagem da laje, além da função de fồma tem a função estrutural de auxiliar a mesa à resistir aos esforços de compressão oriundos da flexão. A resistência dos blocos das lajes se comparada com a resistência do concreto da mesa é muito baixa conseqüentemente despreza-se esta resistência no cálculo das lajes mistas, portanto, na realidade, estas tem o comportamento das lajes nervuradas.

As lajes nervuradas devem, portanto, ser modeladas como grelhas, considerando-se o concreto fissurado, tanto na obtenção dos esforços solicitantes, como nos deslocamentos. Para o prosseguimento da pesquisa indica-se um estudo da determinação dos esforços solicitantes para as lajes nervuradas através do método dos elementos finitos, com a verificação experimental dos resultados obtidos, com a utilização de modelos reduzidos e provas de carga em lajes nervuradas, incluindo-se neste estudo as lajes nervuradas pré-moldadas. 


\section{REFERÊNCIAS BIBLIOGRÁFICAS}

AMERICAN CONCRETE INSTITUTE (1989). ACI - 318

AMERICAN CONCRETE INSTITUTE (1989). ACI - 348

ANDRADE, J.R.L. (1977) - Estruturas Correntes de Concreto Armado - Parte 1.

São Carlos, EESC - USP

ASSOCIAÇÃO BRASILEIRA DE NORMAS TÉCNICAS (1984). NB - 862/84 -

Ações e Segurança nas Estruturas. Rio de Janeiro.

ASSOCIAÇÃO BRASILEIRA DE NORMAS TÉCNICAS (1978). NB - 4/78 -

Cálculo e Execução de Lajes Mistas. Rio de Janeiro.

ASSOCIAÇÃO BRASILEIRA DE NORMAS TÉCNCAS (1980). NB - 5/80 -

Cargas para o Cálculo de Estruturas de Edificações. Rio de Janeiro.

ASSOCIAÇÃO BRASILEIRA DE NORMAS TÉCNICAS (1989). NB - 116/89 -

Projeto de Estruturas de Concreto Protendido. Rio de Janeiro.

ASSOCIAÇÃO BRASILEIRA DE NORMAS TÉCNICAS (1985). NB - 949/85 -

Projeto e Execução de Estruturas de Concreto Pré-Moldado. Rio de Janeiro. ASSOCIAÇÃO BRASILEIRA DE NORMAS TÉCNICAS (1978). NB - 1/78 -

Projeto e Execução de Obras de Concreto Armado. Rio de Janeiro.

BORGES, A. de C. (1972) - Prática das Pequenas Construções, vol.1. São Paulo,

Edgard Blücher.

COMITÉ EURO-INTERNACIONAL DU BÉTON - CEB-FIP Model Code (1990).

LEONHARDT, F. (1978) - Construções de Concreto, Vol.3. Rio de Janeiro, Interciência. 
LIMA, J.C. de O. (1991) - Boletim Técnico - Sistema Treliçado Global, Vol.1 Campinas, mediterr6anea Pré-fabricados de Concreto Ltda.

MACHADO, C.P. (1983) - Fixação Prática e Econômica das Espessuras de Lajes Usuais Maciças e Nervuradas de Concreto Armado. São Paulo.

PINHEIRO, L.M. (1993) - Concreto Armado: Tabelas e Ábacos. São Carlos, EESC - USP.

REZENDE, M.N. de (1990) - Análise de Pavimentos de Edifícios pelo Método dos Elementos Finitos em Microcomputador. São Carlos, Dissertação (Mestrado) - EESC-USP.

SANTOS, L.M. dos (1983). Edifícios de Concreto Armado. São Paulo, EPUSP. SOUZA, J.C.A. de O.; ANTUNES, H.M.C.C. (1992) - Processos Gerais da Hiperestática Clássica. São Carlos, EESC-USP.

SUSSEKIND, J.C. (1979) - Curso de Análise Estrutural - Vol.2 e 3. Porto Alegre, Editora Globo.

SUSSEKIND, J.C. (1985) - Curso de Concreto - Vol. 1. Porto Alegre, Editora Globo.

TAKEYA, T. et alli (1985) - Recomendações para o Projeto e Execução da Estrutura em Lajes Cogumelo Pertencentes às Unidades Básicas de Saúde do Plano Metropolitano de Saúde. São Carlos, EESC-USP. 


\section{BIBLIOGRAFIA CONSULTADA}

AMARAL, N.A. (1971) - Construções de Concreto I - Vol. 1 e 2. São Paulo, EPUSP.

ASSOCIAÇÃO BRASILEIRA DA CONSTRUÇÃO INDUSTRIALIZADA (1987) - Manual Técnico de Pré-fabricados de Concreto. São Paulo, Projeto Editores Associados Ltda.

BALLARINI, A.V. (1990) - Dimensionamento da Ligação do Concreto Prémoldado - Concreto Moldado (in loco) em Estruturas Compostas. São Carlos, EESC-USP.

BARBOSA, A da S. R. - Contribuição à Análise Estrutural de Sistemas LajeVigas de Concreto Armado mediante Analogia de Grelha. São Carlos, 1992. Dissertação (Mestrado), EESC-USP.

BARES, R. - MASSOMET, C. (1968) - Analysis of Beam Grids and Orthotropic Plate New York, Frederic Vigov Publishing Co.

BAUER,L.A.F. (1979) - Materiais de Construção. Rio de Janeiro, Livros Técnicos e Científicos.

BOTELHO, M.H.C. (1991) - Lajes Pré-moldadas de Concreto Armado. São Paulo, Programações Técnicas e Culturais Ltda.

FUSCO, P.B. (1983) - Estruturas de Concreto: Solicitações em Serviço - Parte 1

São Paulo, Escola Politécnica.

GIONGO, J.S. (1991) - Exemplo de Cálculo de uma Viga Calha. São Paulo, $\mathrm{ABCP}$.

LEVITT, M. (1982) - Prescast Concrete, Applied Science Publischers Ltd. England, Essex. 
L'HERMITE, R. - Ao Pé do Muro - Trab. L.A. Falcão Bauer. Distrito Federal, SENAI - Centro de Tecnologia e Construção.

MAZZILLI, A.R.P.(1988) - Influência da Flexibilidade das Vigas de Aço no

Cálculo de Estruturas de Edificios. São Paulo, Escola Politécnica (Dissertação Mestrado orientada por P.B. Fusco).

ORDONEZ, J.A.F et Alli (1974) - Prefabricacion: Teoria y Pratica. Barcelona, Editores Técnicos Associados.

PINHEIRO, L.M. - GIONGO, J.S. (1986) - Concreto Armado Propriedade dos Materias. São Carlos, EESC-USP.

ROGÉRIO, P.L. (1983) - Problemas Resolvidos de Concreto Estrutural. São

Paulo, Werner Puttnce.

SILVA, M.R. (1985) - Materiais de Construção. São Paulo, Pini.

TIMOSHENKOS,S. (1940) - Theory of Plates and Shells. New York, McGraw Hill Book Company INC.

VIEIRA, C.A.P. - CAMPOS FILHO, O.R.A. (1981) - Concreto Usinado - Trab. da disp. de pós-graduação de Materiais de Construção. São Carlos.

VILAGUT, F. - Pré-fabricados de Hormigon - Vol. 2. Barcelona, Ed. Gustavo Gili S/A 